\title{
(Epi)genetic profiling of cutaneous melanoma: diagnostic, prognostic, and biological relevance
}

Citation for published version (APA):

van den Hurk, K. (2015). (Epi)genetic profiling of cutaneous melanoma: diagnostic, prognostic, and biological relevance. [Doctoral Thesis, Maastricht University]. Datawyse / Universitaire Pers Maastricht. https://doi.org/10.26481/dis.20150702kh

Document status and date:

Published: 01/01/2015

DOI:

10.26481/dis.20150702kh

Document Version:

Publisher's PDF, also known as Version of record

\section{Please check the document version of this publication:}

- A submitted manuscript is the version of the article upon submission and before peer-review. There can be important differences between the submitted version and the official published version of record.

People interested in the research are advised to contact the author for the final version of the publication, or visit the DOI to the publisher's website.

- The final author version and the galley proof are versions of the publication after peer review.

- The final published version features the final layout of the paper including the volume, issue and page numbers.

Link to publication

\footnotetext{
General rights rights.

- You may freely distribute the URL identifying the publication in the public portal. please follow below link for the End User Agreement:

www.umlib.nl/taverne-license

Take down policy

If you believe that this document breaches copyright please contact us at:

repository@maastrichtuniversity.nl

providing details and we will investigate your claim.
}

Copyright and moral rights for the publications made accessible in the public portal are retained by the authors and/or other copyright owners and it is a condition of accessing publications that users recognise and abide by the legal requirements associated with these

- Users may download and print one copy of any publication from the public portal for the purpose of private study or research.

- You may not further distribute the material or use it for any profit-making activity or commercial gain

If the publication is distributed under the terms of Article $25 \mathrm{fa}$ of the Dutch Copyright Act, indicated by the "Taverne" license above, 


\section{(Epi)genetic profiling of cutaneous melanoma: Diagnostic, prognostic, and biological relevance}

Karin van den Hurk
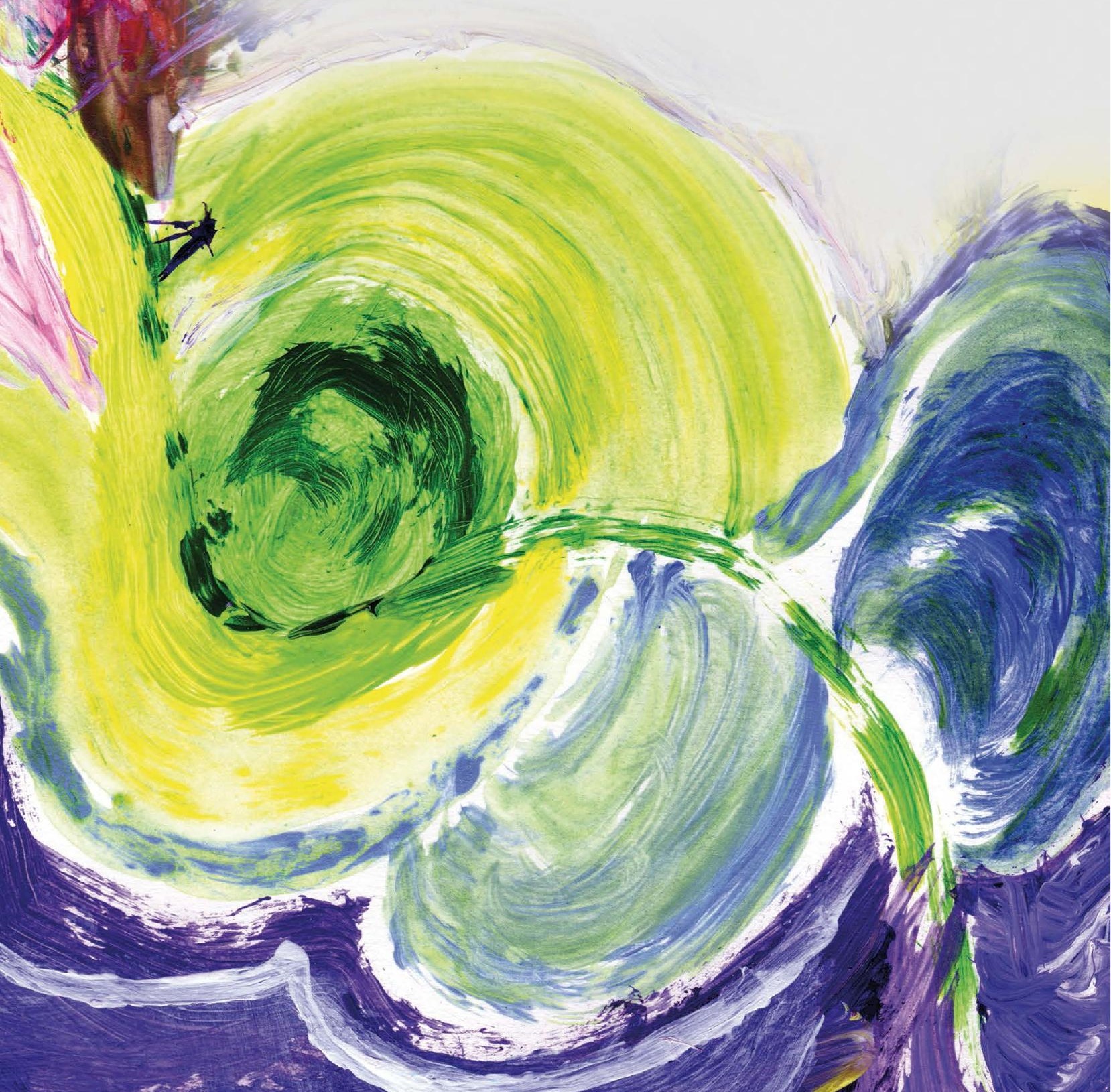
(Epi)genetic profiling of cutaneous melanoma: Diagnostic, prognostic, and biological relevance Karin van den Hurk

ISBN: 978-94-6159-446-4

Cover: $\quad$ Painting made by Marij Lousberg

Cover design: Kevin Gerritsen

Lay-out: Karin van den Hurk

Printed by: Datawyse I Universitaire Pers Maastricht

(C)2015, Karin van den Hurk

All rights preserved. No part of this thesis may be reproduced or transmitted in any form or by any means, electronic or mechanical, including photocopying, recording or any information storage or retrieval system, without permission in writing from the author, or, when appropriate, from the publishers of the publications. 


\title{
(Epi)genetic profiling of cutaneous melanoma: \\ Diagnostic, prognostic, and biological relevance
}

\author{
PROEFSCHRIFT \\ Ter verkrijging van de graad van doctor \\ aan de Universiteit Maastricht, \\ op gezag van Rector Magnificus, \\ Prof. dr. L.L.G. Soete, \\ volgens het besluit van het College van Decanen, \\ in het openbaar te verdedigen \\ op donderdag 2 juli 2015 om 12.00 uur
}

door

Karin van den Hurk

Geboren op 2 juli 1985 te Valkenburg a/d Geul

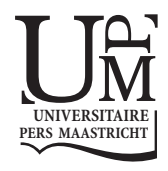




\section{Promotor}

Prof. dr. M. van Engeland

\section{Copromotores}

Dr. V.J.L. Winnepenninckx

Dr. L.P.J. van Neste

\section{Beoordelingscommissie}

Prof. dr. M.P. Zeegers (voorzitter)

Prof. dr. J.B.A.G. Haanen (Nederlands Kanker Instituut - Antoni van Leeuwenhoek ziekenhuis te Amsterdam)

Prof. dr. W.J. Mooi (VU Medisch Centrum (VUMC) te Amsterdam)

Prof. dr. F.C.S. Ramaekers

Dr. M.R. Thissen

\section{Oncomark MD*Health}

Financial support by OncoMark Ltd., MDxHealth, Stichting Melanoom, Greiner BioOne, 3DHISTECH Ltd., and Amgen B.V. for publication of this thesis is gratefully acknowledged. 


\section{List of abbreviations}

\begin{tabular}{|c|c|}
\hline AJCC & American Joint Committee on Cancer \\
\hline ALM & acral lentiginous melanoma \\
\hline BFPE & boonfix-fixed, paraffin-embedded \\
\hline BMCA & bisulphite melting curve analysis \\
\hline BRAF & B-Raf proto-oncogene, serine/threonine kinase \\
\hline $\mathrm{CDH} 11$ & cadherin 11 \\
\hline CIMP & CpG methylator phenotype \\
\hline CLDN11 & claudin 11 \\
\hline CMM & cutaneous malignant melanoma \\
\hline CTLA-4 & cytotoxic T lymphocyte-associated antigen 4 \\
\hline decitabine & 5-aza-2'-deoxycytidine \\
\hline DNMT & DNA methyltransferase \\
\hline DTIC & dacarbazine \\
\hline FAMMM & familial atypical multiple mole melanoma \\
\hline FDA & Food and Drug Administration \\
\hline FFPE & formalin-fixed, paraffin-embedded \\
\hline GNMT & glycine N-methyltransferase \\
\hline HAAO & 3-hydroxyanthranilate 3,4-dioxygenase \\
\hline HDAC & histone deacetylase \\
\hline $\mathrm{HE}$ & haematoxylin \& eosin \\
\hline HGF & hepatocyte growth factor \\
\hline $\mathrm{HR}$ & hazards ratio \\
\hline IFN $\alpha-2 b$ & interferon alpha-2b \\
\hline $\mathrm{IHC}$ & immunohistochemistry \\
\hline IL-2 & interleukin-2 \\
\hline Infinium-27K & Illumina human methylation 27 BeadChip \\
\hline Infinium-450K & Illumina human methylation 450 BeadChip \\
\hline LDH & lactate dehydrogenase \\
\hline LMM & lentigo maligna melanoma \\
\hline LVI & lymphovascular invasion \\
\hline LY75 & lymphocyte antigen 75 \\
\hline MAPK & mitogen-activated protein kinase \\
\hline MAPK13 & mitogen-activated protein kinase 13 \\
\hline MBD & methyl-binding domain \\
\hline MET & cellular-mesenchymal to epithelial transcription factor \\
\hline MITF & microphthalmia-associated transcription factor \\
\hline MSP & methylation-specific polymerase chain reaction \\
\hline NHEM & normal human epidermal melanocytes \\
\hline NM & nodular melanoma \\
\hline PcG & Polycomb group \\
\hline
\end{tabular}




$\begin{array}{ll}\text { PD-1 } & \text { programmed cell death protein 1 } \\ \text { PI3K } & \text { phosphatidylinositol 3'kinase } \\ \text { PPP1R3C } & \text { protein phosphatase 1, regulatory subunit 3C } \\ \text { PRC } & \text { Polycomb repressive complex } \\ \text { RGP } & \text { radial growth phase } \\ \text { RTK } & \text { receptor tyrosine kinase } \\ \text { SSM } & \text { superficial spreading melanoma } \\ \text { SYNPO2 } & \text { synaptopodin 2 (myopodin) } \\ \text { TCGA } & \text { The Cancer Genome Atlas } \\ \text { TILS } & \text { tumor infiltrating lymphocytes } \\ \text { TNM } & \text { tumor (T), node (N), metastasis (M) classification } \\ \text { TSG } & \text { tumor suppressor gene } \\ \text { UV } & \text { ultraviolet } \\ \text { V600E } & \text { valine at amino acid 600 replaced by glutamic acid, BRAF mutant } \\ \text { VGP } & \text { vertical growth phase }\end{array}$




\section{CONTENTS}

Page:

$\begin{array}{lll}\text { Chapter } 1 \text { General introduction } & 9\end{array}$

Chapter 2 Genetics and epigenetics of cutaneous malignant melanoma: 19

A concert out of tune

Chapter 3 High-throughput oncogene mutation profiling reveals

demographic differences in BRAF mutation rates among melanoma patients

Chapter $4 \quad$ BRAF $^{\mathrm{V} 600 \mathrm{E}}$ immunopositive melanomas show low frequency of heterogeneity and association with epithelioid tumor cells

Chapter 5 Promoter CpG island hypermethylation in dysplastic nevus and melanoma: CLDN11 as an epigenetic biomarker for malignancy

Chapter 6 Prognostic significance of promoter hypermethylation and diminished gene expression of SYNPO2 in melanoma

Chapter 7 Comprehensive epigenomic and transcriptomic analysis of melanoma identifies LY75 CpG island promoter methylation as an independent marker of poor clinical outcome

Chapter 8 General discussion

Valorization

Summary

Samenvatting (summary in Dutch)

Dankwoord (acknowledgement in Dutch) 



\section{CHAPTER 1}

General introduction 
Cutaneous melanoma accounts for approximately $1.6 \%$ of all adult malignancies and is the leading cause of skin cancer-related deaths worldwide. Melanoma is considered a major health problem as the incidence rate is rising faster than for any other solid tumor $^{1,2}$. In 2012, an estimated 232,130 new cases and 55,489 people died of this disease worldwide ${ }^{3}$. In the same year, the annual estimated cases and deaths were respectively 100,442 and 22,212 within Europe ${ }^{3}$.

The incidence of melanoma in the Netherlands is one of the highest in Europe, 5,287 new cases and 793 deaths were reported in $2012^{4}$ and incidence rates have been rising on average $4.5 \%$ each year over the last two decades (men $5 \%$, women $4 \%)^{4}$ and are expected to rise even further ${ }^{5}$. Mortality rates in The Netherlands increased as well although not as rapidly as the incidence rates ${ }^{6}$.

The skin represents the largest organ of the human body and provides protection against exogenous influences, e.g. ultraviolet (UV) radiation, infections and mechanic stress $^{7}$. The epidermis forms the outer layer of the skin of which keratinocytes are the most prevalent cells. Cutaneous melanocytes, derived from the neural crest during vertebrate development, are pigmented cells that reside on the basal layer of the epidermis ${ }^{8}$. These cells function primarily to synthesize melanin which they transfer by dendritic processes in packages, melanosomes, to adjacent keratinocytes as protection against UV radiation ${ }^{9}$. The malignant transformation of melanocytes gives rise to melanoma.

Traditionally, melanoma have been classified into four major clinical subtypes based on histopathologic features of the tumor; superficial spreading melanoma (SSM), nodular melanoma (NM), acral lentiginous melanoma (ALM), and lentigo maligna melanoma $(\mathrm{LMM})^{10,11}$. Of these, the SSM histological subtype is by far the most common form of melanoma in Western countries followed by the NM subtype, approximately $70 \%$ and $20 \%$, respectively ${ }^{12}$. Although used clinically as descriptive tools, the different melanoma subtypes have little prognostic significance ${ }^{13}$.

Clark et al. ${ }^{14}$ described a tumor progression model of melanocytic neoplasms that implies that melanoma develops and progresses in a sequence of steps from healthy melanocytes to metastatic melanoma (Figure 1). The first step is the clustering of melanocytes resulting in the formation of a common nevus, which might progress to a dysplastic nevus when cells become atypical. The next step of the model represents the malignant transformation towards a radial growth phase (RGP) melanoma where melanoma cells grow upwards into the epidermis. When cells start invading the dermis it progresses to a vertical growth phase (VGP) melanoma. From this point onwards cells can metastasize via surrounding lymph or blood vessels and form local or distant metastases. The histologic features characterizing each step of progression are the result of underlying molecular changes that progressively accumulate ${ }^{15}$. Hence, the model is a leading paradigm for molecular studies of melanoma. 
During the past decades, critical molecular alterations in melanoma have been identified, such as oncogenic mutations of BRAF (50-70\%), NRAS (15-30\%), CKIT (<5\%), and mutations in tumor suppressor genes (TSG) including p16INK4A (20\%), p14ARF (12\%), and PTEN (10\%), that underpin key signaling pathways of which the mitogenactivated protein kinase (MAPK) pathway and the phosphatidylinositol 3'kinase (PI3K) are most commonly alterated ${ }^{13,16,17}$. Efforts of The Cancer Genome Atlas (TCGA) project revealed that melanoma has the highest mutation frequency of cancers sequenced to date that is largely caused by UV exposure ${ }^{18}$.

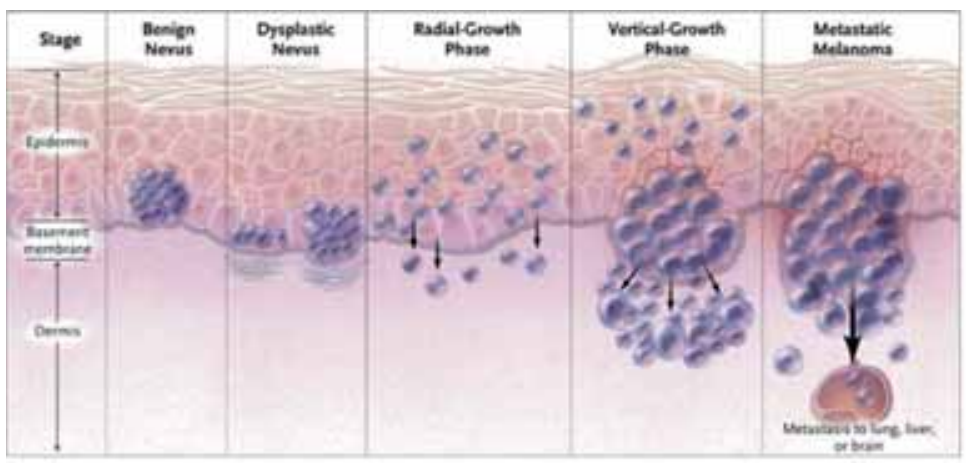

Figure 1. Progression model of cutaneous melanoma. Depiction of the multistep progression of benign or common nevus towards metastatic melanoma. Each step is accompanied by several molecular alterations that are described in more detail in Chapter 2 of this thesis. Figure adapted with permission from Miller AJ, Mihm, MC Jr. N ENG J Med 2006; 355:51-65 ${ }^{15}$, Copyright Massachusetts Medical Society.

Currently, melanoma diagnosis and staging is based on the Tumor Node Metastasis (TNM) classification that is centered on the evaluation of the primary tumor (T), including tumor thickness according to Breslow's method ${ }^{19}$, ulceration, and mitotic rate as prognostic markers; the presence or absence of lymph node (N) metastases, including the number of positive lymph nodes as indicator of worse prognosis; and the presence or absence of distant metastases (M), with metastatic site and lactate dehydrogenase (LDH) concentrations as prognostic factors ${ }^{20}$.

This tumor classification is subdivided in four stage groupings. Stage I and stage II melanoma are localized primary tumors, stage III is characterized by regional spread through lymphatic vessels and stage IV by distant metastasis ${ }^{20}$. Up to $95 \%$ of stage I melanoma is curable with surgery, i.e. a diagnostic excision followed by therapeutic reexcision. Fortunately, the vast majority (approximately $80 \%$ ) of melanoma is diagnosed at this early stage ${ }^{21}$. Ten-year survival for Stage II melanoma patients can decrease to approximately $40 \%$, primarily depending on the Breslow thickness and ulceration status $^{20}$. Furthermore, patients with lymph node metastasis (stage III) represent a heterogeneous group with regard to prognosis, i.e. ten-year survival decreases to $25 \%$ $70 \%$ mostly depending on the number of positive nodes, Breslow thickness and 
presence of ulceration. Prognosis for patients with distant metastases is generally poor with a median survival time of only 6-9 months, and a three-year survival of $15 \%$.

Until 2011, dacarbazine (DTIC), interleukin-2 (IL-2), and interferon- $\alpha-2 b$ (IFN $\alpha-2 b$ ) have been the treatments of choice for patients with advanced (stage IV or locally advanced, unresectable stage III) melanoma. Recently, this therapeutic landscape has changed drastically as two divergent therapeutic approaches, immunomodulation and targeted therapy, have shown significant survival benefits for patients with metastatic melanoma ${ }^{22}$.

Recent discoveries of driver mutations in melanoma are guiding the development of molecules that inhibit mutated proteins, also called targeted therapy or precision medicine ${ }^{23}$. Especially the observation that approximately half of melanoma patients have an oncogenic BRAF mutation and the subsequent development of specific, clinically effective inhibitors of V600-mutant BRAF is considered a major milestone in the field of personalized medicine. So far, two inhibitors of the mutant BRAF protein have been approved by the FDA for the treatment of BRAF-mutant metastatic melanoma, i.e. vemurafenib and dabrafenib ${ }^{24,25}$. Another approved targeted drug for BRAF-mutant melanoma, trametinib, inhibits the MEK kinase downstream of BRAF in the MAPK signaling pathway ${ }^{26}$. Although these therapies show high initial response rates of approximately $50 \%$, responses generally do not last long, with a short median length of six months ${ }^{24-26}$. Many of the molecular changes that cause resistance to BRAF inhibitors do so by reactivating the MAPK signaling pathway ${ }^{27}$. Therefore, it was investigated if combination therapy of BRAF and MEK, resulting in the blockage of the MAPK signaling pathway in two places, achieved more durable responses ${ }^{28}$. Combination therapy using dabrafenib and trametinib indeed enhanced clinical responses to response rates of $76 \%$ and median progression-free survival of 9.4 months. Optimizing treatment protocols might lead to further health gain, for instance BRAF or MEK inhibitor-resistant melanoma patients may regain sensitivity to these drugs after a 'drug holiday ${ }^{29}$. Moreover, many clinical trials with additional small molecule inhibitors are currently ongoing to determine their efficacy either alone or in combination with other treatments ${ }^{23,30}$.

In addition to the development of these novel targeted therapies, next-generation immunotherapies are successfully being generated. In 2011, the US Food and Drug Administration (FDA) approved the use of ipilimumab to treat patients with metastatic melanoma $^{31}$. Ipilimumab is an immunomodulatory agent that binds and inhibits cytotoxic T lymphocyte-associated antigen 4 (CTLA-4) leading to T-cell activation, which might induce tumor regression via an antitumor immune response. Ipilimumab has shown overall survival duration of two years or longer in approximately $20 \%$ of advanced melanoma patients ${ }^{31-34}$. Pooled survival data of 1861 ipilimumab-treated patients revealed a median overall survival of 11.4 months with a three-year overall survival rate of $22 \%{ }^{35}$. Also in 2011, a long-acting pegylated form of IFNa-2b (peginterferon- $\alpha-2 b$ ) received FDA-approval, although improvement of overall survival has not been consistently demonstrated ${ }^{36}$. A crucial immune checkpoint is the 
pathway between programmed cell death protein 1 (PD-1) and its ligand, PD-L1. About $40 \%$ of melanoma express PD-L1, which binds to PD1 present on activated lymphocytes, this subsequently causes apoptosis of the activated lymphocytes and thus prevents immune recognition and destruction of melanoma cells ${ }^{37}$. Blocking this interaction may restore the human body's inherent antitumor surveillance. Recently, in September 2014, pembrolizumab (formerly known as lambrolizumab), an anti-PD1 antibody, was granted accelerated FDA approval for the treatment of advanced melanoma patients that progressed after ipilimumab or BRAF inhibitor treatment based on an objective response rate of $24 \%{ }^{38}$. Clinical trials with nivolumab, another anti-PD-1 antibody, showed response rates between $30 \%-50 \%$ and a median overall survival of 16.8 months with a one- and two-year overall survival of $60 \%$ and $40 \%$, respectively ${ }^{39-42}$. Treatment of advanced melanoma patients with nivolumab was granted accelated FDA approval in December 2014. Interestingly, treatment with nivolimab was also associated with significant improvement in overall survival in patients without a BRAF mutation ${ }^{43}$ and thus a good alternative treatment option for those patients. Moreover, as CTLA-4 and PD-1 play complementary roles in regulating the immune system it has been investigated whether a combined blockade of CTLA-4 and PD-1 achieved more pronounced anti-tumor activity than blockade of either pathway alone ${ }^{44}$. First data indicate that combination therapy of ipilimumab and nivolumab might improve response rates up to $65 \%$ of patients. Figure 2 summarizes the FDA-approval timeline for immunotherapy and targeted therapy for melanoma.

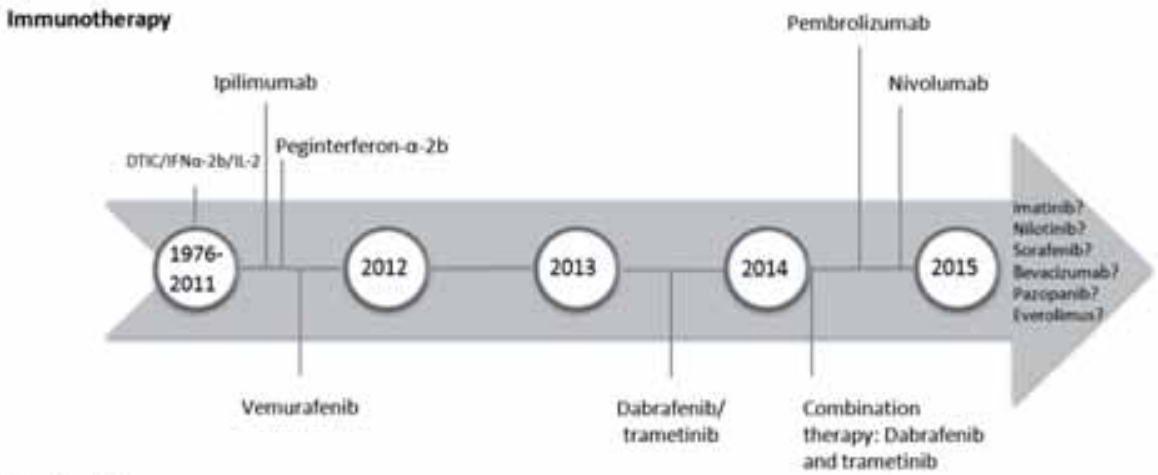

Targeted therapy

Figure 2. FDA-approval timeline for immunotherapy and targeted therapy for cutaneous melanoma. From 1976 until March 2011, approved treatment options for advanced melanoma were limited to dacarbazine (1976), interferon- $\alpha-2 b$ (1995), and high-dose IL-2 (1998). In 2011, immunotherapies ipilimumab and peginterferon- $\alpha-2 b$, as well as targeted therapy with the mutant BRAF inhibitor vemurafenib were approved. In 2013, dabrafenib and trametinib, a BRAF and MEK inhibitor respectively were approved, and PD-1 inhibitors, pembrolizumab and nivolumab were approved in 2014. Several other agents, c-KIT inhibitors (imatinib, nilotinib), tyrosine kinase inhibitors (sorafenib, pazopanib), angiogenesis inhibitor (bevacizumab), and $\mathrm{m}$-TOR inhibitor (everolimus), are still under investigation. In addition, it is examined if combination therapy of two immunomodulators or two therapeutic strategies, treatment with both immunotherapy and targeted therapy, will achieve better responses than treating patients with monotherapy. 
In spite of the above described advances in unraveling the molecular background of melanoma and progresses in the treatment of melanoma, advanced melanoma remains a challenging disease. One of the foremost challenges at present is to thoroughly understand the clinical significance of molecular data, including yet undiscovered data, and learn how to best utilize this for personalized patient care. Hence, the identification and clinical translation of biomarkers is a necessary step to further improve clinical melanoma management.

Biomarkers can be classified into three major groups. Diagnostic markers should lead to a more accurate characterization of melanoma, prognostic markers can identify those patients that are at high risk to develop metastatic disease and might benefit from adjuvant therapy, and predictive biomarkers indicate whether an individual patient is likely to benefit from a particular therapy. These markers should provide a personal tumor profile to guide personalized medicine and prevent overtreatment, thereby reducing health care costs.

Besides genetic alterations, epigenetic changes have been recognized the level of DNA (DNA methylation), RNA (RNA interference by non-coding RNAs), and protein (histone modifications, polycomb group proteins, and chromatin remodeling) ${ }^{45}$. In particular, research on DNA-methylation changes in neoplasia has provided a plethora of biomarkers for diagnosis, prognosis and response to treatment with application for clinical management of several types of cancer ${ }^{46}$. The stability and frequency of aberrant DNA hypermethylation in cancer, the possibility to profile methylation in routinely accessible and relevant clinical samples such as formalin-fixed, paraffinembedded (FFPE) tissue biopsies, and the simple and low costs tests that are available to examine DNA methylation, make these epigenetic marks a promising group of biomarkers that can be readily identified ${ }^{47}$. In addition, a tight link between early epigenetic events and cancer has been described that occur at much higher frequencies than mutations in TSGs, stressing their clinical usefulness as biomarkers ${ }^{48}$. DNA methylation changes in cancer include a massive global loss of DNA methylation along with loci-specific hypermethylation predominantly affecting $\mathrm{CpG}$ islands in gene regulatory regions ${ }^{45}$. Downstream transcriptional alterations have been described at all stages of tumor progression, affecting basically all signaling pathways and thereby transforming the cell phenotype. In contrast to genetic profiling of CMM development and progression, the full profile of epigenetic alterations is not well defined and studies reporting DNA methylation changes mainly focused on candidate gene approaches to identify the presence of DNA methylation in a limited number of tumor samples ${ }^{49}$. In addition, studies often lacked examination of non-malignant samples, thereby making it impossible to distinguish cancer-specific from tissue-specific methylation events. New powerful technologies, such as comprehensive probe-based, DNA-methylation microarrays, genome-wide bisulfite sequencing, and enrichmentbased technologies have recently been developed ${ }^{50-52}$. This allows analysis of DNA methylation in a high-throughput manner, thus making it possible to examine DNA methylation across the whole genome at a single-base resolution. Exploring the 
melanoma methylome will be a major step forward to better understand melanoma biology and to identify and develop clinically relevant biomarkers, ultimately improving melanoma patient management through personalized medicine.

\section{Hypothesis, aim and outline of this thesis}

Due to the rapid development of precision and personalized medicine, clinical pathological evaluation of melanoma is increasingly based on a combination of traditional histopathology with molecular analysis. The aim of this thesis was to profile (epi)genetic aberrations that are underlying the development and progression of cutaneous melanoma. We hypothesized that this molecular profiling will enhance our understanding of melanoma biology and lead to the identification of novel, clinically relevant biomarkers for accurate diagnosis of melanoma and the identification of patients that have a worse prognosis and therefore might benefit from additional therapy.

In Chapter 2 we reviewed the current knowledge on the genetic and epigenetic mechanisms that are underlying melanoma development. We point out that it is the concerted action of genetics and epigenetics that effectively leads to distorted gene expression patterns. To further increase our knowledge of mutational events that accompany melanoma progression we adapted high-throughput genotyping to profile 159 known single nucleotide mutations in 33 cancer-related genes in 154 melanoma tissues from Ireland and Belgium (Chapter 3). Our aim in Chapter 4 was to determine by using immunohistochemistry the extent of intratumor and intrapatient heterogeneity of $\mathrm{BRAF}^{\mathrm{V} 600 \mathrm{E}}$, the most important biomarker for melanoma patients to date, and examine if morphological tumor heterogeneity correlates with BRAF ${ }^{\mathrm{V} 600 \mathrm{E}}$ expression.

We continued our research by profiling epigenetic aberrations that are underlying melanoma development. The accuracy of melanoma diagnosis is critical for optimal clinical guidance of this malignancy, since the stage at diagnosis is a significant factor that defines both treatment and prognosis of patients ${ }^{20}$. However, the histological differentiation of melanoma from dysplastic nevus can be doubtful in a number of cases and misdiagnosis of melanoma is one of the most frequent causes of malpractice ${ }^{53}$. In Chapter 5, we aimed to investigate if dysplastic nevus and melanoma can be distinguished based on promoter $\mathrm{CpG}$ island methylation. A diagnostic 5-marker panel comprising of CDH11, CLDN11, GNMT, MAPK13, and PPP1R3C methylation was examined for its diagnostic potential.

Our aim in Chapter $\mathbf{6}$ and $\mathbf{7}$ was to investigate if differential methylation events among primary melanomas can be used to improve the assessment of prognosis of melanoma patients. Promoter CpG island methylation and gene expression of SYNPO2 was examined for its prognostic potential in Chapter 6. Using a combination of methylbinding-domain (MBD)-sequencing and RNA-sequencing on melanoma cell lines and 
normal melanocytes, and genome-wide beadchip methylation array data (Infinium$450 \mathrm{~K})$ on nevus and publically available methylation data on clinical melanoma specimens from the TCGA project, we describe a work-flow that identified 85 candidate methylation markers for melanoma prognosis in Chapter 7. The general discussion in Chapter 8 summarizes and discusses the main findings of the studies presented in this thesis and suggestions for future research plans are given. Finally, the paragraph on valorization highlights the societal and economical value that can be created out of the knowledge generated in this thesis. 


\section{References}

1. Ferlay J, Shin HR, Bray F, et al. Estimates of worldwide burden of cancer in 2008: GLOBOCAN 2008. Int J Cancer, 2010. 127(12): p. 2893-2917.

2. MacKie RM, Hauschild A, Eggermont AM. Epidemiology of invasive cutaneous melanoma. Ann Oncol, 2009. 20 Suppl 6: p. vi1-7.

3. Ferlay J, Soerjomataram I, Ervik M, Dikshit R, Eser S, Mathers C, Rebelo M, Parkin DM, Forman D, Bray, F. GLOBOCAN 2012 v1.0, Cancer Incidence and Mortality Worldwide: IARC CancerBase No. 11 [Internet]. Lyon, France: International Agency for Research on Cancer; 2013. Available from: http://globocan.iarc.fr, accessed on 01/09/2014.

4. Nederlandse Kankerregistratie, beheerd door IKNL (c) August 2014 (website: http://www.cijfersoverkanker.nl/).

5. de Vries E, van de Poll-Franse LV, Louwman WJ, et al. Predictions of skin cancer incidence in the Netherlands up to 2015. Br J Dermatol, 2005. 152(3): p. 481-488.

6. Hollestein LM, van den Akker SA, Nijsten T, et al. Trends of cutaneous melanoma in The Netherlands: increasing incidence rates among all Breslow thickness categories and rising mortality rates since 1989. Ann Oncol, 2012. 23(2): p. 524-530.

7. Fuchs E, Raghavan S. Getting under the skin of epidermal morphogenesis. Nat Rev Genet, 2002. 3(3): p. 199209.

8. Dupin E, Le Douarin NM. Development of melanocyte precursors from the vertebrate neural crest. Oncogene, 2003. 22(20): p. 3016-3023.

9. Scherer D, Kumar R. Genetics of pigmentation in skin cancer--a review. Mutat Res, 2010. 705(2): p. 141-153.

10. Clark WH, Jr., From L, Bernardino EA, et al. The histogenesis and biologic behavior of primary human malignant melanomas of the skin. Cancer Res, 1969. 29(3): p. 705-727.

11. McGovern VJ, Mihm MC, Jr., Bailly C, et al. The classification of malignant melanoma and its histologic reporting. Cancer, 1973. 32(6): p. 1446-1457.

12. Barnhill RL, Mihm MC, Jr. The histopathology of cutaneous malignant melanoma. Semin Diagn Pathol, 1993. 10(1): p. 47-75.

13. Scolyer RA, Long GV, Thompson JF. Evolving concepts in melanoma classification and their relevance to multidisciplinary melanoma patient care. Mol Oncol, 2011. 5(2): p. 124-136.

14. Clark WH, Jr., Elder DE, Guerry Dt, et al. A study of tumor progression: the precursor lesions of superficial spreading and nodular melanoma. Hum Pathol, 1984. 15(12): p. 1147-1165.

15. Miller AJ, Mihm MC, Jr. Melanoma. N Engl J Med, 2006. 355(1): p. 51-65.

16. Vidwans SJ, Flaherty KT, Fisher DE, et al. A melanoma molecular disease model. PLoS One, 2011. 6(3): p. e18257.

17. Hodis E, Watson IR, Kryukov GV, et al. A landscape of driver mutations in melanoma. Cell, 2012. 150(2): p. 251-263.

18. Watson IR. Comprehensive genomic characterization of cutaneous melanoma. The Cancer Genome Atlas' 3rd Annual Scientific Symposium, May 12-13, 2014, Bethesda, Maryland, 2014. p.

19. Breslow A. Measurements of tumor thickness. Hum Pathol, 1978. 9(2): p. 238-239.

20. Balch CM, Gershenwald JE, Soong SJ, et al. Final version of 2009 AJCC melanoma staging and classification. J Clin Oncol, 2009. 27(36): p. 6199-6206.

21. Gray-Schopfer V, Wellbrock C, Marais R. Melanoma biology and new targeted therapy. Nature, 2007. 445(7130): p. 851-857.

22. Eggermont AM, Spatz A, Robert C. Cutaneous melanoma. Lancet, 2014. 383(9919): p. 816-827.

23. Griewank KG, Scolyer RA, Thompson JF, et al. Genetic alterations and personalized medicine in melanoma: progress and future prospects. J Natl Cancer Inst, 2014. 106(2): p. djt435.

24. Chapman PB, Hauschild A, Robert $C$, et al. Improved survival with vemurafenib in melanoma with BRAF V600E mutation. N Engl J Med, 2011. 364(26): p. 2507-2516.

25. Hauschild A, Grob JJ, Demidov LV, et al. Dabrafenib in BRAF-mutated metastatic melanoma: a multicentre, open-label, phase 3 randomised controlled trial. Lancet, 2012. 380(9839): p. 358-365.

26. Flaherty $\mathrm{KT}$, Robert $\mathrm{C}$, Hersey $\mathrm{P}$, et al. Improved survival with MEK inhibition in BRAF-mutated melanoma. $\mathrm{N}$ Engl J Med, 2012. 367(2): p. 107-114.

27. Bucheit $A D$, Davies MA. Emerging insights into resistance to BRAF inhibitors in melanoma. Biochem Pharmacol, 2014. 87(3): p. 381-389.

28. Flaherty $K T$, Infante $J R$, Daud $A$, et al. Combined BRAF and MEK inhibition in melanoma with BRAF V600 mutations. N Engl J Med, 2012. 367(18): p. 1694-1703.

29. Sun C, Wang L, Huang S, et al. Reversible and adaptive resistance to BRAF(V600E) inhibition in melanoma. Nature, 2014. 508(7494): p. 118-122. 
30. Flaherty KT, Hodi FS, Fisher DE. From genes to drugs: targeted strategies for melanoma. Nat Rev Cancer, 2012. 12(5): p. 349-361.

31. Hodi FS, O'Day SJ, McDermott DF, et al. Improved survival with ipilimumab in patients with metastatic melanoma. N Engl J Med, 2010. 363(8): p. 711-723.

32. Robert $C$, Thomas L, Bondarenko I, et al. Ipilimumab plus dacarbazine for previously untreated metastatic melanoma. N Engl J Med, 2011. 364(26): p. 2517-2526.

33. McDermott D, Haanen J, Chen TT, et al. Efficacy and safety of ipilimumab in metastatic melanoma patients surviving more than 2 years following treatment in a phase III trial (MDX010-20). Ann Oncol, 2013. 24(10): p. 2694-2698.

34. Maio M, Bondarenko I, Robert $\mathrm{C}$, et al. Survival analysis with 5 years of follow-up in a phase III study of ipilimumab and dacarbazine in metastatic melanoma [abstract 3704]. Presented at: European Cancer Congress 2013; 27 September - 1 Ocotber 2013; Amsterdam, The Netherlands, 2013. p.

35. Schadendorf D, Hodi FS, Robert C, et al. Pooled analysis of long-term survival data from phase II and phase III trials of ipilimumab in metastatic or locally advanced, unresectable melanoma [abstract 24]. Presented at: European Cancer Congress 2013; 27 September - 1 October 2013; Amsterdam, The Netherlands, 2013. p.

36. Eggermont AM, Suciu S, Testori A, et al. Long-term results of the randomized phase III trial EORTC 18991 of adjuvant therapy with pegylated interferon alfa- $2 \mathrm{~b}$ versus observation in resected stage III melanoma. J Clin Oncol, 2012. 30(31): p. 3810-3818.

37. Gogas H, Polyzos A, Kirkwood J. Immunotherapy for advanced melanoma: fulfilling the promise. Cancer Treat Rev, 2013. 39(8): p. 879-885.

38. Bagcchi S. Pembrolizumab for treatment of refractory melanoma. Lancet Oncol, 2014. 15(10): p. e419.

39. Topalian SL, Sznol M, McDermott DF, et al. Survival, durable tumor remission, and long-term safety in patients with advanced melanoma receiving nivolumab. J Clin Oncol, 2014. 32(10): p. 1020-1030.

40. Hamid O, Robert C, Daud A, et al. Safety and tumor responses with lambrolizumab (anti-PD-1) in melanoma. N Engl J Med, 2013. 369(2): p. 134-144.

41. Brahmer JR, Tykodi SS, Chow LQ, et al. Safety and activity of anti-PD-L1 antibody in patients with advanced cancer. N Engl J Med, 2012. 366(26): p. 2455-2465.

42. Sznol M, Kluger HM, Hodi FS, et al. Survival and long-term follow-up of safety and response in patients (pts) with advanced melanoma (MEL) in a phase I trial of nivolumab (anti-PD-1; BMS-936558; ONO-4538). [abstract CRA 9006]. Journal of Clinical Oncology, 2013. 31, No 18_suppl (June 20 Supplement): p.

43. Robert C, Long GV, Brady B, et al. Nivolumab in Previously Untreated Melanoma without BRAF Mutation. N Engl J Med, 2014.

44. Wolchok JD, Kluger H, Callahan MK, et al. Nivolumab plus ipilimumab in advanced melanoma. N Engl J Med, 2013. 369(2): p. 122-133.

45. Esteller M. Epigenetics in cancer. N Engl J Med, 2008. 358(11): p. 1148-1159.

46. Rodriguez-Paredes M, Esteller M. Cancer epigenetics reaches mainstream oncology. Nat Med, 2011. 17(3): p. 330-339.

47. Laird PW. The power and the promise of DNA methylation markers. Nat Rev Cancer, 2003. 3(4): p. 253-266.

48. Schuebel KE, Chen W, Cope L, et al. Comparing the DNA hypermethylome with gene mutations in human colorectal cancer. PLoS Genet, 2007. 3(9): p. 1709-1723.

49. van den Hurk K, Niessen HE, Veeck J, et al. Genetics and epigenetics of cutaneous malignant melanoma: a concert out of tune. Biochim Biophys Acta, 2012. 1826(1): p. 89-102.

50. Sandoval J, Heyn H, Moran S, et al. Validation of a DNA methylation microarray for $450,000 \mathrm{CpG}$ sites in the human genome. Epigenetics, 2011. 6(6): p. 692-702.

51. Harris RA, Wang T, Coarfa C, et al. Comparison of sequencing-based methods to profile DNA methylation and identification of monoallelic epigenetic modifications. Nat Biotechnol, 2010. 28(10): p. 1097-1105.

52. Mensaert K, Denil S, Trooskens G, et al. Next-generation technologies and data analytical approaches for epigenomics. Environ Mol Mutagen, 2014. 55(3): p. 155-170.

53. Troxel DB. Pitfalls in the diagnosis of malignant melanoma: findings of a risk management panel study. Am J Surg Pathol, 2003. 27(9): p. 1278-1283. 


\section{CHAPTER 2}

\section{Genetics and epigenetics of cutaneous malignant melanoma: A concert out of tune}

Karin van den Hurk, Hanneke E.C. Niessen, Jürgen Veeck, Joost J. van den Oord, Maurice A.M. van Steensel, Axel zur Hausen, Manon van Engeland, Véronique J.L. Winnepenninckx

Biochimica et Biophysica Acta-Reviews on Cancer 2012; 1826 (1): 89-102 


\section{Abstract}

Cutaneous malignant melanoma (CMM) is the most life-threatening neoplasm of the skin and is considered a major health problem as both incidence and mortality rates continue to rise. Once CMM has metastasized it becomes therapy-resistant and is an inevitably deadly disease. Understanding the molecular mechanisms that are involved in the initiation and progression of CMM is crucial for overcoming the commonly observed drug resistance as well as developing novel targeted treatment strategies. This molecular knowledge may further lead to the identification of clinically relevant biomarkers for early CMM detection, risk stratification, or prediction of response to therapy, altogether improving the clinical management of this disease. In this review we summarize the currently identified genetic and epigenetic alterations in CMM development. Although the genetic components underlying CMM are clearly emerging, a complete picture of the epigenetic alterations on DNA (DNA methylation), RNA (non-coding RNAs), and protein level (histone modificiations, Polycomb group proteins, and chromatin remodeling) and the combinatorial interactions between these events is lacking. More detailed knowledge, however, is accumulating for genetic and epigenetic interactions in the aberrant regulation of the INK4b-ARF-INK4a and microphthalmia-associated transcription factor (MITF) loci. Importantly, we point out that it is this interplay of genetics and epigenetics that effectively leads to distorted gene expression patterns in CMM. 


\section{Introduction}

Cutaneous malignant melanoma (CMM) is a highly aggressive skin tumor that originates from melanocytes, i.e. pigment cells which reside in the basal layer of the epidermis in humans and are derived from the neural crest during vertebrate development ${ }^{1}$. CMM is the most life-threatening neoplasm of the skin and is considered a major health problem because both incidence and mortality rates continue to rise $\mathrm{e}^{2-4}$. In 2008, about 197,000 CMM cases were reported worldwide and 46,000 patients died as a result of this disease ${ }^{4}$, thereby ranking it the deadliest form of all skin cancers. Approximately $10 \%$ of CMM occur in a familial setting ${ }^{5}$.

$\mathrm{CMM}$ is currently classified into four major clinical subtypes: Superficial spreading, nodular, acral lentiginous, and lentigo maligna, of which superficial spreading melanoma is by far the most common form (approximately $70 \%$ ) of $\mathrm{CMM}^{5,6}$. In addition, a molecular classification in which CMM are classified according to their molecular subtype has been developed ${ }^{7,8}$.

Seminal findings by Clark et al. ${ }^{9}$ have led to a model of CMM progression, which has become instrumental in the understanding of the multistep pathogenesis of CMM. According to this theory, the first step is the clustering of melanocytes resulting in the development of a benign nevus. The development of cytological atypia in dysplastic nevi represents the second step. A dysplastic nevus can either regress or advance into a radial growth phase (RGP) melanoma which can then progress into a more aggressive vertical growth phase (VGP) melanoma. It should be noted that not all CMM pass through each of these individual phases, and that RGP and VGP melanoma can both develop directly from transformed melanocytes or nevi ${ }^{10}$. The final step in the progression of CMM is the formation of local or distant metastases.

Patient outcome for CMM is highly dependent on the stage of the disease. Histological features of the primary melanoma, i.e. tumor thickness, ulceration, and mitotic rate are important hallmarks of CMM prognosis and staging ${ }^{11}$. Other relevant prognostic factors are micrometastatic disease based on either sentinel lymph node biopsy or elective node dissection, the number of metastatic lymph nodes, distant metastatic disease, and serum lactate dehydrogenase levels. CMM that is less invasive and locally defined at diagnosis has a five-year survival rate of more than $95 \%$ after treatment by surgical excision alone ${ }^{12}$. Fortunately, the vast majority of CMM (approximately $80 \%$ ) are diagnosed at this early stage. If the cancer is more advanced, however, survival rates drop substantially to $30 \%$ to $60 \%$ after five years, depending on the tumor thickness in millimeters (Breslow's depth). Metastatic disease has poor patient outcomes as treatment options are limited.

Current systemic treatment options include the chemotherapeutic drug dacarbazine ${ }^{13-17}$ and immunomodulatory agents, such as interleukin- $2^{18-20}$ or high-dose interferon alpha-2 $b^{21-24}$. Recently, a novel immunomodulatory agent, ipilimumab, that binds and thereby inhibits cytotoxic $T$ lymphocyte-associated antigen $4^{25,26}$ has been approved by the US Food and Drug Administration (FDA) for use in patients with 
metastatic CMM, either as initial therapy or after relapse. In addition, vemurafenib (PLX4032) was approved by the FDA for the first-line treatment of both metastatic and unresectable CMM for patients whose tumors have V600E mutations in the BRAF gene (approximately $50 \%$ of $\mathrm{CMM})^{27,28}$. Vemurafenib is a BRAF inhibitor that blocks the function of the BRAF ${ }^{\mathrm{V} 600 \mathrm{E}}$ protein.

Recent clinical trials in metastatic melanoma determining the efficacy of imatinib, an inhibitor of receptor tyrosine kinase $\mathrm{KIT}^{29,30}$ as well as the approval of vemurafenib for clinical practice established a new paradigm for targeted drug development. However, despite these promising developments in improving the treatment of CMM, therapeutic resistance and adverse effects to available therapies emphasize that CMM represents a major challenge for the medical oncologist. This underscores the importance to clarify the pathobiology of $\mathrm{CMM}$, which ultimately will lead to a molecular medicine-based approach of treating $\mathrm{CMM}$, including early detection, risk stratification and prediction of response to therapy.

\section{Genetic alterations in CMM development}

Extensive studies of CMM during the last decades have revealed key signaling pathways that are genetically disrupted in the pathogenesis of this disease (Table $1)^{10,12,31}$. Aberrant activity of the mitogen-activated protein kinase (MAPK) signaling pathway represents a critical factor in the initiation and development of $\mathrm{CMM}^{32}$. Extracellular signal-regulated kinase (ERK), a downstream target of MAPK signaling, has been reported to be hyperactivated in up to $90 \%$ of $\mathrm{CMM}_{\text {cases }}{ }^{33}$. Activation in CMM can be the result of largely mutually exclusive somatic mutations of $\mathrm{KIT}^{(\mathrm{L576P)}}(<17 \%$ of $\mathrm{CMM}^{34-38}, \mathrm{NRAS}^{(\mathrm{Q} 61 \mathrm{~K})}(15 \% \text { to } 30 \% \text { of } \mathrm{CMM})^{39-41}$, or more frequently, BRAF ${ }^{(\mathrm{V} 600 \mathrm{E})}(50 \%$ to $70 \%$ of $\mathrm{CMM})^{42,43}$. BRAF mutations are already found in benign nevi, which represent a precursor in melanomagenesis ${ }^{44}$. Congenital nevi were shown to frequently harbor NRAS mutations but no BRAF mutations ${ }^{45}$. The presence of various oncogenic mutations in benign nevi suggests that they are driving nevogenesis ${ }^{46}$, but that other/additional molecular changes are required for initiating malignancy. This is strengthened by the observation that not necessarily all CMM with an associated nevus arise from melanocytes with mutant $\mathrm{BRAF}^{47}$ and that mutant BRAF protein induces cellular senescence (oncogene-induced senescence) by increasing the expression of $\mathrm{p} 16^{\mathrm{INK} 4 \mathrm{a}}$ in normal melanocytes ${ }^{48}$ and presumably nevus cells as well.

Loss of $\mathrm{p} 16^{\mathrm{INK} 4 \mathrm{a}}$ leads to the formation of dysplastic nevi, representing the next step in CMM development. P16 ${ }^{\mathrm{INK} 4 \mathrm{a}}$ is transcribed from chromosome $9 \mathrm{p} 21$, and is part of a major genomic locus involved in CMM pathogenesis and predisposition (the INK4bARF-INK4a locus). Three candidate tumor suppressor genes have been identified in this region: $\mathrm{P} 15^{\mathrm{INK} 4 \mathrm{~b}}$, which is transcribed from cyclin-dependent kinase inhibitor $2 \mathrm{~B}$ (CDKN2B), and 2 transcripts from cyclin-dependent kinase inhibitor 2A (CDKN2A), i.e. $\mathrm{p} 16^{\text {INK4a }}$ and $\mathrm{p} 14^{\mathrm{ARF}}$. No specific germline mutations of the CDKN2B (INK4B) gene have been reported yet in $\mathrm{CMM}^{49-51}$. Somatic point mutations in this gene, however, were 
described in patients with sporadic $\mathrm{CMM}^{52}$. CDKN2A (ARF-INK4a) represents the most frequently mutated gene inherited in familial CMM (25\% to $40 \%)$ and it is inactivated by somatic mutations in the majority of sporadic CMM as well ${ }^{53,54}$.

Germline mutations in the oncogenic cyclin-dependent kinase 4 (CDK4) gene, whose protein product interacts with $\mathrm{p} 16^{\mathrm{INK} 4 \mathrm{a}}$, is another important high penetrance locus for CMM susceptibility, although these mutations occur very rare ${ }^{55-57}$.

In addition to mutations, CMM is characterized by chromosomal gains (e.g. 1q, 3p, $6 p, 7,8 q, 11 q, 12 q 14,17 q$, and 20q) which encompass the melanoma oncogenes CDK4, cyclin D1 (CCND1), v-myc myelocytomatosis viral oncogenehomolog (MYC), murine double minute 2 (MDM 2), and microphthalmia-associated transcription factor (M ITF), and chromosomal losses (e.g. 1p, 6q, 9p, 10q, 11q, 17p, and 21q) which harbor the tumor suppressors $\mathrm{p} 15^{\mathrm{INK} 4 \mathrm{~b}}, \mathrm{p} 16^{\mathrm{INK} 4 \mathrm{a}}, \mathrm{p} 14^{\mathrm{ARF}}$, and phosphatase and tensin homolog (PTEN), among others ${ }^{58-68}$.

The PTEN gene (10q23) has gained substantial attention as the understanding of CMM pathogenesis has increased. In addition to deletions (30\% to $50 \%$ ) which occur already in dysplastic nevi, somatic mutations of PTEN have been found in approximately $10 \%$ of primary $\mathrm{CMM}^{69}$. PTEN loss eliminates the negative regulation on protein kinase $\mathrm{B}$ (PKB, or AKT) and accordingly mammalian target of rapamycin (mTOR), both downstream components of the phosphatidylinositol 3 kinase (PI3K) pathway and leads to alterations in the control of the cell cycle, apoptosis, cell contact and migration ${ }^{70}$. It is believed that PTEN loss, particular in melanocytes with mutant BRAF, lead to malignant transformation of nevi ${ }^{70}$. Furthermore, DNA copy number gain of the AKT3 locus, which is found in $40 \%$ to $60 \%$ of $\mathrm{CMM}^{71}$, results in enhanced activity of AKT in CMM and correlates with disease progression. Increased levels of activated AKT are found from the third step of CMM progression, i.e. RGP melanomas ${ }^{71}$. Genetic interaction between PTEN and NRAS mutations rarely occurs. In contrast, BRAF mutations are found in conjunction with PTEN loss in approximately $20 \%$ of $\mathrm{CMM}^{72}$. Interestingly, NRAS mutations can, besides activating MAPK signaling, also activate the PI3K pathway ${ }^{73}$.

Table 1. Important genes structurally affected in CMM

\begin{tabular}{llll}
\hline Gene type & Genes & Genetic alteration & References \\
\hline Proto-oncogenes & NRAS & $15-30 \%$ mutated & $39-41$ \\
& BRAF & $50-70 \%$ mutated & 42 \\
& KIT & $<17 \%$ mutated & $34-38$ \\
MITF & $10 \%$ mutated, 10\% amplified & $67,75-77$ \\
& AKT3 & $40-60 \%$ amplified & 71 \\
& CCND1 & $10-40 \%$ amplified & $59,66,78$ \\
& CDK4 & Rarely mutated, 5\% amplified & $57,59,60$ \\
Tumor suppressor genes & MDM2 & $5 \%$ amplified & 60 \\
& PTEN & $10 \%$ mutated, 30-50\% deleted & $62,69,70,79$ \\
& TP53 & $10 \%$ mutated & 80 \\
& P14 & $40-70 \%$ mutated/deleted & $55,58,63,66$ \\
& P15 & $52,58,63$ \\
& P16 & & \\
& INK4a & $30-70 \%$ mutated/deleted & $53-55,58,63,66$ \\
\hline
\end{tabular}

This table summarizes genes involved in major signaling pathways that are genetically altered in CMM by mutations and/or copy number alterations. 
Clark et al. ${ }^{9}$ proposed that (dysplastic) nevi regress through differentiation which requires cell cycle exit and the expression of pigment genes. The M ITF gene (3p14.1p12.3) regulates the development and differentiation of melanocytes ${ }^{74}$ and is required for melanocyte cell survival ${ }^{81}$, proliferation, and cell cycle progression ${ }^{82-84}$. M ITF has been proposed to act as a lineage survival oncogene in CMM - it is amplified in $10 \%$ of primary $\mathrm{CMM}$ and $15 \%$ to $20 \%$ of metastatic CMM, most frequently in tumors with a poor prognosis ${ }^{67}$. In addition, M ITF is somatically mutated ${ }^{75}$ in approximately $10 \%$ of CMM and a novel germline mutation in the MITF gene (E318K) that impairs MITF SUMOylation has been recently identified by two independent studies ${ }^{76,77}$. In healthy cells, MITF expression is tightly regulated as expression levels dictate functional outcome. MITF is regulated at the post-translational level through the ERK component of the MAPK signaling pathway, i.e. ERK phosphorylates MITF and thereby induces its degradation ${ }^{85}$. The cyclic adenosine monophosphate (CAMP) signaling and winglesstype mammary tumor virus integration site family (WNT) pathways regulate MITF at the transcriptional level ${ }^{10}$. CAMP signaling regulates pigmentation through the melanocortin 1 receptor (MC1R). Upon activation, MC1R initiates a complex signaling cascade that ultimately leads to the induction of MITF and subsequent upregulation of pigment synthetic genes ${ }^{86}$. In addition, MITF regulates the transcription of melan-A (MLANA), silver homologue (SILV), and melastatin1 (TRPM 1), which are used as diagnostic CMM markers ${ }^{87,88}$. CMM that are deficient in these proteins have a poor prognosis $^{89,90}$. MITF also causes cell cycle arrest by the induction of $\mathrm{p} 16^{\mathrm{INK} 4 \mathrm{a}}$ and suppression of apoptosis via direct targeting and upregulation of B-cell lymphoma 2 $(B C L 2){ }^{81,82}$. As previously mentioned, M ITF is also a target gene of the WNT pathway ${ }^{91}$, as is the cell-cycle mediator $\mathrm{CCND1}^{92}$. These genes increase proliferation and survival of CMM cells. Furthermore, WNT signaling indirectly modulates E-cadherin (CDH1) expression via induction of epithelial-to-mesenchymal transition (EMT) regulators, including snail (SNAI1), slug, TWIST, and the CDH1 repressors ZEB1 and $2^{93}$. Progression of RGP to VGP melanoma is marked by the loss of CDH1 expression and the induction of $\mathrm{N}$-cadherin $(\mathrm{CDH} 2)$ expression ${ }^{94,95}$. Additionally, loss of $\mathrm{CDH} 1$ expression has been reported to correlate with increased $\mathrm{CMM}$ thickness ${ }^{96}$ and shortened survival ${ }^{94}$.

Hence, structural alterations in genes that are part of important signaling pathways are key to the development of CMM. Interestingly, some aberrations are present already at high frequency in common nevi.

\section{Epigenetic contributions to CMM development}

The malignant transformation of healthy melanocytes requires not only structural genetic changes but is also driven by epigenetic alterations. Epigenetic regulation describes heritable changes in gene expression that do not underlie alterations in the primary DNA sequence, and manifest at the levels of DNA, RNA, and protein ${ }^{97}$. 


\section{DNA methylation}

It is becoming increasingly clear that aberrant regulation of DNA methylation plays an important role in the development and progression of CMM. The first indication comes from the observation that enzymes establishing DNA methylation patterns, DNA methyltransferases DNMT3A and DNMT3B are significantly upregulated during CMM progression ${ }^{98}$. Inhibition of DNMT3A expression by RNA interference dramatically inhibited melanoma growth and metastasis in mouse models ${ }^{99}$. A recent study additionally showed that DNMT1 is suppressed by BRAF ${ }^{\mathrm{V} 600 \mathrm{E}}$ knockdown in CMM cells, thus suggesting upregulation of DNMT1 in BRAF ${ }^{\mathrm{V} 600 \mathrm{E}}$ signaling ${ }^{100}$.

In addition, hypomethylation and subsequent activation of normally silenced cancer germline (CG) (or cancer-testis) genes, such as melanoma antigen (MAGE), have been identified in $\mathrm{CMM}^{101-103}$. It is suggested that $\mathrm{CG}$ genes directly contribute to the malignant phenotype and response to therapy in cancer cells ${ }^{104}$. One mechanism that has been proposed to contribute to DNA hypomethylation of CG genes is "brother of the regulator of imprinted sites" (BORIS or CTCFL) expression ${ }^{105-107}$. Activation of BORIS has indeed been found in $\mathrm{CMM}^{108}$. However, the frequency of BORIS activation was considerably lower than that of M AGE-Al and other CG genes and forced expression of BORIS in melanoma cell lines did not result in the activation of these genes ${ }^{108}$. This suggests that BORIS is not the sole regulator of CG gene activation in CMM.

The third line of evidence for an aberrant regulation of DNA methylation in CMM comes from the observation that, to date, more than 70 genes have been identified as hypermethylated in $\mathrm{CMM}^{109-113}$. Aberrant promoter DNA hypermethylation preferably occurs at $\mathrm{CpG}$ dinucleotide dense regions, also known as $\mathrm{CpG}$ islands, leading to the downregulation of the expression of tumor suppressive genes ${ }^{114}$. In CMM, several fundamental pathways are deregulated by this mechanism, including MAPK, PI3K, WNT, pRb, hormonal response, as well as pathways regulating the cell cycle, DNA repair, apoptosis, invasion and metastasis, and growth (Table 2). Hence, CpG island hypermethylation affects many of the pathways that are targeted by mutational events as well.

The most frequent and best characterized promoter hypermethylated genes in CMM are the retinoic acid receptor, beta (RARB) $)^{103,115-118}$, RAS association domain family $1 A$ (RASSF1A $)^{103,115-120}$, and 0-6-methylguanine-DNA methyltransferase $(M G M T)^{115,116,118,121}$, with methylation frequencies in CMM lesions from both primary and metastatic sites of approximately $59 \%, 28 \%$, and $26 \%$, respectively. In serum of CMM patients containing free circulating tumor DNA promoter hypermethylation of RARB $^{115,118}$, RASSF $1 A^{115,118,122}$ and M GMT ${ }^{115,118,122}$ was found in $17 \%, 37 \%$ and, $30 \%$ of cases, respectively. Undoubtedly, research on larger patient cohorts is needed to determine whether these genes are useful as detection and/or prognostic markers. RASSF1A promoter methylation was additionally found to be a potential marker for predicting biochemotherapy (immunotherapy in conjunction with chemotherapy) response and overall survival in $\mathrm{CMM}$ patients ${ }^{118}$. In a phase II study of extended-dose 
temozolomide in patients with unresectable stage III and stage IV CMM, MGMT promoter methylation level of more than $25 \%$ correlated with partial clinical response ${ }^{123}$. Other genes with potential predictive value have been identified as well, such as methylated estrogen receptor- $\alpha(E S R 1)^{124}$ and metallothionein $1 E(M T 1 E)^{125}$. These observations are worthy of further study in larger numbers of patients.

The recognition of a CpG methylator phenotype $(\mathrm{CIMP})^{126,127}$ in colorectal cancer (CRC) identifying tumors with significantly more promoter methylation than others motivated Tanemura et al. ${ }^{117}$ to examine this phenotype in CMM. To determine whether a clinically relevant CIMP related to CMM progression exists, promoter CpG island methylation of six genes that are known to exhibit epigenetic aberrations associated with malignancy (RASSF1A, TFPI2, RARB, WIF1, SOCS1, and GATA4), and seven methylated-in-tumor (MINT) genes were examined by methylation-specific PCR in a series of 122 CMM of different clinical stages. Promoter methylation of RASSF1A, TFPI2, WIF1, and SOCS1, were shown to significantly increase with advanced clinical stage. Moreover, MINT17 and M INT31 methylation were present in conjunction with methylation of the other genes and therefore suggested to be representative of a CIMP for CMM. Unfortunately, the melanoma CIMP has not been explored in additional studies yet, thus it cannot be considered a validated phenotype. In CRC, the path to accepting CIMP tumors as an etiologically and clinically distinct group of the disease has not been without controversy, and to date, the cause of CIMP remains unknown ${ }^{128}$.

So far, epigenetic profiling of CMM has been restricted generally to promoter CpG island methylation of selected genes. Several studies have performed an indirect global analysis of epigenetic inactivation in melanoma cells using a microarray-based screen for genes that are upregulated following treatment with the DNA demethylating agent 5-aza-2'-deoxycytidine (decitabine) ${ }^{129-133}$. Using this approach numerous potential methylation markers have been identified of which methylation of TSPY, ${ }^{129}$ MT1E, FAPB5 ${ }^{125}$, QPCT, CYP1B1, LXN ${ }^{130}$, TFPI- $2^{131}$, PPP1R3C, ENC1, RARRES1, TP53INP1 ${ }^{132}$, CHRDL1, SFRP1, TMEM 47, LPL, RARRES1, PLCXD1, and KOX15 ${ }^{133}$ were examined and validated in small series of primary and metastatic CMM. Unfortunately, except for MT1E, methylation was not examined in control or benign tissue samples leaving the question open whether methylation of those genes indeed is a cancer-specific event.

In addition, direct genome-wide searches have been performed for the identification of promoter methylation in $\mathrm{CMM}^{137,145,148,149}$. Furuta et al. ${ }^{148}$ were the first to report a direct genome-wide search using methylation-sensitive representational difference analysis (MS-RDA). Using this approach they identified 34 genes that were methylated in at least one out of 13 melanoma cell lines but not in two normal melanocyte cultures. Methylation of only two genes, PRDX2 and TM EM 22, was examined in $39 \mathrm{CMM}$ specimens and methylation levels of $8 \%$ and $24 \%$ were detected, respectively. Koga et al. ${ }^{145}$ provided the first genome-wide integrative analysis of promoter methylation and gene expression to identify novel markers in CMM. For the detection of methylated genes they used the methylated DNA immuno- 
Table 2. Promoter $\mathrm{CpG}$ island hypermethylated genes in $\mathrm{CMM}$.

\begin{tabular}{|c|c|}
\hline Signaling pathways/ cancer hallmarks & Promoter CpG island hypermethylated genes \\
\hline MAPK & RASSF1A $^{103,115-120,122}$, RASSF10 $0^{134}$, SYK$^{* 116}$ \\
\hline PI3K & PIEN $^{120,135}$ \\
\hline JAK/STAT & SOCS1 $116,117,122$, SOCS2 $2^{116,122}$ \\
\hline WNT & APC $*^{116,136}$, WIF1 ${ }^{* 117}$, FRZB $^{137}$ \\
\hline $\mathrm{pRb}$ & 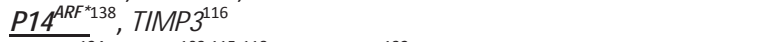 \\
\hline Hormonal response & ${\text { ESR1 }{ }^{12} 4}^{12}$, RARB $^{103,115-118}$, RARRES1 ${ }^{132}$ \\
\hline IGF & IGFBP7* $*^{139}$ \\
\hline Cell cycle regulation & $\underline{\mathbf{P 1}}^{\mathbf{I N K A a ^ { * }} 116,120,122,138,140-142},{\underline{\mathrm{CDKN}} 1 \mathrm{~B}^{143}}^{147}$ \\
\hline Transcription regulation & GATA4* ${ }^{117}$, RUNX3 $^{* 144}$ \\
\hline DNA repair & M GM T $^{115,116,118,121,122}$, DDIT4L*145 \\
\hline Apoptosis & TNFRSF10A, TNFRSF10C, TNFRSF10D ${ }^{116}$, DAPK**115, PYCARD ${ }^{116,146}$ \\
\hline Angiogenesis & THBS1*142 \\
\hline Invasion and metastasis & TFPI2*116,117,131,$\underline{\text { TCF2 }}^{147}$ \\
\hline Growth & $\mathrm{WFDCl}^{116}$ \\
\hline Transmembrane proteins & TMEM $22^{148}$ \\
\hline Tanemura CIMP panel $^{117}$ & RASSF1A, TFPI2*, RARB, WIF1*, SOCS1, GATA4*, MINT17, M INT31 \\
\hline
\end{tabular}

This table, which is not exhaustive, summarizes genes of major signaling pathways/cancer hallmarks that are epigenetically silenced in $\mathrm{CMM}$ by promoter $\mathrm{CpG}$ hypermethylation. Only research data obtained from clinical specimens (both normal and cancer tissue) is included.

*Polycomb target gene; mutation targets are presented in boldface; deletion targets are underscored.

CIMP, CpG island methylator phenotype; IGF, insulin-like growth factor; JAK/STAT, Janus kinase/signal transducer and activator of transcription; MAPK; mitogen-activated protein kinase; PI3K, phosphatidylinositol 3 kinase; pRb, retinoblastoma pathway; WNT, wingless-type MMTV integration site family

precipitation (MeDIP) approach combined with hybridization of the fragments to a whole-genome promoter array. In eight early-passage human melanoma cell strains they identified 76 methylation markers, of which 68 were hypermethylated and eight were hypomethylated as compared to normal melanocytes. However, promoter methylation and the expression level of only five markers (COL1A2, NPM2, HSPB6, DDIT4L, and M TIG) were validated in a small series of snap-frozen CMM tissues $(n=24)$ and nevi $(n=9)$. Conway et al. ${ }^{137}$ evaluated genome-wide promoter methylation using high-throughput DNA methylation array-based profiling of benign nevi $(n=27)$ and primary invasive CMM $(n=22)$ and created a DNA methylation signature that discriminates one from the other. Unfortunately, in this study DNA methylation was not validated by other techniques (e.g. bisulfite genomic sequencing) on single samples and these results were also not validated in second series. Bonazzi et al. ${ }^{149}$ integrated gene expression and methylation array analysis of melanoma cell lines to identify epigenetically regulated putative tumor suppressor genes. Methylation of UCHL1, COL1A2, THBS1, and TNFRSF10D was validated in $30 \mathrm{CMM}$ samples, and tumors were methylated for $21 \%, 13 \%, 15 \%$, and $30 \%$, respectively. Methylation could not be detected in normal melanocytes, but again samples from normal skin or nevi were not examined in this study.

Although, the above described research claims to be "genome-wide" they still investigated pre-selected promoter regions for the presence of DNA methylation in a limited number of CMM samples. In addition, studies often lack examination of non- 
malignant samples, thereby making it impossible to distinguish cancer-specific from tissue-specific methylation events. Over the last years, research has gradually conferred a broader understanding that intragenic methylation patterns, or methylation on CPG island shores may also have a role in transcriptional regulation ${ }^{150-}$ 152. In addition, the exact location of hypermethylated $\mathrm{CPG}$ dinucleotides that are associated with gene expression, and thus functionally and clinically relevant, has not been investigated for the majority of methylation markers so far identified in $\mathrm{CMM}^{153}$. Future research should aim to map the functional DNA methylome of CMM with care of using control tissue.

\section{Non-coding RNAs}

Non-coding RNAs (ncRNA) can interfere with gene regulation on the RNA level, and they are increasingly considered as key players in CMM development. Research on small, non-coding RNAs (sncRNA) is rapidly progressing while long, non-coding RNAs (IncRNA) are less well studied and therefore lacking behind. SncRNAs can affect the expression of hundreds of genes, and thereby exhibit many gene and pathway regulatory functions ${ }^{154-157}$.

Knowledge about the deregulation of microRNAs (miRNA) and their specific function in CMM development is rapidly increasing ${ }^{158-160}$ (Table 3). Numerous studies using miRNA arrays and genomic sequencing have been performed to characterize the CMM "miRNA-ome"161-171. MiRNAs regulate CMM target genes that mainly affect the cell cycle, such as CCND1, CDKN1A/B, CDK4/6 and MET, invasion and metastasis by regulating expression of MITF and FOXO3, as well as EMT. In addition, expression of Dicer, a central enzyme involved in cleaving precursor miRNAs to functionally mature forms, is upregulated in CMM samples ${ }^{76,172}$.

Expression of MITF is regulated by miR- $137^{173}$, miR- $148^{174}$, and miR- $182^{175}$ which are all deregulated in CMM. In addition, Ozsolak et al. ${ }^{176}$ identified a number of miRNAs that are regulated by MITF in melanoma cells, including members of the let-7 family, miR-221/222, miR-29, miR-146a, miR-148b, and miR-125b, emphasizing the key role of M ITF in CMM development.

The let-7 family is highly conserved across species. They were the first miRNAs identified in humans, and have meanwhile been recognized as key regulators in development and cancer ${ }^{177}$. Schultz et al. ${ }^{178}$ showed downregulation of let-7 family members in primary CMM as compared with benign nevi. Targets of these miRNAs include important molecules involved in CMM development, including NRAS, MYC, CCND1, CCND3, and CDK4. Other studies have confirmed the deregulation of let-7 family members in CMM (Table 3) ${ }^{163,166,179,180}$. 
Table 3. Overview of deregulated miRNAs in CMM

\begin{tabular}{|c|c|c|c|}
\hline MicroRNAs & Expression in CMM & Function in CMM & References \\
\hline Let-7a & Downregulated & Decreasing invasiveness via targeting ITGB3 & $163,166,178-180$ \\
\hline Let-7b & Downregulated & $\begin{array}{l}\text { Delaying cell cycle progression via targeting CCND1, } \\
\text { CCND3, CDK4 and RAS }\end{array}$ & 163,178 \\
\hline Let-7i & Upregulated & Negative association with survival & 162,165 \\
\hline $\operatorname{miR}-9^{\#}$ & $\begin{array}{l}\text { Upregulated, } \\
\text { Downregulated by } \\
\text { hypermethylation }\end{array}$ & $\begin{array}{l}\text { Implicated in metastasis formation, targeting SNAI1 } \\
\text { and upregulating } \mathrm{CDH} 1 \text { expression }\end{array}$ & $\begin{array}{l}161,166,171,178,183 \\
188\end{array}$ \\
\hline miR-15b & Upregulated & $\begin{array}{l}\text { Correlates with tumor cell proliferation and } \\
\text { apoptosis, negative association with survival }\end{array}$ & 189 \\
\hline miR-17-5p & Upregulated & $\begin{array}{l}\text { Regulation of apoptosis and proliferation by } \\
\text { targeting E2F, CDKN1A, BIM }\end{array}$ & $163,190,191$ \\
\hline miR-20b & Upregulated & $\begin{array}{l}\text { Transiently knockdown in melanoma cells did not } \\
\text { have an effect on colony formation of invasiveness }\end{array}$ & 171 \\
\hline miR-21 & Upregulated & Promoting invasion and metastasis & $166,171,192-194$ \\
\hline $\operatorname{miR}-29 \mathrm{c}$ & Downregulated & $\begin{array}{l}\text { Downregulation is associated with CIMP and } \\
\text { disease outcome }\end{array}$ & 98 \\
\hline miR-30b $\#$ & $\begin{array}{l}\text { Upregulated, } \\
\text { downregulated }\end{array}$ & $\begin{array}{l}\text { Upregulation correlates with tumor stage, } \\
\text { metastatic potential, shorter time-to-recurrence, } \\
\text { reduced overall survival }\end{array}$ & $167,178,195$ \\
\hline miR-30d & Upregulated & $\begin{array}{l}\text { Upregulation correlates with tumor stage, } \\
\text { metastatic potential, shorter time-to-recurrence, } \\
\text { reduced overall survival }\end{array}$ & 167,195 \\
\hline miR-31 & Downregulated & $\begin{array}{l}\text { Downregulation promotes invasion and } \\
\text { proliferation }\end{array}$ & 178,191 \\
\hline miR-34a & $\begin{array}{l}\text { Downregulated by } \\
\text { hypermethylation }\end{array}$ & $\begin{array}{l}\text { Targeting CDK6, promoting invasion and } \\
\text { proliferation }\end{array}$ & $170,184,189,191$ \\
\hline miR-34b & $\begin{array}{l}\text { Downregulated by } \\
\text { hypermethylation }\end{array}$ & $\begin{array}{l}\text { Implicated in metastasis formation, targeting C- } \\
\text { MYC, CDK6, E2F3, MET }\end{array}$ & $178,183,185,187$ \\
\hline miR-34c & $\begin{array}{l}\text { Downregulated by } \\
\text { hypermethylation }\end{array}$ & $\begin{array}{l}\text { Implicated in metastasis formation, targeting C- } \\
\text { MYC, CDK6, E2F3, MET }\end{array}$ & $178,183,187$ \\
\hline miR-125b & Downregulated & $\begin{array}{l}\text { Overexpression induces cellular senescence, } \\
\text { inhibition decreases apoptosis }\end{array}$ & $\begin{array}{l}163,164,166,171,178, \\
180,181\end{array}$ \\
\hline $\operatorname{miR}-137^{\#}$ & $\begin{array}{l}\text { Upregulated, } \\
\text { downregulated }\end{array}$ & Targeting MITF & $170,173,174,178,196$ \\
\hline $\operatorname{miR}-141^{\#}$ & $\begin{array}{l}\text { Upregulated, } \\
\text { downregulated }\end{array}$ & n.a. & $161,163,171,178$ \\
\hline miR-148 & n.a. & Targeting MITF & 174 \\
\hline miR-148a & $\begin{array}{l}\text { Downregulated by } \\
\text { hypermethylation }\end{array}$ & Implicated in metastasis formation, targeting TGIF2 & 166,183 \\
\hline miR-149 & Downregulated & n.a. & $163,166,171,178$ \\
\hline miR-155 & $\begin{array}{l}\text { Upregulated, } \\
\text { downregulated }\end{array}$ & $\begin{array}{l}\text { Inhibiting proliferation and induces metastasis, } \\
\text { mediates CMM growth via targeting SKI }\end{array}$ & $166,167,190,194,197$ \\
\hline $\operatorname{miR}-182^{\#}$ & $\begin{array}{l}\text { Upregulated, } \\
\text { downregulated }\end{array}$ & $\begin{array}{l}\text { Promotes metastasis by repressing } \mathrm{FOXO} 3 \text { and } \\
\text { MITF }\end{array}$ & $161,171,175,178,198$ \\
\hline miR-184 & Downregulated & $\begin{array}{l}\text { Downregulation promotes invasion and } \\
\text { proliferation }\end{array}$ & $166,178,191$ \\
\hline $\operatorname{miR}-185^{\#}$ & Downregulated & $\begin{array}{l}\text { Downregulation promotes invasion and } \\
\text { proliferation }\end{array}$ & $163,178,191$ \\
\hline miR-191 & n.a. & Downregulation is associated with short survival & 162 \\
\hline $\begin{array}{l}\text { miR-192-194 } \\
\text { cluster }\end{array}$ & Downregulated & Regulated by TP 53 & $161,162,198$ \\
\hline
\end{tabular}


Table 3. Overview of deregulated miRNAs in CMM continued

\begin{tabular}{|c|c|c|c|}
\hline MicroRNAs & Expression in CMM & Function in CMM & References \\
\hline miR-193a & n.a. & Association with BRAF mutation status & 162 \\
\hline miR-193b" & $\begin{array}{l}\text { Upregulated, } \\
\text { downregulated }\end{array}$ & $\begin{array}{l}\text { Regulates proliferation by targeting CCND1, } \\
\text { targeting MCL1, association with survival. }\end{array}$ & $162,163,166,167,171$ \\
\hline miR-196a & Downregulated & $\begin{array}{l}\text { Targeting } \mathrm{HOX}-\mathrm{B} 7 \text { and } \mathrm{HOX}-\mathrm{C} 8 \text {, induction of BMP4, } \\
\text { invasive potential }\end{array}$ & $166,199,200$ \\
\hline miR-199a & Downregulated & Targeting MET oncogene expression & $166,178,187$ \\
\hline $\operatorname{miR}-200 a / b / c^{\#}$ & $\begin{array}{l}\text { Downregulated, } \\
\text { Upregulated }\end{array}$ & Inhibition of EMT by targeting ZEB1 and ZEB2 & $\begin{array}{l}161,163,166,171,178 \\
198,201\end{array}$ \\
\hline miR-203 & Downregulated & n.a. & $163,166,171,198$ \\
\hline miR-204 & Downregulated & $\begin{array}{l}\text { Downregulation promotes invasion and } \\
\text { proliferation }\end{array}$ & $163,170,171,178,191$ \\
\hline miR-205 & Downregulated & $\begin{array}{l}\text { Association with EMT by targeting ZEB1 and ZEB2, } \\
\text { suppression of proliferation by targeting E2F1 and } \\
\text { E2F5 }\end{array}$ & $163,166,169,171$ \\
\hline $\operatorname{miR}-211^{\#}$ & $\begin{array}{l}\text { Upregulated, } \\
\text { downregulated }\end{array}$ & $\begin{array}{l}\text { Transcribed from TRPM 1, loss of TRPM1 expression } \\
\text { strongly predicts progression and poor clinical } \\
\text { outcome, decreases both colony formation and } \\
\text { invasiveness, targeting BRN2 which represses MITF } \\
\text { expression }\end{array}$ & $\begin{array}{l}162,163,170,171,178, \\
198,202,203\end{array}$ \\
\hline miR-214 & $\begin{array}{l}\text { Upregulated, } \\
\text { downregulated }\end{array}$ & $\begin{array}{l}\text { Targeting TFAP2C; involved in disease progression } \\
\text { and metastasis formation }\end{array}$ & $163,170,204$ \\
\hline $\operatorname{miR}-221$ & Upregulated & Targeting c-KIT and CDKN1B & 205-208 \\
\hline $\operatorname{miR}-222$ & Upregulated & Targeting C-KIT and CDKN1B & $178,206,207$ \\
\hline $\operatorname{miR}-365$ & Upregulated & Negative association with survival & 162,165 \\
\hline $\operatorname{miR}-375$ & $\begin{array}{l}\text { Downregulated by } \\
\text { hypermethylation }\end{array}$ & Involved in invasion and proliferation & 186 \\
\hline $\begin{array}{l}\text { miR-506-514 } \\
\text { cluster }\end{array}$ & Upregulated & $\begin{array}{l}\text { Regulates growth, apoptosis, invasion, and soft agar } \\
\text { colony formation }\end{array}$ & 182 \\
\hline $\operatorname{miR}-565$ & n.a. & Distinguishes BRAF mutant from BRAF wild type & 162 \\
\hline miR-663 & n.a. & $\begin{array}{l}\text { Downregulated in NRAS mutant compared with } \\
\text { BRAF/NRAS wild type cases }\end{array}$ & 162 \\
\hline
\end{tabular}

This table summarizes miRNAs that are deregulated in CMM, clinical specimens and/or melanoma cell lines. "Research results are inconsistent. CIMP, CpG island methylator phenotype; CMM, cutaneous malignant melanoma; EMT, epithelial-to-mesenchymal transition; MiRNA, microRNA; n.a. data not available

Several studies have identified the downregulation of miR-125b in $\mathrm{CMM}^{163,164,166,171,178,180}$. This miRNA influences cell survival and induces senescence in $\mathrm{CMM}$ cells by targeting AKT3, BCL2, and E2F2 ${ }^{181}$. Recently, the miRNA-506-514 cluster, a cluster of 14 miRNAs on the $\mathrm{X}$ chromosome, which is overexpressed in CMM samples was identified as oncogenic in regulating cell growth, apoptosis, invasion, and colony formation $^{182}$. Overexpression of the miRNA-506-514 cluster was regardless of mutations in BRAF and NRAS ${ }^{182}$. Future studies are needed to fully understand the molecular mechanism downstream of this miRNA cluster. Caramuta et al. ${ }^{162}$ also investigated miRNA expression within the context of genetic alterations. A low expression of miR-193a, miR-338, and miR-565 was associated with patients carrying a $\mathrm{BRAF}^{\mathrm{V} 600 \mathrm{E}}$ mutation, and reduced expression of miR-663 was associated with NRAS mutated patients $^{162}$. 
Furthermore, miRNAs can regulate DNMT expression and indirectly modify DNA methylation patterns, e.g. miR-29C was found to inversely correlate to DNMT3A/B expression and CIMP in $\mathrm{CMM}^{98}$. Further evidence for the interplay between miRNAs and DNA methylation comes from the observation that the tumor suppressors miR$9^{183}$, miR-34a ${ }^{184}$, miR-34b ${ }^{183,185}$, miR-34c, miR-148a, and miR-375 $5^{186}$ are silenced by promoter hypermethylation in CMM (Table 3). Hypermethylation of miR-34b/c is associated with a strong expression of CDK6 in primary $\mathrm{CMM}^{183}$. A reduced expression of miR-34b, miR-34c, and miRNA-199a and subsequent upregulation of MET oncogene expression was demonstrated in cells derived from primary $\mathrm{CMM}^{187}$.

Members of the miR-200 family (miR-200b, miR-200c, and miR-141) regulate the expression of $\mathrm{CDH} 1$ through directly targeting transcriptional repressors of $\mathrm{CDH} 1$, i.e. ZEB1 and ZEB2, which inhibit EMT ${ }^{209-211}$. In doing so, the miR-200 family becomes an important regulator of EMT, a key process for initializing metastasis ${ }^{212}$. Members of the miR-200 family, and miR-205, are downregulated in CMM patient samples when compared to common nevi ${ }^{163,166,169,171,178}$. However, inconsistent results are shown for miR-200c between patient samples ${ }^{178}$ and melanoma cell lines ${ }^{161,201}$ where this miRNA is found to be upregulated. The recent observation that data derived on melanoma cell lines do not cluster together with CMM tissues underscores the use of patient specimens and questions the validity of studies using cell lines only ${ }^{171}$. MiR-9, which is downregulated in metastatic $\mathrm{CMM}$, was identified to regulate $\mathrm{CDH} 1$ expression as well $^{188}$. This miRNA directly binds to sites within the NF-KB 3'-UTR, resulting in suppression of SNAI1 and upregulation of $\mathrm{CDH} 1$ expression ${ }^{188}$.

Although the current literature is dominated by sncRNAs (miRNAs), the identification of antisense ncRNA in the INK4 locus (ANRIL) underscores the potential importance of IncRNAs ${ }^{213}$. ANRIL is affected by a germline deletion of the currently most clinically relevant melanoma susceptibility locus, INK4b-ARF-INK4a, in CMMneural system tumor syndrome families ${ }^{214}$. ANRIL is transcribed from this locus, where it is presumed to play a regulatory role. Expression of ANRIL was found to co-cluster with $\mathrm{p} 14^{\mathrm{ARF}}$ (and, to a lesser extent $\mathrm{p} 16^{\mathrm{INK} 4 \mathrm{a}}$ and $\mathrm{p} 15^{\mathrm{INK} 4 \mathrm{~b}}$ ) in both physiological (various normal human tissues) and pathological conditions (various human tumors) suggesting that these two genes may share a coordinated transcription ${ }^{214}$. Genome-wide association studies (GWAS) recently identified ANRIL as a risk locus for several cancers, including breast cancer, nasopharyngeal carcinoma, basal cell carcinoma, and glioma $^{215-219}$. However, the exact function of ANRIL in CMM remains to be determined.

Furthermore, expression of SPRY4-IT1, a IncRNA derived from an intron within the sprouty 4 (SPRY4, an inhibitor of the MAPK signaling pathway) gene, was found to be substantially increased in $\mathrm{CMM}^{220}$. Knock-down of SPRY4-IT1 expression results in defects in cell growth, decreased invasion and migration, and increased rates of apoptosis in melanoma cells ${ }^{220}$. More research on IncRNAs will most likely identify further promising markers that are deregulated in CMM biology. 


\section{Histone modifications, Polycomb group proteins, and chromatin remodeling}

Data on aberrant post-translational modifications of histones in CMM are limited. Histone modifications can disrupt contacts within and between nucleosomes and recruit proteins, thus generate a higher-order chromatin structure ${ }^{221}$. Despite the lack of strong data, aberrant post-translational modifications of histones, in particular their hypoacetylation, is thought to control CMM biology by affecting the same pathways that are affected by mutations and $\mathrm{CpG}$ island hypermethylation. Histone modifications of genes involved in cell cycle regulation and apoptosis have been characterized, e.g. histone hypoacetylation-mediated downregulation of CDKN1A ${ }^{222}$, and upregulation of the pro-apoptotic proteins APAF- ${ }^{223}, \mathrm{BAX}, \mathrm{BAK}, \mathrm{BID}, \mathrm{BIM}$, caspase- 3 and caspase $-88^{224,225}$, TNFRSF10A, and TNFRSF10B ${ }^{226}$.

Polycomb group $(\mathrm{PcG})$ proteins are transcriptional repressors that function through recognition and modification of histone methylation, histone ubiquitination, and chromatin structure ${ }^{227}$. They function through the formation of Polycomb repressive complexes (PRCs) including PRC1 and PRC2, and are important in embryonic gene regulation ${ }^{228}$ and tumor development ${ }^{229}$. Protein levels of enhancer of zeste homologue 2 (EZH2), the catalytic subunit of PRC2, increase incrementally from benign nevi to CMM, which suggests that EZH2 may play a role in the pathogenesis and progression of $\mathrm{CMM}^{222,230,231}$.

Interestingly, a strong link of BRAF ${ }^{\mathrm{V} 600 \mathrm{E}}$ signaling with $\mathrm{EZH} 2$ expression in $\mathrm{CMM}$ cells was recently demonstrated ${ }^{100}$ potentially causing BRAF $^{\mathrm{V} 600 \mathrm{E}}$-promoted gene hypermethylation. Furthermore, it was shown that in CMM cells, EZH2 suppresses senescence by repressing CDKN1A expression independent of $\mathrm{p} 16^{\mathrm{INK} 4 \mathrm{a}}$ expression or p53 function ${ }^{222}$. Loss of EZH2 substantially increased histone acetylation at CDKN1A due to loss of histone deacetylase 1 (HDAC1) at this locus. The INK4b-ARF-INK4a locus is also suppressed by PcG proteins, specifically by BMI1, which is part of PRC1 ${ }^{229,232}$. Loss of expression of BMI1 is associated with CMM development, aggressive tumor subgroups and reduced patient survival ${ }^{233}$. BMI1 does not suppress $p 16^{1 \mathrm{NK} 4 a}$ expression indicating that BMI1 may act through a mechanism involving the p14 ${ }^{\text {ARF }}-p 53$ pathway. Moreover, the histone 3 lysine 27 (H3K27) demethylase jumonji domaincontaining 3 (JMJD3 or KDM6B) neutralizes PcG-mediated silencing at the INK4b-ARFINK4a locus. JMJD3 is upregulated in nevi in response to oncogenic RAS signaling that leads to oncogene-induced senescence ${ }^{234,235}$. In addition, lysine (K)-specific demethylase 5B (KDM5B or JARID1B), a H3K4 demethylase, is associated with pRBmediated cell cycle control in $\mathrm{CMM}^{236,237}$. KDM5B is highly expressed in nevi whereas primary and metastatic $\mathrm{CMM}$ only contain a small percentage of cells that express $\mathrm{KDM}^{2} \mathrm{~B}^{238}$. Moreover, KDM5B is considered a CMM stem cell marker ${ }^{239}$.

Chromatin remodeling refers to the enzyme-assisted movement of nucleosomes on DNA which modulates gene transcription ${ }^{240}$. SWI/SNF complexes are ATP-dependent chromatin remodeling enzymes that remodel nucleosome structure and are capable of mobilizing nucleosomes both by sliding and by catalyzing the ejection and insertion of 
histone octamers ${ }^{240,241}$. Dynamic activities of these complexes have essential roles in regulating gene expression and deregulation of the complexes have been linked to CMM development ${ }^{139,242-246}$, as reviewed by Vinod Salidi et al. ${ }^{247}$.

BRG1, a subunit of the SWI/SNF complex, was recognized as an important tumor suppressor in CMM, and is downregulated in both primary and metastatic $\mathrm{CMM}^{242,243}$. Interestingly, this is more pronounced in primary CMM compared to metastatic CMM, suggesting a stage-specific modulation of BRG1 in CMM progression ${ }^{242}$. The SWI/SNF subunit BRM is also downregulated in CMM cells, but a combined loss of both BRG1 and BRM expression has not been observed ${ }^{243}$. Therefore, although SWI/SNF activity is reduced in CMM cells to some extent by downregulation of particular subunits, at least one functional SWI/SNF ATPase must be retained to promote aspects of CMM tumorigenicity $^{243}$. Moreover, BRG1 is recognized as a binding partner of p16 ${ }^{\text {INK4a }}$. It is speculated that the SWI/SNF complex regulates overall signaling through $\mathrm{p} 16^{\mathrm{INK} 4 a}-\mathrm{pRB}$ - E2F by directly binding to $\mathrm{pRb}$ and facilitating the expression of $\mathrm{pRb}$ and E2F target genes $^{248-251}$.

In a tissue culture model of melanocyte differentiation, MITF was shown to promote recruitment of SWI/SNF enzymes to the promoters of melanocyte-specific genes, such as tyrosinase-related protein 1 (TYRP1), where these enzymes remodel chromatin to activate gene expression ${ }^{244}$. Keenen et al. $^{243}$ also reported that the expression of several MITF target genes was dependent on the SWI/SNF chromatin remodeling complex. Interestingly, in melanoma cells it has been shown as well that SWI/SNF acts upstream of MITF and is critically in the expression of MITF itself ${ }^{245}$. Thus, it seems that the SWI/SNF complex is a coactivator of MITF target genes expression, and in addition an essential cofactor for transcription of MITF itself in melanoma cells.

Furthermore, induction of HDAC1 is recognized as a pivotal step in oncogeneinduced senescence of melanocytes, with the BRM1 subunit being associated with heterochromatic foci in senescing melanocytes ${ }^{246}$. This is consistent with the observation that loss of IGFBP7 and subsequent downregulation of SMARCB1, a component of the SWI/SNF chromatin remodeling complex, is important for bypassing oncogenic $\mathrm{BRAF}^{\mathrm{V} 600 \mathrm{E}}$-induced apoptosis and senescence in melanocytes ${ }^{139}$.

\section{Concerted action of genetic and epigenetic alterations in regulating gene expression}

Genetic and epigenetic alterations cooperate in altering gene expression in CMM development (Table 2). The frequent changes of the INK4b-ARF-INK4a locus, as described above, provide an illustrative example (Figure 1). Besides being inactivated by mutations and deletions, the key tumor suppressors $\mathrm{p} 14^{\mathrm{ARF}}$ and $\mathrm{p} 16^{\mathrm{INK} 4 \mathrm{a}}$ are also epigenetically silenced by DNA methylation ${ }^{138,141}$. No correlation between hypermethylation of $\mathrm{p} 16^{\text {INK4a }}$ and mutation of BRAF and NRAS was observed ${ }^{120}$. One explanation for the frequent alteration of this locus is its key role in the induction of 
oncogene-induced senescence. These molecules are frequently upregulated in premalignant lesions, thus limiting tumor progression ${ }^{252}$. For example, p16 $16^{\text {INK4a }}$ expression is a marker of oncogene-induced senescence in melanocytic nevi expressing activated BRAF ${ }^{48,253}$. Given the relevance of the INK4b-ARF-INK4a locus in cell cycle control, it is essential that this functional unit is tightly regulated.

One critical layer to achieve this control is through PRCs, and the INK4b-ARF-INK4a locus is indeed a target of PcG proteins ${ }^{232}$. It is becoming evident that PcG target genes are predisposed to promoter $\mathrm{CpG}$ island hypermethylation ${ }^{254}$, and many genes reported to be hypermethylated in CMM indeed are PcG target genes ${ }^{255}$ (Table 2). Overexpression of different PCG members, such as BMI1, CBX7 or CBX8, results in repression of the INK4b-ARF-INK4a locus thus bypassing senescence ${ }^{232,256,257}$. On the other hand, cells lacking PRC1 components BMI1 or RING1B show aberrant expression of the INK4b-ARF-INK4a locus ${ }^{232,258}$. Moreover, Bracken et al. ${ }^{259}$ showed that in senescent cells, PcG proteins, e.g. EZH2, are disassociated from the INK4b-ARF-INK4a locus resulting in a decreased level of histone $\mathrm{H} 3 \mathrm{~K} 27 \mathrm{me} 3$ and reactivation of $\mathrm{p} 14^{\mathrm{ARF}}$ and $\mathrm{p} 16^{\mathrm{INK} 4 \mathrm{a}}$ genes. Hence, the upregulation of PcG protein expression in nevi could contribute to the loss of tumor suppressor activity and drive malignant transformation ${ }^{259}$. Recently, IncRNAs, such as ANRIL, were found to contribute to the targeting of PRCs to the INK4b-ARF-INK4a locus ${ }^{260}$. Furthermore, regulation of PcG protein expression can be mediated by miRNAs. Genomic loss of miR-101 in cancer is associated with the induction of EZH2 expression ${ }^{261,262}$, and might be a potential mechanism for the observed EZH2 activation ${ }^{222,230,231}$ in CMM as well. MiRNAs themselves, e.g. miR-24, can also directly suppress $\mathrm{p} 16^{\mathrm{INK4a}}$ expression in human diploid fibroblasts and cervical carcinoma cells ${ }^{263}$, thus they could be a means for interfering with the INK4b-ARF-INK4a locus in CMM. Moreover, the INK4b-ARF-INK4a locus is, at least in malignant rhabdoid tumors, targeted by SWI/SNF chromatin remodeling complexes, and a direct interplay between SWI/SNF and PCG is emerging ${ }^{264,265}$. SWI/SNF displaces PcG silencing complexes from the INK4b-ARF-INK4a locus. Also, the direct interaction on protein level between BRG1 and $p 16^{\text {INK4a }}$ is a mechanism by which SWI/SNF chromatin remodeling activity may be intertwined with p $16^{\text {INK4a }}$ in $\mathrm{CMM}^{242}$. The observed loss of the SWI/SNF subunit SMARCB1 in CMM may also compromise the expression of $\mathrm{p} 16^{\mathrm{INK} 4 \mathrm{a}}$ and other senescence-promoting genes by preventing SWI/SNF recruitment to the promoters of these genes, and thus supporting malignant progression ${ }^{139}$.

This illustrates the interconnectivity and dynamics of diverse genetic and epigenetic alterations in control of the INK4b-ARF-INK4a locus in CMM. (Figure 1).

Additional evidence for the interplay of genetic and epigenetic mechanisms is derived from the MITF gene, another key player in CMM development which is targeted by mutations $s^{75}$, gene amplification ${ }^{67,266}$, and miRNAs ${ }^{173,175}$ (Figure 1). In addition, the SWI/SNF complex acts upstream of MITF to regulate its expression ${ }^{245}$. MITF further can upregulate SWI/SNF chromatin remodeling enzymes ${ }^{243,244}$ and interestingly, the expression of p16 $6^{\text {INK4a }} 82$ and p21 (CDKN1A), another cell cycle 


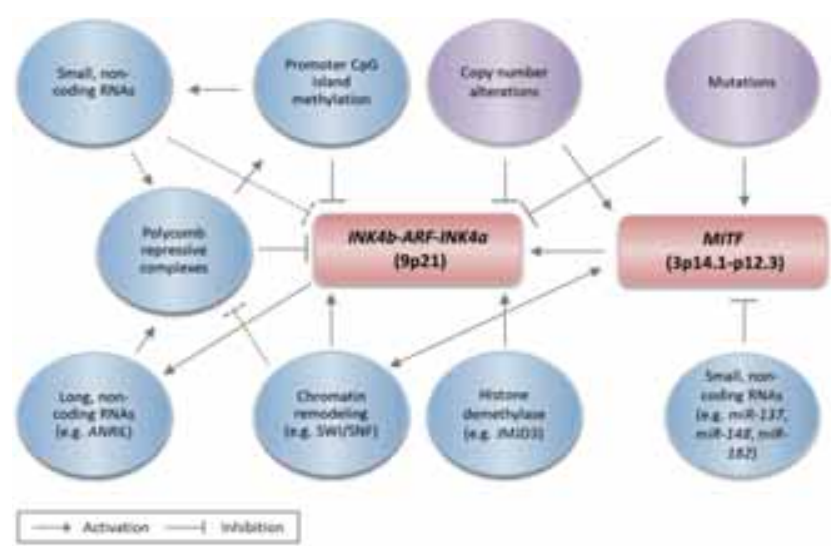

Figure 1. Regulation of the INKAb-ARF-INKAa locus and MITFin CMM. Deregulation of the INK4b-ARF-INK4a locus and MITF is a result of both genetic (purple balloons) and epigenetic (blue balloons) aberrations. Irreversible genetic mutations and deletions lead to the silencing of the tumor suppressive INK4b-ARF-INK4a locus while the oncogenic MITF gene is activated by mutations and gene amplification. Epigenetic regulation involving promoter $\mathrm{CpG}$ island methylation, non-coding RNAs, polycomb repressive complexes (PRCs), chromatin remodeling and histone modifications lead to transcriptional activation or silencing of the INK4bARF-INK4a locus. MITF also directly induces expression of $\mathrm{p} 16^{\mathrm{INK4a}}$ or indirectly via upregulation of SWI/SNF chromatin remodeling enzymes. MITF expression is furthermore known to be altered by the SWI/SNF complex and miRNAs. The exact interplay between all these processes has not been fully elucidated, but evidence for causal relationships exist (grey lines). Straight lines, evidence for the association in CMM; Dashed lines, association found in cancers other than CMM.

inhibitor $^{83}$. Furthermore, malignant transformation of immortalized human melanocytes occurred through the cooperation of M ITF and activated BRAF ${ }^{\mathrm{V} 600 \mathrm{E}}$, and mutated BRAF and p16 ${ }^{\text {INK4a }}$ loss accompanied MITF amplification in melanoma cell lines ${ }^{67}$. Hence, it seems that two of the most frequent events associated with the pathogenesis of CMM, i.e. activation of BRAF and loss of p16 ${ }^{\text {INK4a }}$, both oppose an anticancerous action of M ITF.

In CMM, simultaneous gene mutation ${ }^{69,70}$, deletion ${ }^{79}$, and promoter $\mathrm{CpG}$ island methylation ${ }^{120,135}$ has also been described for PTEN. As was shown for p16 $6^{\text {INK4a }}$, mutation of BRAF and NRAS and PTEN methylation did not correlate ${ }^{120}$. Interestingly, PTEN methylation was shown to act as an independent prognostic parameter but not superior to tumor thickness and ulceration ${ }^{120}$.

Furthermore, runt-related transcription factor 3 (RUNX3) is implicated in CMM progression as mRNA levels were shown to decrease from normal tissues via primary CMM to metastatic $\mathrm{CMM}^{144}$. RUNX3 is epigenetically regulated in CMM by both CpG island hypermethylation and miRNA-532-5 $p^{144}$. In addition, the $1 p 36$ region, where RUNX3 is located, shows allelic imbalance in $\mathrm{CMM}^{267-269}$. These three types of molecular aberrations together may suppress RUNX3 expression during the development and metastasis of CMM.

In summary, diverse genetic and epigenetic alterations underlie aberrant gene expression in $\mathrm{CMM}$ and the complexity behind the initiation and progression of CMM 
is becoming more and more evident. Our understanding is growing but still in its infancy.

\section{Conclusions and future perspectives}

Understanding the molecular mechanisms that are involved in the initiation and progression of CMM as well as the knowledge of their interplay has great potential for the clinical management of this disease. Although the genetic components underlying $\mathrm{CMM}$ are emerging, a complete picture of the epigenetic alterations and the combinatorial interactions between these events is lacking. A more detailed understanding is beginning to emerge for genetic and epigenetic interactions in the aberrant regulation of the INK4b-ARF-INK4a locus and M ITF transcription factor as we discussed in this review. It is expected that a detailed molecular picture for CMM will be generated in the near future by using and integrating novel techniques to map the CMM genome and epigenome.

Knowledge of the molecular complexities underlying CMM development and progression is crucial for understanding the commonly observed drug resistance as well as the development of novel targeted treatment strategies. Systemic treatment of CMM patients with the epigenetic drug decitabine in combination with chemotherapy and/or immunotherapy may provide a valuable treatment strategy for CMM patients $^{270}$.

Detailed molecular knowledge of CMM biology will further be instrumental in the identification of novel biomarkers for early detection, risk stratification, or prediction of response to therapy, altogether improving the clinical management of this disease. Once such markers have been identified, attention should be directed to the development and validation of biomarker assays. Currently, many studies in CMM, especially on epigenetic markers, are difficult to compare due to differences in the methods and assays to detect the markers and limited sample numbers with often a lack of non-malignant control tissues. It is therefore important to validate these potential markers in large patient cohorts for their diagnostic, prognostic or predictive value in order to effectively translate these findings into the clinic.

\section{Acknowledgements}

This work was supported by Profileringsfonds Maastricht University Medical Centre (PF-278). 


\section{References}

1. Dupin E, Le Douarin NM. Development of melanocyte precursors from the vertebrate neural crest. Oncogene, 2003. 22(20): p. 3016-3023.

2. Houghton AN, Polsky D. Focus on melanoma. Cancer Cell, 2002. 2(4): p. 275-278.

3. MacKie RM, Hauschild A, Eggermont AM. Epidemiology of invasive cutaneous melanoma. Ann Oncol, 2009. 20 Suppl 6: p. vi1-7.

4. Ferlay J, Shin HR, Bray F, et al. Estimates of worldwide burden of cancer in 2008: GLOBOCAN 2008. Int J Cancer, 2010. 127(12): p. 2893-2917.

5. McGovern VJ, Mihm MC, Jr., Bailly C, et al. The classification of malignant melanoma and its histologic reporting. Cancer, 1973. 32(6): p. 1446-1457.

6. Clark WH, Jr., From L, Bernardino EA, et al. The histogenesis and biologic behavior of primary human malignant melanomas of the skin. Cancer Res, 1969. 29(3): p. 705-727.

7. Vidwans SJ, Flaherty KT, Fisher DE, et al. A melanoma molecular disease model. PLoS One, 2011. 6(3): p. e18257.

8. Scolyer RA, Long GV, Thompson JF. Evolving concepts in melanoma classification and their relevance to multidisciplinary melanoma patient care. Mol Oncol, 2011. 5(2): p. 124-136.

9. Clark WH, Jr., Elder DE, Guerry Dt, et al. A study of tumor progression: the precursor lesions of superficial spreading and nodular melanoma. Hum Pathol, 1984. 15(12): p. 1147-1165.

10. Miller AJ, Mihm MC, Jr. Melanoma. N Engl J Med, 2006. 355(1): p. 51-65.

11. Balch CM, Gershenwald JE, Soong SJ, et al. Final version of 2009 AJCC melanoma staging and classification. J Clin Oncol, 2009. 27(36): p. 6199-6206.

12. Gray-Schopfer V, Wellbrock C, Marais R. Melanoma biology and new targeted therapy. Nature, 2007. 445(7130): p. 851-857.

13. Bedikian AY, Millward $\mathrm{M}$, Pehamberger $\mathrm{H}$, et al. Bcl-2 antisense (oblimersen sodium) plus dacarbazine in patients with advanced melanoma: the Oblimersen Melanoma Study Group. J Clin Oncol, 2006. 24(29): p. 4738-4745.

14. Avril MF, Aamdal S, Grob JJ, et al. Fotemustine compared with dacarbazine in patients with disseminated malignant melanoma: a phase III study. J Clin Oncol, 2004. 22(6): p. 1118-1125.

15. Chapman PB, Einhorn LH, Meyers ML, et al. Phase III multicenter randomized trial of the Dartmouth regimen versus dacarbazine in patients with metastatic melanoma. J Clin Oncol, 1999. 17(9): p. 2745-2751.

16. Eggermont AM, Kirkwood JM. Re-evaluating the role of dacarbazine in metastatic melanoma: what have we learned in 30 years? Eur J Cancer, 2004. 40(12): p. 1825-1836.

17. Middleton MR, Grob JJ, Aaronson N, et al. Randomized phase III study of temozolomide versus dacarbazine in the treatment of patients with advanced metastatic malignant melanoma. J Clin Oncol, 2000. 18(1): p. 158166.

18. Atkins $M B$, Lotze $M T$, Dutcher JP, et al. High-dose recombinant interleukin 2 therapy for patients with metastatic melanoma: analysis of 270 patients treated between 1985 and 1993. J Clin Oncol, 1999. 17(7): p. 2105-2116.

19. Atkins MB, Kunkel L, Sznol M, et al. High-dose recombinant interleukin-2 therapy in patients with metastatic melanoma: long-term survival update. Cancer J Sci Am, 2000. 6 Suppl 1: p. S11-14.

20. Rosenberg SA, Yang JC, Topalian SL, et al. Treatment of 283 consecutive patients with metastatic melanoma or renal cell cancer using high-dose bolus interleukin 2. Jama, 1994. 271(12): p. 907-913.

21. Pectasides D, Dafni U, Bafaloukos D, et al. Randomized phase III study of 1 month versus 1 year of adjuvant high-dose interferon alfa-2b in patients with resected high-risk melanoma. J Clin Oncol, 2009. 27(6): p. 939944.

22. Kirkwood JM, Strawderman MH, Ernstoff MS, et al. Interferon alfa-2b adjuvant therapy of high-risk resected cutaneous melanoma: the Eastern Cooperative Oncology Group Trial EST 1684. J Clin Oncol, 1996. 14(1): p. 717.

23. Kirkwood JM, Manola J, Ibrahim J, et al. A pooled analysis of eastern cooperative oncology group and intergroup trials of adjuvant high-dose interferon for melanoma. Clin Cancer Res, 2004. 10(5): p. 1670-1677.

24. Eggermont AM, Suciu S, Santinami M, et al. Adjuvant therapy with pegylated interferon alfa- $2 b$ versus observation alone in resected stage III melanoma: final results of EORTC 18991, a randomised phase III trial. Lancet, 2008. 372(9633): p. 117-126.

25. Hodi FS, O'Day SJ, McDermott DF, et al. Improved survival with ipilimumab in patients with metastatic melanoma. N Engl J Med, 2010. 363(8): p. 711-723.

26. Robert $\mathrm{C}$, Thomas $\mathrm{L}$, Bondarenko I, et al. Ipilimumab plus dacarbazine for previously untreated metastatic melanoma. N Engl J Med, 2011. 364(26): p. 2517-2526.

27. Flaherty KT, Yasothan U, Kirkpatrick P. Vemurafenib. Nat Rev Drug Discov, 2011. 10(11): p. 811-812. 
28. Chapman PB, Hauschild A, Robert C, et al. Improved survival with vemurafenib in melanoma with BRAF V600E mutation. N Engl J Med, 2011. 364(26): p. 2507-2516.

29. Carvajal RD, Antonescu CR, Wolchok JD, et al. KIT as a therapeutic target in metastatic melanoma. Jama, 2011. 305(22): p. 2327-2334.

30. Guo J, Si L, Kong Y, et al. Phase II, open-label, single-arm trial of imatinib mesylate in patients with metastatic melanoma harboring c-Kit mutation or amplification. J Clin Oncol, 2011. 29(21): p. 2904-2909.

31. Bogenrieder T, Herlyn M. The molecular pathology of cutaneous melanoma. Cancer Biomark, 2011. 9(1-6): $p$. 267-286.

32. Govindarajan B, Bai X, Cohen C, et al. Malignant transformation of melanocytes to melanoma by constitutive activation of mitogen-activated protein kinase kinase (MAPKK) signaling. J Biol Chem, 2003. 278(11): p. 97909795.

33. Cohen C, Zavala-Pompa A, Sequeira JH, et al. Mitogen-actived protein kinase activation is an early event in melanoma progression. Clin Cancer Res, 2002. 8(12): p. 3728-3733.

34. Beadling $\mathrm{C}$, Jacobson-Dunlop E, Hodi FS, et al. KIT gene mutations and copy number in melanoma subtypes. Clin Cancer Res, 2008. 14(21): p. 6821-6828.

35. Curtin JA, Busam K, Pinkel D, et al. Somatic activation of KIT in distinct subtypes of melanoma. J Clin Oncol, 2006. 24(26): p. 4340-4346.

36. Woenckhaus C, Giebel J, Failing K, et al. Expression of AP-2alpha, c-kit, and cleaved caspase-6 and -3 in naevi and malignant melanomas of the skin. A possible role for caspases in melanoma progression? J Pathol, 2003. 201(2): p. 278-287.

37. Willmore-Payne $C$, Holden JA, Hirschowitz $S$, et al. BRAF and c-kit gene copy number in mutation-positive malignant melanoma. Hum Pathol, 2006. 37(5): p. 520-527.

38. Willmore-Payne C, Holden JA, Tripp S, et al. Human malignant melanoma: detection of BRAF- and c-kitactivating mutations by high-resolution amplicon melting analysis. Hum Pathol, 2005. 36(5): p. 486-493.

39. van 't Veer $\mathrm{L}$, Burgering $B M$, Versteeg $R$, et al. $N$-ras mutations in human cutaneous melanoma from sunexposed body sites. Mol Cell Biol, 1989. 9(7): p. 3114-3116.

40. Albino AP, Nanus DM, Mentle IR, et al. Analysis of ras oncogenes in malignant melanoma and precursor lesions: correlation of point mutations with differentiation phenotype. Oncogene, 1989. 4(11): p. 1363-1374.

41. Ball NJ, Yohn JJ, Morelli JG, et al. Ras mutations in human melanoma: a marker of malignant progression. J Invest Dermatol, 1994. 102(3): p. 285-290.

42. Davies H, Bignell GR, Cox C, et al. Mutations of the BRAF gene in human cancer. Nature, 2002. 417(6892): p. 949-954.

43. Gray-Schopfer VC, da Rocha Dias S, Marais R. The role of B-RAF in melanoma. Cancer Metastasis Rev, 2005. 24(1): p. 165-183.

44. Pollock PM, Harper UL, Hansen KS, et al. High frequency of BRAF mutations in nevi. Nat Genet, 2003. 33(1): p. 19-20.

45. Bauer J, Curtin JA, Pinkel D, et al. Congenital melanocytic nevi frequently harbor NRAS mutations but no BRAF mutations. J Invest Dermatol, 2007. 127(1): p. 179-182.

46. Ross AL, Sanchez MI, Grichnik JM. Molecular nevogenesis. Dermatol Res Pract, 2011. 2011: p. 463184.

47. Maldonado JL, Fridlyand J, Patel $\mathrm{H}$, et al. Determinants of BRAF mutations in primary melanomas. J Natl Cancer Inst, 2003. 95(24): p. 1878-1890.

48. Michaloglou C, Vredeveld LC, Soengas MS, et al. BRAFE600-associated senescence-like cell cycle arrest of human naevi. Nature, 2005. 436(7051): p. 720-724.

49. Platz A, Hansson J, Mansson-Brahme E, et al. Screening of germline mutations in the CDKN2A and CDKN2B genes in Swedish families with hereditary cutaneous melanoma. J Natl Cancer Inst, 1997. 89(10): p. 697-702.

50. Stone $S$, Dayananth $P$, Jiang $P$, et al. Genomic structure, expression and mutational analysis of the P15 (MTS2) gene. Oncogene, 1995. 11(5): p. 987-991.

51. Flores JF, Pollock PM, Walker GJ, et al. Analysis of the CDKN2A, CDKN2B and CDK4 genes in 48 Australian melanoma kindreds. Oncogene, 1997. 15(24): p. 2999-3005.

52. Matsumura $Y$, Nishigori $C$, Yagi $T$, et al. Mutations of $p 16$ and $p 15$ tumor suppressor genes and replication errors contribute independently to the pathogenesis of sporadic malignant melanoma. Arch Dermatol Res, 1998. 290(4): p. 175-180.

53. Kamb A, Shattuck-Eidens D, Eeles R, et al. Analysis of the p16 gene (CDKN2) as a candidate for the chromosome 9p melanoma susceptibility locus. Nat Genet, 1994. 8(1): p. 23-26.

54. Hussussian CJ, Struewing JP, Goldstein AM, et al. Germline p16 mutations in familial melanoma. Nat Genet, 1994. 8(1): p. 15-21.

55. Sharpless E, Chin L. The INK4a/ARF locus and melanoma. Oncogene, 2003. 22(20): p. 3092-3098.

56. Goldstein AM, Chan M, Harland $M$, et al. High-risk melanoma susceptibility genes and pancreatic cancer, neural system tumors, and uveal melanoma across GenoMEL. Cancer Res, 2006. 66(20): p. 9818-9828. 
57. Helsing P, Nymoen DA, Ariansen $\mathrm{S}$, et al. Population-based prevalence of CDKN2A and CDK4 mutations in patients with multiple primary melanomas. Genes Chromosomes Cancer, 2008. 47(2): p. 175-184.

58. Bastian BC, LeBoit PE, Hamm H, et al. Chromosomal gains and losses in primary cutaneous melanomas detected by comparative genomic hybridization. Cancer Res, 1998. 58(10): p. 2170-2175.

59. Curtin JA, Fridlyand J, Kageshita T, et al. Distinct sets of genetic alterations in melanoma. N Engl J Med, 2005. 353(20): p. 2135-2147.

60. Muthusamy V, Hobbs C, Nogueira C, et al. Amplification of CDK4 and MDM2 in malignant melanoma. Genes Chromosomes Cancer, 2006. 45(5): p. 447-454.

61. Walker GJ, Palmer JM, Walters MK, et al. A genetic model of melanoma tumorigenesis based on allelic losses. Genes Chromosomes Cancer, 1995. 12(2): p. 134-141.

62. Isshiki K, Elder DE, Guerry D, et al. Chromosome 10 allelic loss in malignant melanoma. Genes Chromosomes Cancer, 1993. 8(3): p. 178-184.

63. Isshiki K, Seng BA, Elder DE, et al. Chromosome 9 deletion in sporadic and familial melanomas in vivo. Oncogene, 1994. 9(6): p. 1649-1653.

64. Herbst RA, Weiss J, Ehnis A, et al. Loss of heterozygosity for 10q22-10qter in malignant melanoma progression. Cancer Res, 1994. 54(12): p. 3111-3114.

65. Healy E, Belgaid C, Takata M, et al. Prognostic significance of allelic losses in primary melanoma. Oncogene, 1998. 16(17): p. 2213-2218.

66. Jonsson G, Dahl C, Staaf J, et al. Genomic profiling of malignant melanoma using tiling-resolution arrayCGH. Oncogene, 2007. 26(32): p. 4738-4748.

67. Garraway LA, Widlund HR, Rubin MA, et al. Integrative genomic analyses identify MITF as a lineage survival oncogene amplified in malignant melanoma. Nature, 2005. 436(7047): p. 117-122.

68. Gerami $P$, Jewell SS, Pouryazdanparast $P$, et al. Copy number gains in $11 q 13$ and $8 q 24$ [corrected] are highly linked to prognosis in cutaneous malignant melanoma. J Mol Diagn, 2011. 13(3): p. 352-358.

69. Tsao $H$, Zhang $X$, Benoit $E$, et al. Identification of PTEN/MMAC1 alterations in uncultured melanomas and melanoma cell lines. Oncogene, 1998. 16(26): p. 3397-3402.

70. Wu H, Goel V, Haluska FG. PTEN signaling pathways in melanoma. Oncogene, 2003. 22(20): p. 3113-3122.

71. Stahl JM, Sharma A, Cheung M, et al. Deregulated Akt3 activity promotes development of malignant melanoma. Cancer Res, 2004. 64(19): p. 7002-7010.

72. Tsao H, Goel V, Wu H, et al. Genetic interaction between NRAS and BRAF mutations and PTEN/MMAC1 inactivation in melanoma. J Invest Dermatol, 2004. 122(2): p. 337-341.

73. Downward J. Targeting RAS signalling pathways in cancer therapy. Nat Rev Cancer, 2003. 3(1): p. 11-22.

74. Hemesath TJ, Steingrimsson E, McGill G, et al. microphthalmia, a critical factor in melanocyte development, defines a discrete transcription factor family. Genes Dev, 1994. 8(22): p. 2770-2780.

75. Cronin JC, Wunderlich J, Loftus SK, et al. Frequent mutations in the MITF pathway in melanoma. Pigment Cell Melanoma Res, 2009. 22(4): p. 435-444.

76. Bertolotto C, Lesueur F, Giuliano S, et al. A SUMOylation-defective MITF germline mutation predisposes to melanoma and renal carcinoma. Nature, 2011. 480(7375): p. 94-98.

77. Yokoyama S, Woods SL, Boyle GM, et al. A novel recurrent mutation in MITF predisposes to familial and sporadic melanoma. Nature, 2011. 480(7375): p. 99-103.

78. Sauter ER, Yeo UC, von Stemm A, et al. Cyclin D1 is a candidate oncogene in cutaneous melanoma. Cancer Res, 2002. 62(11): p. 3200-3206.

79. Stahl JM, Cheung M, Sharma A, et al. Loss of PTEN promotes tumor development in malignant melanoma. Cancer Res, 2003. 63(11): p. 2881-2890.

80. Straume $\mathrm{O}$, Akslen LA. Alterations and prognostic significance of $\mathrm{p} 16$ and p53 protein expression in subgroups of cutaneous melanoma. Int J Cancer, 1997. 74(5): p. 535-539.

81. McGill GG, Horstmann M, Widlund HR, et al. Bcl2 regulation by the melanocyte master regulator Mitf modulates lineage survival and melanoma cell viability. Cell, 2002. 109(6): p. 707-718.

82. Loercher AE, Tank EM, Delston RB, et al. MITF links differentiation with cell cycle arrest in melanocytes by transcriptional activation of INK4A. J Cell Biol, 2005. 168(1): p. 35-40.

83. Carreira S, Goodall J, Aksan I, et al. Mitf cooperates with Rb1 and activates p21Cip1 expression to regulate cell cycle progression. Nature, 2005. 433(7027): p. 764-769.

84. Du J, Widlund HR, Horstmann MA, et al. Critical role of CDK2 for melanoma growth linked to its melanocytespecific transcriptional regulation by MITF. Cancer Cell, 2004. 6(6): p. 565-576.

85. Wellbrock C, Marais R. Elevated expression of MITF counteracts B-RAF-stimulated melanocyte and melanoma cell proliferation. J Cell Biol, 2005. 170(5): p. 703-708.

86. Goding CR. Mitf from neural crest to melanoma: signal transduction and transcription in the melanocyte lineage. Genes Dev, 2000. 14(14): p. 1712-1728.

87. Du J, Miller AJ, Widlund HR, et al. MLANA/MART1 and SILV/PMEL17/GP100 are transcriptionally regulated by MITF in melanocytes and melanoma. Am J Pathol, 2003. 163(1): p. 333-343. 
88. Miller AJ, Du J, Rowan $\mathrm{S}$, et al. Transcriptional regulation of the melanoma prognostic marker melastatin (TRPM1) by MITF in melanocytes and melanoma. Cancer Res, 2004. 64(2): p. 509-516.

89. Takeuchi H, Kuo C, Morton DL, et al. Expression of differentiation melanoma-associated antigen genes is associated with favorable disease outcome in advanced-stage melanomas. Cancer Res, 2003. 63(2): p. 441448.

90. Duncan LM, Deeds J, Hunter J, et al. Down-regulation of the novel gene melastatin correlates with potential for melanoma metastasis. Cancer Res, 1998. 58(7): p. 1515-1520.

91. Widlund HR, Horstmann MA, Price ER, et al. Beta-catenin-induced melanoma growth requires the downstream target Microphthalmia-associated transcription factor. J Cell Biol, 2002. 158(6): p. 1079-1087.

92. Shtutman M, Zhurinsky J, Simcha I, et al. The cyclin D1 gene is a target of the beta-catenin/LEF-1 pathway. Proc Natl Acad Sci U S A, 1999. 96(10): p. 5522-5527.

93. Katoh M. Network of WNT and other regulatory signaling cascades in pluripotent stem cells and cancer stem cells. Curr Pharm Biotechnol, 2011. 12(2): p. 160-170.

94. Tucci MG, Lucarini G, Brancorsini D, et al. Involvement of E-cadherin, beta-catenin, Cdc42 and CXCR4 in the progression and prognosis of cutaneous melanoma. Br J Dermatol, 2007. 157(6): p. 1212-1216.

95. Hsu MY, Wheelock MJ, Johnson KR, et al. Shifts in cadherin profiles between human normal melanocytes and melanomas. J Investig Dermatol Symp Proc, 1996. 1(2): p. 188-194.

96. Jaeger J, Koczan D, Thiesen HJ, et al. Gene expression signatures for tumor progression, tumor subtype, and tumor thickness in laser-microdissected melanoma tissues. Clin Cancer Res, 2007. 13(3): p. 806-815.

97. Esteller M. Epigenetics in cancer. N Engl J Med, 2008. 358(11): p. 1148-1159.

98. Nguyen T, Kuo C, Nicholl MB, et al. Downregulation of microRNA-29c is associated with hypermethylation of tumor-related genes and disease outcome in cutaneous melanoma. Epigenetics, 2011. 6(3): p. 388-394.

99. Deng $\mathrm{T}$, Kuang $\mathrm{Y}$, Wang $\mathrm{L}$, et al. An essential role for DNA methyltransferase 3a in melanoma tumorigenesis. Biochem Biophys Res Commun, 2009. 387(3): p. 611-616.

100. Hou P, Liu D, Dong J, et al. The BRAFV600E causes widespread alterations in gene methylation in the genome of melanoma cells. Cell Cycle, 2012. 11(2): p.

101. van Doorn R, Gruis NA, Willemze R, et al. Aberrant DNA methylation in cutaneous malignancies. Semin Oncol, 2005. 32(5): p. 479-487.

102. Sigalotti L, Coral S, Nardi G, et al. Promoter methylation controls the expression of MAGE2, 3 and 4 genes in human cutaneous melanoma. J Immunother, 2002. 25(1): p. 16-26.

103. Furuta J, Umebayashi $Y$, Miyamoto $\mathrm{K}$, et al. Promoter methylation profiling of 30 genes in human malignant melanoma. Cancer Sci, 2004. 95(12): p. 962-968.

104. Simpson AJ, Caballero OL, Jungbluth A, et al. Cancer/testis antigens, gametogenesis and cancer. Nat Rev Cancer, 2005. 5(8): p. 615-625.

105. Klenova EM, Morse HC, 3rd, Ohlsson R, et al. The novel BORIS + CTCF gene family is uniquely involved in the epigenetics of normal biology and cancer. Semin Cancer Biol, 2002. 12(5): p. 399-414.

106. Robertson KD. DNA methylation and human disease. Nat Rev Genet, 2005. 6(8): p. 597-610.

107. Vatolin S, Abdullaev Z, Pack SD, et al. Conditional expression of the CTCF-paralogous transcriptional factor BORIS in normal cells results in demethylation and derepression of MAGE-A1 and reactivation of other cancer-testis genes. Cancer Res, 2005. 65(17): p. 7751-7762.

108. Kholmanskikh O, Loriot A, Brasseur F, et al. Expression of BORIS in melanoma: lack of association with MAGEA1 activation. Int J Cancer, 2008. 122(4): p. 777-784.

109. Rothhammer T, Bosserhoff AK. Epigenetic events in malignant melanoma. Pigment Cell Res, 2007. 20(2): p. 92-111.

110. Howell PM, Jr., Liu S, Ren S, et al. Epigenetics in human melanoma. Cancer Control, 2009. 16(3): p. $200-218$.

111. Richards HW, Medrano EE. Epigenetic marks in melanoma. Pigment Cell Melanoma Res, 2009. 22(1): p. 1429.

112. Schinke C, Mo Y, Yu Y, et al. Aberrant DNA methylation in malignant melanoma. Melanoma Res, 2010. 20(4): p. $253-265$.

113. Sigalotti L, Covre A, Fratta E, et al. Epigenetics of human cutaneous melanoma: setting the stage for new therapeutic strategies. J Transl Med, 2010. 8: p. 56.

114. Herman JG, Baylin SB. Gene silencing in cancer in association with promoter hypermethylation. N Engl J Med, 2003. 349(21): p. 2042-2054

115. Hoon DS, Spugnardi M, Kuo C, et al. Profiling epigenetic inactivation of tumor suppressor genes in tumors and plasma from cutaneous melanoma patients. Oncogene, 2004. 23(22): p. 4014-4022.

116. Liu $S$, Ren $S$, Howell $P$, et al. Identification of novel epigenetically modified genes in human melanoma via promoter methylation gene profiling. Pigment Cell Melanoma Res, 2008. 21(5): p. 545-558.

117. Tanemura A, Terando AM, Sim MS, et al. CpG island methylator phenotype predicts progression of malignant melanoma. Clin Cancer Res, 2009. 15(5): p. 1801-1807. 
118. Mori T, O'Day SJ, Umetani N, et al. Predictive utility of circulating methylated DNA in serum of melanoma patients receiving biochemotherapy. J Clin Oncol, 2005. 23(36): p. 9351-9358.

119. Spugnardi M, Tommasi S, Dammann R, et al. Epigenetic inactivation of RAS association domain family protein 1 (RASSF1A) in malignant cutaneous melanoma. Cancer Res, 2003. 63(7): p. 1639-1643.

120. Lahtz C, Stranzenbach R, Fiedler E, et al. Methylation of PTEN as a prognostic factor in malignant melanoma of the skin. J Invest Dermatol, 2010. 130(2): p. 620-622.

121. Kohonen-Corish MR, Cooper WA, Saab J, et al. Promoter hypermethylation of the O(6)-methylguanine DNA methyltransferase gene and microsatellite instability in metastatic melanoma. J Invest Dermatol, 2006. 126(1): p. 167-171.

122. Marini A, Mirmohammadsadegh A, Nambiar S, et al. Epigenetic inactivation of tumor suppressor genes in serum of patients with cutaneous melanoma. J Invest Dermatol, 2006. 126(2): p. 422-431.

123. Rietschel P, Wolchok JD, Krown S, et al. Phase II study of extended-dose temozolomide in patients with melanoma. J Clin Oncol, 2008. 26(14): p. 2299-2304.

124. Mori T, Martinez SR, O'Day SJ, et al. Estrogen receptor-alpha methylation predicts melanoma progression. Cancer Res, 2006. 66(13): p. 6692-6698.

125. Faller WJ, Rafferty M, Hegarty $S$, et al. Metallothionein $1 \mathrm{E}$ is methylated in malignant melanoma and increases sensitivity to cisplatin-induced apoptosis. Melanoma Res, 2010. 20(5): p. 392-400.

126. Toyota $\mathrm{M}$, Ahuja $\mathrm{N}$, Ohe-Toyota $\mathrm{M}$, et al. $\mathrm{CpG}$ island methylator phenotype in colorectal cancer. Proc Natl Acad Sci U S A, 1999. 96(15): p. 8681-8686.

127. Issa JP. CpG island methylator phenotype in cancer. Nat Rev Cancer, 2004. 4(12): p. 988-993.

128. Hughes LA, Khalid-de Bakker CA, Smits KM, et al. The CpG island methylator phenotype in colorectal cancer: Progress and problems. Biochim Biophys Acta, 2012. 1825(1): p. 77-85.

129. Gallagher WM, Bergin OE, Rafferty $M$, et al. Multiple markers for melanoma progression regulated by DNA methylation: insights from transcriptomic studies. Carcinogenesis, 2005. 26(11): p. 1856-1867.

130. Muthusamy V, Duraisamy S, Bradbury CM, et al. Epigenetic silencing of novel tumor suppressors in malignant melanoma. Cancer Res, 2006. 66(23): p. 11187-11193.

131. Nobeyama Y, Okochi-Takada E, Furuta J, et al. Silencing of tissue factor pathway inhibitor-2 gene in malignant melanomas. Int J Cancer, 2007. 121(2): p. 301-307.

132. Bonazzi VF, Irwin D, Hayward NK. Identification of candidate tumor suppressor genes inactivated by promoter methylation in melanoma. Genes Chromosomes Cancer, 2009. 48(1): p. 10-21.

133. Mithani SK, Smith IM, Califano JA. Use of integrative epigenetic and cytogenetic analyses to identify novel tumor-suppressor genes in malignant melanoma. Melanoma Res, 2011. 21(4): p. 298-307.

134. Helmbold P, Richter AM, Walesch S, et al. RASSF10 Promoter Hypermethylation Is Frequent in Malignant Melanoma of the Skin but Uncommon in Nevus Cell Nevi. J Invest Dermatol, 2011. p.

135. Mirmohammadsadegh A, Marini A, Nambiar S, et al. Epigenetic silencing of the PTEN gene in melanoma. Cancer Res, 2006. 66(13): p. 6546-6552.

136. Worm J, Christensen C, Gronbaek K, et al. Genetic and epigenetic alterations of the APC gene in malignant melanoma. Oncogene, 2004. 23(30): p. 5215-5226.

137. Conway K, Edmiston SN, Khondker ZS, et al. DNA-methylation profiling distinguishes malignant melanomas from benign nevi. Pigment Cell Melanoma Res, 2011. 24(2): p. 352-360.

138. Freedberg DE, Rigas SH, Russak J, et al. Frequent p16-independent inactivation of p14ARF in human melanoma. J Natl Cancer Inst, 2008. 100(11): p. 784-795.

139. Wajapeyee N, Serra RW, Zhu X, et al. Oncogenic BRAF induces senescence and apoptosis through pathways mediated by the secreted protein IGFBP7. Cell, 2008. 132(3): p. 363-374.

140. Gonzalgo ML, Bender CM, You EH, et al. Low frequency of p16/CDKN2A methylation in sporadic melanoma: comparative approaches for methylation analysis of primary tumors. Cancer Res, 1997. 57(23): p. 5336-5347.

141. Straume O, Smeds J, Kumar R, et al. Significant impact of promoter hypermethylation and the $540 \mathrm{C}>\mathrm{T}$ polymorphism of CDKN2A in cutaneous melanoma of the vertical growth phase. Am J Pathol, 2002. 161(1): $p$. 229-237.

142. Healey MA, Deaton SL, Alder JK, et al. Id1 overexpression is independent of repression and epigenetic silencing of tumor suppressor genes in melanoma. Epigenetics, 2010. 5(5): p. 410-421.

143. Worm J, Bartkova J, Kirkin AF, et al. Aberrant p27Kip1 promoter methylation in malignant melanoma. Oncogene, 2000. 19(44): p. 5111-5115.

144. Kitago M, Martinez SR, Nakamura $T$, et al. Regulation of RUNX3 tumor suppressor gene expression in cutaneous melanoma. Clin Cancer Res, 2009. 15(9): p. 2988-2994.

145. Koga $Y$, Pelizzola $M$, Cheng $E$, et al. Genome-wide screen of promoter methylation identifies novel markers in melanoma. Genome Res, 2009. 19(8): p. 1462-1470.

146. Guan X, Sagara J, Yokoyama T, et al. ASC/TMS1, a caspase-1 activating adaptor, is downregulated by aberrant methylation in human melanoma. Int J Cancer, 2003. 107(2): p. 202-208. 
147. Arab K, Smith LT, Gast A, et al. Epigenetic deregulation of TCF21 inhibits metastasis suppressor KISS1 in metastatic melanoma. Carcinogenesis, 2011. 32(10): p. 1467-1473.

148. Furuta J, Nobeyama Y, Umebayashi Y, et al. Silencing of Peroxiredoxin 2 and aberrant methylation of 33 CpG islands in putative promoter regions in human malignant melanomas. Cancer Res, 2006. 66(12): p. 60806086.

149. Bonazzi VF, Nancarrow DJ, Stark MS, et al. Cross-platform array screening identifies COL1A2, THBS1, TNFRSF10D and UCHL1 as genes frequently silenced by methylation in melanoma. PLoS One, 2011. 6(10): p. e26121.

150. Irizarry RA, Ladd-Acosta C, Wen B, et al. The human colon cancer methylome shows similar hypo- and hypermethylation at conserved tissue-specific CpG island shores. Nat Genet, 2009. 41(2): p. 178-186.

151. Maunakea AK, Nagarajan RP, Bilenky M, et al. Conserved role of intragenic DNA methylation in regulating alternative promoters. Nature, 2010. 466(7303): p. 253-257.

152. Shenker N, Flanagan JM. Intragenic DNA methylation: implications of this epigenetic mechanism for cancer research. Br J Cancer, 2011. p.

153. van Vlodrop IJ, Niessen HE, Derks $\mathrm{S}$, et al. Analysis of promoter $\mathrm{CpG}$ island hypermethylation in cancer: location, location, location! Clin Cancer Res, 2011. 17(13): p. 4225-4231.

154. Ambros V. microRNAs: tiny regulators with great potential. Cell, 2001. 107(7): p. 823-826.

155. Bartel DP. MicroRNAs: genomics, biogenesis, mechanism, and function. Cell, 2004. 116(2): p. 281-297.

156. He L, Hannon GJ. MicroRNAs: small RNAs with a big role in gene regulation. Nat Rev Genet, 2004. 5(7): p. 522531.

157. Kim VN. Small RNAs: classification, biogenesis, and function. Mol Cells, 2005. 19(1): p. 1-15.

158. Mueller DW, Bosserhoff AK. Role of miRNAs in the progression of malignant melanoma. Br J Cancer, 2009. 101(4): p. 551-556.

159. Bonazzi VF, Stark MS, Hayward NK. MicroRNA regulation of melanoma progression. Melanoma Res, 2011. p.

160. Mueller DW, Bosserhoff AK. The evolving concept of 'melano-miRs'-microRNAs in melanomagenesis. Pigment Cell Melanoma Res, 2010. 23(5): p. 620-626.

161. Mueller DW, Rehli M, Bosserhoff AK. miRNA expression profiling in melanocytes and melanoma cell lines reveals miRNAs associated with formation and progression of malignant melanoma. J Invest Dermatol, 2009. 129(7): p. 1740-1751.

162. Caramuta S, Egyhazi S, Rodolfo M, et al. MicroRNA expression profiles associated with mutational status and survival in malignant melanoma. J Invest Dermatol, 2010. 130(8): p. 2062-2070.

163. Chen J, Feilotter HE, Pare GC, et al. MicroRNA-193b represses cell proliferation and regulates cyclin D1 in melanoma. Am J Pathol, 2010. 176(5): p. 2520-2529.

164. Glud M, Rossing M, Hother $C$, et al. Downregulation of miR-125b in metastatic cutaneous malignant melanoma. Melanoma Res, 2010. 20(6): p. 479-484.

165. Leidinger $\mathrm{P}$, Keller A, Borries $\mathrm{A}$, et al. High-throughput miRNA profiling of human melanoma blood samples. BMC Cancer, 2010. 10: p. 262.

166. Philippidou $D$, Schmitt $M$, Moser $D$, et al. Signatures of microRNAs and selected microRNA target genes in human melanoma. Cancer Res, 2010. 70(10): p. 4163-4173.

167. Segura MF, Belitskaya-Levy I, Rose AE, et al. Melanoma MicroRNA signature predicts post-recurrence survival. Clin Cancer Res, 2010. 16(5): p. 1577-1586.

168. Stark MS, Tyagi S, Nancarrow DJ, et al. Characterization of the Melanoma miRNAome by Deep Sequencing. PLoS One, 2010. 5(3): p. e9685.

169. Dar AA, Majid S, de Semir D, et al. miRNA-205 suppresses melanoma cell proliferation and induces senescence via regulation of E2F1 protein. J Biol Chem, 2011. 286(19): p. 16606-16614.

170. Chan E, Patel R, Nallur S, et al. MicroRNA signatures differentiate melanoma subtypes. Cell Cycle, 2011. 10(11): p. 1845-1852.

171. Xu Y, Brenn T, Brown ER, et al. Differential expression of microRNAs during melanoma progression: miR-200c, miR-205 and miR-211 are downregulated in melanoma and act as tumour suppressors. Br J Cancer, 2012. p.

172. Sand M, Gambichler T, Sand D, et al. Immunohistochemical expression patterns of the microRNA-processing enzyme Dicer in cutaneous malignant melanomas, benign melanocytic nevi and dysplastic melanocytic nevi. Eur J Dermatol, 2011. 21(1): p. 18-21.

173. Bemis $\mathrm{LT}$, Chen $\mathrm{R}$, Amato $\mathrm{CM}$, et al. MicroRNA-137 targets microphthalmia-associated transcription factor in melanoma cell lines. Cancer Res, 2008. 68(5): p. 1362-1368.

174. Haflidadottir BS, Bergsteinsdottir K, Praetorius C, et al. miR-148 regulates Mitf in melanoma cells. PLoS One, 2010. 5(7): p. e11574.

175. Segura MF, Hanniford D, Menendez S, et al. Aberrant miR-182 expression promotes melanoma metastasis by repressing FOXO3 and microphthalmia-associated transcription factor. Proc Natl Acad Sci U S A, 2009. 106(6): p. 1814-1819. 
176. Ozsolak F, Poling LL, Wang Z, et al. Chromatin structure analyses identify miRNA promoters. Genes Dev, 2008. 22(22): p. 3172-3183.

177. Roush S, Slack FJ. The let-7 family of microRNAs. Trends Cell Biol, 2008. 18(10): p. 505-516.

178. Schultz J, Lorenz P, Gross $G$, et al. MicroRNA let-7b targets important cell cycle molecules in malignant melanoma cells and interferes with anchorage-independent growth. Cell Res, 2008. 18(5): p. 549-557.

179. Muller DW, Bosserhoff AK. Integrin beta 3 expression is regulated by let-7a miRNA in malignant melanoma. Oncogene, 2008. 27(52): p. 6698-6706.

180. Holst LM, Kaczkowski B, Glud M, et al. The microRNA molecular signature of atypic and common acquired melanocytic nevi: differential expression of miR-125b and let-7c. Exp Dermatol, 2011. 20(3): p. 278-280.

181. Glud $M$, Manfe $V$, Biskup $E$, et al. MicroRNA miR-125b induces senescence in human melanoma cells. Melanoma Res, 2011. 21(3): p. 253-256.

182. Streicher $\mathrm{KL}$, Zhu W, Lehmann KP, et al. A novel oncogenic role for the miRNA-506-514 cluster in initiating melanocyte transformation and promoting melanoma growth. Oncogene, 2011. p.

183. Lujambio A, Calin GA, Villanueva A, et al. A microRNA DNA methylation signature for human cancer metastasis. Proc Natl Acad Sci U S A, 2008. 105(36): p. 13556-13561.

184. Lodygin D, Tarasov V, Epanchintsev A, et al. Inactivation of miR-34a by aberrant CpG methylation in multiple types of cancer. Cell Cycle, 2008. 7(16): p. 2591-2600.

185. Mazar J, Khaitan D, DeBlasio D, et al. Epigenetic regulation of microRNA genes and the role of miR-34b in cell invasion and motility in human melanoma. PLoS One, 2011. 6(9): p. e24922.

186. Mazar J, DeBlasio D, Govindarajan SS, et al. Epigenetic regulation of microRNA-375 and its role in melanoma development in humans. FEBS Lett, 2011. 585(15): p. 2467-2476.

187. Migliore C, Petrelli A, Ghiso E, et al. MicroRNAs impair MET-mediated invasive growth. Cancer Res, 2008. 68(24): p. 10128-10136.

188. Liu S, Kumar SM, Lu H, et al. MicroRNA-9 up-regulates E-cadherin through inhibition of NF-kappaB1-Snail1 pathway in melanoma. J Pathol, 2012. 226(1): p. 61-72.

189. Satzger I, Mattern A, Kuettler U, et al. MicroRNA-15b represents an independent prognostic parameter and is correlated with tumor cell proliferation and apoptosis in malignant melanoma. Int J Cancer, 2010. 126(11): p. 2553-2562.

190. Levati L, Alvino E, Pagani $\mathrm{E}$, et al. Altered expression of selected microRNAs in melanoma: antiproliferative and proapoptotic activity of miRNA-155. Int J Oncol, 2009. 35(2): p. 393-400.

191. Greenberg E, Hershkovitz L, Itzhaki O, et al. Regulation of cancer aggressive features in melanoma cells by microRNAs. PLoS One, 2011. 6(4): p. e18936.

192. Jiang $L$, Lv $X$, Li J, et al. The status of microRNA-21 expression and its clinical significance in human cutaneous malignant melanoma. Acta Histochem, 2011. p.

193. Yang $\mathrm{CH}$, Yue J, Pfeffer SR, et al. MicroRNA miR-21 regulates the metastatic behavior of B16 melanoma cells. J Biol Chem, 2011. 286(45): p. 39172-39178.

194. Grignol V, Fairchild ET, Zimmerer JM, et al. miR-21 and miR-155 are associated with mitotic activity and lesion depth of borderline melanocytic lesions. Br J Cancer, 2011. 105(7): p. 1023-1029.

195. Gaziel-Sovran A, Segura MF, Di Micco R, et al. miR-30b/30d regulation of GalNAc transferases enhances invasion and immunosuppression during metastasis. Cancer Cell, 2011. 20(1): p. 104-118.

196. Deng $\mathrm{Y}$, Deng H, Bi F, et al. MicroRNA-137 targets carboxyl-terminal binding protein 1 in melanoma cell lines. Int J Biol Sci, 2011. 7(1): p. 133-137.

197. Levati L, Pagani E, Romani S, et al. MicroRNA-155 targets the SKI gene in human melanoma cell lines. Pigment Cell Melanoma Res, 2011. 24(3): p. 538-550.

198. Gaur A, Jewell DA, Liang $Y$, et al. Characterization of microRNA expression levels and their biological correlates in human cancer cell lines. Cancer Res, 2007. 67(6): p. 2456-2468.

199. Mueller DW, Bosserhoff AK. MicroRNA miR-196a controls melanoma-associated genes by regulating HOX-C8 expression. Int J Cancer, 2011. 129(5): p. 1064-1074.

200. Braig S, Mueller DW, Rothhammer T, et al. MicroRNA miR-196a is a central regulator of HOX-B7 and BMP4 expression in malignant melanoma. Cell Mol Life Sci, 2010. 67(20): p. 3535-3548.

201. Elson-Schwab I, Lorentzen A, Marshall CJ. MicroRNA-200 family members differentially regulate morphological plasticity and mode of melanoma cell invasion. PLoS One, 2010. 5(10): $p$.

202. Boyle GM, Woods SL, Bonazzi VF, et al. Melanoma cell invasiveness is regulated by miR-211 suppression of the BRN2 transcription factor. Pigment Cell Melanoma Res, 2011. 24(3): p. 525-537.

203. Sakurai $E$, Maesawa $C$, Shibazaki $M$, et al. Downregulation of microRNA-211 is involved in expression of preferentially expressed antigen of melanoma in melanoma cells. Int J Oncol, 2011. 39(3): p. 665-672.

204. Penna E, Orso F, Cimino $D$, et al. microRNA-214 contributes to melanoma tumour progression through suppression of TFAP2C. EMBO J, 2011. 30(10): p. 1990-2007.

205. Igoucheva O, Alexeev V. MicroRNA-dependent regulation of cKit in cutaneous melanoma. Biochem Biophys Res Commun, 2009. 379(3): p. 790-794. 
206. Felicetti F, Errico MC, Segnalini P, et al. MicroRNA-221 and -222 pathway controls melanoma progression. Expert Rev Anticancer Ther, 2008. 8(11): p. 1759-1765.

207. Felicetti F, Errico MC, Bottero L, et al. The promyelocytic leukemia zinc finger-microRNA-221/-222 pathway controls melanoma progression through multiple oncogenic mechanisms. Cancer Res, 2008. 68(8): p. 27452754.

208. Kanemaru H, Fukushima S, Yamashita J, et al. The circulating microRNA-221 level in patients with malignant melanoma as a new tumor marker. J Dermatol Sci, 2011. 61(3): p. 187-193.

209. Wellner U, Schubert J, Burk UC, et al. The EMT-activator ZEB1 promotes tumorigenicity by repressing stemness-inhibiting microRNAs. Nat Cell Biol, 2009. 11(12): p. 1487-1495.

210. Gregory PA, Bert AG, Paterson EL, et al. The miR-200 family and miR-205 regulate epithelial to mesenchymal transition by targeting ZEB1 and SIP1. Nat Cell Biol, 2008. 10(5): p. 593-601.

211. Park SM, Gaur AB, Lengyel E, et al. The miR-200 family determines the epithelial phenotype of cancer cells by targeting the E-cadherin repressors ZEB1 and ZEB2. Genes Dev, 2008. 22(7): p. 894-907.

212. Bracken $\mathrm{CP}$, Gregory $\mathrm{PA}$, Khew-Goodall $\mathrm{Y}$, et al. The role of microRNAs in metastasis and epithelialmesenchymal transition. Cell Mol Life Sci, 2009. 66(10): p. 1682-1699.

213. Mercer TR, Dinger ME, Mattick JS. Long non-coding RNAs: insights into functions. Nat Rev Genet, 2009. 10(3): p. 155-159.

214. Pasmant $E$, Laurendeau I, Heron $D$, et al. Characterization of a germ-line deletion, including the entire INK4/ARF locus, in a melanoma-neural system tumor family: identification of ANRIL, an antisense noncoding RNA whose expression coclusters with ARF. Cancer Res, 2007. 67(8): p. 3963-3969.

215. Shete S, Hosking FJ, Robertson LB, et al. Genome-wide association study identifies five susceptibility loci for glioma. Nat Genet, 2009. 41(8): p. 899-904.

216. Stacey SN, Sulem $P$, Masson $G$, et al. New common variants affecting susceptibility to basal cell carcinoma. Nat Genet, 2009. 41(8): p. 909-914.

217. Bei JX, Li Y, Jia WH, et al. A genome-wide association study of nasopharyngeal carcinoma identifies three new susceptibility loci. Nat Genet, 2010. 42(7): p. 599-603.

218. Pasmant $E$, Sabbagh $A$, Vidaud $M$, et al. ANRIL, a long, noncoding RNA, is an unexpected major hotspot in GWAS. FASEB J, 2011. 25(2): p. 444-448.

219. Turnbull C, Rahman N. Genome-wide association studies provide new insights into the genetic basis of testicular germ-cell tumour. Int J Androl, 2011. 34(4 Pt 2): p. e86-96; discussion e96-87.

220. Khaitan D, Dinger ME, Mazar J, et al. The melanoma-upregulated long noncoding RNA SPRY4-IT1 modulates apoptosis and invasion. Cancer Res, 2011. 71(11): p. 3852-3862.

221. Kouzarides T. Chromatin modifications and their function. Cell, 2007. 128(4): p. 693-705.

222. Fan $\mathrm{T}$, Jiang $\mathrm{S}$, Chung $\mathrm{N}$, et al. EZH2-dependent suppression of a cellular senescence phenotype in melanoma cells by inhibition of p21/CDKN1A expression. Mol Cancer Res, 2011. 9(4): p. 418-429.

223. Soengas MS, Capodieci $P$, Polsky D, et al. Inactivation of the apoptosis effector Apaf-1 in malignant melanoma. Nature, 2001. 409(6817): p. 207-211.

224. Zhang XD, Gillespie SK, Borrow JM, et al. The histone deacetylase inhibitor suberic bishydroxamate regulates the expression of multiple apoptotic mediators and induces mitochondria-dependent apoptosis of melanoma cells. Mol Cancer Ther, 2004. 3(4): p. 425-435.

225. Zhang XD, Gillespie SK, Borrow JM, et al. The histone deacetylase inhibitor suberic bishydroxamate: a potential sensitizer of melanoma to TNF-related apoptosis-inducing ligand (TRAIL) induced apoptosis. Biochem Pharmacol, 2003. 66(8): p. 1537-1545.

226. Facchetti F, Previdi S, Ballarini $M$, et al. Modulation of pro- and anti-apoptotic factors in human melanoma cells exposed to histone deacetylase inhibitors. Apoptosis, 2004. 9(5): p. 573-582.

227. Sparmann A, van Lohuizen M. Polycomb silencers control cell fate, development and cancer. Nat Rev Cancer, 2006. 6(11): p. 846-856.

228. Jacobs JJ, van Lohuizen M. Polycomb repression: from cellular memory to cellular proliferation and cancer. Biochim Biophys Acta, 2002. 1602(2): p. 151-161.

229. Pasini D, Bracken AP, Helin K. Polycomb group proteins in cell cycle progression and cancer. Cell Cycle, 2004. 3(4): p. 396-400.

230. McHugh JB, Fullen DR, Ma L, et al. Expression of polycomb group protein EZH2 in nevi and melanoma. J Cutan Pathol, 2007. 34(8): p. 597-600.

231. Bachmann IM, Halvorsen OJ, Collett $\mathrm{K}$, et al. EZH2 expression is associated with high proliferation rate and aggressive tumor subgroups in cutaneous melanoma and cancers of the endometrium, prostate, and breast. J Clin Oncol, 2006. 24(2): p. 268-273.

232. Jacobs JJ, Kieboom K, Marino $S$, et al. The oncogene and Polycomb-group gene bmi-1 regulates cell proliferation and senescence through the ink4a locus. Nature, 1999. 397(6715): p. 164-168.

233. Bachmann IM, Puntervoll HE, Otte AP, et al. Loss of BMI-1 expression is associated with clinical progress of malignant melanoma. Mod Pathol, 2008. 21(5): p. 583-590. 
234. Barradas $M$, Anderton $E$, Acosta JC, et al. Histone demethylase JMJD3 contributes to epigenetic control of INK4a/ARF by oncogenic RAS. Genes Dev, 2009. 23(10): p. 1177-1182.

235. Agger K, Cloos PA, Rudkjaer L, et al. The H3K27me3 demethylase JMJD3 contributes to the activation of the INK4A-ARF locus in response to oncogene- and stress-induced senescence. Genes Dev, 2009. 23(10): p. 11711176.

236. Roesch A, Becker B, Schneider-Brachert W, et al. Re-expression of the retinoblastoma-binding protein 2homolog 1 reveals tumor-suppressive functions in highly metastatic melanoma cells. J Invest Dermatol, 2006. 126(8): p. 1850-1859.

237. Roesch A, Mueller AM, Stempfl T, et al. RBP2-H1/JARID1B is a transcriptional regulator with a tumor suppressive potential in melanoma cells. Int J Cancer, 2008. 122(5): p. 1047-1057.

238. Roesch A, Becker B, Meyer S, et al. Retinoblastoma-binding protein 2-homolog 1: a retinoblastoma-binding protein downregulated in malignant melanomas. Mod Pathol, 2005. 18(9): p. 1249-1257.

239. Roesch A, Fukunaga-Kalabis M, Schmidt EC, et al. A temporarily distinct subpopulation of slow-cycling melanoma cells is required for continuous tumor growth. Cell, 2010. 141(4): p. 583-594.

240. Saha A, Wittmeyer J, Cairns BR. Chromatin remodelling: the industrial revolution of DNA around histones. Nat Rev Mol Cell Biol, 2006. 7(6): p. 437-447.

241. Wilson BG, Roberts CW. SWI/SNF nucleosome remodellers and cancer. Nat Rev Cancer, 2011. 11(7): p. 481492.

242. Becker TM, Haferkamp S, Dijkstra MK, et al. The chromatin remodelling factor BRG1 is a novel binding partner of the tumor suppressor p16INK4a. Mol Cancer, 2009. 8: p. 4.

243. Keenen B, Qi H, Saladi SV, et al. Heterogeneous SWI/SNF chromatin remodeling complexes promote expression of microphthalmia-associated transcription factor target genes in melanoma. Oncogene, 2010. 29(1): p. 81-92.

244. de la Serna IL, Ohkawa Y, Higashi $C$, et al. The microphthalmia-associated transcription factor requires SWI/SNF enzymes to activate melanocyte-specific genes. J Biol Chem, 2006. 281(29): p. 20233-20241.

245. Vachtenheim J, Ondrusova L, Borovansky J. SWI/SNF chromatin remodeling complex is critical for the expression of microphthalmia-associated transcription factor in melanoma cells. Biochem Biophys Res Commun, 2010. 392(3): p. 454-459.

246. Bandyopadhyay D, Curry JL, Lin Q, et al. Dynamic assembly of chromatin complexes during cellular senescence: implications for the growth arrest of human melanocytic nevi. Aging Cell, 2007. 6(4): p. 577-591.

247. Vinod Saladi S, Marathe H, de la Serna IL. SWItching on the transcriptional circuitry in melanoma. Epigenetics, 2010. 5(6): p. 469-475.

248. Dunaief JL, Strober BE, Guha S, et al. The retinoblastoma protein and BRG1 form a complex and cooperate to induce cell cycle arrest. Cell, 1994. 79(1): p. 119-130.

249. Zhang HS, Gavin M, Dahiya A, et al. Exit from $G 1$ and $S$ phase of the cell cycle is regulated by repressor complexes containing HDAC-Rb-hSWI/SNF and Rb-hSWI/SNF. Cell, 2000. 101(1): p. 79-89.

250. Isakoff MS, Sansam CG, Tamayo $P$, et al. Inactivation of the Snf5 tumor suppressor stimulates cell cycle progression and cooperates with p53 loss in oncogenic transformation. Proc Natl Acad Sci U S A, 2005. 102(49): p. 17745-17750.

251. Trouche $D$, Le Chalony $C$, Muchardt $C$, et al. RB and hbrm cooperate to repress the activation functions of E2F1. Proc Natl Acad Sci U S A, 1997. 94(21): p. 11268-11273.

252. Peters G. Tumor suppression for ARFicionados: the relative contributions of p16INK4a and p14ARF in melanoma. J Natl Cancer Inst, 2008. 100(11): p. 757-759.

253. Gray-Schopfer VC, Cheong SC, Chong H, et al. Cellular senescence in naevi and immortalisation in melanoma: a role for p16? Br J Cancer, 2006. 95(4): p. 496-505.

254. Ohm JE, McGarvey $\mathrm{KM}, \mathrm{Yu} \mathrm{X}$, et al. A stem cell-like chromatin pattern may predispose tumor suppressor genes to DNA hypermethylation and heritable silencing. Nat Genet, 2007. 39(2): p. 237-242.

255. Bracken AP, Dietrich N, Pasini D, et al. Genome-wide mapping of Polycomb target genes unravels their roles in cell fate transitions. Genes Dev, 2006. 20(9): p. 1123-1136.

256. Gil J, Bernard D, Martinez D, et al. Polycomb CBX7 has a unifying role in cellular lifespan. Nat Cell Biol, 2004. 6(1): p. 67-72.

257. Dietrich N, Bracken AP, Trinh E, et al. Bypass of senescence by the polycomb group protein $C B X 8$ through direct binding to the INK4A-ARF locus. EMBO J, 2007. 26(6): p. 1637-1648.

258. Voncken JW, Roelen BA, Roefs $M$, et al. Rnf2 (Ring1b) deficiency causes gastrulation arrest and cell cycle inhibition. Proc Natl Acad Sci U S A, 2003. 100(5): p. 2468-2473.

259. Bracken AP, Kleine-Kohlbrecher D, Dietrich $N$, et al. The Polycomb group proteins bind throughout the INK4AARF locus and are disassociated in senescent cells. Genes Dev, 2007. 21(5): p. 525-530.

260. Khalil AM, Guttman M, Huarte $M$, et al. Many human large intergenic noncoding RNAs associate with chromatin-modifying complexes and affect gene expression. Proc Natl Acad Sci U S A, 2009. 106(28): p. 11667-11672. 
261. Friedman JM, Liang G, Liu CC, et al. The putative tumor suppressor microRNA-101 modulates the cancer epigenome by repressing the polycomb group protein EZH2. Cancer Res, 2009. 69(6): p. 2623-2629.

262. Varambally S, Cao Q, Mani RS, et al. Genomic loss of microRNA-101 leads to overexpression of histone methyltransferase EZH2 in cancer. Science, 2008. 322(5908): p. 1695-1699.

263. Lal A, Kim HH, Abdelmohsen K, et al. p16(INK4a) translation suppressed by miR-24. PLoS One, 2008. 3(3): p. e1864.

264. Oruetxebarria I, Venturini F, Kekarainen T, et al. P16INK4a is required for hSNF5 chromatin remodelerinduced cellular senescence in malignant rhabdoid tumor cells. J Biol Chem, 2004. 279(5): p. 3807-3816.

265. Kia SK, Gorski MM, Giannakopoulos S, et al. SWI/SNF mediates polycomb eviction and epigenetic reprogramming of the INK4b-ARF-INK4a locus. Mol Cell Biol, 2008. 28(10): p. 3457-3464.

266. Ugurel S, Houben R, Schrama D, et al. Microphthalmia-associated transcription factor gene amplification in metastatic melanoma is a prognostic marker for patient survival, but not a predictive marker for chemosensitivity and chemotherapy response. Clin Cancer Res, 2007. 13(21): p. 6344-6350.

267. Hussein MR, Roggero E, Tuthill RJ, et al. Identification of novel deletion Loci at 1p36 and 9p22-21 in melanocytic dysplastic nevi and cutaneous malignant melanomas. Arch Dermatol, 2003. 139(6): p. 816-817.

268. Poetsch $M$, Dittberner $T$, Woenckhaus $C$. Microsatellite analysis at $1 p 36.3$ in malignant melanoma of the skin: fine mapping in search of a possible tumour suppressor gene region. Melanoma Res, 2003. 13(1): p. 29-33.

269. Fujiwara $\mathrm{Y}, \mathrm{Chi} D \mathrm{D}$, Wang $\mathrm{H}$, et al. Plasma DNA microsatellites as tumor-specific markers and indicators of tumor progression in melanoma patients. Cancer Res, 1999. 59(7): p. 1567-1571.

270. Gollob JA, Sciambi CJ, Peterson BL, et al. Phase I trial of sequential low-dose 5-aza-2'-deoxycytidine plus highdose intravenous bolus interleukin-2 in patients with melanoma or renal cell carcinoma. Clin Cancer Res, 2006. 12(15): p. 4619-4627. 


\section{CHAPTER 3}

\section{High-throughput oncogene mutation profiling reveals demographic differences in BRAF mutation rates among melanoma patients}

Karin van den Hurk, Balazs Balint, Sinead Toomey, Patrick C. O'Leary, Louise Unwin,

Kieran Sheahan, Enda W. McDermott, Ian Murphy, Joost J. van den Oord, Mairin Rafferty, Dara M. FitzGerald, Julie Moran, Robert Cummins, Owen MacEneaney, Elaine

W. Kay, Cathal P. O'Brien, Stephen P. Finn, Cynthia C.B.B. Heffron, Michelle Murphy, Ruben Yela, Derek G. Power, Padraic J. Regan, Clodagh M. McDermott, Allan O'Keeffe, Zsolt Orosz, Paul P. Donnellan, John P. Crown, Bryan T. Hennessy, and William M. 


\section{Abstract}

Because of advances in targeted therapies, the clinical evaluation of cutaneous melanoma is increasingly based on a combination of traditional histopathology and molecular pathology. Therefore, it is necessary to expand our knowledge of the molecular events that accompany the development and progression of melanoma to optimize clinical management. The central objective of this study was to increase our knowledge of the mutational events that complement melanoma progression. Highthroughput genotyping was adapted to query 159 known single nucleotide mutations in 33 cancer-related genes across two melanoma cohorts from Ireland $(n=94)$ and Belgium ( $n=60)$. Results were correlated with various clinicopathological characteristics. A total of 23 mutations in 12 genes were identified, i.e. BRAF, NRAS, MET, PHLPP2, PIK3R1, IDH1, KIT, STK11, CTNNB1, JAK2, ALK, and GNAS. Unexpectedly, we discovered significant differences in BRAF, MET, and PIK3R1 mutations between the cohorts. That is, cases from Ireland showed significantly lower $(P<.001)$ BRAF ${ }^{V 600 E}$ mutation rates (19\%) when compared with the mutation frequency seen in Belgian patients (43\%). Moreover, MET mutations were detected in $12 \%$ of Irish cases, whereas none of the Belgian patients harbored these mutations, and Irish patients significantly more often $(P=.027)$ had PIK3R1-mutant $(33 \%)$ melanoma versus $17 \%$ of Belgian cases. The low incidence of $\mathrm{BRAF}^{\mathrm{V} 600 \mathrm{E}}$-mutant melanoma among Irish patients was confirmed in five independent Irish cohorts, and in total, only 165 of 689 (24\%) Irish cases carried mutant $\mathrm{BRAF}^{\mathrm{V} 600 \mathrm{E}}$. Together, our data show that melanoma-driving mutations vary by demographic area, which has important implications for the clinical management of this disease. 


\section{Introduction}

Cutaneous melanoma is a highly aggressive skin tumor originating from melanocytes ${ }^{1}$. Advanced melanoma is one of the most challenging cancers with traditionally poor patient outcomes as treatment options were limited for a long time. Over the past decade, research has focused on the diverse molecular mechanisms that underlie the development and progression of melanoma. Several key melanoma-driver mutations, including BRAF, NRAS, and KIT, have been identified, with the subsequent establishment of a new paradigm in which melanoma is treated with inhibitors that target these mutated proteins ${ }^{2}$. Vemurafenib (PLX4032) is the first example of targeted therapy in clinical melanoma practice for patients with $\mathrm{BRAF}^{\mathrm{V} 600}$ mutation-positive unresectable or advanced melanoma and is remarkably effective as monotherapy, although nearly all patients eventually relapse ${ }^{3}$. In addition, dabrafenib (GSK2118436), another selective BRAF inhibitor, and trametinib (GSK1120212), a MEK inhibitor, have been approved by the US Food and Drugs Administration (FDA) for patients whose tumors have $\mathrm{V} 600$ mutations in the BRAF gene ${ }^{4-6}$. As a result, BRAF mutations have become one of the most important biomarkers for melanoma patients to date. Moreover, combination therapy with BRAF and MEK inhibitors further improves melanoma treatment ${ }^{7}$. Many clinical trials with additional small molecule inhibitors are currently ongoing to determine their efficacy either alone or in combination with other treatments ${ }^{2}$.

As the clinical management of melanoma is increasingly based on a combination of histopathology and molecular pathology, it is necessary to evolve our molecular understanding of melanoma among various populations worldwide. In addition, oncogene mutations are recognized as relevant therapeutic and possible prognostic biomarkers $^{8}$. Hence, the central objective of this study was to further increase our knowledge of the mutational events that accompany melanoma progression across two European countries, i.e. Ireland and Belgium. To achieve this, we used mass spectrometry-based genotyping to examine a total of 159 known single nucleotide oncogene mutations (Supplementary Table S1) in 33 key cancer-related genes (AKT1, AKT2, AKT3, ALK, BRAF, CDK4, CTNNB1, DEAR1, EGFR, ERa, FRAP, GNAS, HIF1A, IDH1, IDH2, IGF1R, JAK2, KIT, KRAS, MEK1, MET, NRAS, PDGFRA, PDPK1, PHLPP2, PIK3CA, PIK3R1, PRKAG1, PRKAG2, RET, RICTOR, STK11, and TNK2) across 94 melanoma tissues from Ireland and 60 melanoma tissues from Belgium, followed by confirmatory analysis of BRAF alterations in five additional melanoma cohorts from Ireland.

A total of 23 mutations in 12 genes, BRAF, NRAS, MET, PHLPP2, PIK3R1, IDH1, KIT, STK11, CTNNB1, JAK2, ALK, and GNAS, were detected. The presence of one or more mutations in primary melanoma specimens was an indicator of poor prognosis. Unexpectedly, we found a low incidence of $\mathrm{BRAF}^{\mathrm{V} 600 \mathrm{E}}$-mutant melanomas among Irish patients (total of 689 cases), i.e. approximately $24 \%$ (19\% of primary cases and $30 \%$ of metastases), exerting a direct clinical impact on future treatment strategies for Irish melanoma patients. A subsequent key finding of our genotyping study is the presence 
of MET mutations in $12 \%$ of Irish melanoma cases. No mutations in MET were found within the Belgian cohort and MET mutations in melanoma as reported by COSMIC database is only $1 \%{ }^{9}$. Overall, this study contributes towards the basic molecular understanding of the development and progression of melanoma. Our data will support the development of personalized or targeted therapy for melanoma patients.

\section{Material and methods}

\section{Tumor samples}

This study used tumor samples from melanoma patients from seven independent cohorts (Figure 1). The initial high-throughput mutation screen is performed on an Irish cohort consisting of DNA from 94 patients (mean age $64.9 \pm 18.1$ ) diagnosed with primary $(n=81)$, metastatic $(n=11)$ or unspecified $(n=2)$ melanoma between 1994 and 2007 at the St. Vincent's University Hospital, Dublin, Ireland, and a Belgian cohort consisting of DNA from 60 patients (mean age $62.7 \pm 17.4$ ) diagnosed with primary $(n=27)$ or metastatic $(n=33)$ melanoma between 1985 and 2007 at the University Hospital of Leuven, Belgium. Table 1 summarizes patient characteristics of both cohorts. Primary melanoma patient characteristics between the Irish and Belgian cohorts were comparable for gender, age, Breslow thickness, and ulceration status. The Belgian cohort, however, included solely tumors from the superficial spreading (SSM) subtype and significantly more melanomas located on the trunk.

For confirmation of low BRAF ${ }^{\mathrm{V} 600 \mathrm{E}}$ mutation rates among Irish melanoma patients, we made use of five additional Irish melanoma cohorts. That is, Irish cohort 2, which consists of DNA from 137 patients (mean age $63.4 \pm 18.2$ ) diagnosed with primary $(n=111)$ or metastatic $(n=26)$ melanoma between 1993 and 2003 at the Mater Misericordiae University Hospital, Dublin, Ireland; Irish cohort 3, which consists of 76 patients (mean age $58.4 \pm 15.8$ ) diagnosed with primary $(n=31)$ or metastatic $(n=45)$ melanoma in 2012 at the Beaumont Hospital-Royal College of Surgeons in Ireland, Dublin, Ireland; Irish cohort 4, which consists of 182 patients (mean age $61.9 \pm 16.0$ ) diagnosed with melanoma with primary $(n=90)$ or metastatic $(n=92)$ melanoma between 2012 and 2014 at the St. James's Hospital, Dublin, Ireland; Irish cohort 5, which consists of 132 patients (mean age $61.4 \pm 17.3$ ) diagnosed with melanoma with primary $(n=30)$ or metastatic $(n=102)$ melanoma between 2011 and 2014 at the Cork University Hospital, Cork, Ireland; and Irish cohort 6, which consists of 68 patients (mean age $65.2 \pm 16.6)$ diagnosed with primary $(n=29)$ or metastatic $(n=39)$ melanoma between 2012 and 2014 at the Galway University Hospital, Galway, Ireland. Ethical approval for the use of the patient tissue materials described in this study was obtained from the respective research ethics committees at each of the clinical institutions involved. As approved by the respective ethical committees, informed consent from patients was not obtained as the data were analyzed anonymously. 


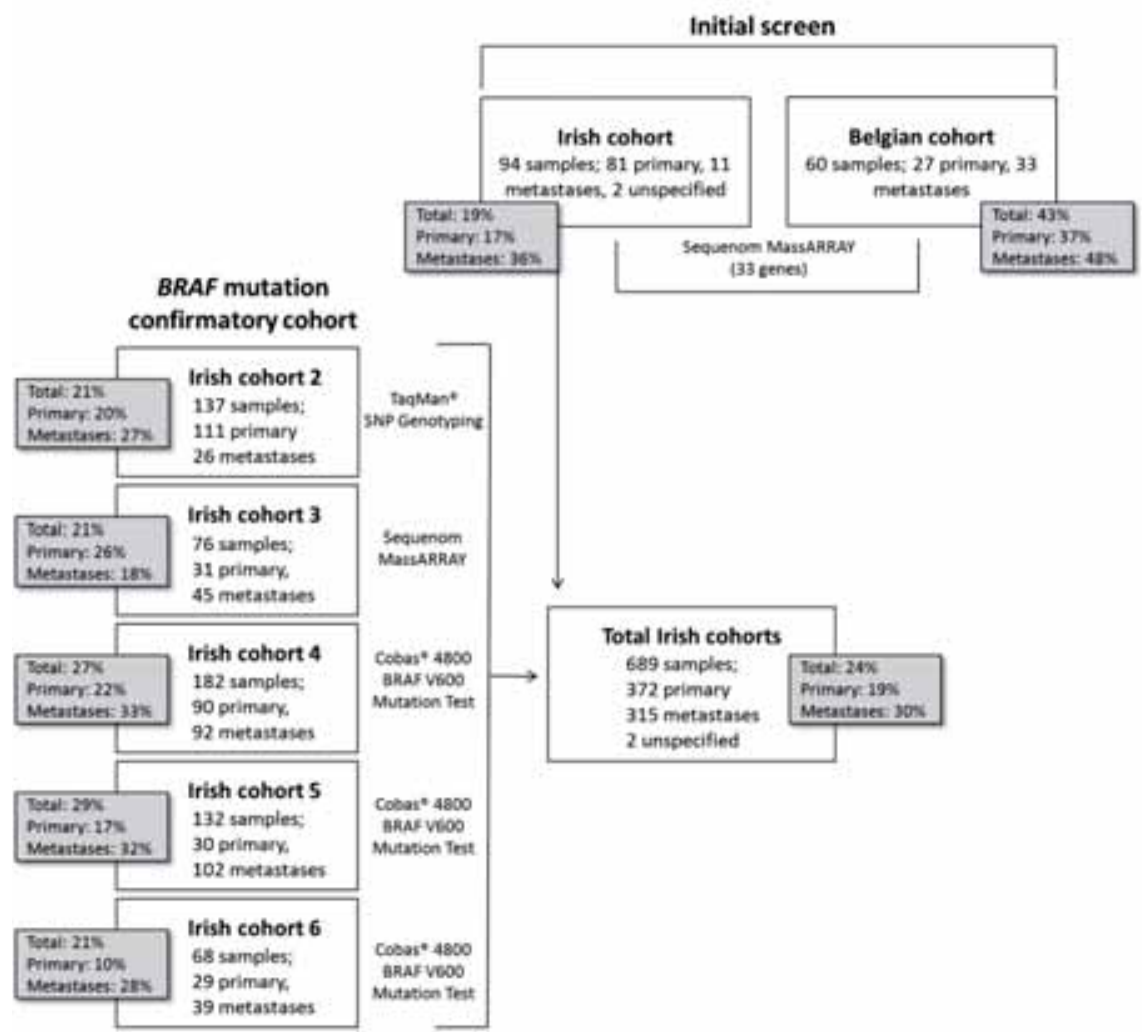

Figure. 1. Depiction of all melanoma cohorts included in the study with corresponding BRAF ${ }^{1600 E}$ mutation rate. Number of examined samples and the method of genotyping are presented for each of the seven patient cohorts. In addition, the BRAF ${ }^{\mathrm{V} 600 \mathrm{E}}$ mutation rate found in each of the cohorts is presented in the grey rectangles. SNP, single nucleotide polymorphism.

\section{Genotyping}

All samples used in this study contained at least $50 \%$ tumor cells. Genomic DNA from the Irish cohort was extracted as described previously ${ }^{10}$. Within the Belgian cohort, DNA was extracted using sections from fresh-frozen samples that were incubated overnight at $37^{\circ} \mathrm{C}$ with DNA lysis buffer $(10 \mathrm{mM}$ Tris $\mathrm{pH} 8.0,100 \mathrm{mM} \mathrm{NaCl}, 10 \mathrm{mM}$ EDTA $\mathrm{pH} 8.0,10 \% \mathrm{SDS}$ ) and proteinase $\mathrm{K}$. DNA was purified using saline solution ( $\mathrm{NaCl} 5 \mathrm{M})$ and $100 \%$ 2-Propanol. Mass spectrometry-based genotyping (Sequenom MassARRAY, Sequenom, San Diego, California, USA) was applied to detect a total of 159 single nucleotide mutations in 33 cancer-related genes (Supplementary Table S1). PCR and extension primers for the multiplexed assay were designed with the Sequenom Assay Design software (Sequenom, San Diego, California, USA). Samples were processed as recommended by the manufacturer. Matrix chips were assayed on a Sequenom MassArray MALDI-TOF Mass Array system. Sequenom Typer Software and visual 
inspection were used to interpret mass spectra. Reactions where $>15 \%$ of the resultant mass ran in the mutant site were scored as positive.

Within Irish cohort 2, BRAF mutational analysis was performed using the ABI Prism TaqMan 7900HT Sequence Detection System (Life Technologies Corporation, Carlsbad, California, USA) in combination with the BRAF ${ }^{\mathrm{V} 600 \mathrm{E}}$ SNP Genotyping assay as described earlier ${ }^{10}$. BRAF genotyping was performed on Irish cohort 3 using Sequenom analysis as described above. Within Irish cohorts 4, 5, and 6 BRAF mutation analysis was performed using the CE-IVD marked and FDA approved Roche Cobas 4800 BRAF mutation detection assay (Roche Diagnostics Limited, West Sussex, UK). DNA extraction, preparation, and analysis were performed according to the manufacturer's protocols.

Table 1. Characteristics and clinical features of patients within the Irish and Belgian discovery cohorts

\begin{tabular}{|c|c|c|c|c|c|}
\hline \multirow[t]{2}{*}{ Characteristics } & \multicolumn{2}{|c|}{$\begin{array}{c}\text { Cases Ireland } \\
(n=94)\end{array}$} & \multicolumn{2}{|c|}{$\begin{array}{l}\text { Cases Belgium } \\
(n=60)\end{array}$} & \multirow[b]{2}{*}{$P$} \\
\hline & No. of Patients* & $\%$ & No. of Patients* & $\%$ & \\
\hline \multicolumn{6}{|c|}{ All clinical specimens } \\
\hline \multicolumn{6}{|l|}{ Tumor type } \\
\hline Primary & 81 & 88 & 27 & 45 & $<.001$ \\
\hline Metastasis & 11 & 12 & 33 & 55 & \\
\hline \multicolumn{6}{|c|}{ Primary tumor specimens } \\
\hline \multicolumn{6}{|l|}{ Gender } \\
\hline Female & 45 & 56 & 13 & 48 & NS \\
\hline Male & 36 & 44 & 14 & 52 & \\
\hline \multicolumn{6}{|l|}{ Age (years) } \\
\hline Mean & $64.9 \pm 18.1$ & & $62.7 \pm 17.4$ & & \\
\hline$\leq 50$ years & 17 & 21 & 8 & 30 & NS \\
\hline$>50$ years & 63 & 79 & 19 & 70 & \\
\hline \multicolumn{6}{|c|}{ Breslow thickness, $\mathrm{mm}$} \\
\hline $0.01-1.0$ & 9 & 11 & 5 & 19 & NS \\
\hline $1.01-2.0$ & 19 & 24 & 4 & 15 & \\
\hline $2.01-4.0$ & 23 & 29 & 8 & 30 & \\
\hline$>4.0$ & 28 & 35 & 10 & 37 & \\
\hline \multicolumn{6}{|l|}{ Ulceration } \\
\hline Absent & 39 & 54 & 13 & 48 & NS \\
\hline Present & 33 & 46 & 14 & 52 & \\
\hline \multicolumn{6}{|c|}{ Histological subtype } \\
\hline SSM & 17 & 21 & 27 & 100 & $<.001$ \\
\hline NM & 28 & 35 & - & - & \\
\hline LMM & 15 & 19 & - & - & \\
\hline Other & 20 & 25 & - & - & \\
\hline \multicolumn{6}{|l|}{ Location } \\
\hline Head and neck & 23 & 30 & 3 & 12 & .033 \\
\hline Trunk & 11 & 14 & 9 & 35 & \\
\hline Extremities & 44 & 56 & 14 & 54 & \\
\hline \multicolumn{6}{|c|}{ Disease recurrence } \\
\hline No & 37 & 54 & 15 & 60 & NS \\
\hline Yes & 31 & 46 & 10 & 40 & \\
\hline \multicolumn{6}{|c|}{ Disease-related death } \\
\hline No & 40 & 55 & 18 & 69 & NS \\
\hline Yes & 33 & 45 & 8 & 31 & \\
\hline
\end{tabular}


Statistical analyses

The statistical significance of genotyping results between independent cohorts was calculated by applying a Fisher's exact test. The Pearson's chi-square $(\chi 2)$ test was used to determine whether there was a correlation between genotype and various tumor characteristics; Fisher's exact test was used if there were less than five objects in any category. Statistical significance of co-occurring mutations (BRAF/NRAS with MET) was calculated using Fisher's exact test. All statistical analyses were two-sided, and a $P$ value less than 0.05 was considered statistically significant. All analyses were done with the statistical package IBM SPSS Statistics 20 (IBM, New York, USA).

\section{Results}

\section{Mass spectrometry-based genotyping of melanoma tissues}

To improve our knowledge of the mutational events that underlie melanoma, we used high-throughput genotyping (Sequenom MassARRAY) to examine the presence of 159 oncogenic mutations in 33 genes (Supplementary Table S1) in a total of 154 melanoma tissues, i.e. 94 melanoma tissues from Ireland and 60 melanoma tissues from Belgium, and correlated this with clinicopathological characteristics. In total, we detected 23 mutations in 12 genes (BRAF, NRAS, M ET, PHLPP2, PIK3R1, IDH1, KIT, STK11, CTNNB1, JAK2, ALK, and GNAS) and found 125 of 154 (81\%) tissues to be mutated at least once (Table 2). Multiple mutations were found in 59 of 154 (38\%) cases, with up to five mutations per tumor sample being detected. A significantly higher mutation frequency $(P=.019)$ was found among melanoma metastases, that is, 41 of $44(93 \%)$ metastatic melanoma tissues harbored at least one mutation versus 83 of 108 (77\%) primary melanomas. Next, we examined if patients with primary melanoma who harbored $\geq 1$ mutation had an increased risk of developing metastatic disease or dying from their disease. Although not significant $(P=.058)$, it was observed that patients who developed metastatic disease more frequently harbored mutated primary melanoma (34 of 41 [83\%] patients) compared with patients who did not develop metastatic disease (34 of 52 [65\%] patients). Moreover, primary melanoma from patients who died from their disease significantly more often ( $P=.012$ ) carried mutations (36 of 41 [88\%] patients) compared with primary melanoma from patients who survived (38 of 58 [66\%] patients). Mutant primary melanoma were comparable with nonmutant primary melanoma in terms of gender, age, Breslow thickness, ulceration status, and tumor location; however, mutations were more often observed $(P=.019)$ in the nodular melanoma (NM) subtype, i.e. 26 of 28 (93\%) NM contained $\geq 1$ mutation versus 56 of 79 (71\%) mutated specimens among all other subtypes. 
Table 2. Single nucleotide mutations detected in the Irish and Belgian cohorts

\begin{tabular}{|c|c|c|c|c|c|c|}
\hline \multirow[t]{2}{*}{ Single nucleotide mutations } & \multicolumn{3}{|c|}{ Combined cohorts $(n=154)$} & \multirow{2}{*}{$\begin{array}{c}\text { Cases Ireland } \\
(n=94)\end{array}$} & & \multirow{2}{*}{$\begin{array}{c}\text { Cases Belgium } \\
(n=60)\end{array}$} \\
\hline & No. & $\%$ & No. & & No. & \\
\hline \multicolumn{7}{|l|}{ BRAF V600 } \\
\hline BRAF_V600E & 44 & 29 & 18 & 19 & 26 & 43 \\
\hline BRAF_V600K & 5 & 3 & 1 & 1 & 4 & 7 \\
\hline BRAF_V600M & 1 & 1 & 1 & 1 & - & - \\
\hline BRAF_V600R & 1 & 1 & - & - & 1 & 2 \\
\hline Wild-type & 103 & 67 & 74 & 79 & 29 & 48 \\
\hline \multicolumn{7}{|l|}{ NRAS Q61 } \\
\hline NRĀS_Q61R & 12 & 8 & 9 & 10 & 3 & 5 \\
\hline NRAS_Q61K & 9 & 6 & 5 & 5 & 4 & 7 \\
\hline NRAS_Q61L & 4 & 3 & 3 & 3 & 1 & 2 \\
\hline NRAS_Q661H & 3 & 2 & 3 & 3 & - & - \\
\hline Wild-type & 126 & 82 & 74 & 79 & 52 & 87 \\
\hline \multicolumn{7}{|l|}{ NRAS (non Q61) } \\
\hline NRAS_G38A & 1 & 1 & 1 & 1 & - & - \\
\hline Wild-type & 153 & 99 & 93 & 99 & 60 & 100 \\
\hline \multicolumn{7}{|l|}{ MET } \\
\hline MET_N375S & 6 & 4 & 6 & 6 & - & - \\
\hline $\mathrm{MET}_{-}^{-} \mathrm{R} 988 \mathrm{C}$ & 2 & 1 & 2 & 2 & - & - \\
\hline MET_T1010I $^{-}$ & 3 & 2 & 3 & 3 & - & - \\
\hline Wild-type & 143 & 93 & 83 & 88 & 60 & 100 \\
\hline \multicolumn{7}{|l|}{ PIK3R1 } \\
\hline PIK3R1_M 326I & 41 & 27 & 31 & 33 & 10 & 17 \\
\hline Wild-type & 113 & 73 & 63 & 67 & 50 & 83 \\
\hline \multicolumn{7}{|l|}{ PHLPP2 } \\
\hline PHLPP2_L1016 & 53 & 34 & 30 & 32 & 23 & 38 \\
\hline Wild-type & 101 & 66 & 64 & 68 & 37 & 62 \\
\hline \multicolumn{7}{|l|}{ STK11 } \\
\hline STK11_P281L & 3 & 2 & 3 & 3 & - & - \\
\hline Wild-tȳpe & 151 & 98 & 91 & 97 & 60 & 100 \\
\hline \multicolumn{7}{|l|}{ KIT } \\
\hline KIT_D816V & 1 & 1 & 1 & 1 & - & - \\
\hline $\mathrm{KIT}_{-}^{-} \mathrm{K} 642 \mathrm{E}$ & 2 & 1 & 1 & 1 & 1 & 2 \\
\hline KIT_V559D & 1 & 1 & 1 & 1 & - & - \\
\hline Wild-type & 150 & 97 & 91 & 97 & 59 & 98 \\
\hline \multicolumn{7}{|l|}{ IDH1 } \\
\hline IDH1_R132C & 6 & 4 & 3 & 3 & 3 & 5 \\
\hline Wild-type & 148 & 96 & 91 & 97 & 57 & 95 \\
\hline \multicolumn{7}{|l|}{ CTNNB1 } \\
\hline CTNNB1_D32 & 2 & 1 & 1 & 1 & 1 & 2 \\
\hline CTNNB1_S37F & 1 & 1 & 1 & 1 & - & - \\
\hline CTNNB1_S45F & 1 & 1 & - & - & 1 & 2 \\
\hline Wild-type & 150 & 97 & 92 & 98 & 58 & 97 \\
\hline \multicolumn{7}{|l|}{ JAK2 } \\
\hline JAK2_V617F & 1 & 1 & 1 & 1 & - & - \\
\hline Wild-type & 153 & 99 & 93 & 99 & 60 & 100 \\
\hline \multicolumn{7}{|l|}{ ALK } \\
\hline ALK_D1091N & 1 & 1 & 1 & 1 & - & - \\
\hline Wild-type & 153 & 99 & 93 & 99 & 60 & 100 \\
\hline \multicolumn{7}{|l|}{ GNAS } \\
\hline GNAS_R201C & 1 & 1 & - & - & 1 & 2 \\
\hline Wild-type & 153 & 99 & 94 & 100 & 59 & 98 \\
\hline
\end{tabular}

Somatic mutations in BRAF (V600) and NRAS (Q61) were common events, i.e. detected in more than $10 \%$ of melanoma cases, as is conventionally expected in melanoma (Table 2) ${ }^{11}$. Mutant BRAF was detected in 51 of 154 (33\%) cases. A significantly increased $(P=.006)$ BRAF mutation rate was found among melanoma metastases, i.e. 
29 of $108(27 \%)$ primary melanomas carried mutant BRAF versus 22 of $44(50 \%)$ metastatic melanomas. As expected, the $\mathrm{BRAF}^{\mathrm{V} 600 \mathrm{E}}$ mutation occurred the highest frequency (44 of 51 [86\%] BRAF mutations). NRAS mutations were detected in 29 of $154(19 \%)$ cases, specifically, 22 of $108(20 \%)$ primary melanomas and seven of 44 (16\%) metastatic melanomas harbored mutant NRAS. Table 3 provides an overview on the correlations of $\mathrm{BRAF}^{\mathrm{V} 600 \mathrm{E}}$ and $\mathrm{NRAS}^{\mathrm{Q} 61}$ mutations with clinicopathologic characteristics. Mutations in primary melanomas carrying $\mathrm{BRAF}^{\mathrm{V} 600 \mathrm{E}}$, compared with BRAF $^{\mathrm{V} 600}$ wild-type primary melanomas, were detected more often $(P=.017)$ in patients $\leq 50$ years of age (Table 3 ). The distribution of histological subtypes and tumor location differed significantly $(P=.012$ and $P=.022$, respectively) between NRAS-mutant melanomas versus NRAS wild-type tumors, that was largely the result from the observation that the mutation was more often detected among the NM subtype and in tumors located on the extremities (Table 3).

Table 3. Clinicopathologic correlations of $B R A F^{\mathrm{V} 600 \mathrm{E}}, \mathrm{NRAS^{ \textrm {Q } 6 1 }}$, and $\mathrm{PIK} 3 \mathrm{R} 1^{\mathrm{M} 3261}$ mutations among primary melanoma cases

\begin{tabular}{|c|c|c|c|c|c|c|c|c|c|c|c|c|c|c|c|}
\hline \multirow[t]{2}{*}{ Characteristics } & \multicolumn{2}{|c|}{$\begin{array}{c}\text { BRAF }^{\text {V600E }} \\
(n=24)\end{array}$} & \multicolumn{3}{|c|}{$\begin{array}{c}\text { BRAF }^{\mathrm{V} 600} \\
\text { wild-type } \\
(\mathrm{n}=79)\end{array}$} & \multicolumn{2}{|c|}{$\begin{array}{l}\text { NRAS }^{Q 61} \\
\text { mutant } \\
(n=21)\end{array}$} & \multicolumn{2}{|c|}{$\begin{array}{l}\text { NRAS }^{Q 61} \\
\text { wild-type } \\
(n=87)\end{array}$} & \multirow[b]{2}{*}{ P } & \multicolumn{2}{|c|}{$\begin{array}{c}\text { PIK3R1 } \\
\text { mutant } \\
(n=32)\end{array}$} & \multicolumn{2}{|c|}{$\begin{array}{c}\text { PIK3R1 } 1^{\text {M326I }} \\
\text { wild-type } \\
(n=76)\end{array}$} & \\
\hline & No.* & $\%$ & No.* & $\%$ & $P$ & No.* & $\%$ & No.* & $\%$ & & No.* & $\%$ & No.* & $\%$ & $P$ \\
\hline \multicolumn{16}{|l|}{ Gender } \\
\hline Female & 12 & 50 & 43 & 54 & NS & 14 & 67 & 44 & 51 & NS & 15 & 47 & 43 & 57 & NS \\
\hline Male & 12 & 50 & 36 & 46 & & 7 & 33 & 43 & 49 & & 17 & 53 & 33 & 43 & \\
\hline \multicolumn{16}{|l|}{ Age (years) } \\
\hline Mean & \multicolumn{2}{|c|}{$57.4 \pm 19.7$} & \multicolumn{3}{|c|}{$66.6 \pm 17$} & \multicolumn{2}{|c|}{$63.8 \pm 15.1$} & \multicolumn{2}{|c|}{$64.5 \pm 18.5$} & & \multicolumn{2}{|c|}{$71.2 \pm 4.6$} & \multicolumn{2}{|c|}{$61.6 \pm 18.4$} & \\
\hline$\leq 50$ years & 10 & 42 & 14 & 18 & .017 & 4 & 20 & 21 & 24 & NS & 2 & 7 & 23 & 30 & .010 \\
\hline$>50$ years & 14 & 58 & 64 & 82 & & 16 & 80 & 66 & 76 & & 29 & 94 & 53 & 70 & \\
\hline \multicolumn{16}{|l|}{ Breslow thickness, } \\
\hline 0.01-1.0 & 5 & 21 & 8 & 10 & NS & - & - & 14 & 17 & NS & 4 & 13 & 10 & 13 & NS \\
\hline $1.01-2.0$ & 6 & 25 & 16 & 21 & & 7 & 33 & 16 & 19 & & 3 & 10 & 20 & 27 & \\
\hline $2.01-4.0$ & 7 & 29 & 23 & 30 & & 8 & 38 & 23 & 27 & & 10 & 32 & 21 & 28 & \\
\hline$>4.0$ & 6 & 25 & 30 & 39 & & 6 & 29 & 32 & 38 & & 14 & 45 & 24 & 32 & \\
\hline \multicolumn{16}{|l|}{ Ulceration } \\
\hline Absent & 12 & 55 & 38 & 53 & NS & 14 & 70 & 38 & 48 & NS & 13 & 48 & 39 & 54 & NS \\
\hline Present & 10 & 46 & 34 & 47 & & 6 & 30 & 41 & 52 & & 14 & 52 & 33 & 46 & \\
\hline \multicolumn{16}{|c|}{ Histological subtype } \\
\hline SSM & 13 & 54 & 28 & 36 & NS & 6 & 30 & 38 & 44 & .012 & 8 & 25 & 36 & 48 & NS \\
\hline NM & 5 & 21 & 21 & 27 & & 11 & 55 & 17 & 20 & & 13 & 41 & 15 & 20 & \\
\hline LMM & 1 & 4 & 14 & 18 & & 1 & 5 & 14 & 16 & & 4 & 13 & 11 & 15 & \\
\hline Other & 5 & 21 & 15 & 19 & & 2 & 10 & 18 & 21 & & 7 & 22 & 13 & 17 & \\
\hline \multicolumn{16}{|l|}{ Location } \\
\hline Head and neck & 2 & 9 & 22 & 29 & NS & 2 & 11 & 24 & 28 & .022 & 10 & 31 & 16 & 22 & NS \\
\hline Trunk & 5 & 22 & 14 & 18 & & 1 & 5 & 19 & 22 & & 7 & 22 & 13 & 18 & \\
\hline Extremities & 16 & 70 & 40 & 53 & & 16 & 84 & 42 & 49 & & 15 & 47 & 43 & 60 & \\
\hline \multicolumn{16}{|l|}{ Disease recurrence } \\
\hline No & 11 & 55 & 40 & 58 & NS & 10 & 63 & 42 & 55 & NS & 13 & 48 & 39 & 59 & NS \\
\hline Yes & 9 & 45 & 29 & 42 & & 6 & 38 & 35 & 46 & & 14 & 52 & 27 & 41 & \\
\hline \multicolumn{16}{|c|}{ Disease-related death } \\
\hline No & 12 & 57 & 44 & 60 & NS & 11 & 58 & 47 & 59 & NS & 10 & 36 & 48 & 68 & .004 \\
\hline Yes & 9 & 43 & 30 & 41 & & 8 & 42 & 33 & 41 & & 18 & 64 & 23 & 32 & \\
\hline
\end{tabular}


Furthermore, PHLPP2 ${ }^{\text {L1016S }}$ and PIK3R1 $1^{\mathrm{M} 3261}$, known germline mutations, were frequently detected in both cohorts. PHLPP2 $2^{\text {L1016S }}$ is a functional germline polymorphism and detected in $34 \%$ of specimens which is in agreement with the general population. When subdividing the cohorts in primary and metastatic subgroups, a progressive trend $(P=.012)$ in $P H L P P 2^{\mathrm{L1016S}}$ mutation rate was observed. That is, primary melanomas displayed a mutation frequency of $29 \%$ (31 of 108 tissues) whereas in metastatic melanoma tissues the mutation frequency increased to $50 \%$ (22 of 44 tissues). The presence of PHLPP2 ${ }^{\mathrm{L} 1016 \mathrm{~S}}$ was not associated with the formation of metastases or survival of patients nor correlated with any other patient characteristics. The PIK3R1 ${ }^{\mathrm{M} 3261}$ germline mutation, a gene encoding $\mathrm{p} 85 \alpha$ which is the inhibitory subunit of phosphatidylinositol 3-kinase (PI3K), was identified in 41 of 154 (27\%) of melanoma patients, with 32 of 108 (30\%) primary melanomas and 8 of 44 (18\%) metastatic melanomas having the single nucleotide polymorphism (SNP). However, this germline SNP has been reported to lack functionality ${ }^{12,13}$. Our genotyping assay did cover multiple functional somatic mutation sites in the PIK3CA oncogene, the catalytic subunit of PI3K, but none of the examined melanoma samples carried these mutations. Interestingly, patients that possessed $\mathrm{PIK} 3 \mathrm{R} 1^{\mathrm{M} 326 \mathrm{I}}$-mutant primary melanoma had a significantly increased risk $(P=.004)$ to die from melanoma (Table 3). Moreover, primary melanomas that harbored PIK3R1 ${ }^{\mathrm{M} 326 \mathrm{I}}$ versus wild-type PIK3R1 melanomas were significantly more often present $(P=.010)$ among patients $>50$ years of age (Table 3).

\section{Demographic differences in BRAF, MET, and PIKBR1 mutation rates}

Next, we compared mutation data from Irish and Belgian patients. Unexpectedly, we discovered significantly lower $(P<.001) \mathrm{BRAF}^{\mathrm{V} 600}$ mutation rates in Irish patients compared with Belgian patients (Figure 2A). Our mutation panel included nine nonV600 mutations in the BRAF gene; however, these mutations were not detected in any of the examined tissues. In more detail, 20 out of 94 Irish patients (21\%) displayed a BRAF mutation; 18 patients (19\%) had the V600E genotype, while one patient (1\%) displayed V600K, and another patient (1\%) carried V600M mutation (Figure 2B).

In contrast, 31 out of 60 Belgian patients (52\%) carried a BRAF mutation; 26 patients $(43 \%)$ had $\mathrm{V} 600 \mathrm{E}$, four patients $(7 \%)$ had $\mathrm{V} 600 \mathrm{~K}$, and one patient $(2 \%)$ harbored $\mathrm{V} 600 \mathrm{R}$ genotype (Figure $2 \mathrm{~B}$ ). Thus, in comparison with $\mathrm{BRAF}^{\mathrm{V} 600}$ wild-type melanomas, the incidence of the BRAF ${ }^{\mathrm{V} 600 \mathrm{E}}$ mutation was significantly lower $(P<.001)$ in melanomas from Irish patients compared with melanomas from Belgian patients, i.e. 18 of $92(20 \%)$ Irish cases (excluding two cases with other BRAF ${ }^{\mathrm{V} 600}$ mutations) and 26 of 55 (47\%) Belgian cases (excluding five cases with other BRAF ${ }^{\mathrm{V} 600}$ mutations) carried the V600E mutation. The proportion of NRAS ${ }^{\mathrm{Q} 61}$ mutant cases was slightly higher among Irish patients compared with Belgian patients (Figure. 2A), however, this was not significantly different, and only partly explains the difference in BRAF mutation rates observed between the cohorts as these genes are mutually exclusive ${ }^{11}$. In the 
Irish cohort, $\mathrm{BRAF}^{\mathrm{V} 600 \mathrm{E}}$-mutant primary melanoma occurred more often $(\mathrm{P}=.005)$ in younger patients, i.e. 7 of 14 (50\%) $\mathrm{BRAF}^{\mathrm{V} 600 \mathrm{E}}$-mutant primary melanomas were from patients aged $\leq 50$ versus 10 of $64(16 \%)$ of $\mathrm{BRAF}^{\mathrm{V} 600}$ wild-type primary melanomas. In the Belgian cohort, none of the patient characteristics did significantly differ between BRAF mutant and BRAF wild-type patients. However, this cohort might be too small to identify any significant correlations.

Remarkably, within the Irish cohort, mutations in the MET oncogene were identified as a common event, whereas none of the Belgian patients possessed MET mutations (Figure 2A). That is, among Irish melanoma patients we detected a total of 11 mutations in MET (12\%), i.e. seven out of 81 (9\%) primary melanomas and two out of $11(18 \%)$ melanoma metastases harbored a MET mutation. This was significantly more often $(P=.007)$ compared with the Belgian cohort where none of the patients had MET mutations. Of the 11 mutation sites that were included in our mutation panel, we detected six mutations within the semaphorin domain of MET (N375S), which harbors the ligand-binding site, and five mutations in the juxtamembrane domain (two R988C, and three T1010I) (Figures 2C and 3). Interestingly, MET mutations did co-occur with BRAF and NRAS mutations, that is, both primary melanoma patients harboring $\mathrm{MET}^{\mathrm{R} 988 \mathrm{C}}$ also possessed $\mathrm{BRAF}^{\mathrm{V} 600 \mathrm{E}}$ mutations $(\mathrm{P}=.043)$; and one of six patients carried both $\mathrm{BRAF}^{\mathrm{V} 600 \mathrm{E}}$ and $\mathrm{MET}^{\mathrm{N} 3755}$ mutations (not significant). Furthermore, one mutant $\mathrm{MET}^{\top 1010 \mathrm{I}}$ melanoma also carried mutant NRAS ${ }^{\mathrm{Q61R}}$. None of the patient or tumor characteristics differed between M ET-mutant versus M ET-wild-type melanomas.

Additionally, within the Irish cohort, the frequency of PIK3R1 ${ }^{\mathrm{M} 326 \mathrm{I}}$ was significantly increased $(P=.027)$ when compared with Belgian patients, i.e. 31 of 94 (33\%) Irish patients and 10 of 60 (17\%) Belgian patients harbored PIK3R1 ${ }^{\mathrm{M} 3261}$ (Figure 2A). Primary melanoma patients from Ireland harboring the mutation had a significantly increased $(P=.048)$ risk to die from melanoma, that is, 15 of $24(63 \%)$ patients possessed the mutation and died versus 18 of $49(37 \%)$ patients that lacked the mutation. Within the

A

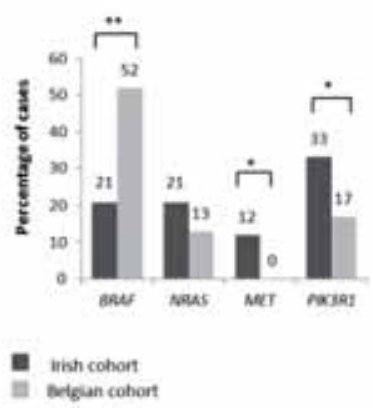

B

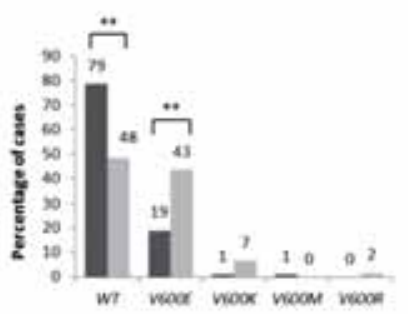

c

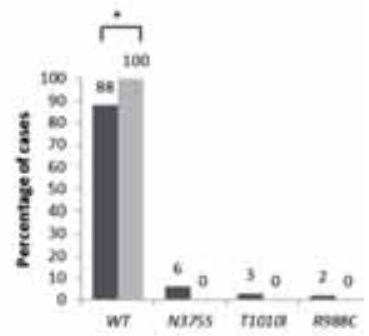

Figure 2. Demographic variation in mutation rates. Bar plots showing the distribution of (A) BRAF, NRAS, MET, and PIK3R1 mutations, (B) BRAF ${ }^{\mathrm{V} 600}$ and (C) MET genotypes in the Irish and Belgian cohorts. Data is presented as the percentage of cases ( $y$-axis) for each mutation ( $x$-axis). ${ }^{*} * P<0.001 * P<0.05$ 
Belgian cohort, this effect is only noticeable as a trend $(P=.072)$ probably due to the lack of power in this cohort. Furthermore, within the Irish cohort, the mutation was significantly associated $(P=.042)$ with patients aged $>50$ years, i.e. 25 of 27 (93\%) PIK3R1 ${ }^{\text {M } 3261}$-mutant primary melanomas were from patients aged $>50$ years versus 38 of $53(72 \%)$ wild-type patients.

\section{Confirmation of reduced BRAF mutation rates among Irish melanoma patients}

To confirm the reduced incidence of $\mathrm{BRAF}^{\mathrm{V} 600 \mathrm{E}}$ mutated melanoma in Ireland, clinical $\mathrm{BRAF}^{\mathrm{V} 600 \mathrm{E}}$ patient data were accrued from five independent hospitals located in the Irish cities Dublin, Cork, and Galway (Figure 1). Within Irish cohort 2, 29 of 137 (21\%) patients possessed $\mathrm{BRAF}^{\mathrm{V} 600 \mathrm{E}}$ mutant melanoma, with 22 of $111(20 \%)$ primary and seven of $26(27 \%)$ metastatic melanomas displaying the mutation. Sixteen out of 76 (21\%) melanoma cases within Irish cohort 3 harbored the BRAF ${ }^{\mathrm{V} 600 \mathrm{E}}$ mutation, with eight of 31 (26\%) primary and eight of 45 (18\%) metastatic tissues exhibiting the mutation. In addition, one patient displayed V600K, and two patients possessed nonV600 mutations. In Irish cohort 4, 50 of 182 patients (27\%) harbored the BRAF ${ }^{\mathrm{V} 600 \mathrm{E}}$ genotype, with 20 out of 90 (22\%) primary melanomas and 30 out of 92 (33\%) metastases displaying the mutation. The BRAF ${ }^{\mathrm{V} 600 \mathrm{E}}$ mutation rate in Irish cohort 5 was $29 \%$ (38 of 132 cases), with five of 30 (17\%) primary melanomas and 33 of 102 (32\%) melanoma metastases harboring the mutation. In Irish cohort 6, 14 of 68 (21\%) melanoma cases harbored the BRAF ${ }^{\mathrm{V} 600 \mathrm{E}}$ genotype, three of $29(10 \%)$ primary cases and 11 of 39 (28\%) melanoma metastases (Figure 1). The tissues in Irish cohort 4, 5, and 6 were genotyped using the FDA approved cobas $^{\circledR} 4800$ BRAF V600 Mutation Test (Roche); although designed to detect $\mathrm{BRAF}^{\mathrm{V} 600 \mathrm{E}}$, this assay has been shown to have a limited ability to detect V600K mutations as well ${ }^{14}$. Hence, we cannot exclude $\mathrm{BRAF}^{\mathrm{V} 600 \mathrm{~K}}$ mutations within these cohorts and this might explain the slightly increased mutation rate for patients in cohort 4 and 5. Combining all six Irish cohorts revealed that only 165 of 689 (24\%) patients carried $\mathrm{BRAF}^{\mathrm{V} 600 \mathrm{E}}$-mutant melanomas (72 of 327 [19\%] primary tumors; 93 of 315 [30\%] metastases). Hence, the frequency of BRAF ${ }^{\mathrm{V} 600 \mathrm{E}}$ is remarkably decreased relative to the frequency found in other Western countries, i.e. approximately $50 \%{ }^{11}$.

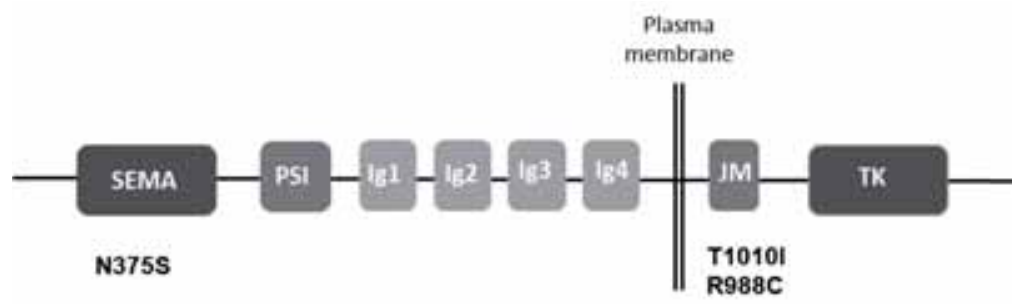

Figure 3. MET mutations identified in Irish melanoma patients. Identified mutations, N375S, T1010I, and R988C, in the semaphorin and juxtamembrane domain of MET. SEMA, semaphorin domain; PSI, plexins, semaphorins, integrins domain; Ig1-4, immunoglobulin domain; JM, juxtamembrane domain; TK, Tyrosine kinase domain. 
For a total of 222 primary cases we had additional information regarding to the histological subtype revealing that BRAF ${ }^{\mathrm{V} 600 \mathrm{E}}$ was present in 12 of 67 (18\%) SSM, 18 of $94(19 \%)$ NM, two of 21 (10\%) lentigo maligna melanomas (LMM), and seven of 40 (18\%) other subtypes, thus at similar frequencies among the different subtypes. Moreover, we had additional BRAF mutation data (13 BRAF mutations screened) for a total of 170 Irish patients, showing that on top of V600E mutations (34 cases; 20\%), two patients possessed V600K (1\%), one patient had V600M (1\%), and two patients carried non-V600 BRAF mutations (1\%). This indicates that the presence of other BRAF mutations cannot explain the low frequency among melanoma patients in Ireland.

\section{Discussion}

Over the last decades, extensive progress has been made in unraveling the genetic background of cutaneous melanoma which led to the development of treatments based on this knowledge. Activating oncogene mutations are recognized as important biomarkers, e.g. mutations in the BRAF gene identifies patients who might benefit from mutant BRAF inhibitors ${ }^{2}$. To further increase our understanding of the mutational events that underlie this disease, we examined the rate of specific mutation hot-spots in melanoma tissues across two European countries, i.e. Ireland and Belgium, and correlated the presence of mutations with clinicopathological characteristics. In total, we found that $81 \%$ of 154 examined tissues contained at least one mutation in the following genes; BRAF, NRAS, MET, PHLPP2, PIK3R1, IDH1, KIT, STK11, CTNNB1, JAK2, $A L K$, and GNAS. Mutations were found significantly more often $(P=.019)$ in melanoma metastases (93\%) versus primary melanoma tissues (77\%). In addition, a high number of specimens (38\%) carried more than one mutation. It is known that melanoma represents a heterogeneous disease with a high mutational load that is partially caused by ultraviolet exposure ${ }^{15,16}$. Hence, the great amount of mutated specimens and number of samples with coinciding mutations discovered in our study is not surprising. Furthermore, primary melanoma tissues that harbored $\geq 1$ mutation had a worse prognosis $(\mathrm{P}=.012)$ when compared with primary melanomas that lacked mutations in the examined genes. The NM subtype significantly more often carried mutations $(P=.019)$ compared to the other subtypes, which is in agreement with the literature ${ }^{17}$.

Somatic mutations in $\mathrm{BRAF}^{\mathrm{V} 600}$ and $\mathrm{NRAS}^{\mathrm{Q} 61}$, and known germline mutations in PHLPP2 ${ }^{\mathrm{L} 1016 \mathrm{~S}}$ and PIK3R1 ${ }^{\mathrm{M} 326 \mathrm{l}}$ were frequently detected, i.e. in more than $10 \%$ of tissues. PHLPP2 binds to and dephosphorylates AKT1, AKT3 and PKC isoforms ${ }^{18,19}$. Characterization of the L1016S mutant has revealed that its phosphatase activity (as measured by activity toward AKT) and its ability to promote apoptosis are defective, thus resulting in elevated AKT phosphorylation, increased PKC levels and reduced apoptosis $^{20}$. Brognard et al. ${ }^{20}$ hypothesized that PHLPP2 might not be involved in early stages of tumorigenesis but, rather, play a role in metastasis. We observed an increased SNP rate $(\mathrm{P}=.012)$ in melanoma metastases compared with primary specimens, i.e. $46 \%$ and $31 \%$ respectively in the Irish cohort and $52 \%$ and $22 \%$ 
respectively in the Belgian cohort. This might indicate that patients possessing this germline SNP have an increased risk of developing metastatic disease. Nevertheless, presence of the PHLPP2 ${ }^{\mathrm{L} 1016 \mathrm{~S}}$ mutation in primary melanomas did not correlate with tumor thickness or ulceration, known prognostic melanoma factors, or associate with disease recurrence or melanoma-related death.

The PIK3R1 ${ }^{\mathrm{M} 326 \mathrm{I}}$ alteration is seemingly not functional, as it was shown to lack impact on PI3K activity and signaling events ${ }^{12,13}$. However, we observed that patients who harbored PIK3R1 ${ }^{\mathrm{M} 326 \mathrm{I}}$-mutant primary melanoma significantly more often died from their disease. Interestingly, no effect on the formation of metastatic disease was observed. Future studies that investigate the role of PIK3R1 ${ }^{\mathrm{M} 3261}$ in melanoma and its possible prognostic significance are needed for a complete understanding of its potential contribution to pathogenesis.

The genetic alteration of BRAF induces constitutive activation of the MAPK signaling pathway resulting in promotion of proliferation, survival, and development of tumor cells ${ }^{21}$. The presence of BRAF-mutant melanoma is of clinical importance as these patients can receive targeted treatment with BRAF and MEK inhibitors ${ }^{3,5,6}$. The $\mathrm{BRAF}^{\mathrm{V} 600 \mathrm{E}}$ mutation is by far the most commonly reported alteration in the BRAF gene (75-90\%), in line with the frequency of $86 \%$ detected in our study. Unexpectedly, we observed a significantly reduced BRAF mutation rate $(P<.001)$ in the Irish cohort $(21 \%)$ compared with the mutation frequency in the Belgian cohort (52\%). It should be noted that the sample size of our Belgian cohort is relatively small and, by comparison of both populations, there is a significant bias towards a greater number of metastatic samples in the Belgian cohort. However, the frequency of BRAF-mutant melanoma has been thoroughly investigated in numerous studies and found to be approximately $50 \%$; hence, significantly lower than the frequency detected in the Irish population ${ }^{11,17,22}$. We used five additional Irish cohorts to independently confirm the reduced BRAF mutation rate using different detection methods. Overall, the mutation frequency of BRAF ${ }^{\mathrm{V} 600 \mathrm{E}}$ detected among Irish patients was $24 \%$ (165 of 689 cases) of which $19 \%$ (72 of 372 ) of primary melanomas and $30 \%$ (93 of 315) of metastatic tissues harbored the mutation. Importantly, a subset of 170 Irish melanoma cases were screened for other mutations in the BRAF gene, including non-V600 mutations, showing only five non-V600E mutations in this subgroup. Therefore, the presence of non-V600E mutations in the BRAF gene cannot alone account for the reduced rate. The $\mathrm{BRAF}^{\mathrm{V} 600 \mathrm{E}}$ mutation prevalence is known to inversely correlate with age ${ }^{22}$; however, age distribution among the cohorts is comparable and also cannot explain the observed difference. Furthermore, the mutation is known to associate with the SSM subtype $^{22}$; though, within our Irish cohorts the mutation prevalence among the SSM subtype $(n=67)$ is only $18 \%$ and similar to the frequency detected among other subtypes and thus can also not explain the low frequency among Irish patients. Hence, our data show that the incidence of BRAF mutation rates varies between different demographic populations, i.e. melanoma patients from Ireland have decreased $\mathrm{BRAF}^{\mathrm{V} 600 \mathrm{E}}$ mutation rates of approximately $24 \%$. This observation directly impacts 
future treatment strategies for Irish patients, as only a minority of them will be able to benefit from BRAF inhibitor treatment.

The identification of substantial mutation rates in the MET oncogene, approximately $12 \%$, provides opportunities for targeting a subset of melanoma patients with MET inhibitors. MET (cellular-mesenchymal to epithelial transcription factor) is a receptor tyrosine kinase (RTK) that activates multiple cellular transduction pathways, including MAPK, PI3K, WNT, and Notch, thereby stimulating the invasive growth of cancer cells and increase their metastatic potential ${ }^{23}$. Of the 11 patients possessing a MET mutation, there were six patients with a mutation in the semaphorin domain of MET (N375S), which harbors the ligand binding site. In lung cancer cells this mutation confers resistance to MET inhibition with SU11274 ${ }^{24}$. It is suggested that the N375S mutation leads to a weaker ligand - receptor interaction, and thus a less than optimal kinase activation, reflecting the increased resistance to MET inhibition. Moreover, three patients had $\mathrm{MET}^{\mathrm{T} 1010 \mathrm{l}}$ genotype and two patients possessed $\mathrm{MET}^{\mathrm{R} 988 \mathrm{C}}$, both activating mutations in the juxtamembrane domain of MET. T1010l and R988C mutations have been linked to increased tumorigenicity ${ }^{25-27}$. Unfortunately, from our study we cannot determine if the detected mutations are germline or somatic, nevertheless, previously all three mutations have been (partly) recognized as somatic mutations ${ }^{28}$.

The relevance of MET mutations in melanoma is not well known, several studies report negative results regarding MET mutations in melanoma ${ }^{29-31}$. However, the above described mutations all have previously been identified in melanoma ${ }^{32,33}$. Moreover, MET amplification occurs in melanoma tissues ${ }^{34}$; and in melanoma cells, MET activation via amplification caused primary resistance to vemurafenib treatment ${ }^{35}$. Additionally, it has been shown that hepatocyte growth factor (HGF), the only known natural ligand for MET, can cause resistance to RAF inhibitors ${ }^{36,37}$. The cooccurrence of MET and BRAF mutations in three patients examined in the present study therefore might indicate that these patients are less likely to respond to BRAF inhibition and, thus, require alternative or additional treatment, such as with MET inhibitors. Moreover, MET inhibition might be a useful treatment for NRAS-mutant melanomas ${ }^{38}$. This is further strengthened by the observation that oncogenic RAS can induce MET overexpression through transcriptional mechanisms ${ }^{39,40}$. Selective MET inhibitors that are currently in clinical trial include crizotinib, tivantinib, and foretinib ${ }^{41}$. A number of clinical trials have demonstrated strong activity of MET inhibitors in patients with a variety of advanced or metastatic tumors, including non-small-lung cancer (NSCLC), breast, prostate, liver, and renal cancer ${ }^{42}$. As yet, no clinical trials with selective MET inhibitors have been conducted on melanoma patients. Future research is needed to determine the impact of MET mutations in melanoma and examine if MET inhibitors, either alone or in combination with inhibitors of other signaling pathways, offer an effective treatment for patients without BRAF mutations or for those patients that are resistant to BRAF inhibition. 
The key question arising from this study is why a difference is seen in the types of mutations occurring across populations? Interestingly, a low level of BRAF mutations $(25 \%)$ has also been found among Scottish melanoma patients ${ }^{43}$. Ireland and Scotland form, together with Wales, Brittany, Cornwall, and Isle of Man, the Celtic nation, which are territories in Northern and Western Europe with relatively low sun exposure. Red hair, resulting from an inactivating mutation in the $M C 1 R$ gene, has long been associated with Celtic people. Indeed, up to $46 \%$ of the Irish population carry a recessive $M C 1 R$ mutation ${ }^{44}$. In addition, a lower rate of mutant BRAF has been reported in carriers of $M C 1 R$ variants ${ }^{45}$, although contradictive data, showing either a higher rate of mutant BRAF in MC1R variants ${ }^{46,47}$, or no relationship between these mutations $^{48,49}$, also exist. This could reflect the difficulty in studying the relationship of MClR with other mutations, as the MClR gene is highly polymorphic, with more than 100 described variants. Interestingly, it has been shown that the introduction of BRaf $^{\mathrm{V} 600 \mathrm{E}}$ into mice carrying MClr mutation leads to a high incidence of invasive melanomas without providing additional gene aberrations or UV exposure ${ }^{50}$. Therefore, we hypothesize that BRAF mutations in the Celtic population might be reduced as a cause of genetic drift or natural selection to protect this population from the most deadly form of skin cancer, melanoma. The observation that melanoma tissues from Irish patients possessed slightly increased NRAS mutation rates and significantly more often harbored MET and $\mathrm{PIK} 3 \mathrm{R}^{\mathrm{M}}{ }^{3261}$ mutations might point to a more predominant role of the PI3K pathway in these tumors, suggesting a distinct etiology. More in-depth studies are needed to completely understand the pathogenesis of melanoma, and the significance of BRAF, MET, and PIK3R1 mutations, among the Irish population.

Taken together, this study contributes towards the molecular understanding of cutaneous melanoma. The observation that mutations vary by demographic location will have important implications for clinically available and novel treatment options.

\section{Acknowledgements}

We would like to posthumously acknowledge Prof. Peter A. Dervan from the Mater Misericordiae University Hospital, Dublin, Ireland, for his valuable contribution to the manuscript. We thank Katherine Stemke Hale from the University of Texas M. D. Anderson Cancer Center for the design of the Sequenom mutation panel.

This work was supported by an EU FP7 Marie Curie Industry-Academia Partnerships and Pathways (IAPP) research programme, Target-Melanoma (www.targetmelanoma.com) (grant number 230614) and a Science Foundation Ireland (SFI) Strategic Research Cluster grant from Molecular Therapeutics for Cancer Ireland (MTCl; www.mtci.ie) (grant number 08/SRC/B1410). 


\section{References}

1. Miller AJ, Mihm MC, Jr. Melanoma. N Engl J Med, 2006. 355(1): p. 51-65.

2. Flaherty $\mathrm{KT}$, Hodi FS, Fisher DE. From genes to drugs: targeted strategies for melanoma. Nat Rev Cancer, 2012. 12(5): p. 349-361.

3. Flaherty KT, Yasothan U, Kirkpatrick P. Vemurafenib. Nat Rev Drug Discov, 2011. 10(11): p. 811-812.

4. Hauschild A, Grob JJ, Demidov LV, et al. Dabrafenib in BRAF-mutated metastatic melanoma: a multicentre, open-label, phase 3 randomised controlled trial. Lancet, 2012. 380(9839): p. 358-365.

5. Masuda S, Izpisua Belmonte JC. Trametinib for patients with advanced melanoma. Lancet Oncol, 2012. 13(10): p. e409; author reply e409-410.

6. Flaherty $\mathrm{KT}$, Robert $\mathrm{C}$, Hersey $\mathrm{P}$, et al. Improved survival with MEK inhibition in BRAF-mutated melanoma. $\mathrm{N}$ Engl J Med, 2012. 367(2): p. 107-114.

7. Smalley KS, Sondak VK. Targeted therapy for melanoma: is double hitting a home run? Nat Rev Clin Oncol, 2013. 10(1): p. 5-6.

8. Griewank KG, Ugurel S, Schadendorf D, et al. New developments in biomarkers for melanoma. Curr Opin Oncol, 2013. 25(2): p. 145-151.

9. Huang YW, Jansen RA, Fabbri E, et al. Identification of candidate epigenetic biomarkers for ovarian cancer detection. Oncol Rep, 2009. 22(4): p. 853-861.

10. Ryan D, Rafferty M, Hegarty S, et al. Topoisomerase I amplification in melanoma is associated with more advanced tumours and poor prognosis. Pigment Cell Melanoma Res, 2010. 23(4): p. 542-553.

11. van den Hurk K, Niessen HE, Veeck J, et al. Genetics and epigenetics of cutaneous malignant melanoma: A concert out of tune. Biochim Biophys Acta, 2012. 1826(1): p. 89-102.

12. Almind K, Delahaye L, Hansen T, et al. Characterization of the Met326lle variant of phosphatidylinositol 3kinase p85alpha. Proc Natl Acad Sci U S A, 2002. 99(4): p. 2124-2128.

13. Cheung LW, Hennessy BT, Li J, et al. High frequency of PIK3R1 and PIK3R2 mutations in endometrial cancer elucidates a novel mechanism for regulation of PTEN protein stability. Cancer Discov, 2011. 1(2): p. 170-185.

14. Halait H, Demartin K, Shah S, et al. Analytical performance of a real-time PCR-based assay for V600 mutations in the BRAF gene, used as the companion diagnostic test for the novel BRAF inhibitor vemurafenib in metastatic melanoma. Diagn Mol Pathol, 2012. 21(1): p. 1-8.

15. Krauthammer $\mathrm{M}$, Kong $\mathrm{Y}, \mathrm{Ha} \mathrm{BH}$, et al. Exome sequencing identifies recurrent somatic RAC1 mutations in melanoma. Nat Genet, 2012. 44(9): p. 1006-1014.

16. Hodis E, Watson IR, Kryukov GV, et al. A landscape of driver mutations in melanoma. Cell, 2012. 150(2): p. 251-263.

17. Yaman B, Akalin T, Kandiloglu G. Clinicopathological Characteristics and Mutation Profiling in Primary Cutaneous Melanoma. Am J Dermatopathol, 2014. p.

18. Brognard J, Sierecki E, Gao T, et al. PHLPP and a second isoform, PHLPP2, differentially attenuate the amplitude of Akt signaling by regulating distinct Akt isoforms. Mol Cell, 2007. 25(6): p. 917-931.

19. Gao T, Brognard J, Newton AC. The phosphatase PHLPP controls the cellular levels of protein kinase C. J Biol Chem, 2008. 283(10): p. 6300-6311.

20. Brognard J, Niederst M, Reyes G, et al. Common polymorphism in the phosphatase PHLPP2 results in reduced regulation of Akt and protein kinase C. J Biol Chem, 2009. 284(22): p. 15215-15223.

21. Govindarajan B, Bai X, Cohen C, et al. Malignant transformation of melanocytes to melanoma by constitutive activation of mitogen-activated protein kinase kinase (MAPKK) signaling. J Biol Chem, 2003. 278(11): p. 97909795.

22. Long GV, Menzies AM, Nagrial AM, et al. Prognostic and clinicopathologic associations of oncogenic BRAF in metastatic melanoma. J Clin Oncol, 2011. 29(10): p. 1239-1246.

23. Peters S, Adjei AA. MET: a promising anticancer therapeutic target. Nat Rev Clin Oncol, 2012. 9(6): p. 314-326.

24. Krishnaswamy $S$, Kanteti R, Duke-Cohan JS, et al. Ethnic differences and functional analysis of MET mutations in lung cancer. Clin Cancer Res, 2009. 15(18): p. 5714-5723.

25. Ma PC, Kijima T, Maulik G, et al. c-MET mutational analysis in small cell lung cancer: novel juxtamembrane domain mutations regulating cytoskeletal functions. Cancer Res, 2003. 63(19): p. 6272-6281.

26. Ma PC, Jagadeeswaran R, Jagadeesh $S$, et al. Functional expression and mutations of c-Met and its therapeutic inhibition with SU11274 and small interfering RNA in non-small cell lung cancer. Cancer Res, 2005. 65(4): p. 1479-1488.

27. Tengs $T$, Lee JC, Paez JG, et al. A transforming MET mutation discovered in non-small cell lung cancer using microarray-based resequencing. Cancer Lett, 2006. 239(2): p. 227-233.

28. Ghiso E, Giordano S. Targeting MET: why, where and how? Curr Opin Pharmacol, 2013. 13(4): p. 511-518. 
29. Kenessey I, Keszthelyi M, Kramer Z, et al. Inhibition of c-Met with the specific small molecule tyrosine kinase inhibitor SU11274 decreases growth and metastasis formation of experimental human melanoma. Curr Cancer Drug Targets, 2010. 10(3): p. 332-342.

30. Seidl $\mathrm{H}$, Weger $\mathrm{W}$, Wolf $\mathrm{P}$, et al. Lack of oncogenic mutations in the c-Met catalytic tyrosine kinase domain in acral lentiginous melanoma. Int J Dermatol, 2008. 47(12): p. 1327-1329.

31. Schmidt L, Junker K, Nakaigawa N, et al. Novel mutations of the MET proto-oncogene in papillary renal carcinomas. Oncogene, 1999. 18(14): p. 2343-2350.

32. Puri $\mathrm{N}$, Ahmed $\mathrm{S}$, Janamanchi $\mathrm{V}$, et al. c-Met is a potentially new therapeutic target for treatment of human melanoma. Clin Cancer Res, 2007. 13(7): p. 2246-2253.

33. Kim S, Gonzalez N, Luthra R, et al. Frequency and clinical characteristics of c-MET mutation in malignant melanoma [abstract]. Cancer Res, 2012. 72(8): p. s4588.

34. Moore SR, Persons DL, Sosman JA, et al. Detection of copy number alterations in metastatic melanoma by a DNA fluorescence in situ hybridization probe panel and array comparative genomic hybridization: a southwest oncology group study (S9431). Clin Cancer Res, 2008. 14(10): p. 2927-2935.

35. Vergani E, Vallacchi V, Frigerio $S$, et al. Identification of MET and SRC activation in melanoma cell lines showing primary resistance to PLX4032. Neoplasia, 2011. 13(12): p. 1132-1142.

36. Straussman $R$, Morikawa $T$, Shee $K$, et al. Tumour micro-environment elicits innate resistance to RAF inhibitors through HGF secretion. Nature, 2012. 487(7408): p. 500-504.

37. Wilson TR, Fridlyand J, Yan Y, et al. Widespread potential for growth-factor-driven resistance to anticancer kinase inhibitors. Nature, 2012. 487(7408): p. 505-509.

38. Chattopadhyay C, Ellerhorst JA, Ekmekcioglu S, et al. Association of activated c-Met with NRAS-mutated human melanomas. Int J Cancer, 2012. 131(2): p. E56-65.

39. Ivan M, Bond JA, Prat $\mathrm{M}$, et al. Activated ras and ret oncogenes induce over-expression of c-met (hepatocyte growth factor receptor) in human thyroid epithelial cells. Oncogene, 1997. 14(20): p. 2417-2423.

40. Furge KA, Kiewlich D, Le $P$, et al. Suppression of Ras-mediated tumorigenicity and metastasis through inhibition of the Met receptor tyrosine kinase. Proc Natl Acad Sci U S A, 2001. 98(19): p. 10722-10727.

41. Cecchi F, Rabe DC, Bottaro DP. Targeting the HGF/Met signaling pathway in cancer therapy. Expert Opin Ther Targets, 2012. 16(6): p. 553-572.

42. Gherardi E, Birchmeier W, Birchmeier C, et al. Targeting MET in cancer: rationale and progress. Nat Rev Cancer, 2012. 12(2): p. 89-103.

43. Lang J, MacKie RM. Prevalence of exon 15 BRAF mutations in primary melanoma of the superficial spreading, nodular, acral, and lentigo maligna subtypes. J Invest Dermatol, 2005. 125(3): p. 575-579.

44. Hooton EA. Stature, head form, and pigmentation of adult male Irish. American Journal of Physical Anthropology, 1940. 26(1): p. 229-249.

45. Scherer D, Rachakonda PS, Angelini S, et al. Association between the germline MC1R variants and somatic BRAF/NRAS mutations in melanoma tumors. J Invest Dermatol, 2010. 130(12): p. 2844-2848.

46. Landi MT, Bauer J, Pfeiffer RM, et al. MC1R germline variants confer risk for BRAF-mutant melanoma. Science, 2006. 313(5786): p. 521-522.

47. Fargnoli MC, Pike K, Pfeiffer RM, et al. MC1R variants increase risk of melanomas harboring BRAF mutations. J Invest Dermatol, 2008. 128(10): p. 2485-2490.

48. Hacker E, Hayward NK, Dumenil T, et al. The association between MC1R genotype and BRAF mutation status in cutaneous melanoma: findings from an Australian population. J Invest Dermatol, 2010. 130(1): p. 241-248.

49. Thomas NE, Kanetsky PA, Edmiston SN, et al. Relationship between germline MC1R variants and BRAF-mutant melanoma in a North Carolina population-based study. J Invest Dermatol, 2010. 130(5): p. 1463-1465.

50. Mitra D, Luo X, Morgan A, et al. An ultraviolet-radiation-independent pathway to melanoma carcinogenesis in the red hair/fair skin background. Nature, 2012. 491(7424): p. 449-453 


\section{Supplementary information}

Supplementary Table S1. Overview of 159 mutations in 33 oncogenes that are detected with the Sequenom genotyping platform

\begin{tabular}{|c|c|c|c|}
\hline Gene_Symbol & SNP_ID & Gene_Symbol & SNP_ID \\
\hline$\overline{\mathrm{AKT1}}$ & AKT1_E17K_G49A & ERa & ERa_G400V \\
\hline AKT1 & AKT1_G173R_G517C & FRAP & FRAP_M135T_T404C \\
\hline AKT1 & AKT1_K179M_A536T & GNAS & GNAS_Q227_C651 \\
\hline AKT2 & AKT2_E17K_G49A & GNAS & GNAS_R201_C601 \\
\hline AKT2 & AKT2_G175R_G523C & HIF1A & HIF1A_Q697E_C2089G \\
\hline AKT3 & AKT3_E17K_G49K & IDH1 & IDH1_R132_C394T \\
\hline AKT3 & AKT3_G171R_G511A & IDH1 & IDH1_R132_G295T \\
\hline ALK & ALK_1174I_T3520A & $\mathrm{IDH} 2$ & IDH2_R172_A514T \\
\hline ALK & ALK_A8777S_G2G29T & $\mathrm{IDH} 2$ & IDH2_R172_G515 \\
\hline ALK & ALK_D1091N_G3271A & IGF1R & IGF1R_A1347V_C40404T \\
\hline ALK & ALK_F1174L_C3522A & JAK2 & JAK2_V617F_G1849T \\
\hline ALK & ALK_F1245C_T3734G & KIT & KIT_D816H_GC \\
\hline ALK & ALK_F1245V_T3734G & KIT & KIT_D816V_AT \\
\hline ALK & ALK_I1171N_T3512A & KIT & KIT_K642E_AG \\
\hline ALK & ALK_I150T_T3749C & KIT & KIT_L576P_TC \\
\hline ALK & ALK_L560F_G1680C & KIT & KIT_N556D_AG \\
\hline ALK & ALK_M1166R_T3497G & KIT & KIT_R634W_CT \\
\hline ALK & ALK_R1275Q & KIT & KIT_V559_T \\
\hline BRAF & BRAF_D594_1781A & KIT & KIT_V560D_TA_SPLICE \\
\hline BRAF & BRAF_E586K_1756GA_Splice & KIT & KIT_V825A_TC \\
\hline BRAF & BRAF_G464_1391G & KIT & KIT_Y553N_TA \\
\hline BRAF & BRAF_G466_1397G & KRAS & KRAS_A146_436 \\
\hline BRAF & BRAF_G466R_1396_GC & KRAS & KRAS_G10R \\
\hline BRAF & BRAF_G469_1407A & KRAS & KRAS_G12_34G \\
\hline BRAF & BRAF_K601E_AG & KRAS & KRAS_G12_35G \\
\hline BRAF & BRAF_K601N_A & KRAS & KRAS_G13_37G \\
\hline BRAF & BRAF_L597R_1790TG & KRAS & KRAS_G13_38G \\
\hline BRAF & BRAF_V600_1798G_1 & KRAS & KRAS_Q61_181C \\
\hline BRAF & BRAF_V600_1799T_1 & KRAS & KRAS_Q61_182A \\
\hline BRAF & BRAF_V600_1799T_2 & KRAS & KRAS_Q61_183A \\
\hline BRAF & BRAF_V600_1800G & MEK1 & MEK1_D67N_G119A \\
\hline CDK4 & CDK4_R24C_C70T_2 & MEK1 & MEK1_K56N \\
\hline CDK4 & CDK4_R24H_G71A & MEK1 & MEK1_Q56P \\
\hline CTNNB1 & CTNNB1_D32_94G & MET & MET_H1112_3335 \\
\hline CTNNB1 & CTNNB1_D32_95A & MET & MET_H1112Y_C3334T \\
\hline CTNNB1 & CTNNB1_G34_101G & MET & MET_H1124D_C3370G \\
\hline CTNNB1 & CTNNB1_S33_97T & MET & MET_M1268T_T3803C \\
\hline CTNNB1 & CTNNB1_S37_109T & MET & MET_N375S \\
\hline CTNNB1 & CTNNB1_S37_110C & MET & MET_N848S \\
\hline CTNNB1 & CTNNB1_S45_133T & MET & MET_R988C \\
\hline CTNNB1 & CTNNB1_S45_134C & MET & MET_T1010I_C3029T \\
\hline CTNNB1 & CTNNB1_T41_121A & MET & MET_Y1248_T3742 \\
\hline Dear1 & Dear1_new & MET & MET_Y1248C_A3743G \\
\hline EGFR & EGFR_G719_G2155 & MET & MET_Y1253D_T3757G \\
\hline EGFR & EGFR_K860I_A2579T & NRAS & NRAS_G12_G34 \\
\hline EGFR & EGFR_L858R_TG & NRAS & NRAS_G12_G35 \\
\hline EGFR & EGFR_S720P_T2158C & NRAS & NRAS_G13_G37 \\
\hline EGFR & EGFR_T790M_C2369T_Splice & NRAS & NRAS_G13_G38 \\
\hline EGFR & EGFR_T854I_C2561T & NRAS & NRAS_Q61_A182 \\
\hline EGFR & EGFR_Y813C_A2438G & NRAS & NRAS_Q61_A183 \\
\hline
\end{tabular}


Supplementary Table S1. Overview of 159 mutations in 33 oncogenes that are detected with the Sequenom genotyping platform continued

\begin{tabular}{|c|c|c|c|}
\hline Gene_Symbol & SNP_ID & Gene_Symbol & SNP_ID \\
\hline NRAS & NRAS_Q61_C181 & PDGFRA & PDGFRA_E996K_G2986 \\
\hline PDGFRA & PDGFRA_D842_A2525T & PDGFRA & PDGFRA_N659K_C1977A \\
\hline PDGFRA & PDGFRA_D842_G2524 & PDGFRA & PDGFRA_N659Y_A1975T \\
\hline PDGFRA & PDGFRA_V561D_T1682A & PIK3CA & PIK3CA_Q060K \\
\hline PDGFRA & PDGFRA_V824L_G2470C & PIK3CA & PIK3CA_Q546_1636C \\
\hline PDPK1 & PDPK1_D527E_C1581G & PIK3CA & PIK3CA_Q546_1637A1 \\
\hline PDPK1 & PDPK1_T354M_C1061T & PIK3CA & PIK3CA_R088Q \\
\hline PHLPP2 & PHLPP2_L1016S_T3047C & PIK3CA & PIK3CA_S405F \\
\hline PIK3CA & PIK3CA_A1046V & PIK3CA & PIK3CA_T1025_3073A \\
\hline PIK3CA & PIK3CA_C420R & PIK3CA & PIK3CA_Y1021_3061T \\
\hline PIK3CA & PIK3CA_C420R & PIK3CA & PIK3CA_Y1021C_3062 \\
\hline PIK3CA & PIK3CA_C420R_2 & PIK3R1 & PIK3R1_D560Y \\
\hline PIK3CA & PIK3CA_E110K & PIK3R1 & PIK3R1_G376R_2 \\
\hline PIK3CA & PIK3CA_E418K & PIK3R1 & PIK3R1_intron1 \\
\hline PIK3CA & PIK3CA_E453K & PIK3R1 & PIK3R1_intron2 \\
\hline PIK3CA & PIK3CA_E542_1624G & PIK3R1 & PIK3R1_M326I_G978 \\
\hline PIK3CA & PIK3CA_E542_1625A & PIK3R1 & PIK3R1_N564K \\
\hline PIK3CA & PIK3CA_E545_1633G & PRKAG1 & PRKAG1_R70Q \\
\hline PIK3CA & PIK3CA_E545_1634A & PRKAG2 & PRKAG2_N488I \\
\hline PIK3CA & PIK3CA_E545_1635G & PRKAG2 & PRKAG2_R531Q \\
\hline PIK3CA & PIK3CA_F909L & RET & RET_M918T \\
\hline PIK3CA & PIK3CA_G1049R & Rictor & Rictor_M675I_G2025A \\
\hline PIK3CA & PIK3CA_H1047 & Rictor & Rictor_S159F_C476T \\
\hline PIK3CA & PIK3CA_H1047_1 & STK11 & STK11_D194_A591T \\
\hline PIK3CA & PIK3CA_H1047Y & STK11 & STK11_D194_G590 \\
\hline PIK3CA & PIK3CA_H701P & STK11 & STK11_F354L_C1062G \\
\hline PIK3CA & PIK3CA_M1043I_G3129 & STK11 & STK11_P281L_C842T \\
\hline PIK3CA & PIK3CA_M1043V & TNK2 & TNK2_E346K_G1036A \\
\hline PIK3CA & PIK3CA_N345K & TNK2 & TNK2_R99Q_G296A \\
\hline PIK3CA & PIK3CA_P539R & & \\
\hline
\end{tabular}




\section{CHAPTER 4}

\section{BRAF $^{\mathrm{V} 600 \mathrm{E}}$ immunopositive melanomas show low frequency of heterogeneity and association with epithelioid tumor cells}

Ivana Verlinden*, Karin van den Hurk*, Ruud Clarijs, Arjan P. Willig, Cecile M.H.A. Stallinga, Guido M.J.M. Roemen, Joost J. van den Oord, Axel zur Hausen, Ernst-Jan M. Speel $^{\#}$, Véronique J.L. Winnepenninckx ${ }^{\#}$

*Authors contributed equally as first author "Authors contributed equally as senior author

Medicine (Baltimore) 2014; 93: e285. 


\section{Abstract}

Treatment of $\mathrm{BRAF}^{\mathrm{V} 600 \mathrm{E}}$-mutant melanoma by small molecule inhibitors that target BRAF or MEK kinases are increasingly used in clinical practice and significantly improve patient outcome. However, patients eventually become resistant and therapeutic improvement is required. Molecular diversity within individual tumors (intratumor heterogeneity) and between tumors within a single patient (intrapatient heterogeneity) poses a significant challenge to precision medicine. Using immunohistochemistry, we determined the extent of BRAF $^{\mathrm{V} 600 \mathrm{E}}$ intratumor and intrapatient heterogeneity and the influence of morphological heterogeneity in a large series of 171 melanomas of 81 patients. The BRAF ${ }^{\mathrm{V} 600 \mathrm{E}}$ mutation rate found in our melanoma series is 44\%, with none of 22 (0\%) melanoma in-situ, 23 of 56 (41\%) primary tumors, 28 of 59 (48\%) regional metastases, and 24 of 34 (71\%) distant metastases harboring the mutation. In general, a diffuse homogeneous immunostaining was seen, even in tumors consisting of more than one cell type, i.e. epithelioid, spindle, and/or small cell types. Nevertheless, BRAF ${ }^{\mathrm{V} 600 \mathrm{E}}$-mutant melanomas more often had a purely epithelioid cell population $(P=.063)$, that is more evident among distant metastases $(\mathrm{P}=.014)$. Only two of $75(3 \%)$ mutated specimens (one primary and one metastasis) displayed heterogeneous BRAF $^{\mathrm{V} 600 \mathrm{E}}$ expression. The primary tumor was also morphologically heterogeneous and exclusively displayed BRAF $^{\mathrm{V} 600 \mathrm{E}}$ in the epithelioid component, confirming an association between BRAF ${ }^{\mathrm{V} 600 \mathrm{E}}$ and epithelioid cells. Twenty-eight of 30 patients (93\%) had concordant BRAF mutation status between their tumors. Taken together, $\mathrm{BRAF}^{\mathrm{V} 600 \mathrm{E}}$ intratumor and intrapatient heterogeneity in melanoma is diminutive, nevertheless, the identified exceptions will have important implications for the clinical management of this disease. 


\section{Introduction}

Cutaneous melanoma is the most aggressive and possibly fatal cutaneous malignancy. When diagnosed early, $95 \%$ of melanoma can be cured with radical surgical resection. Advanced melanoma, however, presents one of the most challenging cancers with poor patient outcome ${ }^{1}$. In addition, treatment options for patients with metastatic melanoma have been very limited. Recent progress in both immunobased and targeted therapies has however revolutionized melanoma treatment, and has shown significant benefit in overall survival of patients with metastatic melanoma ${ }^{2}$. Especially, the identification that approximately $50 \%$ of melanomas harbor a somatic mutation in exon 15 of the BRAF oncogene had a significant effect on the treatment of melanoma ${ }^{3,4}$. BRAF encodes a serine-threonine kinase and is a component of the mitogen-activated protein kinase (MAPK) signaling pathway which is hyperactivated in up to $90 \%$ of melanoma cases ${ }^{5}$. The most common mutation corresponds to a $\mathrm{T}>\mathrm{A}$ transversion at position 1799 , resulting in the substitution of valine by glutamic acid at position 600 of the protein, i.e. BRAF ${ }^{\mathrm{V} 600 \mathrm{E} 3}$. This mutation causes a constitutive activation of the kinase domain of BRAF. The approval of selective BRAF inhibitors, i.e. vemurafenib and dabrafenib, and additionally the approval of trametinib, a selective MEK inhibitor, changed the management of metastatic and non-resectable melanoma for patients whose tumors have BRAF ${ }^{\mathrm{V} 6006,7}$. Although these therapeutics can be very effective, unfortunately all patients eventually become resistant ${ }^{6,8}$. Combination therapy of BRAF and MEK inhibitors was shown to significantly improve progressionfree survival but patients still relapse and further improvement of these therapeutics is required $^{9}$. The clinical detection of BRAF-mutant melanoma is currently performed by using a variety of DNA-based molecular techniques, such as direct sequencing, mutation-specific PCR, and mass-spectrometry genotyping ${ }^{10-12}$. In addition, the immunohistochemical (IHC) detection of the BRAF ${ }^{\mathrm{V} 600 \mathrm{E}}$ mutated protein with the use of the BRAF ${ }^{\mathrm{V} 600 \mathrm{E}}$ mutant-specific monoclonal antibody, VE1, is gaining interest ${ }^{13-19}$.

Recently, several studies have revealed that tumor heterogeneity poses a significant challenge to precision medicine ${ }^{20,21}$. Tumor heterogeneity refers to the existence of subpopulations of cells with distinct molecular variation within individual tumors (intratumor heterogeneity) or between tumors of the same histopathological subtype within a patient (intrapatient heterogeneity) $)^{21}$. Interestingly, evidence suggests that efforts to predict outcome require the identification of genetically and functionally distinct subclones within a tumor, i.e. intratumor heterogeneity, at diagnosis $^{22,23}$. This indicates that small subclones within a tumor confer primary resistance towards therapy and will expand during therapy leading to tumor progression. Using BRAF genotyping techniques the importance of BRAF heterogeneity has drawn attention ${ }^{24-27}$. Lin et al. ${ }^{24}$ showed intratumor heterogeneity of BRAF ${ }^{\mathrm{V} 600 \mathrm{E}}$ in eight of ten primary melanomas with the use of a sensitive Mutector assay, as well as by cloning and sequencing of separated alleles. In addition, Yancovitz et al. ${ }^{26}$ used laser microdissection and mutation detection via sequencing and BRAF $^{\mathrm{V} 600 \mathrm{E}}$-specific 
SNaPshot analysis to show that in six out of nine primary melanomas there are different proportions of BRAF ${ }^{\mathrm{V} 600 \mathrm{E}}$ and BRAF wild-type cells in distinct micro-dissected regions within individual tumors. Lastly, Wilmott et al. ${ }^{27}$ reported a case of intratumor $\mathrm{BRAF}^{\mathrm{V} 600 \mathrm{E}}$ heterogeneity in a melanoma metastasis as determined with real-time PCR and Mass Spectrometric SNP genotyping. In contrast, IHC analyses of BRAF ${ }^{\mathrm{V} 600 \mathrm{E}}$ protein with the use of the BRAF ${ }^{\mathrm{V} 600 \mathrm{E}}$ mutant-specific monoclonal antibody, VE1, in general revealed an intense and homogeneous staining of $B R A F^{V 600 E}$ and hardly any evidence of intratumor and/or intrapatient heterogeneity ${ }^{13,14,17-19,28,29}$. Moreover, Colombino et al. ${ }^{25}$ assessed intrapatient heterogeneity of mutated BRAF/NRAS and revealed that 84 of 99 (85\%) patients who had paired samples of primary and secondary melanomas showed consistent mutation patterns between primary tumors and metastatic lesions. In particular, BRAF/NRAS mutation frequencies were highly consistent between primary tumor and lymph node [78 of 84 patients (93\%)] or visceral metastases [24 of 25 patients (96\%)]. A significantly less consistent pattern of BRAF/NRAS mutations rates between primary tumor and brain [16 of 20 patients (80\%)] or skin metastases [27 of $36(75 \%)$ ] was found, suggesting that in some patients independent subclones are generated. This is in line with research of Yancovitz et al. ${ }^{26}$ that showed intrapatient heterogeneity of BRAF ${ }^{\mathrm{V} 600 \mathrm{E}}$ in melanoma metastases in five of $19(26 \%)$ patients.

Since it is long known that melanoma consists of distinctive subpopulations of cytologically divergent cells, i.e. morphological heterogeneity, the main purpose of the present study was to determine if intratumor morphological heterogeneity correlates with heterogeneous expression of $\mathrm{BRAF}^{\mathrm{V} 600 \mathrm{E}}$ protein. Moreover, we reasoned that it is of particular interest to identify which tumor cells in the primary lesion have the highest metastatic capabilities and associate them with the presence of mutant BRAF. In addition, BRAF ${ }^{\mathrm{V} 600 \mathrm{E}}$ expression was analyzed in patients exhibiting multiple tumors, both primary and metastatic lesions, and we determined the frequency of intrapatient heterogeneity of BRAF ${ }^{\mathrm{V} 600 \mathrm{E}}$ mutant expression.

\section{Materials and Methods}

Tumor material, histopathologic analysis, and clinical data collection

This study used tumor tissues $(n=171)$ from 81 patients 39 male and 42 female; mean age, 58.3 years (age range, 17 to 98 years)] diagnosed between 1995 and 2013 with melanoma in-situ $(n=22)$, primary melanoma $(n=56)$, regional (skin and lymph node metastases) melanoma metastasis $(n=59)$, or distant (skin and visceral metastases) melanoma metastasis ( $n=34$ ) at the Maastricht University Medical Centre, Maastricht; Atrium Hospital, Heerlen; and the Laurentius Hospital, Roermond, all located in The Netherlands. Patient material was used according to the Code for Proper Secondary Use of Human Tissue (Federation of Medical Scientific Societies, The Netherlands; 2003). Informed consent from patients was not obtained as the data were analyzed 
anonymously. In total we collected multiple tumors for 30 patients, including 23 patients with matched primary and metastatic melanomas. Sixteen patients had tissues available from multiple metastatic sites. Haematoxylin \& eosin (HE) slides of 149 tumor specimens (excluding melanoma in-situ) were reviewed by two pathologists (VW and IV) on the basis of histopathological features according to the most recent World Health Organization classification. Moreover, the percentage of melanoma cells with intracytoplasmic melanin pigment was evaluated and assessment of intratumor cell types was performed according to defined cytomorphological criteria ${ }^{30}$, i.e. (1) epithelioid cell, cells that are round, oval or polygonal with moderate to abundant cytoplasm, the round nucleus is eccentrically located with evenly distributed chromatin; (2) spindle cell, bipolar or dendritic cells with long thin cytoplasmic processes and a centrally placed elongated or ovoid nucleus; (3) small/nevoid cells, round and small monomorphic cells with hardly any cytoplasm, the round nucleus is centrally located and has evenly distributed chromatin. Clinical data and tumor characteristics are given in Table 1.

\section{Genotyping}

\section{BRAF and NRAS pyrosequencing}

Forty-five tumor specimens were used to correlate $\mathrm{BRAF}^{\mathrm{V} 600}$ mutation status as determined by pyrosequencing with immunohistochemical staining of BRAF ${ }^{\mathrm{V} 600 \mathrm{E}}$ (see below). In addition, 22 cases were analyzed for NRAS exon 2 and 3 mutations. For this purpose, three to ten 5-10 $\mu \mathrm{m}$ sections from each formalin-fixed, paraffin-embedded (FFPE) tissue block were subjected to DNA extraction using two different protocols; (1) automated genomic DNA extraction was performed using the Maxwell ${ }^{\circledR} 16$ MDx system with the Maxwell ${ }^{\circledR} 16$ FFPE Plus LEV DNA Purification kit (Promega, Leiden, The Netherlands). In brief, tissue sections were digested three to 16 hours at $70^{\circ} \mathrm{C}$ with $180 \mu \mathrm{l}$ of Incubation Buffer and $20 \mu \mathrm{l}$ of Proteinase $\mathrm{K}$ while shaking. Next, $400 \mu \mathrm{l}$ of Lysis Buffer was added and the solution was transferred into a cartridge well after which automatic DNA isolation was performed using the Maxwell 16 MDx instrument according to manufacturer's instructions. (2) For DNA isolation with the 'rawextraction' protocol, tissue sections were deparaffinised prior to DNA extraction. Next, 50 to $100 \mu \mathrm{l}$ TE buffer containing 1\% Tween 20-buffer and 6-10 $\mu$ l Proteinase K was added followed by three hours incubation at $55^{\circ} \mathrm{C}$. Thereafter, Proteinase $\mathrm{K}$ was inactivated by placing the samples five to $10 \mathrm{~min}$ at $95^{\circ} \mathrm{C}$. The tubes were centrifuged (12000rpm for $1 \mathrm{~min}$ ) and the supernatant containing the DNA was transferred to a clean tube. NanoDrop quantification was used to estimate the quality and concentration of extracted DNA (NanoDrop ${ }^{\circledR}$ ND-1000 Spectrophotometer). In addition, the grade of DNA fragmentation per sample was estimated using Specimen Control Size Ladder followed by agarose gel electrophoresis. 
Pyrosequencing analyses for BRAF exon 15 mutations (codon 600), NRAS exon 2 (codon 12 and 13) and exon 3 (codon 61) mutations were performed using the PyroMark Q24 MDx system (Qiagen, Venlo, The Netherlands). Target regions were amplified using the Pyromark PCR kit (Qiagen) followed by pyrosequencing analysis on the Pyromark Q24 MDx instrument according to the manufacturer's instructions. For specific primer sequences see Supplementary Table S1, and for assay conditions Supplementary Table S2. Sequence analysis was performed using the PyroMark Q24 2.0.6 software (Qiagen).

\section{BRAF immunohistochemical analysis}

From 171 tumor specimens, $3 \mu \mathrm{m}$ thick FFPE sections were freshly cut, mounted on microscopic slides [(K8020)Dako, Glostrup, Denmark] and air dried at $65^{\circ} \mathrm{C}$ for $30 \mathrm{~min}$. BRAF immunohistochemical analysis was done on a Dako Autostainer Link 48 system. In brief, antigen retrieval was performed with EDTA $(\mathrm{pH}$ 9) using the PT link (Dako) for $10 \mathrm{~min}$ at $97^{\circ} \mathrm{C}$, subsequently followed by 5 min blocking with EnVision FLEX Peroxidase-Blocking Reagent, 20 min primary antibody incubation with 'Mouse AntiHuman BRAFV600E Monoclonal Antibody VE1 [E19292- Spring Bioscience(1:50 dilution)], 15 min incubation with EnVision FLEX + Mouse (Linker) and $20 \mathrm{~min}$ incubation with Envision FLEX HRP labeled polymer. Visualization was performed using chromogen substrate, either DAB for 10 min or AEC (for heavily pigmented tumors) for $20 \mathrm{~min}$ and tissues were counterstained with hematoxylin. A mutant control [BRAF c.1799 T>A (p. V600E)] as determined by pyrosequencing and a wild-type control (BRAF wild type as determined by pyrosequencing) were included in each staining procedure.

\section{IHC interpretation}

All immunostained slides were evaluated by two pathologists (VW and IV) blinded to all clinical, histopathological, and mutation data. The VE1 staining was scored positive when there was clear cytoplasmic staining in the tumor cells. Faint diffuse staining, finely granular or coarsely clumped cytoplasmic staining, nuclear staining, no staining or weak staining of single cells was scored as negative.

\section{Statistical analyses}

The Pearson's chi-square $(\chi 2)$ test was used to determine an association between VE1 expression and various tumor characteristics, if cells had an expected count of less than five; the Fisher's exact test was applied. The degree of agreement between the IHC and sequencing results was assessed using the Cohen's k coefficient. All statistical analyses were two-sided, and $\mathrm{P}<.05$ was considered statistically significant. All analyses were done with the statistical package IBM SPSS Statistics 21. 
Table 1. Melanoma characteristics and clinical features

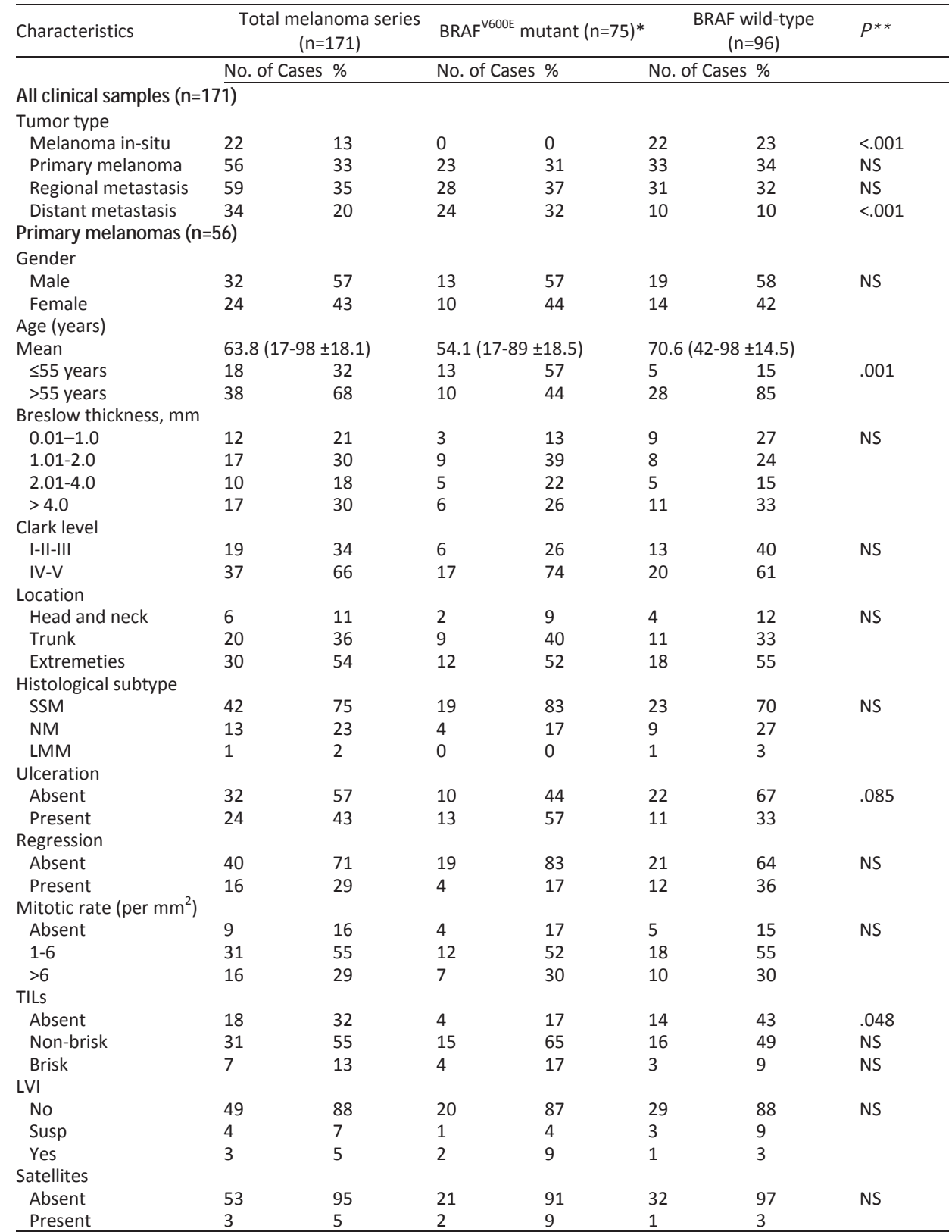

*BRAF mutation determined with immunohistochemistry.

**Pearson's Chi-Square test, when cells had expected count less than five Fisher's exact test.

Abbreviations: LMM, lentigo maligna melanoma; NM, nodular melanoma; NS, not significant; SSM, superficial spreading melanoma; TILs, tumor infiltrating lymphocytes; LVI, Iymphovascular invasion. 


\section{Results}

\section{Melanoma characterization and morphological tumor heterogeneity}

To determine the extent of morphological tumor heterogeneity in our melanoma series, HE stained slides of 149 tumor specimens, including 56 primary melanomas, 59 regional metastases, and 34 distant metastases, were reviewed. In addition, primary tumors were reviewed in detail for histopathological and clinical characteristics, including Breslow thickness, Clark level, location, histological subtype, ulceration, regression, mitotic rate (per $\mathrm{mm}^{2}$ ), presence of tumor infiltrating lymphocytes (TILs), lymphovascular invasion (LVI), presence of microsatellites, and the presence of an adjacent nevus (Table 1). In most cases, melanomas showed a purely epithelioid cell population [118 of 149 cases (79\%)] (Table 2). Our series contained only two tumors, one primary and one distant metastasis, obtained from two patients, that displayed a purely spindle cell population. Additionally, one distant metastatic sample contained purely small cells. Twenty-eight of 149 (19\%) cases displayed morphological intratumor heterogeneity meaning that more than one cell type within the same tumor was observed (Table 2). In cases with a mixed cell population epithelioid cells were always present and in 21 of 28 (75\%) cases this was the major cell component ( $\geq 50 \%$ of cells). Interestingly, primary melanomas more often $(P<.001)$ had a mixed cell population $[19$ of $56(34 \%)]$ and, hence, are morphologically more heterogeneous compared with regional [4 of $59(7 \%)$ ] and distant [5 of $34(15 \%)$ ] metastases (Table 2). Additionally, we determined the grade of pigmentation and found that 25 of 149 (17\%) cases contained melanin in more than $80 \%$ of the tumor cells. Twenty-one (84\%) of these cases had a purely epithelioid cell population, and the other four cases had $\geq 75 \%$ of epithelioid tumor cells. Particularly regional metastases were often heavily pigmented [17 of $59(29 \%)$ ] when compared with primary melanomas [6 of $56(11 \%)$ ] and distant metastases [2 of $34(6 \%)$ ] $(\mathrm{P}=.001$; Table 2$)$. Moreover, these tumors most often had a purely epithelioid cell population, i.e. 55 of 59 (93\%), when compared with primary melanoma [36 of $56(64 \%)$ ] and distant metastases [27 of $34(79 \%)$ ] ( $P=.001$; Table 2$)$.

Table 2. Tumor cell morphology and pigmentation of primary melanomas, regional metastases and distant metastases

\begin{tabular}{|c|c|c|c|c|c|c|c|c|c|c|}
\hline & \multicolumn{5}{|c|}{ Tumor cell morphology* } & \multicolumn{4}{|c|}{ Pigmentation } & \\
\hline & \multicolumn{2}{|c|}{$\begin{array}{c}\text { Purely } \\
\text { epithelioid cells } \\
\text { (n=118) } \\
\end{array}$} & \multicolumn{3}{|c|}{$\begin{array}{c}\text { Mixture of epithelioid + } \\
\text { spindle and/or small } \\
\text { cells }(n=28)\end{array}$} & \multicolumn{2}{|c|}{$\begin{array}{c}\text { 个pigment } \\
(\geq 80 \%)(n=25)\end{array}$} & \multicolumn{2}{|c|}{$\begin{array}{c}\downarrow \text { pigment } \\
(<80 \%)(n=124)\end{array}$} & \\
\hline & $\begin{array}{c}\text { No. of } \\
\text { cases }\end{array}$ & $\%$ & $\begin{array}{l}\text { No. of } \\
\text { cases }\end{array}$ & $\%$ & $\mathrm{P} * *$ & $\begin{array}{c}\text { No. of } \\
\text { cases }\end{array}$ & $\%$ & $\begin{array}{l}\text { No. of } \\
\text { cases }\end{array}$ & $\%$ & $\mathrm{P} * *$ \\
\hline Primary melanoma $(n=56)$ & 36 & 30 & 19 & 68 & $<.001$ & 6 & 24 & 50 & 40 & NS \\
\hline Regional metastasis $(n=59)$ & 55 & 47 & 4 & 14 & .001 & 17 & 68 & 42 & 34 & .001 \\
\hline Distant metastasis $(n=34)$ & 27 & 23 & 5 & 18 & NS & 2 & 8 & 32 & 26 & NS \\
\hline
\end{tabular}

*Excluding three cases; two samples with purely spindle tumor cells and one sample with purely small cells.

**Pearson's Chi-Square test, when cells had expected count less than five Fisher's exact test was used. NS, not significant 
Next, we examined morphological tumor heterogeneity between paired primary and/or metastatic tissues within the same patient. In 20 of 30 (67\%) patients with paired samples the composition of cell population [22 of 30 patients (73\%)] and percentage of melanin pigmentation [22 of 30 patients (73\%)] were similar. If not, in the majority of cases, patients with a primary tumor consisting of mixed cell types harbored metastases displaying exclusively epithelioid cells. Moreover, most metastatic tumors had a higher percentage of pigmented cells when compared with the primary tumor (Supplementary Table S3).

\section{High correlation between BRAF ${ }^{1600 E}$ mutation status and immunopositivity for the mutated protein}

To be able to correlate BRAF-mutant protein expression with tumor characteristics and morphological tumor heterogeneity we first determined the correlation between BRAF $^{\mathrm{V} 600 \mathrm{E}}$-mutant immunopositivity assessed with the specific monoclonal antibody VE1 and the presence of the mutation as determined with pyrosequencing in 45 out of 149 randomly selected tumor samples. Twenty-nine of $45(64 \%)$ tissues harbored the $\mathrm{BRAF}^{\mathrm{V} 600 \mathrm{E}}$ genotype and no other BRAF codon 600 mutations were identified (Table 3). The same tissues were subsequently immunostained for BRAF $^{\mathrm{V} 600 \mathrm{E}}$ protein and a high concordance between $\mathrm{BRAF}^{\mathrm{V} 600 \mathrm{E}}$ genotype and $\mathrm{VE} 1$ expression was observed $(\mathrm{K}=.952$; $\mathrm{P}<.001$; staining sensitivity $98 \%$ and specificity $100 \%$ ). Twenty-eight of 45 (62\%) tissues were stained positive for the mutation (Figure 1A; Table 3). All 16 BRAF wild-type specimens lacked BRAF ${ }^{\mathrm{V} 600 \mathrm{E}}$ expression as determined with IHC demonstrating $100 \%$ specificity of the staining (Figure 1B; Table 3). Importantly, in cases sequenced as wildtype we never observed even single VE1-positive cells. The single discordant tissue was positive for the gene mutation, however, no BRAF ${ }^{\mathrm{V} 600 \mathrm{E}}$ expression was detected (Figure 1C). Also after re-testing, the pyrosequencing result remained positive and IHC negative. Notably, this specimen showed abundant tumor regression.

Table 3. Correlation between $\mathrm{BRAF}^{\mathrm{V} 600}$ gene mutation status and immunopositivity (VE1 IHC) for the mutated protein

\begin{tabular}{|c|c|c|c|c|c|c|c|c|}
\hline & \multicolumn{2}{|c|}{ BRAF mutant } & \multicolumn{2}{|c|}{ VE1 IHC mutant } & \multicolumn{2}{|c|}{ BRAF wild-type } & \multicolumn{2}{|c|}{ VE1 IHC wild-type } \\
\hline & $\begin{array}{l}\text { No. of } \\
\text { cases }\end{array}$ & $\%$ & $\begin{array}{l}\text { No. of } \\
\text { cases }\end{array}$ & $\%$ & $\begin{array}{l}\text { No. of } \\
\text { cases }\end{array}$ & $\%$ & $\begin{array}{c}\text { No. of } \\
\text { cases }\end{array}$ & $\%$ \\
\hline Primary melanoma $(n=18)$ & 11 & 61 & 10 & 56 & 7 & 39 & 8 & 45 \\
\hline Regional metastasis $(n=12)$ & 6 & 50 & 6 & 50 & 6 & 50 & 6 & 50 \\
\hline Distant metastasis $(n=15)$ & 12 & 80 & 12 & 80 & 3 & 20 & 3 & 20 \\
\hline Total $(n=45)$ & 29 & 64 & 28 & 62 & 16 & 36 & 17 & 38 \\
\hline
\end{tabular}




\section{Distribution of $\mathrm{BRAF}^{\mathrm{V} 600 \mathrm{E}}$ and correlation with melanoma characteristics and clinical features}

Next, we immunostained the additional 104 tumor specimens with VE1, and also included 22 in-situ melanomas, hence, together with previously stained 45 specimens we obtained data on BRAF-mutant expression of 171 tissues (Table 1). Primary melanomas displayed BRAF-mutant protein expression in 23 of 56 (41\%) specimens and, for comparison, in 23 of 45 (51\%) patients; 28 of 59 (48\%) regional metastases or 13 of $25(52 \%)$ patients had BRAF $^{\mathrm{V} 600 \mathrm{E}}$ expression, and the highest proportion of $\mathrm{BRAF}^{\mathrm{V} 600 \mathrm{E}}(\mathrm{P}<.001)$ was detected among distant metastases, i.e. 24 of $34(71 \%)$ tumors or 12 of $18(67 \%)$ patients. Intriguingly, none of 22 in-situ melanomas had BRAF ${ }^{\mathrm{V} 600 \mathrm{E}}$ expression $(\mathrm{P}<.001)$. Moreover, $\mathrm{BRAF}^{\mathrm{V} 600 \mathrm{E}}$-mutant primary melanoma inversely correlated with age $(P=.001)$ and correlated with the presence of TILs ( $P=.048$; Table 1$)$. Our series contained two primary melanomas with an adjacent nevus and both melanoma and nevus cells lacked immunoreactivity for the V600-antibody.

\section{Correlation of $\mathrm{BRAF}^{\mathrm{V} 600 \mathrm{E}}$ expression with morphological tumor heterogeneity}

We subsequently compared VE1 protein expression with tumor cell morphology and pigmentation (Table 4). Interestingly, BRAF ${ }^{\mathrm{V} 600 \mathrm{E}}$-mutant melanoma most often harbored a purely epithelioid cell population [64 of $75(85 \%)$ ] $(P=.063)$; this was more evident in the distant metastases subgroup $(P=.014)$. Also, a trend towards an association between a mixed cell population and the BRAF wild-type phenotype was observed [18 of $28(64 \%)$ ] $(P=.086)$, which reached statistical significance among distant metastases $(P=.019)$. No association between pigmentation and the BRAF mutant phenotype was found (Table 4). Notably, off all 28 tumors with a mixed cell population, the epithelioid component represents at least half of the cell population in $21(75 \%)$ cases and nine of these 21 (43\%) cases are BRAF mutant. The remaining seven cases had an epithelioid component that was less than half of the cell population and only one of seven (14\%) cases displayed mutant BRAF expression. This data together postulate that BRAF ${ }^{\mathrm{V} 600 \mathrm{E}}$ mutation is associated with epithelioid tumor cells.

\section{Intratumor and intrapatient heterogeneity of $\mathrm{BRAF}^{\mathrm{V} 600 \mathrm{E}}$ protein expression}

In general, VE1 immunostaining was homogeneously positive $(n=73)$ (Figure $1 \mathrm{~A}$ and 1D) or negative $(n=96)$ (Figure $1 B$ ) except for two tumor samples, i.e. one primary tumor and a paired metastasis, showing heterogeneous expression of BRAF ${ }^{\mathrm{V} 600 \mathrm{E}}$. Interestingly, the primary melanoma that displayed intratumor heterogeneity for $\mathrm{BRAF}^{\mathrm{V} 600 \mathrm{E}}$ was in addition morphologically heterogeneous and the mutation was exclusively displayed in the epithelioid component while the small cell component was negative (Figure 1E). This further strengthens our previous observation that BRAF ${ }^{\mathrm{V} 600 \mathrm{E}}$ 
mutation is associated with the epithelioid cell component. The paired metastasis also displayed heterogeneous VE1 expression in a purely epithelioid background.

Table 4. Histological appearances of primary, regional, and distant metastatic melanoma tissues according to BRAF mutation status

\begin{tabular}{|c|c|c|c|c|c|}
\hline & \multicolumn{2}{|c|}{$\mathrm{BRAF}^{\mathrm{V} 600 \mathrm{E}}$ mutant $(\mathrm{n}=75)^{*}$} & \multicolumn{2}{|c|}{ BRAF wild-type $(n=74)$} & \multirow[b]{2}{*}{$\mathrm{P} * *$} \\
\hline & No. of cases & $\%$ & No. of cases & $\%$ & \\
\hline \multicolumn{6}{|c|}{ All melanoma tissues ( $n=149$ ) } \\
\hline \multicolumn{6}{|l|}{ Morphology } \\
\hline Epithelioid cell purely & 64 & 85 & 54 & 73 & .063 \\
\hline Spindle cell purely & - & - & 2 & 3 & - \\
\hline Small cell purely & 1 & 1 & - & - & - \\
\hline Mixed population & 10 & 13 & 18 & 24 & .086 \\
\hline \multicolumn{6}{|l|}{ Pigmentation } \\
\hline$\uparrow$ pigment ( $\geq 80 \%)$ & 14 & 19 & 11 & 15 & NS \\
\hline$\downarrow$ pigment $(<80 \%)$ & 61 & 81 & 63 & 85 & \\
\hline \multicolumn{6}{|l|}{ Primary melanoma $(n=56)$} \\
\hline \multicolumn{6}{|l|}{ Morphology } \\
\hline Epithelioid cell purely & 15 & 65 & 21 & 64 & NS \\
\hline Spindle cell purely & - & - & 1 & 3 & - \\
\hline Mixed population & 8 & 35 & 11 & 33 & NS \\
\hline \multicolumn{6}{|l|}{ Pigmentation } \\
\hline 个pigment ( $\geq 80 \%)$ & 2 & 9 & 4 & 12 & NS \\
\hline$\downarrow$ pigment $(<80 \%)$ & 21 & 91 & 29 & 88 & \\
\hline \multicolumn{6}{|c|}{ Regional metastases $(n=59)$} \\
\hline \multicolumn{6}{|l|}{ Morphology } \\
\hline Epithelioid cell purely & 27 & 96 & 28 & 90 & NS \\
\hline Mixed population & 1 & 4 & 3 & 10 & \\
\hline \multicolumn{6}{|l|}{ Pigmentation } \\
\hline$\uparrow$ pigment ( $\geq 80 \%)$ & 11 & 39 & 6 & 19 & .091 \\
\hline$\downarrow$ pigment $(<80 \%)$ & 17 & 61 & 25 & 81 & \\
\hline \multicolumn{6}{|l|}{ Distant metastases $(n=34)$} \\
\hline \multicolumn{6}{|l|}{ Morphology } \\
\hline Epithelioid cell purely & 22 & 92 & 5 & 50 & .014 \\
\hline Spindle cell purely & - & - & 1 & 10 & - \\
\hline Small cell purely & 1 & 4 & - & - & - \\
\hline Mixed population & 1 & 4 & 4 & 40 & .019 \\
\hline \multicolumn{6}{|l|}{ Pigmentation } \\
\hline 个pigment ( $\geq 80 \%)$ & 1 & 4 & 1 & 10 & NS \\
\hline$\downarrow$ pigment $(<80 \%)$ & 23 & 96 & 9 & 90 & \\
\hline
\end{tabular}

As we had paired tumor samples for 30 patients we were able to examine intrapatient heterogeneity of mutant BRAF as determined with both pyrosequencing and IHC, and in some cases NRAS mutation as determined with pyrosequencing. All but two patients [28 of $30(93 \%)]$ had concordant BRAF mutation status between their tumors. One patient had a primary tumor that was NRAS wild-type and BRAF mutant and stained homogeneously positive with VE1. Nevertheless, the paired lymph node metastasis stained negative for BRAF ${ }^{\mathrm{V} 600 \mathrm{E}}$ and confirmed to be BRAF wild-type. Unexpectedly, this tumor harbored a NRAS mutation. Moreover, the primary tumor of this patient contained a $20 \%$ pigmented, purely epithelioid cell population whereas the lymph 

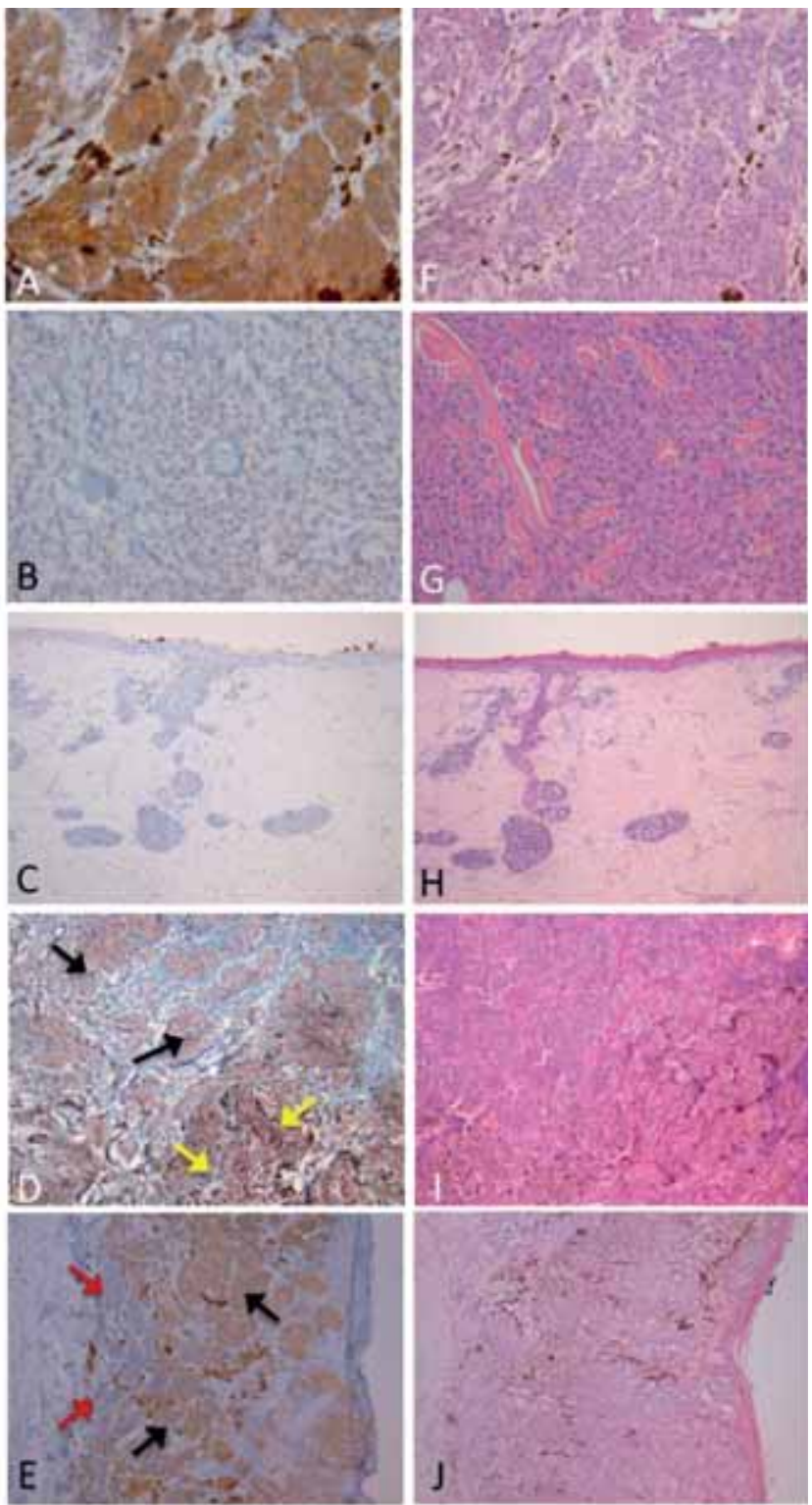

Figure 1. A and F. melanoma, mutated for $\mathrm{BRAF}^{\mathrm{V} 600 \mathrm{E}}$ in purely epithelioid background. A. Diffuse homogeneous immunostaining with VE1. F. Corresponding HE staining. B and G. melanoma, wild-type for BRAFV600E in purely epithelioid background. B. Negative immunostaining with VE1. G. Corresponding HE staining. $\mathrm{C}$ and $\mathrm{H}$. melanoma, discordant case with tumor regression. $\mathrm{C}$. negative immunostaining with VE1. H. Corresponding HE staining. D and I. melanoma, mutant BRAFV600E. D. Diffuse homogeneous immunostaining with VE1 positive epithelioid (black arrows) and spindle (yellow arrows) cells. I. Corresponding HE staining. E and J. melanoma with heterogenic BRAFV600E expression. E. Heterogeneous immunostaining with VE1 positive epithelioid (black arrows) cells and VE1 negative small (red arrows) cells. J. Corresponding HE staining 
node metastasis of the same patient had a mixed population of epithelioid (95\%) and small/nevoid cells (5\%) that were $100 \%$ pigmented. The other patient had a discordant BRAF mutation status between two regional metastases, i.e. a lymph node metastasis that did not display BRAF ${ }^{\mathrm{V} 600 \mathrm{E}}$ and a skin metastasis with the mutation. This patient shared the same histological features, i.e. a pure population of epithelioid tumor cells that were not pigmented, in both metastases.

\section{Discussion}

Cutaneous melanoma represents one of the most aggressive cancers and a major challenge for the medical oncologist. The arrival of the targeted therapy revolution has led to significant improvement in melanoma treatment. However, therapeutic resistance and adverse effects to therapies underscore the importance to clarify the pathobiology of melanoma, which ultimately leads to an enhanced molecular-based medical approach. The goal of this study was to determine the extent of BRAF ${ }^{\mathrm{V} 600 \mathrm{E}}$ intratumor and intrapatient heterogeneity and the influence of morphological heterogeneity in a large series of 171 melanomas belonging to 81 patients.

Cutaneous melanoma is a morphologically heterogeneous malignancy with different histological appearances within one single tumor ${ }^{30}$. By analyzing tumor cell type and the presence of intracytoplasmic pigment (as signs of melanocytic differentiation) within single tumors we observed that primary melanoma specimens more often $[34 \%(P=.001)]$ had a mixed cell population compared with metastatic tissues (10\%). Morphological plasticity is necessary for tumor cells to assume a shape that is suitable for migration and invasion ${ }^{31}$. Hence, the observation that primary melanomas are morphologically more heterogeneous is in line with the idea that these tumor cells endeavor survival and formation of (distant) metastases. Regional metastases generally had a purely epithelioid cell population $[93 \%(P=.001)]$ and these tumors are, compared with primary melanomas (11\%) and distant metastases (6\%), more often heavily pigmented $[29 \%(P=.001)]$. Concerning intrapatient morphological heterogeneity, two thirds of paired cases were comparable in terms of pigmentation and cell population. In the remaining third, the epithelioid and heavily pigmented cells were more often present in the metastases suggesting that these cells might have the highest metastatic potential. This assumption is in line with the observation that epithelioid cell melanomas have greater DNA ploidy abnormalities than spindle cell melanomas ${ }^{32}$. Moreover, epithelioid cell melanomas were found to be a prognostic factor of poor response to immunological treatment ${ }^{33}$. Interestingly, the purely epithelioid cell component had the highest prevalence in both primary (64\%) and metastatic ( $88 \%$ ) melanomas and only $2 \%$ of cases did not contain any epithelioid cells. The observation that the majority of cells in the primary tumor are likely to have a high metastatic potential, i.e. epithelioid cells, might partly explain why this tumor is very aggressive and able to metastasize quickly. 
We reasoned that the presence of distinctive cell populations might underlie a different genetic background or BRAF mutation status as well. This is potentially important in understanding the commonly observed therapeutic resistance to BRAF inhibitors of these tumors. Contradictory statements about the heterogeneity of BRAF mutation status in primary and metastatic melanomas exist ${ }^{13,14,17-19,24-28}$. Most studies using $\mathrm{IHC}$ detection of $\mathrm{BRAF}^{\mathrm{V} 600 \mathrm{E}}$ hardly found any evidence of intratumor heterogeneity and in general most $\mathrm{BRAF}^{\mathrm{V} 600 \mathrm{E}}$ melanomas stained intensely and homogeneously ${ }^{14,18,19,28,29}$. Wilmott et al. ${ }^{13}$ reported a heterogeneous immunoreaction in 13 of $58(22 \%)$ cases. Studies of heterogeneity that analyzed the BRAF genotype in a small number of cases suggest that the majority of melanomas contain both wild-type and mutant BRAF cells ${ }^{24,26,27}$. In the present study we virtually did not observe heterogeneous expression of $\mathrm{BRAF}^{\mathrm{V} 600 \mathrm{E}}$ at the single-cell level. In BRAF wild-type melanomas we never identified a minor positive subpopulation and BRAF-mutant protein expression was homogeneous in most cases (97\%), also when tumors harbored a mixed cell population. This demonstrates that the mutation is most likely a clonal event in cutaneous melanoma and would imply that the alteration into different tumor cell morphologies occurs at a later stage in time, that is, after the BRAF mutation is acquired, e.g. by epigenetic mechanisms. It has for instance been reported that the epithelioid melanoma cell type (versus all other cell types) is the most powerful independent predictor of both RASSF1A and p16 promoter hypermethylation ${ }^{34}$. Interestingly, it was observed that $\mathrm{BRAF}^{\mathrm{V} 600 \mathrm{E}}$-mutant melanoma more often harbored a purely epithelioid cell population that was particularly evident in the distant metastases subgroup. Conversely, an association between a mixed cell population and BRAF wild-type phenotype was observed, which reached statistical significance among distant melanomas. No association between pigmentation and the BRAF mutant phenotype was detected. The fact that the BRAF mutation was found to be associated with epithelioid cells, i.e. cells that potentially have the greatest metastatic capability, might be important to better understand the biologically mechanism that underlie mutant BRAF and melanoma. It has previously been shown that the presence of larger, rounder, i.e. epihelioid cells, and in addition more pigmented tumor cells were distinguishing features of melanomas with BRAF mutation ${ }^{35}$. Our series only contained two melanoma samples, belonging to the same patient, which had heterogeneous expression of BRAF ${ }^{\mathrm{V} 600 \mathrm{E}}$. The primary melanoma exclusively displayed the mutation in the epithelioid component while the small cell component was negative, again confirming the association between $\mathrm{BRAF}^{\mathrm{V} 600 \mathrm{E}}$ and epithelioid tumor cells. A paired metastasis had variable VE1 expression within a purely epithelioid cell population, i.e. with obvious positive and negative cells. In contrast, another distant metastasis from the same patient displayed exclusively BRAF ${ }^{\mathrm{V} 600 \mathrm{E}}$ mutant epithelioid cells. Intriguingly, this patient initially responded well to vemurafenib treatment but relapsed within a few weeks. Autopsy material of this patient showed distinctive BRAF mutant subclones with evidently stronger $\mathrm{BRAF}^{\mathrm{V} 600 \mathrm{E}}$ expression compared to the rest of the tumor tissue. 
As multiple tumors within a patient have been shown to respond heterogeneously to BRAF inhibitor treatment ${ }^{36}$, we also determined the level of intrapatient heterogeneity of $\mathrm{BRAF}^{\mathrm{V} 600 \mathrm{E}}$ in our series. Previous research has shown that $4-25 \%$ of melanoma patients have heterogeneous $\mathrm{BRAF}^{\mathrm{V} 600 \mathrm{E}}$ genotype between their tumors depending on the type of metastasis ${ }^{25,26}$. Our study contained two (7\%) patients with discordant BRAF mutation status between paired tumors. That is, one patient had a primary tumor that displayed BRAF ${ }^{\mathrm{V} 600 \mathrm{E}}$ expression whereas the paired metastasis contained solely BRAF wild-type tumor cells, but harbored a NRAS mutation. The most likely explanation is that this patient had a second primary tumor that did metastasize to the lymph node. The other patient had a discordant BRAF mutation status between two regional metastases, i.e. a BRAF wild-type lymph node metastasis and a BRAF mutant skin metastasis. These patients illustrate clinical treatment difficulties as the presence of molecular variation between tumors within single patients would entail different treatments to eradicate all individual tumors.

The $\mathrm{BRAF}^{\mathrm{V} 600 \mathrm{E}}$ mutation rate found in our melanoma series is $44 \%$ and increases with melanoma progression, i.e. none of melanoma in-situ, $41 \%$ of primary melanomas, $48 \%$ of regional metastases and $71 \%$ of distant metastases displayed the mutation. Several groups have reported a strong inverse correlation between age and BRAF mutation prevalence 37,38 , within our primary melanoma subgroup we also observed a significantly higher BRAF mutation rate among young patients ( $\leq 55$ years). In addition, a significant association between the presence of BRAF ${ }^{\mathrm{V} 600 \mathrm{E}}$ and TILs was observed which is in agreement with current literature and further supports the observation that $\mathrm{BRAF}^{\mathrm{V} 600 \mathrm{E}}$ initiates an immune reaction to the primary melanoma in vivo $^{39,40}$.

The observation that all in-situ melanomas were BRAF wild-type is intriguing. It is known that mutant BRAF protein induces cellular senescence (oncogene-induced senescence) by increasing the expression of $\mathrm{p} 16^{\mathrm{INK} 4 \mathrm{a}}$ in healthy melanocytes ${ }^{41}$. Therefore, most BRAF-mutant nevi never transform to malignant melanoma. We reasoned that the lack of BRAF mutation in early melanoma in-situ prevents these tumor cells to go into senescence, thus maintaining malignant potential. During tumor progression, after cells underwent other/additional molecular changes, the BRAF mutation is acquired or the amount of mutated protein increases in numerous cells leading to increased tumor growth and metastasis formation. This is in line with research performed by Dong et al. ${ }^{42}$ that showed a high frequency (62-72\%) of BRAF mutations in melanocytic nevi, vertical growth phase (VGP) melanomas, and metastatic melanomas, whereas BRAF mutations were only detected in $10 \%$ of the earliest stage or radial growth phase (RGP) melanomas.

The $\mathrm{BRAF}^{\mathrm{V} 600 \mathrm{E}}$ mutation detected by pyrosequencing was almost perfectly predicted by immunostaining with the mutation-specific anti-BRAF ${ }^{\mathrm{V} 600 \mathrm{E}}$ antibody (VE1), thereby confirming previous studies ${ }^{14-16,18}$. Only one tumor tissue carried the BRAF ${ }^{\mathrm{V} 600 \mathrm{E}}$ genotype but did not display mutated protein expression (sensitivity of $98 \%$; sensitivity of $100 \%)$. The discordant tumor tissue showed abundant tumor regression which 
might have interfered with the result. It has been reported that the antigenicity of the VE1 epitope is affected by tissue coagulation or early necrosis ${ }^{14,18}$. Taken together, the immunohistochemical detection of $\mathrm{BRAF}^{\mathrm{V} 600 \mathrm{E}}$ expression seems to be a rapid and accurate method for detection of the $\mathrm{BRAF}^{\mathrm{V} 600 \mathrm{E}}$ mutation and might be generally applied in routine clinical diagnostics.

In summary, our data show that primary melanomas are morphologically more heterogeneous than melanoma metastases and that the epithelioid (pigmented) tumor cell potentially has the greatest metastatic capacity. This study demonstrates that the BRAF mutation is associated with the epithelioid cell type. In general, BRAF mutated protein is present in all tumor cells indicating that this genetic aberration is a common clonal event in melanoma. Intratumor and intrapatient heterogeneity of $\mathrm{BRAF}^{\mathrm{V} 600 \mathrm{E}}$ is very rare; however, few exceptions give emphasis to treatment difficulties as differences in the genetic landscape require different treatment.

\section{Acknowledgments}

We would like to thank Jolanda Peeters, Sarah Hulsmans, Tina Pirens, and Sabine Stevens for technical assistance. This work was supported by Profileringsfonds Maastricht University Medical Centre (PF-278). 


\section{References}

1. van den Hurk K, Niessen $\mathrm{HE}$, Veeck J, et al. Genetics and epigenetics of cutaneous malignant melanoma: A concert out of tune. Biochimica et biophysica acta. Aug 2012;1826(1):89-102.

2. Flaherty KT, Hodi FS, Fisher DE. From genes to drugs: targeted strategies for melanoma. Nature reviews. Cancer. May 2012;12(5):349-361.

3. Davies $\mathrm{H}$, Bignell GR, Cox $\mathrm{C}$, et al. Mutations of the BRAF gene in human cancer. Nature. Jun 27 2002;417(6892):949-954.

4. Curtin JA, Fridlyand J, Kageshita T, et al. Distinct sets of genetic alterations in melanoma. N Engl J M ed. Nov 17 2005;353(20):2135-2147.

5. Cohen C, Zavala-Pompa A, Sequeira JH, et al. Mitogen-actived protein kinase activation is an early event in melanoma progression. Clin Cancer Res. Dec 2002;8(12):3728-3733.

6. Flaherty KT, Yasothan U, Kirkpatrick P. Vemurafenib. Nature reviews. Drug discovery. Nov 2011;10(11):811812.

7. Hauschild A, Grob JJ, Demidov LV, et al. Dabrafenib in BRAF-mutated metastatic melanoma: a multicentre, open-label, phase 3 randomised controlled trial. Lancet. Jul 28 2012;380(9839):358-365.

8. Bucheit $A D$, Davies MA. Emerging insights into resistance to BRAF inhibitors in melanoma. Biochem Pharmacol. Nov 282013.

9. Flaherty KT, Infante JR, Daud A, et al. Combined BRAF and MEK inhibition in melanoma with BRAF V600 mutations. N Engl J Med. Nov 2012;367(18):1694-1703.

10. Spittle C, Ward MR, Nathanson KL, et al. Application of a BRAF pyrosequencing assay for mutation detection and copy number analysis in malignant melanoma. The Journal of molecular diagnostics : JMD. Sep 2007;9(4):464-471.

11. Pichler $\mathrm{M}$, Balic $\mathrm{M}$, Stadelmeyer $\mathrm{E}$, et al. Evaluation of high-resolution melting analysis as a diagnostic tool to detect the BRAF V600E mutation in colorectal tumors. The Journal of molecular diagnostics : JMD. Mar 2009;11(2):140-147.

12. Jarry A, Masson D, Cassagnau E, Parois S, Laboisse C, Denis MG. Real-time allele-specific amplification for sensitive detection of the BRAF mutation V600E. M ol Cell Probes. Oct 2004;18(5):349-352.

13. Wilmott JS, Menzies AM, Haydu LE, et al. BRAF(V600E) protein expression and outcome from BRAF inhibitor treatment in BRAF(V600E) metastatic melanoma. Br J Cancer. Mar 5 2013;108(4):924-931.

14. Long GV, Wilmott JS, Capper $D$, et al. Immunohistochemistry is highly sensitive and specific for the detection of V600E BRAF mutation in melanoma. Am J Surg Pathol. Jan 2013;37(1):61-65.

15. Ghossein RA, Katabi N, Fagin JA. Immunohistochemical Detection of Mutated BRAF V600E Supports the Clonal Origin of BRAF-Induced Thyroid Cancers Along the Spectrum of Disease Progression. J Clin Endocrinol Metab. Aug 2013;98(8):E1414-1421.

16. Ilie $M$, Long $E$, Hofman $V$, et al. Diagnostic value of immunohistochemistry for the detection of the BRAFV600E mutation in primary lung adenocarcinoma Caucasian patients. Ann Oncol. Mar 2013;24(3):742748.

17. Capper D, Berghoff AS, Magerle M, et al. Immunohistochemical testing of BRAF V600E status in 1,120 tumor tissue samples of patients with brain metastases. Acta Neuropathol. Feb 2012;123(2):223-233.

18. Capper D, Preusser M, Habel A, et al. Assessment of BRAF V600E mutation status by immunohistochemistry with a mutation-specific monoclonal antibody. Acta Neuropathol. Jul 2011;122(1):11-19.

19. Marin C, Beauchet A, Capper D, et al. Detection of BRAF p.V600E Mutations in Melanoma by Immunohistochemistry Has a Good Interobserver Reproducibility. Arch Pathol Lab M ed. May 72013.

20. Fisher R, Larkin J, Swanton C. Inter and intratumour heterogeneity: a barrier to individualized medical therapy in renal cell carcinoma? Front Oncol. 2013;2:49.

21. Bedard PL, Hansen AR, Ratain MJ, Siu LL. Tumour heterogeneity in the clinic. Nature. Sep 19 2013;501(7467):355-364.

22. Landau DA, Carter SL, Stojanov $P$, et al. Evolution and impact of subclonal mutations in chronic lymphocytic leukemia. Cell. Feb 14 2013;152(4):714-726.

23. Keats JJ, Chesi M, Egan JB, et al. Clonal competition with alternating dominance in multiple myeloma. Blood. Aug 2 2012;120(5):1067-1076.

24. Lin J, Goto $\mathrm{Y}$, Murata $\mathrm{H}$, et al. Polyclonality of BRAF mutations in primary melanoma and the selection of mutant alleles during progression. Br J Cancer. Feb 1 2011;104(3):464-468.

25. Colombino $M$, Capone $M$, Lissia $A$, et al. BRAF/NRAS mutation frequencies among primary tumors and metastases in patients with melanoma. Journal of clinical oncology : official journal of the American Society of Clinical Oncology. Jul 10 2012;30(20):2522-2529.

26. Yancovitz M, Litterman A, Yoon J, et al. Intra- and inter-tumor heterogeneity of BRAF(V600E))mutations in primary and metastatic melanoma. PLoS One. 2012;7(1):e29336. 
27. Wilmott JS, Tembe V, Howle JR, et al. Intratumoral molecular heterogeneity in a BRAF-mutant, BRAF inhibitor-resistant melanoma: a case illustrating the challenges for personalized medicine. Mol Cancer Ther. Dec 2012;11(12):2704-2708.

28. Boursault L, Haddad V, Vergier B, et al. Tumor homogeneity between primary and metastatic sites for BRAF status in metastatic melanoma determined by immunohistochemical and molecular testing. PLoS One. 2013;8(8):e70826.

29. Menzies AM, Lum T, Wilmott JS, et al. Intrapatient homogeneity of BRAFV600E expression in melanoma. Am J Surg Pathol. Mar 2014;38(3):377-382.

30. Mooi WJ, Krausz T. Pathology of Melanocytic Disorders. Vol 2: Hodder Arnold Publishers; 2007.

31. Yin Z, Sadok A, Sailem H, et al. A screen for morphological complexity identifies regulators of switch-like transitions between discrete cell shapes. Nat Cell Biol. Jul 2013;15(7):860-871.

32. Chi HI, Uyeda Y, Umebayashi Y, Otsuka F. Epithelioid cell melanomas have greater DNA ploidy abnormalities than spindle cell melanomas: cytological evidence for a higher malignant potential of the former. Arch Dermatol Res. 1993;285(7):410-414.

33. Ascierto PA, Mozzillo N, Caraco C, et al. Epithelioid cell-type melanoma as a prognostic factor of poor response to immunological treatment. Ann Oncol. Nov 2000;11(11):1504.

34. Rastetter $M$, Schagdarsurengin $U$, Lahtz $C$, et al. Frequent intra-tumoural heterogeneity of promoter hypermethylation in malignant melanoma. Histol Histopathol. Sep 2007;22(9):1005-1015.

35. Viros A, Fridlyand J, Bauer J, et al. Improving melanoma classification by integrating genetic and morphologic features. PLOS M ed. Jun 3 2008;5(6):e120.

36. Carlino MS, Saunders CA, Haydu LE, et al. (18)F-labelled fluorodeoxyglucose-positron emission tomography (FDG-PET) heterogeneity of response is prognostic in dabrafenib treated BRAF mutant metastatic melanoma. Eur J Cancer. Jan 2013;49(2):395-402.

37. Greaves WO, Verma S, Patel KP, et al. Frequency and Spectrum of BRAF Mutations in a Retrospective, SingleInstitution Study of 1112 Cases of Melanoma. The Journal of molecular diagnostics : JMD. Mar 2013;15(2):220-226.

38. Long GV, Menzies AM, Nagrial AM, et al. Prognostic and clinicopathologic associations of oncogenic BRAF in metastatic melanoma. J Clin Oncol. Apr 1 2011;29(10):1239-1246.

39. Edlundh-Rose E, Egyhazi S, Omholt $\mathrm{K}$, et al. NRAS and BRAF mutations in melanoma tumours in relation to clinical characteristics: a study based on mutation screening by pyrosequencing. Melanoma Res. Dec 2006;16(6):471-478.

40. Andersen $\mathrm{MH}$, Fensterle J, Ugurel $\mathrm{S}$, et al. Immunogenicity of constitutively active V599EBRaf. Cancer Res. Aug 1 2004;64(15):5456-5460.

41. Michaloglou C, Vredeveld LC, Soengas MS, et al. BRAFE600-associated senescence-like cell cycle arrest of human naevi. Nature. Aug 4 2005;436(7051):720-724.

42. Dong J, Phelps RG, Qiao R, et al. BRAF oncogenic mutations correlate with progression rather than initiation of human melanoma. Cancer Res. Jul 15 2003;63(14):3883-3885. 


\section{Supplementary information}

Supplementary Table S1. Primer sequences BRAF and NRAS pyrosequencing analyses

\begin{tabular}{lll}
\hline Gene & Name & Sequence 5'>> 3' $^{\prime}$ \\
\hline BRAF codon 600 & PCR Forward & TGCTCTGATAGGAAAATGAGAT \\
BRAF codon 600 & PCR Reverse & [Btn]GATCCAGACAACTGTTCAAACT \\
BRAF codon 600 & Pyrosequencing & GGTGATTTTGGTCTAGCT \\
NRAS codon 12 and 13 & PCR Forward & AGGTTCTTGCTGGTGTGA \\
NRAS codon 12 and 13 & PCR Reverse & [Btn]GTTCTGGATTAGCTGGATTGT \\
NRAS codon 12 and 13 & Pyrosequencing & TGGTGGTGGTTGGAG \\
NRAS codon 61 & PCR Forward & [Btn]TGTTTGTTGGACATACTGG \\
NRAS codon 61 & PCR Reverse & CTCTCATGGCACTGTACTCT \\
NRAS codon 61 & Pyrosequencing & CATGGCACTGTACTCTTC \\
\hline
\end{tabular}

Supplementary Table S2. Pyrosequencing assay conditions

\begin{tabular}{ll}
\hline BRAF exon 15 (codon 600) & AQ assay \\
Sequence to analyse & ACAGHGAAATCTCGA \\
Dispensation order & GACGAGATCAGAGATCT \\
Peak height Treshhold: Required peak heigth for passed quality & 30 \\
NRAS exon 2 (codon 12 and 13) & AQ assay \\
Sequence to analyse & CAGNTGNTGTTGGGAAAGC \\
Dispensation order & GCTACTGACTACGACTGTG \\
Peak height Treshhold: Required peak heigth for passed quality & 30 \\
NRAS exon 3 (codon 61) & AQ assay \\
Sequence to analyse & TNGTCCAGCTGTATCCAGTATG \\
Dispensation order & ACGTACGACTCAGC \\
Peak height Treshhold: Required peak heigth for passed quality & 30 \\
\hline
\end{tabular}


Supplementary Table S3. Intrapatient heterogeneity of cell morphology and pigmentation in a subset of patients

\begin{tabular}{|c|c|c|c|c|}
\hline & Epithelioid cells (\%) & Spindle cells (\%) & Small cells (\%) & Pigmentation (\%) \\
\hline \multicolumn{5}{|l|}{ Patient 1} \\
\hline Primary tumor $(n=1)$ & 30 & 70 & & 5 \\
\hline Regional metastases $(n=5)$ & All 100 & & & $90,80,95,30,85$ \\
\hline Distant metastases $(n=2)$ & All 100 & & & 30,30 \\
\hline \multicolumn{5}{|l|}{ Patient 2} \\
\hline Primary tumor $(n=1)$ & 85 & & 15 & 75 \\
\hline Regional metastasis $(n=1)$ & 100 & & & 100 \\
\hline Distant metastases $(n=9)$ & All 100 & & & $\begin{array}{l}0,0,0,70,100,0, \\
20,10,55\end{array}$ \\
\hline \multicolumn{5}{|l|}{ Patient 3} \\
\hline Primary tumor $(n=1)$ & 70 & 30 & & 10 \\
\hline Regional metastasis $(n=1)$ & 100 & & & 5 \\
\hline \multicolumn{5}{|l|}{ Patient 4} \\
\hline Primary tumor $(n=1)$ & 95 & 5 & & 5 \\
\hline Regional metastasis $(n=1)$ & 95 & 5 & & 80 \\
\hline \multicolumn{5}{|l|}{ Patient 5} \\
\hline Primary tumor $(n=1)$ & 60 & & 40 & 5 \\
\hline Regional metastasis $(n=1)$ & 85 & 15 & & 5 \\
\hline \multicolumn{5}{|l|}{ Patient 6} \\
\hline Primary tumor $(n=1)$ & 100 & & & 20 \\
\hline Regional metastases $(n=8)$ & All 100 & & & $\begin{array}{l}5,1,95,90,40,90, \\
95,99\end{array}$ \\
\hline \multicolumn{5}{|l|}{ Patient 7} \\
\hline Primary tumor $(n=1)$ & 100 & & & 20 \\
\hline Distant metastases $(n=1)$ & 95 & 5 & & 100 \\
\hline \multicolumn{5}{|l|}{ Patient 8} \\
\hline Regional metastasis $(n=1)$ & 100 & & & 0 \\
\hline Distant metastasis $(\mathrm{n}=1)$ & 0 & & 100 & 0 \\
\hline \multicolumn{5}{|l|}{ Patient 9} \\
\hline Primary tumor $(n=4)$ & $100,100,45,100$ & & $0,0,55,0$ & $90,95,10,15$ \\
\hline \multicolumn{5}{|l|}{ Patient 10} \\
\hline Regional metastases $(n=8)$ & $\begin{array}{l}100,100,90,100,100 \\
100,100,100\end{array}$ & $\begin{array}{l}0,0,10,0,0,0,0, \\
0\end{array}$ & & $\begin{array}{l}80,0,100,30,30, \\
70,100,100\end{array}$ \\
\hline
\end{tabular}




\section{CHAPTER 5}

\section{Promoter CpG island hypermethylation in dysplastic nevus and melanoma: CLDN11 as an epigenetic biomarker for malignancy}

Linda Gao*, Karin van den Hurk*, Peter T.M. Moerkerk, Jelle J. Goeman, Samuel Beck, Nelleke A. Gruis, Joost J. van den Oord, Véronique J.L. Winnepenninckx", Manon van Engeland ${ }^{\#}$, Remco van Doorn ${ }^{\#}$

*Authors contributed equally as first author \#Authors contributed equally as senior author

Journal of Investigative Dermatology 2014; 134 (12): 2957-2966 


\section{Abstract}

Dysplastic nevi are melanocytic lesions that represent an intermediate stage between common nevus and melanoma. Histopathological distinction of dysplastic nevus from melanoma can be challenging and there is a requirement for molecular diagnostic markers. In this study, we examined promoter CpG island methylation of a selected panel of genes, identified in a genome-wide methylation screen, across a spectrum of 405 melanocytic neoplasms. Promoter methylation analysis in common nevi, dysplastic nevi, primary melanomas, and metastatic melanomas demonstrated progressive epigenetic deregulation. Dysplastic nevi were affected by promoter methylation of genes that are frequently methylated in melanoma but not in common nevi. We assessed the diagnostic value of the methylation status of five genes in distinguishing primary melanoma from dysplastic nevus. In particular, CLDN11 promoter methylation was specific for melanoma, as it occurred in $50 \%$ of primary melanomas but in only $3 \%$ of dysplastic nevi. A diagnostic algorithm that incorporates methylation of the CLDN11, CDH11, PPP1R3C, MAPK13, and GNMT genes was validated in an independent sample set and helped distinguish melanoma from dysplastic nevus (area under the curve 0.81). Melanoma specific methylation of these genes supports the utility as epigenetic biomarkers and could point to their significance in melanoma development. 


\section{Introduction}

Cutaneous melanoma is a malignant tumor that arises from melanocytes residing in the skin. The lifetime risk of developing melanoma is approximately $2 \%$ in the United States and Europe and both incidence and mortality rates continue to rise ${ }^{1,2}$. Early diagnosis is important to prevent the formation of lethal metastasis. However, the clinical diagnosis of melanoma is challenging in a proportion of cases. This applies to visual assessment of pigmented skin lesions and to histopathological examination of biopsied tissue, the standard for melanoma diagnosis. A substantial interobserver discordance rate of $14 \%$ in the pathological diagnosis of melanoma has been reported $^{3,4}$. In particular, the sensitivity for diagnosing early-stage melanomas is low and distinction with dysplastic melanocytic nevus can be problematic.

Dysplastic nevi are irregular in shape and pigmentation and occur in approximately $10 \%$ of the population ${ }^{5}$. Histologically, these lesions demonstrate random cytological atypia, architectural disorder, and stromal changes. The relevance of dysplastic nevus to melanoma progression is underscored by observations that dyplastic nevi are found in contiguity with melanoma in a significant subset of cases ${ }^{6,7}$. On the basis of morphological and biological characteristics, dysplastic nevi have been proposed to represent an intermediate lesion between common nevi and malignant melanoma in the multistep tumor progression model of melanocytic neoplasia ${ }^{8}$.

In the melanoma progression model proposed by Clark, melanocytic cells acquire malignant traits in discrete steps, a process driven by accumulation of genetic and epigenetic alterations ${ }^{9}$. Although there is limited information about genetic and epigenetic alterations in dysplastic nevi, patterns of intragenic mutations, chromosomal aberrations, and DNA methylation alterations are assumed to differ from those in melanoma. Therefore, detection of these molecular differences could aid in the correct classification of those cases in which morphological diagnosis fails to discriminate.

Systematic characterization of molecular alterations in melanoma has provided a wealth of information on acquired DNA alterations in melanoma cells, which could be used in the molecular diagnosis of this malignant disease. Recently, we performed a genome-wide promoter methylation analysis of 14495 genes in melanoma and common nevus samples and found widespread aberrant promoter methylation in melanoma ${ }^{10}$. Among the hundreds of gene promoters that exhibited methylation in melanomas but not in common nevi, we identified several tumor suppressor genes, causally implicating epigenetic mechanisms in melanoma development.

The objectives of this study were to gain insight into epigenetic deregulation in the different stages of melanocytic neoplasia and to assess the potential diagnostic value of genes differentially methylated between melanoma and dysplastic nevus. To this end, we examined the methylation status of genes that were previously identified in a genome-wide methylation screen in a cohort of 251 melanocytic neoplasms and subsequently validated a diagnostic algorithm incorporating different gene 
methylation features in a second independent series of 154 dysplastic nevus and primary melanoma samples. The combined analysis of promoter $\mathrm{CpG}$ island methylation of the five genes proposed in this study could be of help in the histopathological distinction of melanoma from dysplastic nevus.

\section{Materials and methods}

\section{Patient samples}

To prioritize the 12 candidate genes, we analyzed an independent set of fresh-frozen or boonfix-fixed, paraffin-embedded (BFPE) tissues from patients diagnosed with common nevus $(n=10)$, dysplastic nevus $(n=20)$, and primary melanoma $(n=15)$ at Leiden University Medical Center (LUMC), the Netherlands. For confirmation of methylation frequencies and testing of diagnostic discriminatory value of the final five genes, we examined FFPE tissues from patients diagnosed with common nevus ( $n=62)$, dysplastic nevus ( $n=72)$, primary melanoma $(n=101)$, and metastatic melanoma $(n=16)$ at the Maastricht University Medical Center (MUMC), the Netherlands, and University Hospitals of the University of Leuven (KUL), Belgium (series 1). For validation of the diagnostic algorithm, we examined fresh-frozen, BFPE, and FFPE tissues from patients diagnosed with dysplastic nevus $(n=74)$ and primary melanoma $(n=82)$ at LUMC, MUMC, and KUL (series 2). The grade of atypia (mild and moderate-severe) of dysplastic nevi was determined by an experienced dermatopathologist (VJW), based on criteria formulated by Arumi-Uria et al., 2003. Detailed clinicopathological information of all samples is listed in Supplementary Table S7. Tissues were processed as previously described ${ }^{11}$; biopsy samples contained at least $50 \%$ melanocytic cells, as analyzed on hematoxylin and eosin-stained sections. Patient consent for experiments was not required because French laws consider human tissue left over from surgery as discarded material.

\section{DNA isolation and bisulfite conversion}

Genomic DNA from fresh-frozen and BFPE tissues was extracted with the Genomic-tip kit (Qiagen, Venlo, The Netherlands) and the RecoverAll Nucleic Acid kit (Ambion, Carlsbad, CA), respectively; DNA from FFPE tissues was extracted by macrodissection with the QIAamp DNA Micro Kit (Qiagen) or with the Maxwell 16 FFPE Plus LEV DNA Purification kit (Promega, Leiden, The Netherlands). Bisulfite conversion was performed using either the EZ DNA methylation kit (Zymo Research, Orange, CA; BMCA) or the EpiTect Bisulfite Kit (Qiagen; MSP analysis).

Bisulfite melting curve analysis

Bisulfite primers were designed, and the sensitivity of primer sets was tested as previously described ${ }^{10}$ (Supplementary Table S8). Methylation could be accurately 
detected if $10 \%$ of the analyzed DNA was methylated. Melting curves were generated for each biopsy sample; a sample was considered methylated if the amplicon had at least $10 \%$ methylated DNA, with the melting curve pattern of a 1:9 methylated to unmethylated DNA mixture serving as scoring standard.

Methylation-specific PCR

MSP analysis using MSP primers on bisulfite-treated DNA was performed as described $^{12,13}$ (Supplementary Table S8). To facilitate MSP analysis on DNA retrieved from FFPE tissue, DNA was first amplified with flanking PCR primers used as template for the PCR. All PCRs were performed with controls for unmethylated alleles (DNA from human umbilical vein endothelial cells, methylated alleles (normal lymphocyte DNA treated in vitro with Sssl methyltransferase (IVD)), and a control without DNA. To ensure reproducibility, MSP reactions have been performed in duplicate or triplicate starting from DNA amplification with flanking PCR primers. The reproducibility was $>93 \%$ for all primer sets. Nonconcordant MSP results were analyzed a third time, and two out of three concordance was used as the end result. Bands with approximately equal intensity for unmethylated and methylated DNA were scored as positive for methylation. Faint methylated bands were considered negative for methylation. Unclear results were analyzed a second time. In most cases, methylation levels were clearly negative (no M-band detected) or positive (strong M-band detected).

Statistical analysis

Fisher's exact test was applied to measure the association between two sample groups within a $2 \times 2$ contingency table; a two-sided P-value $<0.05$ was considered significant. Logistic regression analysis was used to test the diagnostic value of the five genes in the training data set. The logistic regression did not converge because of the strong diagnostic effect of CLDN11; therefore, we opted for a two-step model: data were filtered for samples without CLDN11 methylation, followed by binary logistic regression analysis with a single covariate counting how many of $\mathrm{CDH} 11, \mathrm{PPP} 1 \mathrm{R} 3 \mathrm{C}$, MAPK13, and GNMT were methylated. In the resulting diagnostic score, a patient sample was classified as melanoma if either CLDN11 was methylated or if at least 1, 2, 3, or 4 of CDH11, PPP1R3C, MAPK13, and GNMT were methylated, depending on the chosen cutoff. A receiver operating characteristic curve was plotted for this diagnostic score. For this assessment, an independent test set was used in order to prevent any optimism bias due to overfit. Statistical analyses were performed using SPSS 20 (IBM, Armonk, NY) and R (R Core Team (2013)-http://R-project.org/). 


\section{Results}

\section{Selection of genes for promoter CpG island methylation analysis in common nevus, dysplastic nevus, primary melanoma, and metastatic melanoma}

In a previously performed genome-wide methylation analysis using Infinium 27-k beadchips, we identified 106 genes that were significantly and frequently more methylated in primary cutaneous melanomas than in common nevi ${ }^{10}$. Here, we set out to analyze the methylation status of the 12 most differentially methylated genes in dysplastic nevi, next to an independent set of common nevi and primary melanomas (Figure $1 \mathrm{~A}$ and $\mathrm{B}$ ). Primers for bisulfite melting curve analysis (BMCA) were designed to encompass or to be in close proximity of the corresponding 50-mer probe sequence on the beadchip. C4orf8 and HIST1H3E were excluded for further methylation analyses owing to suboptimal primer design; in their place, PPP1R3C and CLDN11 were included, as we had observed that they exhibited notable differential methylation between primary melanoma and common nevus samples ${ }^{10}$. In the independent set of 10 common nevus, 20 dysplastic nevus, and 15 primary melanoma biopsy samples, BMCA showed that Clorf106, MAPK13, CDH11, GNMT, PPP1R3C, and CLDN11 methylation was absent in common and dysplastic nevi, whereas frequent methylation (20-67\%) was observed in primary melanomas (Figure 1C). The promoters of HOXA9 and CNTN1 were nonprogressively methylated in $10-80 \%$ of common nevi, dysplastic nevi, and primary melanomas. Interestingly, PLEKHG6 showed progressively higher levels of methylation with tumor progression, that is, in $0 \%$ of common nevi, $35 \%$ of dysplastic nevi, and $60 \%$ of primary melanomas, suggesting that transition from a benign melanocytic lesion to a malignant tumor can be accompanied by a gradual increase in methylation of certain genes (Figure 1C). LEP showed mosaic methylation in melanoma and nevi, with only subtle differences between these sample groups, whereas the ABCA3 promoter region appeared to be unmethylated in melanoma, as well as in nevi (Supplementary Figure S1). Genes showing frequent methylation in melanoma, but not, or scarcely, in common and dysplastic nevi, were prioritized for further analyses in a large series of samples.

\section{Differential promoter methylation of QDN11, CHI1, PPPIR3C, MAPK13, and GNMT in common nevus, dysplastic nevus, and melanoma}

Promoter methylation of CLDN11, CDH11, PPP1R3C, MAPK13, and GNMT was assessed in a large series of 251 formalin-fixed, paraffin-embedded (FFPE) biopsy samples consisting of 62 common nevi, 72 dysplastic nevi, 101 primary melanomas, and 16 melanoma metastases, designated series 1 . We applied nested methylation-specific PCR (MSP) because this method is better suited for analysis of FFPE samples than $B M C A^{13}$. To compare the results of BMCA and MSP, we subjected 31 samples to methylation analysis using BMCA and MSP. This revealed a high concordance rate of 
A.

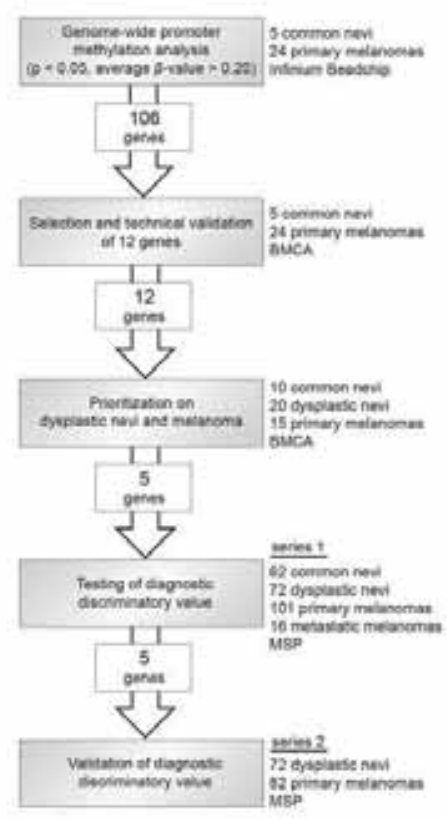

B.

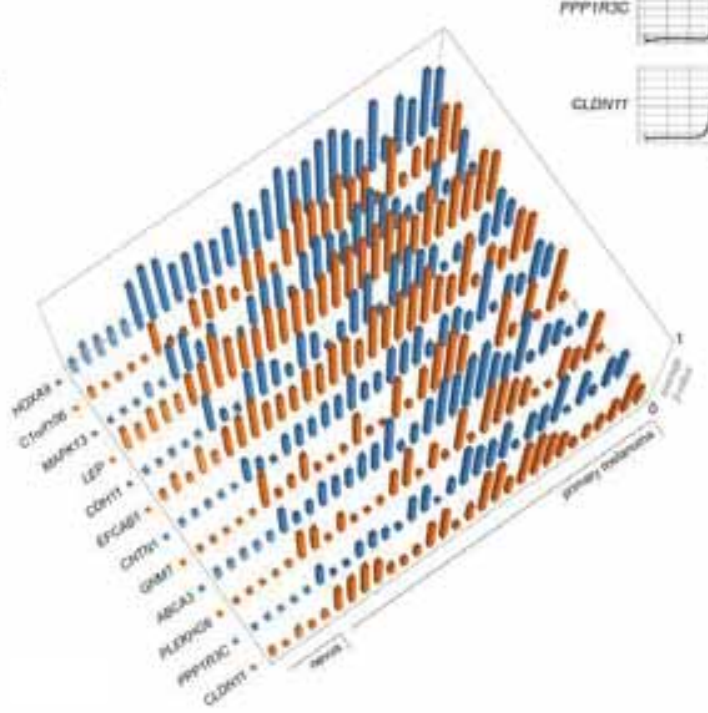

c.

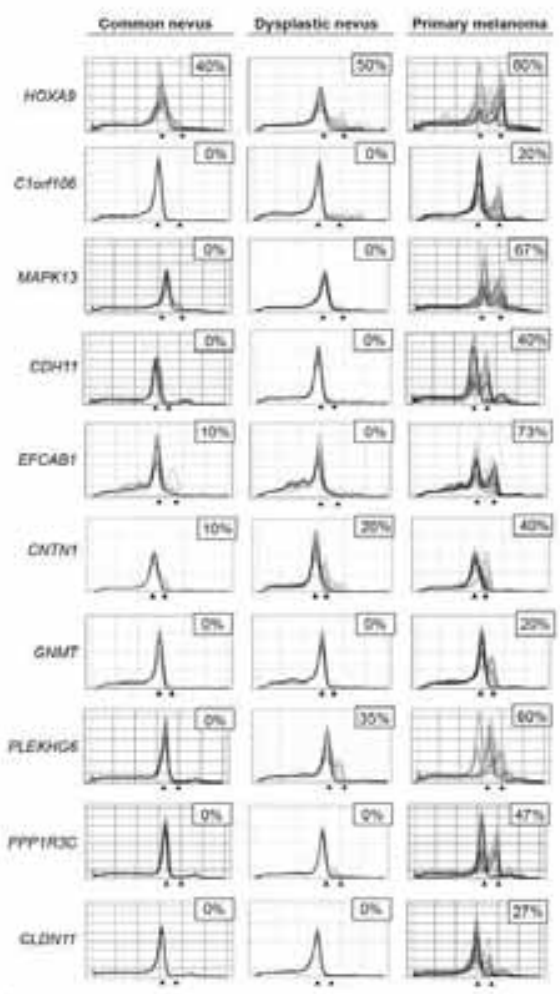

Figure 1. Differential promoter methylation of HOXA9, Clorf106, MAPK13, CHH1, EFAB1, ONIN1, GNMT, PLEHGG, PPPIR3C, and QDN11 in common nevi, dysplastic nevi, and primary melanomas.

A. Schematic depiction of the workflow used to select candidate genes for methylation analyses in large series of melanocytic biopsy samples. B. The 12 most frequently methylated genes identified by comparative analysis of genome-wide methylation data from 24 primary melanomas and five common nevi. C. Methylation frequency of 10 genes in an independent set of 10 common nevi, 20 dysplastic nevi, and 15 primary melanomas as assessed by bisulfite melting curve analysis (BMCA). Black triangles indicate the position of the melting curve peak for the respective positive (fully methylated) and negative (fully unmethylated) control. 
Table 1. Characteristics of five genes that were selected for methylation analysis in common nevus, dysplastic nevus, primary melanoma, and metastatic melanoma biopsy samples

\begin{tabular}{|c|c|c|c|c|c|c|}
\hline \multirow[t]{2}{*}{ Gene } & \multirow[t]{2}{*}{ Function } & \multirow[t]{2}{*}{ Location } & \multirow{2}{*}{$\begin{array}{c}\text { Tumor } \\
\text { suppressor }\end{array}$} & \multirow{2}{*}{$\begin{array}{l}\text { Methylation- } \\
\text { associated } \\
\text { silencing }\end{array}$} & \multicolumn{2}{|c|}{$\begin{array}{l}\text { Described in literature } \\
\text { as methylated in: }\end{array}$} \\
\hline & & & & & Cancer & Melanoma \\
\hline MAPK13 & $\begin{array}{l}\text { p38 MAP kinase involved in relaying } \\
\text { intracellular signals for a variety of cellular } \\
\text { processes }\end{array}$ & $\begin{array}{l}\text { chr6: } \\
36098261- \\
36112301\end{array}$ & Putative $^{10}$ & Yes $^{10}$ & $x$ & $x$ \\
\hline $\mathrm{CDH} 11$ & $\begin{array}{l}\text { Type Il classical cadherin that is an integral } \\
\text { membrane protein mediating calcium- } \\
\text { dependent cell-cell adhesion }\end{array}$ & $\begin{array}{l}\text { chr16: } \\
64980683- \\
65155919\end{array}$ & Established $^{14-16}$ & Yes $^{10}$ & $x$ & $x$ \\
\hline GNMT & $\begin{array}{l}\text { Enzyme that catalyzes the conversion of S- } \\
\text { adenosyl-L-methionine to S-adenosyl-L- } \\
\text { homocysteine and sarcosine }\end{array}$ & $\begin{array}{l}\text { chr6: } \\
42928500- \\
42931618\end{array}$ & Putative $^{17}$ & Yes $^{18}$ & $x$ & $x$ \\
\hline PPP1R3C & $\begin{array}{l}\text { Regulatory subunit of protein phosphatase- } \\
1 \text { (PP1) that catalyzes reversible protein } \\
\text { phosphorylation important for a variety of } \\
\text { cellular activities }\end{array}$ & $\begin{array}{l}\text { chr10: } \\
93388197- \\
93392858\end{array}$ & Putative $^{19}$ & Yes $^{19}$ & & $x$ \\
\hline CLDN11 & $\begin{array}{l}\text { Claudin family member that is an integral } \\
\text { membrane protein and component of tight- } \\
\text { junction strands }\end{array}$ & $\begin{array}{l}\text { chr3: } \\
170136653- \\
170152479\end{array}$ & Putative $^{10}$ & $\mathrm{Yes}^{20}$ & $x$ & $x$ \\
\hline
\end{tabular}

84-97\% between both techniques, with higher sensitivity for detecting methylation of MSP (Supplementary Table S1). Clorf106 was excluded at this stage owing to suboptimal MSP primer design, and methylation analysis by MSP was performed for CLDN11, CDH11, PPP1R3C, MAPK13, and GNMT. The characteristics of the five genes are detailed in Table 1. The promoter CpG island regions of these genes as studied by MSP and BMCA are depicted in Figure 2a. MSP was successfully performed in 87-98\% of the samples in series 1 (Figure 2b, Supplementary Table S2).

Methylation frequencies of CLDN11, CDH11, PPP1R3C, MAPK13, and GNMT in common nevi, dysplastic nevi, and primary and metastatic melanomas are presented in Table 2. For further analyses and generation of a diagnostic algorithm, only methylation data of samples for which MSP was performed successfully for all five genes ( 55 common nevi, 57 dysplastic nevi, 79 primary melanomas, and 15 metastatic melanomas) are included in Table 2 and Figure 3. (Results for all analyzed samples of series 1 are given in Supplementary Table S3). Remarkably, CLDN11 displayed the absence of methylation in both common and dysplastic nevi, whereas it was

Table 2. Methylation frequency of five candidate genes in biopsy samples of series 1 ( 55 common nevi, 57 dysplastic nevi, 79 primary melanomas, and 15 metastatic melanomas), together with the specificity and sensitivity of each gene for the distinction of primary melanoma samples from dysplastic nevus samples of series 1.

\begin{tabular}{|c|c|c|c|c|c|c|c|c|c|c|}
\hline & \multicolumn{2}{|c|}{$\begin{array}{c}\text { Common } \\
\text { nevus }\end{array}$} & \multicolumn{2}{|c|}{$\begin{array}{c}\text { Dysplastic } \\
\text { nevus }\end{array}$} & \multicolumn{2}{|c|}{$\begin{array}{l}\text { Primary } \\
\text { melanoma }\end{array}$} & \multicolumn{2}{|c|}{$\begin{array}{l}\text { Metastatic } \\
\text { melanoma }\end{array}$} & \multicolumn{2}{|c|}{$\begin{array}{l}\text { Dysplastic nevus }(n=57) \\
\text { Primary melanoma }(n=79)\end{array}$} \\
\hline & \multicolumn{8}{|c|}{ Methylation frequency } & \multirow[b]{2}{*}{ Specificity } & \multirow[b]{2}{*}{ Sensitivit } \\
\hline & $\begin{array}{c}\text { No. of } \\
\text { samples }\end{array}$ & $\%$ & $\begin{array}{c}\text { No. of } \\
\text { samples }\end{array}$ & $\%$ & $\begin{array}{c}\text { No. of } \\
\text { samples }\end{array}$ & $\%$ & $\begin{array}{c}\text { No. of } \\
\text { samples }\end{array}$ & $\%$ & & \\
\hline CLDN11 & $0 / 55$ & 0 & $0 / 57$ & 0 & $38 / 79$ & 48 & $11 / 15$ & 73 & $100 \%$ & $48 \%$ \\
\hline $\mathrm{CDH} 11$ & $0 / 55$ & 0 & $3 / 57$ & 5 & $32 / 79$ & 41 & $7 / 15$ & 47 & $95 \%$ & $41 \%$ \\
\hline PPP1R3C & $0 / 55$ & 0 & $8 / 57$ & 14 & $41 / 79$ & 52 & $9 / 15$ & 60 & $86 \%$ & $52 \%$ \\
\hline MAPK13 & $10 / 55$ & 18 & $15 / 57$ & 26 & $49 / 79$ & 62 & $10 / 15$ & 67 & $74 \%$ & $62 \%$ \\
\hline GNMT & $2 / 55$ & 4 & $6 / 57$ & 11 & $36 / 79$ & 46 & $7 / 15$ & 47 & $89 \%$ & $46 \%$ \\
\hline
\end{tabular}



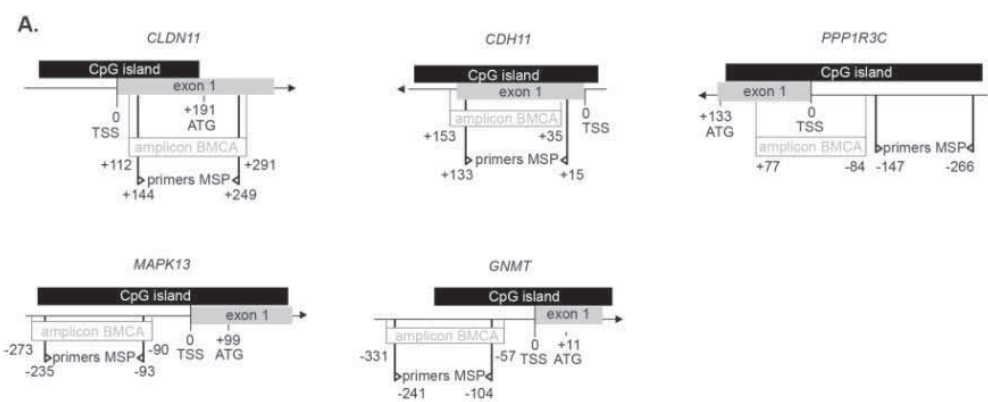

B.

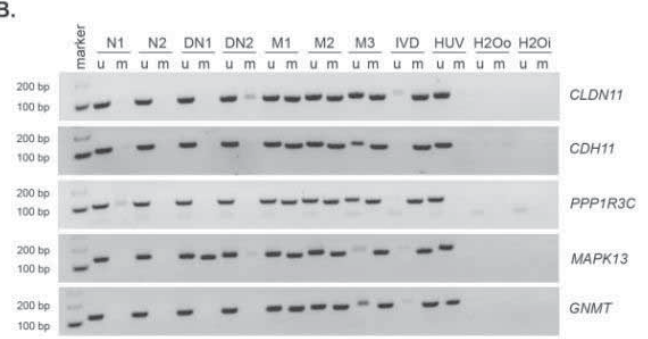

Figure 2. Methylation analysis of QDN11, GH1, PPPIR3C, MAPK13, and GNMT in large series of common nevi, dysplastic nevi, primary and metastatic melanomas. A. $\mathrm{CpG}$ island promoter region of the five genes, with the location of the primers used for methylation-specific PCR (MSP) and bisulfite melting curve analysis (BMCA) in this study. B. Electrophoretic analysis of MSP amplification products of CLDN11, CDH11, PPP1R3C, MAPK13, and GNMT. N, common nevus; DN, dysplastic nevus; M, melanoma; u, unmethylated; $\mathrm{m}$, methylated; IVD, positive control for methylated alleles (lymphocyte DNA treated with Sss1 methyltransferase); HUV, negative control for unmethylated alleles (DNA from human umbilical vein endothelial cells); $\mathrm{H} 2 \mathrm{Oo}$, no template control for first amplification with flanking primers; $\mathrm{H} 2 \mathrm{Oi}$, no template control for second amplification with primers specific for methylated and unmethylated DNA.

methylated in $48 \%$ of primary melanomas and $73 \%$ of metastatic melanomas in series 1 (Table 2). CDH11 and PPP1R3C showed the absence of methylation in common nevi; only 5 and $14 \%$ of dysplastic nevi harbored methylation for $\mathrm{CDH} 11$ and PPP1R3C, respectively. Methylation frequencies in primary and metastatic melanomas were 41 and $47 \%$ for $\mathrm{CDH} 11$, and 52 and $60 \%$ for PPP1R3C, respectively. GNMT harbored promoter methylation in $4 \%$ of common and $11 \%$ of dysplastic nevi, but yet again higher methylation frequencies were found in primary (46\%) and metastatic (47\%) melanomas. For MAPK13, methylation was observed in $18 \%$ of common and $26 \%$ of dysplastic nevi, with higher methylation frequencies in primary (62\%) and metastatic (67\%) melanomas. The methylation patterns of the five genes, showing progressive increase in methylation frequency in different stages of melanocytic neoplasia, are depicted in Figure 3A. We noted significantly higher promoter methylation frequencies in particular following the transition to melanoma. Methylation of each of the five genes was detected only 12 times (4\%) in 55 common nevi and 32 times (11\%) in 57 dysplastic nevi, significantly lower when compared to 196 times $(50 \%)$ in 79 primary melanomas ( $\mathrm{P}=0.001)$ and 44 times $(59 \%)$ in 15 metastatic melanomas (Figure 3B). 

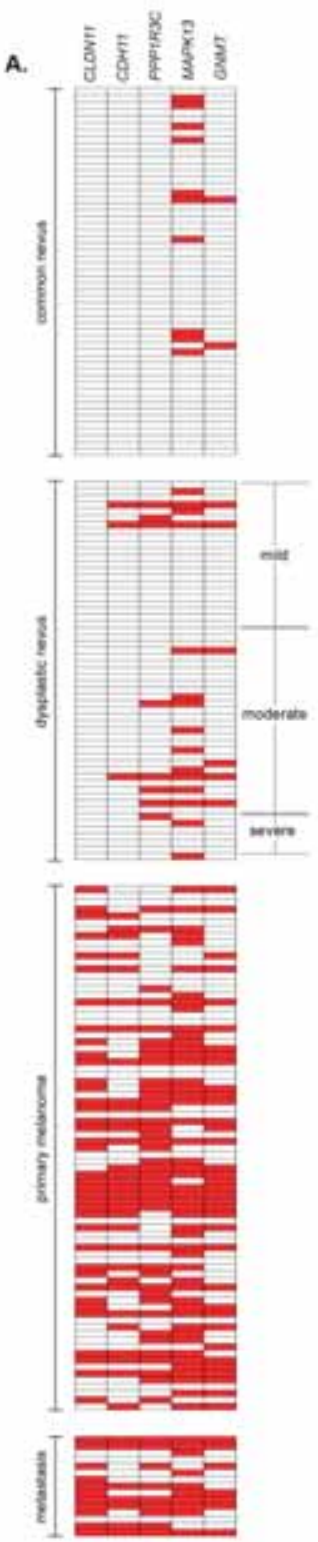

B.

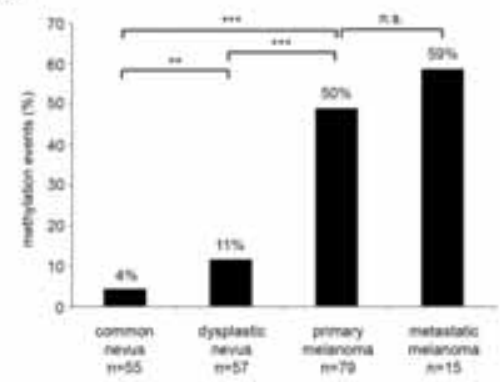

C.

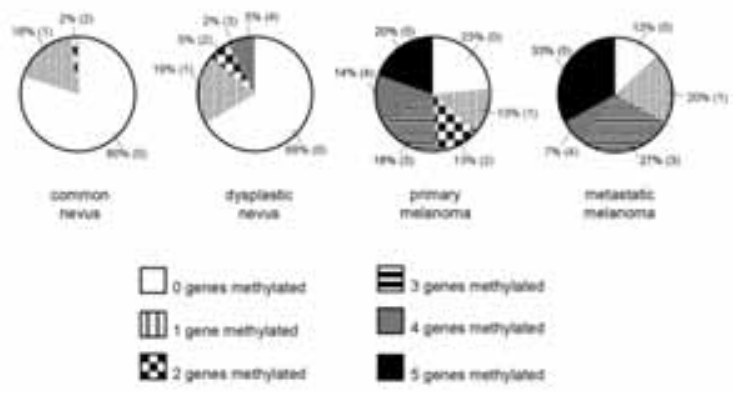

Figure 3. Pattern and frequency of QDN11, CH11, PPPIR3C, MAPK13, and GNMT promoter methylation in a large series of common nevi, dysplastic nevi, primary melanomas, and metastatic melanomas (series 1). A. Heatmap depiction of CLDN11, CDH11, PPP1R3C, M APK13, and GNMT promoter methylation status in 55 common nevi, 57 dysplastic nevi, 79 primary melanomas, and 15 metastatic melanomas from series 1. White, unmethylated; red, methylated. B. Percentage of methylation events (methylated genes) found in each sample within the groups of common nevus, dysplastic nevus, primary melanoma, and metastatic melanoma. ${ }^{* *} \mathrm{P}<0.01$ and ${ }^{* * *} \mathrm{P}<0.001$ by two-sided Fisher's exact test. C. Overview of total number of genes that were methylated in each sample within the groups of common nevus, dysplastic nevus, primary melanoma, and metastatic melanoma. NS, nonsignificant. 
Complete absence of methylation for all five genes was found in 44 of 55 (80\%) common nevi, 39 of 57 (68\%) dysplastic nevi, 18 of 79 (23\%) primary melanomas, and 2 of 15 (13\%) metastatic melanomas (Figure 3C). There was no significant correlation between the grade of atypia of dysplastic nevi and promoter methylation frequency.

Promoter hypermethylation is known to increase with age, and the mean age of the melanoma patients was higher (63 years) than of the dysplastic nevus patients (46 years). The differences in methylation frequencies of CLDN11, CDH11, PPP1R3C, MAPK13, and GNMT between melanomas and dysplastic nevi were comparable in the subset of patients younger than 50 years and those older than 50 years (Supplementary Table S4a). From this it can be concluded that the observed methylation differences between melanoma and dysplastic nevus cannot be attributed to age. For gender, similar results were obtained (Supplementary Table S5a). CLDN11, CDH11, PPP1R3C, MAPK13, and GNMT promoter methylation has been demonstrated to be associated with transcriptional silencing in tumor cell lines (Table 1). Additional pathway analysis specified that the products of these five genes and their predicted interactors are part of gene signaling networks involved in cell-cell adhesion, cell junction assembly, and adherens junction organization (Supplementary Figure S2).

\section{A diagnostic algorithm combining epigenetic markers to distinguish melanoma and dysplastic nevus}

The diagnostic specificities and sensitivities of CLDN11, CDH11, PPP1R3C, M APK13, and GNMT for the distinction of primary melanomas from dysplastic nevi of series 1 are given in Table 2. After having determined these characteristics of the five methylation markers individually, we continued by examining which combinations of markers could aid in the differential diagnosis of primary melanoma and dysplastic nevus. Diagnostic algorithms were created using the set of 57 dysplastic nevi and 79 primary melanomas from series 1 , and the accuracy of these models was subsequently tested in a second sample set consisting of 72 dysplastic nevus and 82 primary melanoma biopsy samples, designated series 2 . In series 1 , the three most differentially methylated genes were CLDN11, CDH11, and PPP1R3C. A first, simple three-gene diagnostic model was created that considers methylation of either of these three genes as indicative of melanoma. This model yielded a specificity of $89 \%$ and sensitivity of $67 \%$ in series 2 used as test set (Figure 4A).

As CLDN11 methylation occurred exclusively in melanoma in series 1 used as training set, this epigenetic event had the highest discriminatory value with a specificity of $100 \%$ and sensitivity of $48 \%$ (Table 2). On the basis of a logistic regression model, a diagnostic algorithm was constructed consisting of two discrete steps. First, CLDN11 methylation was evaluated, and, if present, a lesion was classified as melanoma. Second, methylation of CDH11, PPP1R3C, MAPK13, and GNMT was taken in consideration for samples with no CLDN11 methylation (Figure 4A). Adding methylation information of the other four genes generated additional diagnostic value 
A.

\begin{tabular}{|c|c|c|c|c|}
\hline & \multicolumn{2}{|c|}{$\begin{array}{l}\text { Series } 1 \\
\text { (trairing set) }\end{array}$} & \multicolumn{2}{|c|}{$\begin{array}{l}\text { Series } 2 \\
\text { (test set? }\end{array}$} \\
\hline & Specificity & Senubvity & Specticity & Senuitivity \\
\hline \multicolumn{5}{|c|}{ 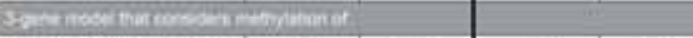 } \\
\hline CLOVIf or CONff or PPpirac & $86 \leqslant$ & $66 \mathrm{~s}$ & $\mathrm{Bs}$ & $67 \%$ \\
\hline \multicolumn{5}{|c|}{ 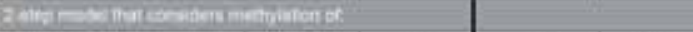 } \\
\hline CLDWit only & $100 \mathrm{~s}$ & $46 \%$ & $94 \mathrm{~s}$ & $52 \%$ \\
\hline CLDWff or 4 other genes & $95 \%$ & 495 & $94 \%$ & $\operatorname{sen}$ \\
\hline CLOWtt or a 3 other genes & 935 & $57 \%$ & $90 \%$ & $60 \%$ \\
\hline CLDWfI or $\geq 2$ other genes & BS5 & $65 \%$ & 895 & $60 \%$ \\
\hline CLDWIt or a 1 other gene & $\cos$ & $m s$ & $67 \times$ & Tas \\
\hline
\end{tabular}

B.

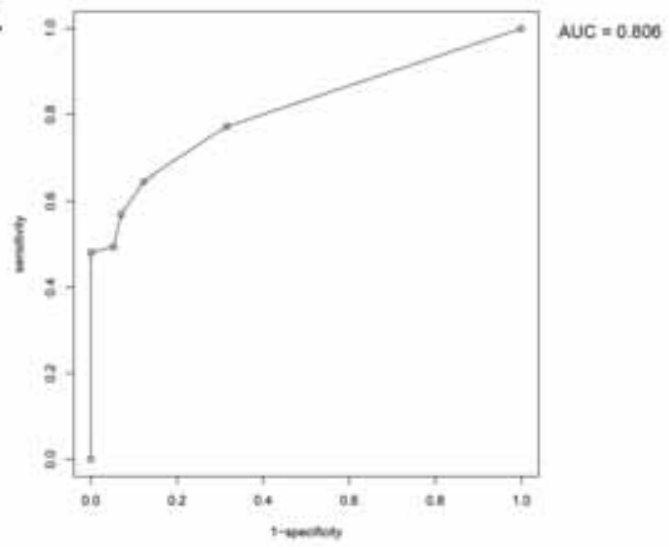

c.

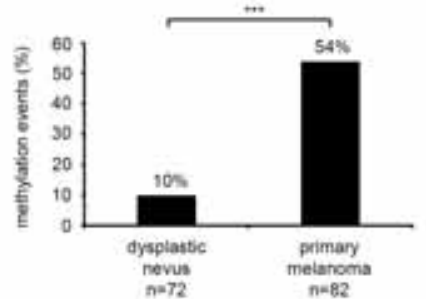

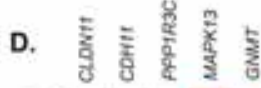
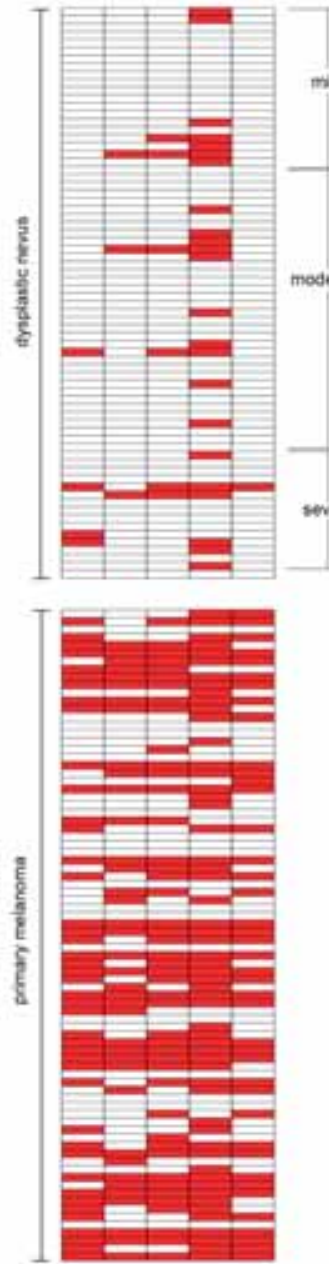

Figure 4. Testing and validation of diagnostic models that incorporate CLDN11, CDH11, PPP1R3C, MAPK13, and GNMT promoter methylation. A. Diagnostic value was tested in 57 dysplastic nevi and 79 primary melanomas from series 1 (training set), yielding diagnostic scores in the form of a three-gene model and a two-step model, followed by validation of these models in 72 dysplastic nevi and 82 primary melanomas from series 2 (test set). B. Receiver operating characteristic curve of the two-step diagnostic model. C. Percentage of methylation events within the dysplastic nevi and primary melanomas of series $2 .{ }^{* * *} \mathrm{P}<0.001$ by two-sided Fisher's exact test. D. Promoter methylation status of the five genes in 72 dysplastic nevi and 82 primary melanomas from series 2 . White, unmethylated; red, methylated. 
by increasing the sensitivity of the model to detect melanoma. This model has a receiver operating characteristic curve with an area under the curve of 0.806 (Figure $4 \mathrm{~B})$. The condition that a lesion is classified as melanoma if CLDN11 or at least two other genes are methylated yields a specificity of $89 \%$ and sensitivity of $66 \%$ in series 2 (Figure 4A). Promoter methylation frequencies and patterns of the five interrogated genes in series 2, visualized in Figure $4 C$ and $D$ and reported in Supplementary Table S6a online, were generally similar to that of series 1 . In series 2, CLDN11 methylation was detected in $6 \%$ of dysplastic nevus samples and $52 \%$ of primary melanoma samples. Validation of methylation frequencies for the five genes in sample series 2 demonstrated that, in addition to CLDN11, also methylation of CDH11, PPP1R3C, and GNMT have high specificity for melanoma.

\section{Discussion}

Dysplastic nevi are melanocytic neoplasms with cytonuclear and architectural atypia and stromal alterations and are generally considered to constitute an intermediate stage between common nevi and melanoma. These lesions have an increased risk of developing into melanoma, and it can be difficult to clinically distinguish dysplastic nevus from early-stage melanoma ${ }^{5}$. In this study, we examined promoter CpG island methylation of 12 genes, previously identified in a genome-wide methylation screen, in metastatic and primary melanoma, dysplastic nevus, and common nevus biopsy specimens. We observed progressive promoter $\mathrm{CpG}$ island hypermethylation of these genes, with the methylation frequencies increasing from common nevus to metastatic melanoma. Dysplastic nevi, although less commonly than melanoma, demonstrate promoter hypermethylation of genes with tumor-suppressive functions, including $\mathrm{CDH} 11$. This shows that dysplastic nevi may already resemble their malignant counterparts at the epigenetic level and suggests that epigenetic instability can occur early, in premalignant stages of melanocytic neoplasia. In addition, it reinforces the notion of dysplastic nevus as an intermediate step in melanoma progression.

Promoter $\mathrm{CpG}$ island methylation analysis in a first, smaller series of samples using BMCA suggested that promoters of the CLDN11, CDH11, PPP1R3C, MAPK13, and GNMT genes could be selectively methylated in melanoma. This would render these methylation events suitable epigenetic biomarkers to improve the diagnosis of melanoma and to allow distinction with dysplastic nevus. Using MSP in a large series of 251 melanocytic neoplasm samples, we were able to show the discriminatory value of detecting promoter methylation of these five genes. Methylation detection by the MSP technique is especially suited in this setting, as it yields reproducible results and can directly be applied to FFPE-based samples in the clinic. On the basis of a logistic regression model analysis, we developed a diagnostic score that incorporates different gene methylation features, consisting of assessment of CLDN11 methylation first, followed by determination of the methylation frequency of CDH11, PPP1R3C, M APK13, and GNM T in DNA isolated from a biopsy sample. Testing of the diagnostic accuracy of 
this score in another independent series consisting of 82 primary melanoma and 72 dysplastic nevus samples revealed a receiver operating characteristic area under the curve of 0.806 in this independent test set. A simpler three-gene model that incorporates only CLDN11, CDH11, and PPP1R3C as marker of melanoma has a specificity of $89 \%$ and sensitivity of $67 \%$ in the validation sample set. In our analysis, we have pursued methylation events that are present in melanoma and do not occur in dysplastic nevus. This has resulted in a panel of epigenetic markers with very high specificity for melanoma, but with moderate sensitivity. In particular for screening purposes, a sensitive test would be preferred over a more specific test. By varying the parameters of the logistic regression model or addition of genes that are more frequently methylated in melanoma, such as HOXA9, an increase in sensitivity can be achieved, but at the expense of specificity. The binary results of methylation detection may confer an advantage over comparative genomic hybridization, fluorescent in situ hybridization, or combined immunohistochemical detection of melanoma markers, where interpretation of results can have higher interobserver variability ${ }^{21-23}$. Comparative genomic hybridization and fluorescent in situ hybridization, genomic methodologies used primarily in the research setting, may yield higher diagnostic accuracy than methylation detection of a few genes.

Remarkably, methylation of the CLDN11 gene was completely specific for melanoma, that is, methylation affected $48 \%$ of primary melanoma and $73 \%$ of metastatic samples, whereas it was absent in common and dysplastic nevi in the first large sample series. In the second sample series, used to validate the diagnostic algorithm, CLDN11 was found to be methylated in $6 \%$ of dysplastic nevus samples. Detection of CLDN11 methylation might in particular be used clinically to distinguish malignant from benign melanocytic lesions. Its methylation was shown previously to be associated with transcriptional silencing ${ }^{20}$. CLDN11 encodes a member of the claudin family, components of tight junctions that maintain a physical barrier and polarity of cells. CLDN11 hypermethylation was previously reported in bladder and gastric cancer, where epigenetic silencing increased cell motility and invasiveness ${ }^{20,24}$. Interestingly, in mouse skin tumorigenesis, changes were found in the distribution pattern of claudin tight-junction proteins, where epidermal expression of claudin proteins including Cldn11 decreased during tumor progression ${ }^{25}$. We hypothesize that in melanoma development loss of CLDN11 expression through promoter hypermethylation facilitates invasive behavior by disrupting intercellular cohesion provided by tight-junction structures. In addition, methylation of CDH11, PPP1R3C, and GNMT occurred in more than half of melanomas but rarely in dysplastic nevi. The results for $\mathrm{CDH} 11$ are in line with previous studies showing that methylation of this cadherin gene that inhibits tumor growth and metastasis preferentially occurs in lymph node metastases of melanoma patients ${ }^{26}$. Tumor-suppressive properties have also been reported for PPP1R3C and GNMT.

Thus far, promoter methylation studies in melanoma often used a limited number of clinical specimens and lacked examination of non-malignant samples, thereby 
making it impossible to distinguish cancer-specific from tissue-specific methylation events $^{27}$. Only few studies analyzed promoter methylation in dysplastic nevi, and most of them examined single candidate genes in small sample sets ${ }^{28-30}$. To our knowledge, this is a previously unreported study that makes use of a large series of clinical specimens to show that promoter methylation of several genes, including tumor suppressor genes, is present to a small extent in dysplastic nevi. Using the methylation pattern of five genes, we propose a diagnostic algorithm to distinguish melanoma from benign melanocytic lesions. The presence of CLDN11, CDH11, PPP1R3C, and GNMT methylation in a suspicious melanocytic lesion might be regarded as an indicator of malignancy. Taken together, the findings presented in this study provide insight in the epigenetic changes that occur in melanoma development and can aid in the molecular diagnosis of melanocytic lesions.

\section{Acknowledgements}

We thank Kathleen Daenen and Kim van Straeten for excellent technical assistance. RvD is supported by a Melanoma Research Alliance young investigator award. This work was supported by Profileringsfonds Maastricht University Medical Center (PF=278). 


\section{References}

1. Bauer J, Garbe C. Acquired melanocytic nevi as risk factor for melanoma development. A comprehensive review of epidemiological data. Pigment Cell Res, 2003. 16(3): p. 297-306.

2. Ferlay J, Shin HR, Bray F, et al. Estimates of worldwide burden of cancer in 2008: GLOBOCAN 2008. Int J Cancer, 2010. 127(12): p. 2893-2917.

3. Brochez L, Verhaeghe E, Grosshans E, et al. Inter-observer variation in the histopathological diagnosis of clinically suspicious pigmented skin lesions. J Pathol, 2002. 196(4): p. 459-466.

4. Shoo BA, Sagebiel RW, Kashani-Sabet M. Discordance in the histopathologic diagnosis of melanoma at a melanoma referral center. J Am Acad Dermatol, 2010. 62(5): p. 751-756.

5. Naeyaert JM, Brochez L. Clinical practice. Dysplastic nevi. N Engl J Med, 2003. 349(23): p. 2233-2240.

6. Sagebiel RW. Melanocytic nevi in histologic association with primary cutaneous melanoma of superficial spreading and nodular types: effect of tumor thickness. J Invest Dermatol, 1993. 100(3): p. 322S-325S.

7. Weatherhead SC, Haniffa M, Lawrence CM. Melanomas arising from naevi and de novo melanomas--does origin matter? Br J Dermatol, 2007. 156(1): p. 72-76.

8. Elder DE. Dysplastic naevi: an update. Histopathology, 2010. 56(1): p. 112-120.

9. Clark WH, Jr., Elder DE, Guerry Dt, et al. A study of tumor progression: the precursor lesions of superficial spreading and nodular melanoma. Hum Pathol, 1984. 15(12): p. 1147-1165.

10. Gao L, Smit MA, van den Oord JJ, et al. Genome-wide promoter methylation analysis identifies epigenetic silencing of MAPK13 in primary cutaneous melanoma. Pigment Cell Melanoma Res, 2013. 26(4): p. 542-554.

11. Winnepenninckx V, Lazar V, Michiels $S$, et al. Gene expression profiling of primary cutaneous melanoma and clinical outcome. J Natl Cancer Inst, 2006. 98(7): p. 472-482.

12. Herman JG, Graff JR, Myohanen S, et al. Methylation-specific PCR: a novel PCR assay for methylation status of CpG islands. Proc Natl Acad Sci U S A, 1996. 93(18): p. 9821-9826.

13. Derks S, Lentjes MH, Hellebrekers DM, et al. Methylation-specific PCR unraveled. Cell Oncol, 2004. 26(5-6): p. 291-299.

14. Futreal PA, Coin L, Marshall M, et al. A census of human cancer genes. Nat Rev Cancer, 2004. 4(3): p. 177-183.

15. Li L, Ying J, Li H, et al. The human cadherin 11 is a pro-apoptotic tumor suppressor modulating cell stemness through Wnt/beta-catenin signaling and silenced in common carcinomas. Oncogene, 2012. 31(34): p. 39013912.

16. Marchong MN, Yurkowski C, Ma C, et al. Cdh11 acts as a tumor suppressor in a murine retinoblastoma model by facilitating tumor cell death. PLoS Genet, 2010. 6(4): p. e1000923.

17. DebRoy S, Kramarenko, II, Ghose S, et al. A novel tumor suppressor function of glycine N-methyltransferase is independent of its catalytic activity but requires nuclear localization. PLoS One, 2013. 8(7): p. e70062.

18. Huidobro C, Torano EG, Fernandez AF, et al. A DNA methylation signature associated with the epigenetic repression of glycine $\mathrm{N}$-methyltransferase in human hepatocellular carcinoma. J Mol Med (Berl), 2013. 91(8): p. 939-950.

19. Bonazzi VF, Irwin D, Hayward NK. Identification of candidate tumor suppressor genes inactivated by promoter methylation in melanoma. Genes Chromosomes Cancer, 2009. 48(1): p. 10-21.

20. Agarwal $R$, Mori $Y$, Cheng $Y$, et al. Silencing of claudin-11 is associated with increased invasiveness of gastric cancer cells. PLoS One, 2009. 4(11): p. e8002.

21. Gerami P, Wass A, Mafee M, et al. Fluorescence in situ hybridization for distinguishing nevoid melanomas from mitotically active nevi. Am J Surg Pathol, 2009. 33(12): p. 1783-1788.

22. Kashani-Sabet M, Rangel J, Torabian $\mathrm{S}$, et al. A multi-marker assay to distinguish malignant melanomas from benign nevi. Proc Natl Acad Sci U S A, 2009. 106(15): p. 6268-6272.

23. Zhang G, Li G. Novel multiple markers to distinguish melanoma from dysplastic nevi. PLoS One, 2012. 7(9): p. e45037.

24. Awsare NS, Martin TA, Haynes MD, et al. Claudin-11 decreases the invasiveness of bladder cancer cells. Oncol Rep, 2011. 25(6): p. 1503-1509.

25. Arabzadeh A, Troy TC, Turksen K. Changes in the distribution pattern of Claudin tight junction proteins during the progression of mouse skin tumorigenesis. BMC Cancer, 2007. 7: p. 196.

26. Carmona FJ, Villanueva A, Vidal A, et al. Epigenetic disruption of cadherin-11 in human cancer metastasis. J Pathol, 2012. 228(2): p. 230-240.

27. van den Hurk K, Niessen HE, Veeck J, et al. Genetics and epigenetics of cutaneous malignant melanoma: a concert out of tune. Biochim Biophys Acta, 2012. 1826(1): p. 89-102.

28. Sharma SP. New prediction model for melanoma. Lancet Oncol, 2006. 7(9): p. 711.

29. Conway K, Edmiston SN, Khondker ZS, et al. DNA-methylation profiling distinguishes malignant melanomas from benign nevi. Pigment Cell Melanoma Res, 2011. 24(2): p. 352-360. 
30. Helmbold P, Richter AM, Walesch S, et al. RASSF10 promoter hypermethylation is frequent in malignant melanoma of the skin but uncommon in nevus cell nevi. J Invest Dermatol, 2012. 132(3 Pt 1): p. 687-694. 


\section{Supplementary information}

Supplementary Table S1. Percentage of samples that had concordant results when methylation analysis was performed using BMCA and MSP on the same set of common nevi $(n=11)$, dysplastic nevi $(n=10)$ and melanomas $(n=10)$.

\begin{tabular}{|c|c|c|c|c|c|c|c|c|c|c|}
\hline \multirow[b]{3}{*}{ Common } & \multicolumn{2}{|c|}{ CLDN11 } & \multicolumn{2}{|l|}{$\mathrm{CDH} 11$} & \multicolumn{2}{|c|}{ PPP1R3C } & \multicolumn{2}{|c|}{ MAPK13 } & \multicolumn{2}{|l|}{ GNMT } \\
\hline & $\%$ & $\begin{array}{c}\text { No. of } \\
\text { samples }\end{array}$ & $\%$ & $\begin{array}{c}\text { No. of } \\
\text { samples }\end{array}$ & $\%$ & $\begin{array}{c}\text { No. of } \\
\text { samples }\end{array}$ & $\%$ & $\begin{array}{c}\text { No. of } \\
\text { samples }\end{array}$ & $\%$ & $\begin{array}{c}\text { No. of } \\
\text { samples }\end{array}$ \\
\hline & 100 & $11 / 11$ & 100 & $11 / 11$ & 100 & $11 / 11$ & 64 & $7 / 11$ & 100 & $11 / 11$ \\
\hline $\begin{array}{l}\text { Dysplastic } \\
\text { nevus }\end{array}$ & 90 & $9 / 10$ & 90 & $9 / 10$ & 80 & $8 / 10$ & 90 & $9 / 10$ & 90 & $9 / 10$ \\
\hline $\begin{array}{l}\text { Primary } \\
\text { melanoma }\end{array}$ & 80 & $8 / 10$ & 100 & $10 / 10$ & 90 & $9 / 10$ & 100 & $10 / 10$ & 70 & $7 / 10$ \\
\hline$\overline{\text { Total }}$ & 90 & $28 / 31$ & 97 & $30 / 31$ & 90 & $28 / 31$ & 84 & $26 / 31$ & 87 & $27 / 31$ \\
\hline
\end{tabular}

Supplementary Table S2. Percentage of bisulphite-converted genomic DNA samples that was successfully amplified using MSP. In series 1, DNA was obtained from FFPE biopsy specimens of common nevus, dysplastic nevus, primary melanoma and metastatic melanoma $(n=251)$. In series 2, DNA was obtained from FFPE, BFPE, and fresh frozen biopsy specimens of dysplastic nevus and primary melanoma $(n=156)$.

\begin{tabular}{lllll}
\hline & Series 1 & \multicolumn{3}{c}{ Series 2 } \\
\cline { 2 - 5 } CLDN11 & 98 & No. of samples & $\%$ & No. of samples \\
CDH11 & 92 & $247 / 251$ & 99 & $154 / 156$ \\
PPP1R3C & 97 & $230 / 251$ & 99 & $154 / 156$ \\
MAPK13 & 87 & $244 / 251$ & 99 & $155 / 156$ \\
GNMT & 96 & $218 / 251$ & 99 & $155 / 156$ \\
\hline
\end{tabular}

Supplementary Table S3. Methylation-specific PCR (MSP) was performed on series 1 consisting of 62 common nevus, 72 dysplastic nevus, 101 primary melanoma, and 16 metastatic melanoma samples to determine methylation frequency of five candidate genes. In this table, all MSP results are presented whereas in Table 2, only samples for which MSP data was complete for all five genes were included.

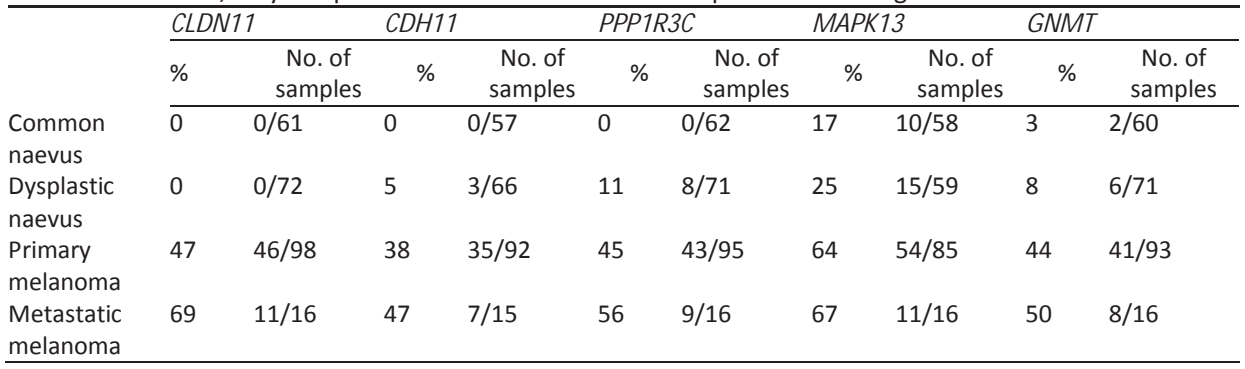


Supplementary information

Supplementary Table S4a. Methylation frequency of five candidate genes in dysplastic nevus and primary melanoma biopsy samples from series 1 based on age of the patients. Dysplastic nevus and primary melanoma samples for which age was known $(n=130)$ were grouped into patients younger than 50 years $(n=57)$ and those that were 50 years or older $(n=73)$.

\begin{tabular}{|c|c|c|c|c|c|c|c|c|c|c|}
\hline & \multicolumn{4}{|c|}{$>50$ years $(n=57)$} & \multicolumn{6}{|c|}{$\leq 50$ years $(n=73)$} \\
\hline & \multicolumn{2}{|c|}{$\begin{array}{l}\text { Dysplastic nevus } \\
\qquad(n=40)\end{array}$} & \multicolumn{2}{|c|}{$\begin{array}{l}\text { Primary melanoma } \\
\qquad(n=17)\end{array}$} & \multicolumn{3}{|c|}{$\begin{array}{l}\text { Dysplastic nevus } \\
\qquad(n=17)\end{array}$} & \multicolumn{2}{|c|}{$\begin{array}{l}\text { Primary melanoma } \\
\qquad(n=56)\end{array}$} & \\
\hline CLDN11 & 0 & 0 & 41 & 7 & $<0.001$ & 0 & 0 & 46 & 26 & $<0.001$ \\
\hline PPP1R3C & 13 & 5 & 53 & 9 & 0.002 & 18 & 3 & 48 & 27 & 0.028 \\
\hline M APK13 & 28 & 11 & 71 & 12 & 0.003 & 24 & 4 & 57 & 32 & 0.025 \\
\hline GNMT & 10 & 4 & 35 & 6 & 0.051 & 12 & 2 & 46 & 26 & 0.011 \\
\hline
\end{tabular}

Supplementary Table S4b. Methylation frequency of five candidate genes in dysplastic nevus and primary melanoma biopsy samples from series 2 based on age of the patients. Dysplastic nevus and primary melanoma samples $(n=154)$ were grouped into patients younger than 50 years $(n=53)$ and those that were 50 years or older $(n=101)$.

\begin{tabular}{|c|c|c|c|c|c|c|c|c|c|c|}
\hline & \multicolumn{4}{|c|}{$>50$ years $(n=53)$} & \multicolumn{6}{|c|}{$\leq 50$ years $(n=101)$} \\
\hline & \multicolumn{2}{|c|}{$\begin{array}{c}\text { Dysplastic nevus } \\
\qquad(\mathrm{n}=35)\end{array}$} & \multicolumn{2}{|c|}{$\begin{array}{l}\text { Primary melanoma } \\
\qquad(\mathrm{n}=18)\end{array}$} & \multicolumn{3}{|c|}{$\begin{array}{l}\text { Dysplastic nevus } \\
\qquad(\mathrm{n}=37)\end{array}$} & \multicolumn{2}{|c|}{$\begin{array}{l}\text { Primary melanoma } \\
\qquad(\mathrm{n}=64)\end{array}$} & \multirow{2}{*}{ P-value } \\
\hline & $\%$ & $\begin{array}{l}\text { No. of } \\
\text { samples }\end{array}$ & $\%$ & $\begin{array}{l}\text { No. of } \\
\text { samples }\end{array}$ & P-value & $\%$ & $\begin{array}{l}\text { No. of } \\
\text { samples }\end{array}$ & $\%$ & $\begin{array}{l}\text { No. of } \\
\text { samples }\end{array}$ & \\
\hline CLDN11 & 3 & 1 & 56 & 10 & $<0.001$ & 8 & 3 & 52 & 33 & $<0.001$ \\
\hline $\mathrm{CDH} 11$ & 0 & 0 & 50 & 9 & $<0.001$ & 8 & 3 & 45 & 29 & $<0.001$ \\
\hline PPP1R3C & 3 & 1 & 50 & 9 & $<0.001$ & 14 & 5 & 56 & 36 & $<0.001$ \\
\hline MAPK13 & 26 & 9 & 61 & 11 & 0.017 & 38 & 14 & 70 & 45 & 0.002 \\
\hline GNMT & 0 & 0 & 44 & 8 & $<0.001$ & 3 & 1 & 52 & 33 & $<0.001$ \\
\hline
\end{tabular}

Supplementary Table S5a. Methylation frequency of five candidate genes in dysplastic nevus and primary melanoma biopsy samples from series 1 based on gender of the patients. The dysplastic nevus and primary melanoma samples for which gender was known $(n=130)$ were grouped into male $(n=53)$ and female $(n=77)$ patients.

\begin{tabular}{|c|c|c|c|c|c|c|c|c|c|c|}
\hline & \multicolumn{4}{|c|}{ Male $(n=53)$} & \multicolumn{6}{|c|}{ Female $(n=77)$} \\
\hline & \multicolumn{2}{|c|}{$\begin{array}{l}\text { Dysplastic nevus } \\
(\mathrm{n}=25)\end{array}$} & \multicolumn{2}{|c|}{$\begin{array}{l}\text { Primary melanoma } \\
(\mathrm{n}=28)\end{array}$} & \multirow[b]{2}{*}{ P-value } & \multicolumn{2}{|c|}{$\begin{array}{l}\text { Dysplastic nevus } \\
(n=32)\end{array}$} & \multicolumn{3}{|c|}{$\begin{array}{l}\text { Primary } \\
(n=45)\end{array}$} \\
\hline & $\%$ & $\begin{array}{l}\text { No. of } \\
\text { samples }\end{array}$ & $\%$ & $\begin{array}{l}\text { No. of } \\
\text { samples }\end{array}$ & & $\%$ & $\begin{array}{l}\text { No. of } \\
\text { samples }\end{array}$ & $\%$ & $\begin{array}{l}\text { No. of } \\
\text { samples }\end{array}$ & P-value \\
\hline CLDN11 & $\overline{0}$ & 0 & 54 & 15 & $<0.001$ & 0 & 0 & 40 & 18 & $<0.001$ \\
\hline $\mathrm{CDH} 11$ & 0 & 0 & 39 & 11 & $<0.001$ & 9 & 3 & 36 & 16 & 0.014 \\
\hline PPP1R3C & 8 & 2 & 61 & 17 & $<0.001$ & 19 & 6 & 42 & 19 & 0.047 \\
\hline M APK13 & 16 & 4 & 64 & 18 & $<0.001$ & 34 & 11 & 58 & 26 & 0.064 \\
\hline GNMT & 0 & 0 & 61 & 17 & $<0.001$ & 19 & 6 & 33 & 15 & 0.199 \\
\hline
\end{tabular}


Supplementary Table S5b. Methylation frequency of five candidate genes in dysplastic nevus and primary melanoma biopsy samples from series 2 based on gender of the patients. The dysplastic nevus and primary melanoma samples for which gender was known $(n=153)$ were grouped into male $(n=76)$ and female $(n=77)$ patients.

\begin{tabular}{|c|c|c|c|c|c|c|c|c|c|c|}
\hline & \multicolumn{4}{|c|}{ Male $(n=76)$} & \multicolumn{6}{|c|}{ Female $(n=77)$} \\
\hline & \multicolumn{2}{|c|}{$\begin{array}{l}\text { Dysplastic nevus } \\
\qquad(\mathrm{n}=31)\end{array}$} & \multicolumn{2}{|c|}{$\begin{array}{l}\text { Primary melanoma } \\
\qquad(\mathrm{n}=45)\end{array}$} & \multirow[b]{2}{*}{ P-value } & \multicolumn{2}{|c|}{$\begin{array}{l}\text { Dysplastic nevus } \\
\qquad(n=40)\end{array}$} & \multicolumn{2}{|c|}{$\begin{array}{l}\text { Primary melanoma } \\
\qquad(\mathrm{n}=37)\end{array}$} & \multirow[b]{2}{*}{ P-value } \\
\hline & $\%$ & $\begin{array}{l}\text { No. of } \\
\text { samples }\end{array}$ & $\%$ & $\begin{array}{l}\text { No. of } \\
\text { samples }\end{array}$ & & $\%$ & $\begin{array}{l}\text { No. of } \\
\text { samples }\end{array}$ & $\%$ & $\begin{array}{l}\text { No. of } \\
\text { samples }\end{array}$ & \\
\hline CLDN11 & $\overline{10}$ & 3 & 53 & 24 & $<0.001$ & 3 & 1 & 51 & 19 & $<0.001$ \\
\hline $\mathrm{CDH} 11$ & 10 & 3 & 53 & 24 & $<0.001$ & 0 & 0 & 38 & 14 & $<0.001$ \\
\hline PPP1R3C & 16 & 5 & 60 & 27 & $<0.001$ & 3 & 1 & 49 & 18 & $<0.001$ \\
\hline MAPK13 & 55 & 17 & 73 & 33 & 0.140 & 15 & 6 & 62 & 23 & $<0.001$ \\
\hline GNMT & 3 & 1 & 56 & 25 & $<0.001$ & 0 & 0 & 43 & 16 & $<0.001$ \\
\hline
\end{tabular}

Supplementary Table S6a. Methylation frequency of five candidate genes in biopsy samples of series 2 (72 dysplastic nevi and 82 primary melanomas), together with the specificity and sensitivity of each gene for the distinction of primary melanoma samples from dysplastic nevus samples.

\begin{tabular}{|c|c|c|c|c|c|c|}
\hline \multicolumn{7}{|c|}{ Series 2 (test set) } \\
\hline & \multirow{2}{*}{\multicolumn{2}{|c|}{ Dysplastic nevus }} & \multirow{2}{*}{\multicolumn{2}{|c|}{ Primary melanoma }} & \multirow{2}{*}{\multicolumn{2}{|c|}{$\begin{array}{l}\text { Dysplastic nevus ( } n=72) \\
\text { Primary melanoma }(n=82)\end{array}$}} \\
\hline & & & & & & \\
\hline & \multicolumn{4}{|c|}{ Methylation frequency } & \multirow{2}{*}{ Specificity } & \multirow{2}{*}{ Sensitivity } \\
\hline & $\%$ & No. of samples & $\%$ & No. of samples & & \\
\hline CLDN11 & 6 & $4 / 72$ & 52 & $43 / 82$ & $94 \%$ & $52 \%$ \\
\hline $\mathrm{CDH} 11$ & 4 & $3 / 72$ & 46 & $38 / 82$ & $96 \%$ & $46 \%$ \\
\hline PPP1R3C & 8 & $6 / 72$ & 55 & $45 / 82$ & $92 \%$ & $55 \%$ \\
\hline MAPK13 & 32 & $23 / 72$ & 68 & $56 / 82$ & $68 \%$ & $68 \%$ \\
\hline GNMT & 1 & $1 / 72$ & 50 & $41 / 82$ & $99 \%$ & $50 \%$ \\
\hline
\end{tabular}

Supplementary Table S6b. Methylation frequency of five candidate genes in biopsy samples of series 1 and 2 (129 dysplastic nevi and 161 primary melanomas), together with the specificity and sensitivity of each gene for the distinction of primary melanoma samples from dysplastic nevus samples.

\begin{tabular}{|c|c|c|c|c|c|c|}
\hline \multicolumn{7}{|c|}{ Series 1 and 2 (training + test set) } \\
\hline & \multirow{2}{*}{\multicolumn{2}{|c|}{ Dysplastic nevus }} & \multirow{2}{*}{\multicolumn{2}{|c|}{ Primary melanoma }} & \multirow{2}{*}{\multicolumn{2}{|c|}{$\begin{array}{c}\text { Dysplastic nevus ( } n=129) \\
\text { Primary melanoma }(n=161)\end{array}$}} \\
\hline & & & & & & \\
\hline & \multicolumn{4}{|c|}{ Methylation frequency } & \multirow{2}{*}{ Specificity } & \multirow{2}{*}{ Sensitivity } \\
\hline & $\%$ & No. of samples & $\%$ & No. of samples & & \\
\hline CLDN11 & 3 & $4 / 129$ & 50 & $81 / 161$ & $97 \%$ & $50 \%$ \\
\hline $\mathrm{CDH} 11$ & 5 & $6 / 129$ & 43 & $70 / 161$ & $95 \%$ & $43 \%$ \\
\hline PPP1R3C & 11 & $14 / 129$ & 53 & $86 / 161$ & $89 \%$ & $53 \%$ \\
\hline MAPK13 & 29 & $38 / 129$ & 65 & $105 / 161$ & $71 \%$ & $65 \%$ \\
\hline GNMT & 5 & $7 / 129$ & 48 & $77 / 161$ & $95 \%$ & $48 \%$ \\
\hline
\end{tabular}


Supplementary Table S7a. Patients used for independent validation with BMCA.

\begin{tabular}{|c|c|c|}
\hline Characteristics & No. of Specimens & $\%$ \\
\hline \multicolumn{3}{|c|}{ All clinical Samples $(n=45)$} \\
\hline \multicolumn{3}{|l|}{ Specimen type } \\
\hline Common nevus & 10 & 22 \\
\hline Dysplastic nevus & 20 & 44 \\
\hline Primary melanoma & 15 & 33 \\
\hline \multicolumn{3}{|l|}{ Common nevus $(n=10)$} \\
\hline \multicolumn{3}{|l|}{ Gender } \\
\hline Male & 3 & 30 \\
\hline Female & 7 & 70 \\
\hline Mean age (years) & 37 & \\
\hline \multicolumn{3}{|l|}{ Dysplastic nevus ( $n=20)$} \\
\hline \multicolumn{3}{|l|}{ Gender } \\
\hline Male & 8 & 40 \\
\hline Female & 12 & 60 \\
\hline Mean age (years) & 41 & \\
\hline \multicolumn{3}{|l|}{ Location } \\
\hline Trunk & 15 & 75 \\
\hline Extremities & 5 & 25 \\
\hline \multicolumn{3}{|l|}{ Atypia } \\
\hline Mild & 10 & 50 \\
\hline Moderate & 7 & 35 \\
\hline Severe & 3 & 15 \\
\hline \multicolumn{3}{|c|}{ Primary melanoma $(n=15)$} \\
\hline \multicolumn{3}{|l|}{ Gender } \\
\hline Male & 7 & 47 \\
\hline Female & 8 & 53 \\
\hline Mean age (years) & 69 & \\
\hline \multicolumn{3}{|l|}{ Location } \\
\hline Head/neck & 1 & 7 \\
\hline Trunk & 5 & 33 \\
\hline Extremities & 9 & 60 \\
\hline \multicolumn{3}{|l|}{ Breslow thickness, mm } \\
\hline$<2.0$ & 7 & 47 \\
\hline $2.01-4.0$ & 5 & 33 \\
\hline$>4.0$ & 3 & 20 \\
\hline
\end{tabular}


Supplementary Table S7b. Independent validation with MSP series 1

\begin{tabular}{|c|c|c|}
\hline Characteristics & No. of Specimens & $\%$ \\
\hline \multicolumn{3}{|c|}{ All clinical Samples $(n=251)$} \\
\hline \multicolumn{3}{|l|}{ Specimen type } \\
\hline Common nevus & 62 & 25 \\
\hline Dysplastic nevus & 72 & 29 \\
\hline Primary melanoma & 101 & 40 \\
\hline Metastatic melanoma & 16 & 6 \\
\hline \multicolumn{3}{|l|}{ Common nevus ( $n=62)$} \\
\hline \multicolumn{3}{|l|}{ Gender } \\
\hline Male & 23 & 37 \\
\hline Female & 39 & 63 \\
\hline Mean age (years) & 33 & \\
\hline \multicolumn{3}{|l|}{ Location } \\
\hline Head/neck & 13 & 24 \\
\hline Trunk & 31 & 56 \\
\hline Extremities & 11 & 20 \\
\hline \multicolumn{3}{|l|}{ Dysplastic nevus ( $n=72$ ) } \\
\hline \multicolumn{3}{|l|}{ Gender } \\
\hline Male & 31 & 43 \\
\hline Female & 41 & 57 \\
\hline Mean age (years) & 46 & \\
\hline \multicolumn{3}{|l|}{ Location } \\
\hline Head/neck & 3 & 4 \\
\hline Trunk & 48 & 69 \\
\hline Extremities & 19 & 27 \\
\hline \multicolumn{3}{|l|}{ Atypia } \\
\hline Mild & 26 & 38 \\
\hline Moderate & 35 & 51 \\
\hline Severe & 8 & 12 \\
\hline \multicolumn{3}{|c|}{ Primary melanoma $(n=101)$} \\
\hline \multicolumn{3}{|l|}{ Gender } \\
\hline Male & 36 & 38 \\
\hline Female & 59 & 62 \\
\hline Mean age (years) & 63 & \\
\hline \multicolumn{3}{|l|}{ Location } \\
\hline Head/neck & 14 & 16 \\
\hline Trunk & 20 & 23 \\
\hline Extremities & 54 & 61 \\
\hline \multicolumn{3}{|l|}{ Breslow thickness, $\mathrm{mm}$} \\
\hline$<2.0$ & 32 & 35 \\
\hline $2.01-4.0$ & 24 & 26 \\
\hline$>4.0$ & 35 & 38 \\
\hline \multicolumn{3}{|c|}{ Metastatic melanoma $(n=16)$} \\
\hline \multicolumn{3}{|l|}{ Gender } \\
\hline Male & 6 & 38 \\
\hline Female & 10 & 63 \\
\hline Mean age (years) & 67 & \\
\hline
\end{tabular}


Supplementary Table S7c. Independent validation with MSP series 2

\begin{tabular}{|c|c|c|}
\hline Characteristics & No. of Specimens & $\%$ \\
\hline \multicolumn{3}{|c|}{ All clinical Samples ( $n=154)$} \\
\hline \multicolumn{3}{|l|}{ Specimen type } \\
\hline Dysplastic nevus & 72 & 47 \\
\hline Primary melanoma & 82 & 53 \\
\hline \multicolumn{3}{|l|}{ Dysplastic nevus $(n=72)$} \\
\hline \multicolumn{3}{|l|}{ Gender } \\
\hline Male & 31 & 44 \\
\hline Female & 40 & 56 \\
\hline Mean age (years) & 49 & \\
\hline \multicolumn{3}{|l|}{ Location } \\
\hline Head/neck & 5 & 7 \\
\hline Trunk & 47 & 69 \\
\hline Extremities & 16 & 24 \\
\hline \multicolumn{3}{|l|}{ Atypia } \\
\hline Mild & 20 & 28 \\
\hline Moderate & 36 & 51 \\
\hline Severe & 15 & 21 \\
\hline \multicolumn{3}{|c|}{ Primary melanoma $(n=82)$} \\
\hline \multicolumn{3}{|c|}{ Gender } \\
\hline Male & 45 & 55 \\
\hline Female & 37 & 45 \\
\hline Mean age (years) & 62 & \\
\hline \multicolumn{3}{|l|}{ Location } \\
\hline Head/neck & 18 & 23 \\
\hline Trunk & 24 & 30 \\
\hline Extremities & 38 & 48 \\
\hline \multicolumn{3}{|l|}{ Breslow thickness, mm } \\
\hline$<2.0$ & 23 & 29 \\
\hline $2.01-4.0$ & 24 & 31 \\
\hline$>4.0$ & 31 & 40 \\
\hline
\end{tabular}


Supplementary Table S8a. BMCA primers

\begin{tabular}{|c|c|c|c|c|c|c|}
\hline Gene & & Primer sequence & $\begin{array}{l}\text { CpG's in } \\
\text { Amplicon }\end{array}$ & $\begin{array}{c}\text { Position Relative } \\
\text { to TSS }\end{array}$ & $\begin{array}{l}\mathrm{Tm}\left({ }^{\circ} \mathrm{C}\right) \\
\text { Unmeth. }\end{array}$ & $\begin{array}{l}\mathrm{Tm}\left({ }^{\circ} \mathrm{C}\right) \\
\text { Meth. }\end{array}$ \\
\hline \multirow[t]{2}{*}{ HOXA9 } & $F$ & ATGGTTATTATTGGGGTTTTGGGGTAA & \multirow[t]{2}{*}{38} & \multirow{2}{*}{$74+$ to $416+$} & \multirow{2}{*}{80.8} & \multirow{2}{*}{85.6} \\
\hline & $\mathrm{R}$ & TAAACTCCAACCAAAAACGCATATAC & & & & \\
\hline \multirow{2}{*}{ clorf106 } & $\mathrm{F}$ & GGAATGAAAATTGGTTTTAGTTAGGTTAG & \multirow{2}{*}{30} & \multirow{2}{*}{337 - to 19 - } & \multirow{2}{*}{79.8} & \multirow{2}{*}{84.4} \\
\hline & $\mathrm{R}$ & CAAAАСАТСТАТССССТААААСАТАСС & & & & \\
\hline \multirow{2}{*}{ MAPK13 } & $\mathrm{F}$ & GAGGGAATTGGGAAGTATTGTTTT & \multirow{2}{*}{18} & \multirow{2}{*}{273 - to $90-$} & \multirow{2}{*}{81.8} & \multirow{2}{*}{86} \\
\hline & $\mathrm{R}$ & АACСTATCCAACCCTACGCTCC & & & & \\
\hline \multirow{2}{*}{ LEP } & $\mathrm{F}$ & TAGAGAAGGGGTGGGATTTTAGAATT & \multirow{2}{*}{28} & \multirow{2}{*}{566 - to 300 - } & \multirow{2}{*}{78.6} & \multirow{2}{*}{83} \\
\hline & $\mathrm{R}$ & AAACCAACCCCTTAAAAAAATACTTC & & & & \\
\hline \multirow{2}{*}{$\mathrm{CDH} 11$} & $\mathrm{~F}$ & GTCGTTGATTTGTGAATGGGAT & \multirow{2}{*}{8} & \multirow{2}{*}{$35+$ to $153+$} & \multirow{2}{*}{79.6} & \multirow{2}{*}{82.6} \\
\hline & $\mathrm{R}$ & САССТСАССТАAАAСССТTAAAAAT & & & & \\
\hline \multirow{2}{*}{ EFCAB1 } & $\mathrm{F}$ & GCGGGGTTTAGTTGTAGTTTTGGT & \multirow{2}{*}{28} & \multirow{2}{*}{146 - to $167+$} & \multirow{2}{*}{79.2} & \multirow{2}{*}{83.6} \\
\hline & $\mathrm{R}$ & АССТАТССААСАСТАСАТТСТТАСТТАСАА & & & & \\
\hline \multirow{2}{*}{ CNTN1 } & $\mathrm{F}$ & TAAGGTAGGACGGTAGTGTTTTAGAAGA & \multirow{2}{*}{9} & \multirow{2}{*}{$368+$ to $494+$} & 782 & 808 \\
\hline & $\mathrm{R}$ & ACCGAAACGATATAACATCCCTAAAAC & & & 10.2 & 00.0 \\
\hline GNMT & $\mathrm{F}$ & GATTTTAGGGGATGGAGTGGTAATT & 18 & 335 & 798 & 826 \\
\hline & $\mathrm{R}$ & ACAACCCCACCTAACCAATAACAAAT & & 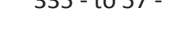 & & \\
\hline ABCA3 & $\mathrm{F}$ & TTTCGTATTGCGGGTAGTGTTTGA & 10 & 43 & 794 & 832 \\
\hline 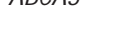 & $\mathrm{R}$ & TACATATCCACCTTCTAAACGCACAC & 10 & $435+\tau$ & 19.4 & 83.2 \\
\hline PLEKHG6 & $\mathrm{F}$ & AGGGTATCGTTACGTGAGTTGTTTT & 20 & 103 & & \\
\hline & $\mathrm{R}$ & CCCGATACCCAACCTAAAACTAAAAT & 20 & $103+$ & 81.6 & 85.2 \\
\hline PPP1R3C & $\mathrm{F}$ & GTTTTAGTTGGGCGTTGGTTG & 14 & 84 & 811 & 85 \\
\hline & $\mathrm{R}$ & AACCACAACTCCAAACCTTACCC & 14 & $84-$ to & 81.4 & 85 \\
\hline CLDN11 & $\mathrm{F}$ & GTATTTGGGTAGGTATTGTTTAGTTTAGG & 10 & $112+$ to $291+$ & 80.4 & 832 \\
\hline & $\mathrm{R}$ & CAАATСАССАСССААТСАТТААТАAА & & $112+10291+$ & & \\
\hline
\end{tabular}

Supplementary Table S8b. MSP primers

\begin{tabular}{|c|c|c|c|c|c|}
\hline Gene & & Sense primer $\left(5^{\prime}->3^{\prime}\right)$ & Antisense primer $\left(3^{\prime}->5^{\prime}\right)$ & $\begin{array}{c}\text { Annealing } \mathrm{T} \\
\left({ }^{\circ} \mathrm{C}\right)\end{array}$ & $\begin{array}{c}\text { No. of } \\
\text { PCR } \\
\text { cycles }\end{array}$ \\
\hline \multirow{3}{*}{ M APK13 } & Flank & GGGAATTGGGAAGTATTGTTTT & CCRAACCTATCCAACCCTAC & 56 & 30 \\
\hline & U & GATTTATTAGTTTTGTTGTTGGTTTGT & СТАТССААСССТАСАСТСССАСА & 68 & 30 \\
\hline & M & ATTAGTTTCGTCGTTGGTTCGC & AACCCTACGCTCCCGCG & 68 & 30 \\
\hline \multirow{3}{*}{$\mathrm{CDH} 11$} & Flank & GYGGGTYGAGGAGTAGATGT & TCACCTAAAACCCTTAAAAATAAA & 56 & 30 \\
\hline & U & TGTGGGGGTTGTTTGTAGTTGTT & AAAATAAACACAACCTCCAAACCA & 68 & 25 \\
\hline & M & GGGGGTCGTTCGTAGTCGTC & AACGCAACCTCCGAACCG & 68 & 25 \\
\hline \multirow{3}{*}{ GNMT } & Flank & GGGTTAAGTGGGTAGAGGGTT & GGGTTAAGTGGGTAGAGGGTT & 56 & 30 \\
\hline & U & GGTTTTGAGGGTTTTTTTTTTGTT & CCAAACTTTAAACCAAACACCCA & 68 & 30 \\
\hline & M & GTTTCGAGGGTTTTTTTTTCGTC & ACTTTAAACCGAACGCCCG & 68 & 30 \\
\hline \multirow{3}{*}{ PPP1R3C } & Flank & GTYGTTTTAAGTTTGAGGTATTGG & AAACRTACAAAAAACTATCTAAACATC & 56 & 30 \\
\hline & U & AGGTATTGGTGTTTTGTTTGGGT & ACCAACTAAAACCAACCACATAACA & 66 & 30 \\
\hline & M & TGGCGTTTCGTTTGGGC & ACTAAAACCAACCGCGTAACG & 66 & 30 \\
\hline \multirow{3}{*}{ CLDN11 } & Flank & GGTATTGTTTAGTTTAGGTTTAGGTAT & ACCCAATCATTAATAAAАATAАТСАС & 56 & 30 \\
\hline & U & AGGTATAGTTGTGAGGGGTGAGGTAT & - CCAATCCAACCCACAAAACTCA & 66 & 30 \\
\hline & M & TAGTCGTGAGGGGCGAGGTAC & GATCCAACCCACGAAACTCG & 66 & 30 \\
\hline
\end{tabular}




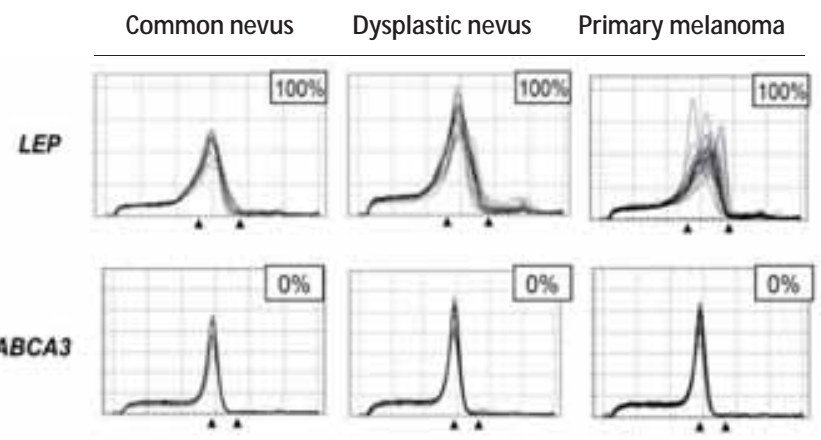

Supplementary Figure S1. LEP and ABCA3 promoter methylation status in 20 dysplastic nevi, next to an independent set of 10 common nevi and 15 primary melanomas as analyzed by bisulphite melting curve analysis (BMCA). Black triangles indicate position of the melting curve peak for the respective positive (fully methylated) and negative (fully unmethylated) control. 


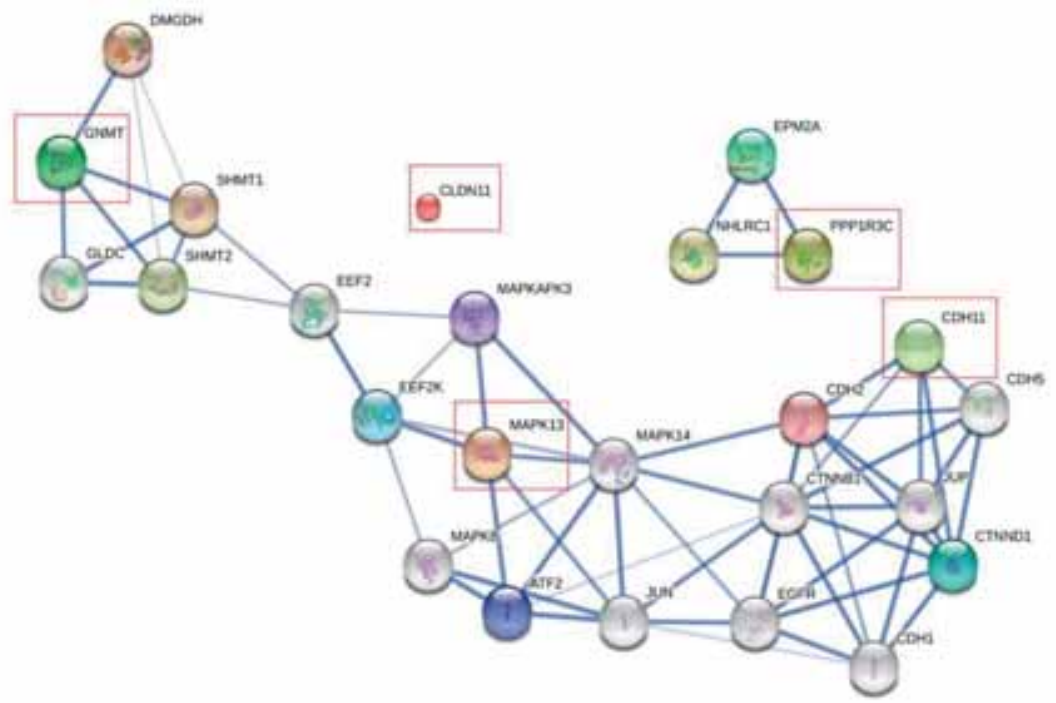

GO Biological Processes*

\begin{tabular}{llcc}
\hline GO ID & Term & Number of genes & P-value FDR \\
\hline GO:0034332 & adherens junction organization & 6 & $6.99 \mathrm{E}-7$ \\
GO:0016337 & cell-cell adhesion & 6 & $4.65 \mathrm{E}-3$ \\
GO:0045216 & cell-cell junction organization & 5 & $4.65 \mathrm{E}-3$ \\
GO:0034329 & cell junction assembly & 5 & $4.65 \mathrm{E}-3$ \\
GO:0034330 & cell junction organization & 5 & $4.65 \mathrm{E}-3$ \\
GO:0000165 & MAPK cascade & 5 & $4.28 \mathrm{E}-2$ \\
GO:0032880 & regulation of protein localization & 5 & $4.65 \mathrm{E}-3$ \\
GO:0035666 & TRIF-dependent toll-like receptor signaling pathway & 4 & $4.65 \mathrm{E}-3$ \\
GO:0034138 & toll-like receptor 3 signaling pathway & 4 & $4.65 \mathrm{E}-3$ \\
GO:0002756 & MyD-88independent toll-like receptor signaling pathway & 4 & $4.65 \mathrm{E}-3$ \\
GO:0034130 & toll-like receptor 1 signaling pathway & 4 & $4.65 \mathrm{E}-3$ \\
GO:0034134 & toll-like receptor 2 signaling pathway & 4 & $4.65 \mathrm{E}-3$ \\
GO:0002755 & MyD-88dependent toll-like receptor signaling pathway & 4 & $4.65 \mathrm{E}-3$ \\
GO:0034142 & toll-like receptor 4 signaling pathway & 4 & $4.65 \mathrm{E}-3$ \\
GO:0008063 & Toll signaling pathway & 4 & $4.65 \mathrm{E}-3$ \\
GO:0043406 & positive regulation of MAP kinase activity & 4 & $4.28 \mathrm{E}-2$ \\
\hline
\end{tabular}

*Only biological processes with 4 or more involved genes and P-value $<0.05$ are listed

GO Molecular Functions*

\begin{tabular}{|c|c|c|c|}
\hline GO ID & Term & Number of genes & P-value FDR \\
\hline GO:0019903 & protein phosphatase binding & 5 & $2.33 \mathrm{E}-4$ \\
\hline GO:0019902 & phosphatase binding & 5 & 1.19E-3 \\
\hline GO:0042153 & RPTP-like protein binding & 4 & $1.24 \mathrm{E}-7$ \\
\hline GO:0019842 & vitamin binding & 4 & $2.55 \mathrm{E}-2$ \\
\hline GO:0008168 & methyltransferase activity & 4 & 4.37E-2 \\
\hline GO:0004708 & MAP kinase kinase activity & 3 & $1.73 \mathrm{E}-3$ \\
\hline GO:0008732 & L-allo-threonine aldolase activity & 2 & $1.73 \mathrm{E}-3$ \\
\hline GO:0016832 & aldehyde-lyase activity & 2 & $8.88 \mathrm{E}-3$ \\
\hline
\end{tabular}

*Only molecular functions with P-value $<0.05$ are listed

Supplementary Figure S2. Interaction network analysis of CLDN11, CDH11, PPP1R3C, MAPK13 and GNMT Predicted physical or functional associations are depicted by blue lines. Stronger associations are represented by thicker lines. 


\section{CHAPTER 6}

\section{Prognostic significance of promoter hypermethylation and diminished gene expression of SYNPO2 in melanoma}

Linda Gao*, Karin van den Hurk*, Jérémie Nsengimana*, Jon P. Laye, Joost J. van den Oord, Samuel Beck, Nelleke A. Gruis, Wim H. Zoutman, Manon van Engeland, Julia A. Newton-Bishop, Véronique J.L. Winnepenninckx, Remco van Doorn 
Once cutaneous melanoma metastasizes prognosis of patients is generally poor in spite of recent therapeutic advances. Prognostic biomarkers are needed to better identify those patients with primary melanoma who are at increased risk of metastatic disease. Gene expression signatures have been defined that are associated with metastatic capacity of primary melanoma and survival ${ }^{1,2}$. Genomic characterization has revealed diverse recurrent genetic alterations including those that drive the tumorigenic process, still the underlying molecular changes that confer melanoma cells the capacity to migrate and colonize distant body sites remain to be defined. Promoter CpG island hypermethylation constitutes a major mechanism responsible for deregulated expression of genes involved in metastasis ${ }^{3-5}$. We and others have identified epigenetic alterations in melanoma affecting genes with a potential role in tumour cell dissemination including $\mathrm{CDH} 11$ and SERPINB5 $5^{3,4,6,7}$. Additionally a 17-gene methylation signature was found to predict disease course of stage IIIC melanoma patients ${ }^{8}$. As epigenetic biomarker for metastasis, promoter hypermethylation has the advantage that it is stable and can be reliably detected in clinical samples. The purpose of this study was to identify methylation events that can predict development of lethal metastatic disease in patients with primary cutaneous melanoma.

To this end, we collected clinical follow-up data of 24 patients with primary melanoma whose tumors had been previously subjected to genome-wide Illumina Infinium HumanMethylation27K profiling, analyzing the methylation status of 14,495 genes ${ }^{4}$. Thirteen patients had developed distant metastases, all of whom died due to melanoma, and in 11 patients no metastatic dissemination or tumor recurrence had been detected during a follow-up period of at least six years after diagnosis. We compared the methylation profiles from primary melanomas of patients who developed lethal distant organ metastasis $(\mathrm{M}+)$ to those from primary melanomas of patients who had not developed metastasis (M-). CpG probes with an average $\beta$-value difference (a measure of differential DNA methylation reflecting fluorescence intensity ratios between methylated and unmethylated alleles) higher than 0.20 between $\mathrm{M}+$ and $\mathrm{M}$ - primary melanomas were considered indicative of hypermethylation of the corresponding gene promoter region. This re-analysis yielded six candidate hypermethylated genes in melanoma with metastatic behavior ( $\mathrm{M}+)$ : M CHR1, SYNPO2, Clorf106, HIST1H3G, ZNF35, and GNMT (Figure 1A). We did not find genes hypomethylated in melanoma with metastatic behavior $(\mathrm{M}+)$. Validation of these six genes in an independent series of 20 fresh-frozen $\mathrm{M}+$ primary melanomas and $25 \mathrm{M}$ primary melanomas using bisulphite melting curve analysis showed promoter hypermethylation of MCHR1 and SYNPO2 to be associated with metastatic behavior (Supplementary Table S1). We proceeded with promoter methylation analysis of MCHR1 and SYNPO2 in an independent series of 113 formalin-fixed paraffin-embedded (FFPE) primary invasive cutaneous melanoma samples with available melanomaspecific survival data using methylation-specific PCR (methods are described in Supplementary Material; sample characteristics can be found in Supplementary Table S2a-c). This demonstrated for the MCHR1 promoter a gradual, but not absolute 
methylation difference between metastatic and non-metastatic melanoma samples, precluding its use as prognostic biomarker. There was however a marked difference in methylation of the SYNPO2 promoter between metastatic and non-metastatic melanomas (Figure 1B). Primary melanomas with SYNPO2 promoter hypermethylation had a significantly shorter survival (hazards ratio for melanoma-related death 2.01, 95\% confidence interval 1.06-3.82; $\mathrm{P}<0.034$ in univariate analysis) (Figure 2A, Supplementary Table S2). Importantly, SYNPO2 promoter hypermethylation remained a statistically significant prognostic factor after adjusting for tumor thickness (hazards ratio for melanoma-related death 2.02, 95\% confidence interval 1.05-3.89, P<0.034 in multivariate analysis) (Supplementary Table S2). When considering tumor thickness, age (as continuous variables), gender and ulceration as covariates in multivariate analysis, still an association of SYNPO2 methylation and reduced melanoma-specific survival was observed that did not reach statistical significance in this sample series (Supplementary Table S2).

A.

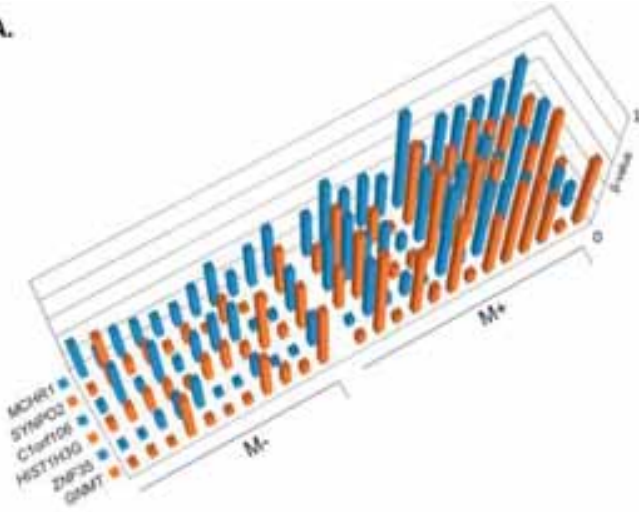

B.

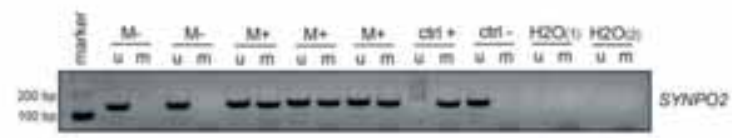

Figure 1. Differential promoter methylation in primary melanomas with different metastatic outcome. A. Methylation profiles of primary melanomas from patients who developed lethal distant organ metastasis $(M+, n=13)$ were compared to those from patients who had not developed metastasis $(M-, n=11)$, yielding six genes with average $\beta$-value difference higher than 0.20. B. SYNPO2 amplification products from MSP are shown for two $\mathrm{M}$ - primary melanomas and three $\mathrm{M}+$ primary melanomas. $\mathrm{u}$, unmethylated; $\mathrm{m}$, methylated; ctrl +, positive control (lymphocyte DNA treated with Sss1 methyltransferase); ctrl -, negative control (DNA from human umbilical vein endothelial cells); $\mathrm{H} 2 \mathrm{O}(1)$, no template control for first amplification with flanking primers; $\mathrm{H} 2 \mathrm{O}(2)$, no template control for second amplification with primers specific for methylated and unmethylated DNA. 

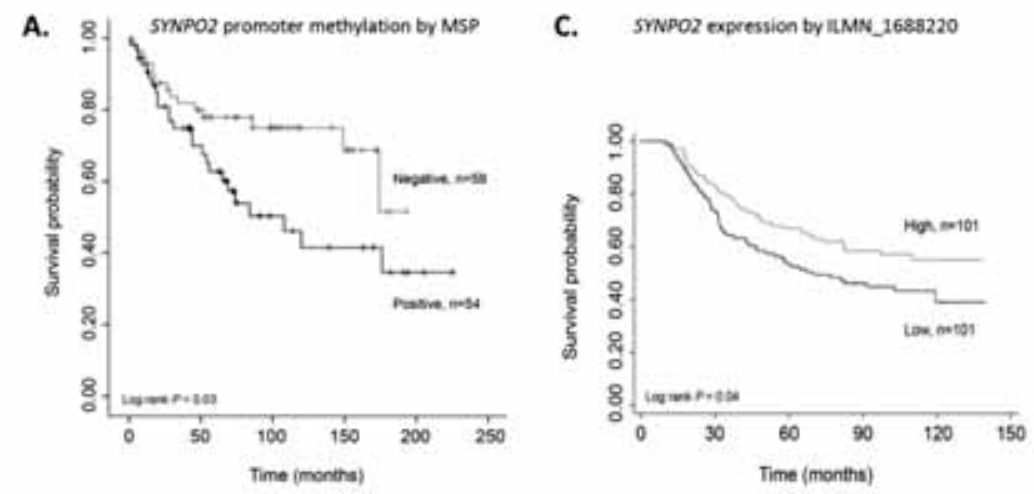

B.

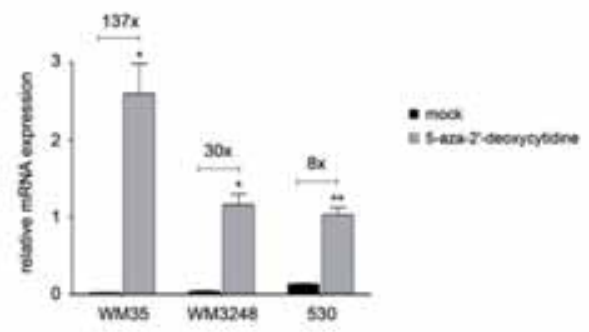

Figure 2. STNO2 promoter methylation and expression status are associated with survival outcome. A. Kaplan-Meier estimate of the survival function for melanoma-related death (death event=1) by SYNPO2 promoter methylation status was calculated and plotted against TTDOLC (time until dead or last contact (months)). Grey line, primary melanomas scored as negative for SYNPO2 promoter methylation using MSP; black line, primary melanomas scored as positive for SYNPO2 promoter methylation. $\mathrm{P}<0.05$ from Logrank test was considered significant. B. Relative SYNPO2 mRNA expression in melanoma cell lines WM35, WM3248 and 530 treated with either mock or $5 \mu \mathrm{M}$ 5-aza-2'-deoxycytidine for 96 hours. Expression levels were analysed in duplicate. ${ }^{*} \mathrm{P}<0.05 ;{ }^{*} \mathrm{P}<0.01$. C. Kaplan-Meier estimate of the survival function for melanoma-related death by probe ILMN_1688220 measuring SYNPO2 expression in 202 primary melanomas from the Leeds Melanoma cohort. Grey line, primary melanomas with high SYNPO2 expression; black line, primary melanomas with low SYNPO2 expression. P $<0.05$ from Logrank test was considered significant.

SYNPO2 promoter methylation has been demonstrated to be associated with transcriptional repression ${ }^{9}$. Demethylation of three SYNPO2-methylated melanoma cell lines resulted in reactivation of expression in 5-aza-2'-deoxycytidine treated cells, as opposed to those mock treated, providing evidence for a direct link between promoter methylation and transcriptional regulation in melanoma (Figure 2B, Supplementary Figure S1). To examine if SYNPO2 gene expression levels provided prognostic information and to support a role for epigenetic silencing of this gene in acquisition of metastatic behavior, we investigated its expression in 202 primary melanomas from The Leeds Melanoma cohort and tested correlation with melanoma-specific survival $^{2,10}$. Illumina DASL HT12 v4 arrays were used to measure whole genome gene expression in FFPE tumors and after quantile normalization melanoma-specific survival 
analysis was conducted (methods are described in Supplementary Material; sample characteristics can be found in Supplementary Table S2d). Two SYNPO2 probes were available on the array (ILMN_1688220 and ILMN_1730218). The association of low expression with shorter melanoma-specific survival was statistically significant for ILMN_1688220 before and after adjusting for age, gender and tumor thickness in Cox proportional hazards regression (hazards ratio for melanoma-related death 2.04, 95\% confidence interval 1.08-3.85, $\mathrm{P}<0.04$ ) (Figure 2D, Supplementary Table S4). The ILMN_1730218 probe showed a similar trend in association with melanoma-specific survival although it did not reach statistical significance after adjusting for covariates (Supplementary Table S3). These gene expression data are therefore consistent with an association between SYNPO2 silencing by promoter methylation and shorter survival. SYNPO2 has multiple isoforms, which may explain a weaker association found for one of the probes ${ }^{11}$.

Together these results demonstrate that SYNPO2 hypermethylation and diminished expression are associated with shorter melanoma-specific survival. Moreover, we found that prognostic significance of SYNPO2 hypermethylation and gene expression was independent of tumor thickness. In line with our observations in melanoma, SYNPO2 methylation was found to associate with tumor aggressiveness and poor clinical outcome in patients with bladder and colon cancer ${ }^{12,13}$. A frequently deleted region encompassing locus 4 q26 with SYNPO2 was identified in prostate cancer biopsies and coincided with highly invasive tumors ${ }^{14}$. More recently, genome-wide association studies (GWAS) identified $4 \mathrm{q} 26$ as one of six new susceptibility loci in BRCA1 and BRCA2 mutation carriers at high risk of epithelial ovarian cancer ${ }^{15}$. SYNPO2 encodes myopodin (synaptopodin 2), a member of synaptopodin family of actinbinding proteins. Human myopodin is found in human skeletal muscle, and in prostate cancer cells it colocalizes with actin filaments ${ }^{11,16}$. SYNPO2 generates multiple isoforms via alternative splicing and promoter usage that were found to either promote or suppress migration of prostate cancer cells, depending on nature of the migration stimulus ${ }^{17,18}$. This may explain why observations indicative of tumor suppression, but also in favor of tumor formation, were made in studies performed to delineate human myopodin function ${ }^{19-21}$. The end effect of myopodin on cell migration and invasion (either inhibiting or promoting), may be the result of inducing distinct changes in the actin cytoskeleton architecture by different isoforms ${ }^{18}$. The potential involvement of SYNPO2 in melanoma cell dissemination deserves further examination. The clinical value of SYNPO2 methylation in predicting metastatic behavior of primary melanoma should be addressed in larger prospective studies, possibly combined with other candidate epigenetic markers. 


\section{Acknowledgments}

R.v.D. is supported by a Melanoma Research Alliance young investigator award. V.W. and K.v.d.H. are supported by Profileringsfonds Maastricht University Medical Center (PF=278). J.N., J.L. and J.N.B. are funded by CRUK Programme grant C588/A19167. 


\section{References}

1. Winnepenninckx V, Lazar V, Michiels S, et al. Gene expression profiling of primary cutaneous melanoma and clinical outcome. J Natl Cancer Inst, 2006. 98(7): p. 472-482.

2. Conway C, Mitra A, Jewell R, et al. Gene expression profiling of paraffin-embedded primary melanoma using the DASL assay identifies increased osteopontin expression as predictive of reduced relapse-free survival. Clin Cancer Res, 2009. 15(22): p. 6939-6946.

3. Carmona FJ, Villanueva A, Vidal A, et al. Epigenetic disruption of cadherin-11 in human cancer metastasis. J Pathol, 2012. 228(2): p. 230-240.

4. Gao L, Smit MA, van den Oord JJ, et al. Genome-wide promoter methylation analysis identifies epigenetic silencing of MAPK13 in primary cutaneous melanoma. Pigment Cell Melanoma Res, 2013. 26(4): p. 542-554.

5. Tanemura A, Terando AM, Sim MS, et al. CpG island methylator phenotype predicts progression of malignant melanoma. Clin Cancer Res, 2009. 15(5): p. 1801-1807.

6. Dahl C, Abildgaard C, Riber-Hansen R, et al. KIT is a frequent target for epigenetic silencing in cutaneous melanoma. J Invest Dermatol, 2015. 135(2): p. 516-524.

7. Denk AE, Bettstetter M, Wild PJ, et al. Loss of maspin expression contributes to a more invasive potential in malignant melanoma. Pigment Cell Res, 2007. 20(2): p. 112-119.

8. Sigalotti L, Covre A, Fratta E, et al. Whole genome methylation profiles as independent markers of survival in stage IIIC melanoma patients. J TransI Med, 2012. 10: p. 185.

9. Cebrian V, Alvarez M, Aleman A, et al. Discovery of myopodin methylation in bladder cancer. J Pathol, 2008. 216(1): p. 111-119.

10. Jewell R, Elliott F, Laye J, et al. The clinicopathological and gene expression patterns associated with ulceration of primary melanoma. Pigment Cell Melanoma Res, 2015. 28(1): p. 94-104.

11. De Ganck A, De Corte V, Staes A, et al. Multiple isoforms of the tumor suppressor myopodin are simultaneously transcribed in cancer cells. Biochem Biophys Res Commun, 2008. 370(2): p. 269-273.

12. Alvarez-Mugica M, Cebrian V, Fernandez-Gomez JM, et al. Myopodin methylation is associated with clinical outcome in patients with T1G3 bladder cancer. J Urol, 2010. 184(4): p. 1507-1513.

13. Esteban S, Moya P, Fernandez-Suarez A, et al. Diagnostic and prognostic utility of methylation and protein expression patterns of myopodin in colon cancer. Tumour Biol, 2012. 33(2): p. 337-346.

14. Lin F, Yu YP, Woods J, et al. Myopodin, a synaptopodin homologue, is frequently deleted in invasive prostate cancers. Am J Pathol, 2001. 159(5): p. 1603-1612.

15. Kuchenbaecker KB, Ramus SJ, Tyrer J, et al. Identification of six new susceptibility loci for invasive epithelial ovarian cancer. Nat Genet, 2015. 47(2): p. 164-171.

16. Weins A, Schwarz K, Faul C, et al. Differentiation- and stress-dependent nuclear cytoplasmic redistribution of myopodin, a novel actin-bundling protein. Journal of Cell Biology, 2001. 155(3): p. 393-403.

17. Kai F, Tanner K, King C, et al. Myopodin isoforms alter the chemokinetic response of PC3 cells in response to different migration stimuli via differential effects on Rho-ROCK signaling pathways. Carcinogenesis, 2012. 33(11): p. 2100-2107.

18. Kai F, Duncan R. Prostate cancer cell migration induced by myopodin isoforms is associated with formation of morphologically and biochemically distinct actin networks. FASEB J, 2013. 27(12): p. 5046-5058.

19. Jing L, Liu L, Yu YP, et al. Expression of myopodin induces suppression of tumor growth and metastasis. Am J Pathol, 2004. 164(5): p. 1799-1806.

20. De Ganck A, De Corte V, Bruyneel E, et al. Down-regulation of myopodin expression reduces invasion and motility of PC-3 prostate cancer cells. Int J Oncol, 2009. 34(5): p. 1403-1409.

21. Yu YP, Luo JH. Phosphorylation and interaction of myopodin by integrin-link kinase lead to suppression of cell growth and motility in prostate cancer cells. Oncogene, 2011. 30(49): p. 4855-4863. 


\section{Supplementary information}

\section{Materials and methods}

\section{Patient samples}

For first validation of our findings in 24 patients with primary melanoma (Supplementary Table S2a) previously subjected to genome-wide Illumina Infinium HumanMethylation27K profiling, BFPE (fixed-in-boonfix and paraffin-embedded) biopsy samples from 45 patients diagnosed with primary melanoma were used (Supplementary Table S2b). For further assessment of M CHR1 and SYNPO2 promoter methylation status and survival analysis, we examined formalin-fixed, paraffinembedded (FFPE) tissues from patients diagnosed with primary melanoma $(n=113)$ at the Maastricht University Medical Center (MUMC), the Netherlands, and University Hospitals of the University of Leuven (KUL), Belgium (Supplementary Table S2c). Excised tumor biopsies were reviewed by an expert dermatopathologist and tissues were processed as previously described ${ }^{1}$; biopsy samples contained at least $50 \%$ melanocytic cells as analyzed on H\&E-stained sections. Collection, storage and use of all tissues and patient data were performed in agreement with the "Code for Proper Secondary Use of Human Tissue in the Netherlands". Informed consent from patients was not obtained as the corresponding data were de-linked and anonymized.

\section{Comparative analysis of Infinium HumanM ethylation27K data}

Average $ß$-value for each probe on the Beadchip was calculated for primary melanoma from patients that developed distant metastases $(M+, n=13)$ and for primary melanoma from patients where no metastatic dissemination or tumor recurrence was detected $(M-, n=11)$ during a follow-up period of at least six years after diagnosis. Comparison of methylation profiles between $\mathrm{M}+$ and $\mathrm{M}$ - primary melanomas was performed by subtraction of average $\beta$-values of $M$ - group from $M+$ group ( $\beta$-value $\mathrm{M}_{\mathrm{H}}$ $\beta$-value $\mathrm{M}_{\mathrm{-}}$ ). Most interrogated gene promoter regions were represented by two to three probes per gene on the Infinium HumanMethylation27K Beadchip. For comparative analysis, the probe with highest $\beta$-value difference was considered; those probes with an average $\beta$-value difference higher than 0.20 between $\mathrm{M}+$ and $\mathrm{M}$ primary melanomas were considered indicative of hypermethylation of the corresponding gene promoter region.

\section{DNA isolation and bisulphite conversion}

Genomic DNA from FF and BFPE tissues was extracted with the Genomic-tip kit (Qiagen, Venlo, The Netherlands) and RecoverAll Nucleic Acid kit (Ambion, Carlsbad, CA) respectively; DNA from FFPE tissues was extracted by macro dissection with the QIAamp DNA Micro Kit (Qiagen, Venlo, The Netherlands). Bisulphite conversion was 
performed using either the EZ DNA methylation kit (Zymo Research, Orange, CA) or the EpiTect Bisulphite Kit (Qiagen, Venlo, The Netherlands).

Bisulphite melting curve analysis (BM CA)

For design of primers for BMCA, location of the CPG island within gene promoter region was based on prediction by EMBOSS Cpgplot (http://www.ebi.ac.uk/Tools/seqstats/emboss_cpgplot/) or UCSC Genome Browser assembly GRChr37 (http://genome-euro.ucsc.edu). For each candidate gene, sequence of promoter region and first exon are based on SYNPO2 isoform a NM_133477, SYNPO2-201 (ENST00000307142); MCHR1 transcript NM_005297, MCHR1-001 (ENST00000249016); Clorf106 transcript NM_018265, C1orf106-001 (ENST00000367342); HIST1H3G transcript NM_003534, HIST1H3G-001 (ENST00000614378); ZNF35 transcript NM_003420, ZNF35-001 (ENST00000396056), and GNMT transcript NM_018960, GNMT-001 (ENST00000372808), respectively. Primers for BMCA were designed and sensitivity of primer sets was tested as previously described ${ }^{2}$. Primer details and genomic position can be found in Supplementary Table S5a, with depiction of each primer amplicon within interrogated gene promoter regions in Supplementary Figure S2. Methylation could be accurately detected if $10 \%$ of the analyzed DNA was methylated. Melting curves were generated for each melanoma biopsy sample; a sample was considered methylated if the amplicon had at least $10 \%$ methylated DNA, with the melting curve pattern of a 1:9 methylated to unmethylated DNA mixture serving as scoring standard.

Methylation-specific polymerase chain reaction (M SP)

MSP analysis using MSP primers on bisulphite-treated DNA was performed as previously described $^{3,4}$. Details of MSP primers interrogating SYNPO2 promoter region can be found in Supplementary Table S5b and Supplementary Figure S2. To facilitate MSP analysis on DNA retrieved from FFPE tissue, DNA was first amplified with flanking PCR primers used as template for the PCR reaction. All PCRs were performed with controls for unmethylated alleles (DNA from human umbilical vein endothelial cells (HUVEC), methylated alleles (normal lymphocyte DNA treated in vitro with Sssl methyltransferase (IVD)), and a control without DNA. To ensure reproducibility, MSP reactions have been performed in duplicate or triplicate starting from DNA amplification with flanking PCR primers. Nonconcordant MSP results were analyzed a third time and two out of three concordance was used as end result.

Leeds melanoma cohort expression profiling

Expression data were generated in three batches from 204 primary tumors from Leeds Melanoma Cohort (LMC, ethical approval MREC 1/3/57, PIAG 3-09(d)/2003). Histopathological information was available for the majority of samples and cause of 
death was available for all but two patients who have died (Supplementary Table S2d). The mRNA was extracted from the tumor cores following a previously described protocol $^{5,6}$ and whole genome gene expression was quantified using Illumina DASL HT12 v4 array. GenomeStudio was used to extract raw data from image files after which background correction and quantile normalisation were conducted using Lumi package in R. SYNPO2 gene had two probes on the array: ILMN_1688220 and ILMN_1730218.

Cell lines, drug treatment, and SYNPO2 expression analysis

Three melanoma cell lines (WM35, WM3248 and 530) provided by Dr. Léon van Kempen (McGill University, Montreal, Canada) were used to examine direct association between SYNPO2 methylation and expression. WM35 and WM3248 were cultured in W489 medium consisting of four parts of MCDB153 (Sigma-Aldrich, Zwijndrecht, The Netherlands) and one part of L15 (Sigma-Aldrich, Zwijndrecht, The Netherlands). Cell line 530 was cultured in Dulbecco's modified Eagle's medium (Invitrogen, Breda, the Netherlands). Cells were supplemented with $2 \%$ or $10 \%$ heat inactivated fetal calf serum (Hyclone Perbio Science, Erembodegem-Aalst, Belgium), respectively. All melanoma cell lines were treated with 5'aza-2-deoxycytidine to inhibit DNA methylation. Approximately $10 \%$ confluent cells were cultured in media containing 5 $\mu \mathrm{M}$ 5'aza-2-deoxycytidine (Sigma-Aldrich, Zwijndrecht, The Netherlands; stock solution: $1 \mathrm{mM}$ in PBS) for 96 hours, replacing media and 5'aza-2-deoxycytidine every 24 hours. Mock treated cells were grown in parallel with 5'aza-2-deoxycytidine treatment by addition of equal volumes of PBS without drugs. RNA of mock-, and 5'aza-2-deoxycytidine-treated cells was isolated using Sigma's GenElute Mammalian Total RNA Kit (Sigma-Aldrich, Zwijndrecht, The Netherlands) according to manufacturers' instructions.

For quantitative real-time PCR (qPCR), complementary DNA (cDNA) was synthesized by using the iScript ${ }^{\mathrm{TM}}$ cDNA Synthesis kit (Biorad, Veenendaal, The Netherlands) according to manufacturer's instructions. qPCR was performed with iQ SYBR Green Supermix (Bio-Rad) on a CFX384 Touch Real-Time Detection System (Bio-Rad). qPCR primers were designed to span exon-exon barriers and were successfully tested for amplification efficiency. Details of primers and amplification efficiencies for SYNPO2 and the stably expressed reference genes TBP and CPSF6 can be found in Supplementary Table S5c. TBP and CPSF6 expression was validated using geNorm analysis ${ }^{7}$. Data were normalized according to $\Delta \Delta \mathrm{Cq}$ method ${ }^{8}$ and presented as relative mRNA expression.

Statistical analyses

$2 \times 2$ Contingency Table was used to obtain odds ratio and to perform Pearson's chisquare test of association between promoter methylation status as measured by 
BMCA, and presence or absence of distant metastases as indicated by patient data, $\mathrm{P}<0.05$ was considered significant.

Survival analyses of SYNPO2 methylation data as measured by MSP were performed in SPSS 21 (IBM Corp, Armonk, NY, USA). SYNPO2 promoter methylation status (positive $=1$, negative $=0$ ) was analyzed with Cox proportional hazards regression, unadjusted and then adjusting tumour thickness $(\mathrm{mm})$, age (years), and gender (male $=0$, female=1). Curves of Kaplan-Meier estimates of the survival function for melanoma-related death (death event $=1$ ) by SYNPO2 promoter methylation status were plotted against TTDOLC (time till dead or last contact (months)), $\mathrm{P}<0.05$ was considered significant.

Survival analyses of Illumina DASL HT12 v4 array data were conducted in STATA 12. Log2(expression) was analysed with Cox proportional hazards regression, unadjusted and then adjusting tumour thickness, age and gender. Kaplan-Meier curves were plotted dichotomising the expression relative to the median. All regression analyses (adjusted and unadjusted) additionally controlled the batch effect. 


\section{References: Materials and methods}

1. Winnepenninckx V, Lazar V, Michiels S, et al. Gene expression profiling of primary cutaneous melanoma and clinical outcome. J Natl Cancer Inst, 2006. 98(7): p. 472-482.

2. Gao L, Smit MA, van den Oord JJ, et al. Genome-wide promoter methylation analysis identifies epigenetic silencing of MAPK13 in primary cutaneous melanoma. Pigment Cell Melanoma Res, 2013. 26(4): p. 542-554.

3. Derks S, Lentjes MH, Hellebrekers DM, et al. Methylation-specific PCR unraveled. Cell Oncol, 2004. 26(5-6): p. 291-299.

4. Herman J, van der Bruggen P, Luescher IF, et al. A peptide encoded by the human MAGE3 gene and presented by HLA-B44 induces cytolytic T lymphocytes that recognize tumor cells expressing MAGE3. Immunogenetics, 1996. 43(6): p. 377-383.

5. Conway C, Mitra A, Jewell R, et al. Gene expression profiling of paraffin-embedded primary melanoma using the DASL assay identifies increased osteopontin expression as predictive of reduced relapse-free survival. Clin Cancer Res, 2009. 15(22): p. 6939-6946.

6. Jewell R, Elliott F, Laye J, et al. The clinicopathological and gene expression patterns associated with ulceration of primary melanoma. Pigment Cell Melanoma Res, 2015. 28(1): p. 94-104.

7. Vandesompele J, De Preter K, Pattyn F, et al. Accurate normalization of real-time quantitative RT-PCR data by geometric averaging of multiple internal control genes. Genome Biol, 2002. 3(7): p. RESEARCH0034.

8. Livak KJ, Schmittgen TD. Analysis of relative gene expression data using real-time quantitative PCR and the 2(Delta Delta C(T)) Method. Methods, 2001. 25(4): p. 402-408. 


\section{Supplementary Tables}

Supplementary Table S1. Methylation frequency of six candidate genes in an independent series consisting of primary melanomas of patients who developed lethal distant organ metastasis $(M+; n=20)$, and primary melanomas of patients who had not developed metastasis ( $M-; n=25)$.

\begin{tabular}{lcccccc}
\hline & \multicolumn{7}{c}{ M +} & \multicolumn{5}{c}{ M- } \\
\cline { 2 - 7 } & $\%$ & $\begin{array}{c}\text { No. of } \\
\text { specimens }\end{array}$ & $\%$ & $\begin{array}{c}\text { No. of } \\
\text { specimens }\end{array}$ & OR (95\%-Cl) & P-value \\
\hline MCHR1 & 90 & $18 / 20$ & 52 & $13 / 25$ & $8.31(1.58-43.62)$ & 0.01 \\
SYNP02 & 65 & $13 / 20$ & 40 & $10 / 25$ & $2.79(0.82-9.42)$ & 0.10 \\
c10rf106 & 37 & $7 / 19$ & 26 & $6 / 23$ & $1.65(0.44-6.17)$ & 0.45 \\
HIST1H3G & 70 & $14 / 20$ & 52 & $12 / 23$ & $2.14(0.61-7.53)$ & 0.23 \\
ZNF35 & 30 & $6 / 20$ & 32 & $7 / 22$ & $0.92(0.25-3.41)$ & 0.90 \\
GNMT & 32 & $6 / 19$ & 25 & $5 / 20$ & $1.39(0.34-5.62)$ & 0.65 \\
\hline
\end{tabular}

Supplementary Table S2a. Histological characteristics of primary melanoma samples $(n=24)$ for initial methylation profiling study. M-, Primary melanoma from patients with no metastatic dissemination or tumor recurrence; $\mathrm{M}+$, Primary melanoma from patients who developed distant metastases.

\begin{tabular}{|c|c|c|c|c|}
\hline \multirow{2}{*}{ Characteristics } & \multicolumn{2}{|c|}{$M-(n=11)$} & \multicolumn{2}{|c|}{$M+(n=13)$} \\
\hline & No. of specimens & $\%$ & No. of specimens & $\%$ \\
\hline \multicolumn{5}{|l|}{ Gender } \\
\hline Male & 4 & 36 & 6 & 46 \\
\hline Female & 7 & 64 & 7 & 54 \\
\hline Mean age (years) & 52.8 & & 66.6 & \\
\hline \multicolumn{5}{|l|}{ Location } \\
\hline Head/neck & 1 & 9 & 3 & 23 \\
\hline Trunk & 6 & 55 & 4 & 31 \\
\hline Extremeties & 4 & 36 & 6 & 46 \\
\hline \multicolumn{5}{|c|}{ Tumor thickness, $\mathrm{mm}$} \\
\hline$<2.0$ & 7 & 64 & 1 & 8 \\
\hline $2.01-4.0$ & 3 & 27 & 5 & 39 \\
\hline$>4.0$ & 1 & 9 & 7 & 54 \\
\hline
\end{tabular}


Supplementary Table $\mathbf{S} \mathbf{2 b}$. Histological characteristics of samples $(n=45)$ for independent validation with BMCA.

\begin{tabular}{|c|c|c|c|c|}
\hline \multirow{2}{*}{ Characteristics } & \multicolumn{2}{|c|}{$M-(n=25)$} & \multicolumn{2}{|l|}{$M+(n=20)$} \\
\hline & No. of specimens & $\%$ & No. of specimens & $\%$ \\
\hline \multicolumn{5}{|l|}{ Gender } \\
\hline Male & 12 & 48 & 10 & 50 \\
\hline Female & 13 & 52 & 10 & 50 \\
\hline Mean age (years) & 64.1 & & 62.2 & \\
\hline \multicolumn{5}{|l|}{ Location } \\
\hline Head/neck & 4 & 16 & 2 & 10 \\
\hline Trunk & 12 & 48 & 11 & 55 \\
\hline Extremeties & 9 & 36 & 7 & 35 \\
\hline \multicolumn{5}{|c|}{ Tumor thickness, $\mathrm{mm}$} \\
\hline$<2.0$ & 2 & 8 & 2 & 10 \\
\hline $2.01-4.0$ & 17 & 68 & 14 & 70 \\
\hline$>4.0$ & 6 & 24 & 4 & 20 \\
\hline \multicolumn{5}{|l|}{ Metastasis type } \\
\hline Visceral & & & 10 & 50 \\
\hline Cutaneous & & & 6 & 30 \\
\hline Brain & & & 3 & 15 \\
\hline Spinal cord & & & 1 & 5 \\
\hline
\end{tabular}

Supplementary Table S2c. Histological characteristics of samples $(n=113)$ for independent validation with MSP. U, negative for SYNPO2 promoter methylation; M, positive for SYNPO2 promoter methylation.

\begin{tabular}{|c|c|c|c|c|}
\hline \multirow{2}{*}{ Characteristics } & \multicolumn{2}{|c|}{$U(n=59)$} & \multicolumn{2}{|l|}{$M(n=54)$} \\
\hline & No. of specimens & $\%$ & No. of specimens & $\%$ \\
\hline \multicolumn{5}{|l|}{ Gender } \\
\hline Male & 17 & 29 & 19 & 35 \\
\hline Female & 42 & 71 & 35 & 65 \\
\hline Mean age (years) & 55.0 & & 65.4 & \\
\hline$\leq 50$ years & 24 & 41 & 11 & 20 \\
\hline$>50$ years & 35 & 59 & 43 & 80 \\
\hline \multicolumn{5}{|l|}{ Location } \\
\hline Head/neck & 5 & 9 & 14 & 26 \\
\hline Trunk & 18 & 31 & 11 & 20 \\
\hline Extremeties & 35 & 59 & 28 & 52 \\
\hline \multicolumn{5}{|c|}{ Tumor thickness, $\mathrm{mm}$} \\
\hline $0.01-1.0$ & 21 & 36 & 10 & 19 \\
\hline $1.01-2.0$ & 13 & 22 & 13 & 24 \\
\hline $2.01-4.0$ & 10 & 17 & 15 & 28 \\
\hline$>4.0$ & 15 & 25 & 16 & 30 \\
\hline \multicolumn{5}{|l|}{ Ulceration } \\
\hline Absent & 44 & 75 & 34 & 63 \\
\hline Present & 15 & 25 & 30 & 37 \\
\hline \multicolumn{5}{|c|}{ Time till last contact (months) } \\
\hline$<50$ & 20 & 34 & 25 & 46 \\
\hline $50-100$ & 18 & 31 & 17 & 31 \\
\hline $100-150$ & 10 & 17 & 4 & 7 \\
\hline$\geq 150$ & 11 & 19 & 8 & 15 \\
\hline
\end{tabular}


Supplementary Table S2d. Histological characteristics of samples ( $\mathrm{n}=202$ ) Leeds Melanoma Cohort. Low, low SYNPO2 expression; high, high SYNPO2 expression.

\begin{tabular}{|c|c|c|c|c|}
\hline \multirow{2}{*}{ Characteristics } & \multicolumn{2}{|c|}{ low $(n=101)$} & \multicolumn{2}{|c|}{ high $(n=101)$} \\
\hline & No. of specimens & $\%$ & No. of specimens & $\%$ \\
\hline \multicolumn{5}{|l|}{ Gender } \\
\hline Male & 55 & 55 & 43 & 43 \\
\hline Female & 46 & 46 & 58 & 57 \\
\hline Mean age (years) & 55.8 & & 55.1 & \\
\hline$\leq 50$ years & 31 & 31 & 33 & 33 \\
\hline$>50$ years & 70 & 69 & 68 & 67 \\
\hline \multicolumn{5}{|l|}{ Tumor thickness, $\mathrm{mm}$} \\
\hline $0.01-1.0$ & 5 & 5 & 1 & 1 \\
\hline $1.01-2.0$ & 29 & 29 & 37 & 37 \\
\hline $2.01-4.0$ & 34 & 34 & 38 & 38 \\
\hline$>4.0$ & 32 & 32 & 24 & 24 \\
\hline \multicolumn{5}{|l|}{ Ulceration } \\
\hline Absent & 47 & 54 & 39 & 46 \\
\hline Present & 41 & 47 & 45 & 54 \\
\hline \multicolumn{5}{|l|}{ Dead/alive status } \\
\hline Died from melanoma & 57 & 56 & 43 & 43 \\
\hline Alive & 44 & 44 & 58 & 57 \\
\hline \multicolumn{5}{|c|}{ Time till last contact (months) } \\
\hline$<50$ & 42 & 42 & 33 & 33 \\
\hline $50-100$ & 30 & 30 & 30 & 30 \\
\hline $100-150$ & 29 & 29 & 38 & 38 \\
\hline$\geq 150$ & - & - & - & - \\
\hline
\end{tabular}


Supplementary Table S3. Effect of SYNPO2 promoter methylation on melanoma-related death $(\mathrm{n}=113)$

\begin{tabular}{llll}
\hline & Model & $\mathrm{HR}(95 \%-\mathrm{Cl})^{*}$ & $\mathrm{P}$-value \\
\hline SYNP02 methylation & Unadjusted & $2.01(1.06-3.82)$ & 0.03 \\
& Adjusting tumor thickness & $2.02(1.05-3.89)$ & 0.03 \\
& $\begin{array}{l}\text { Adjusting gender and tumor thickness } \\
\text { Adjusting age, gender, and tumor }\end{array}$ & $2.00(1.05-3.82)$ & 0.04 \\
& $\begin{array}{l}\text { thickness } \\
\text { Adjusting age, gender, tumor thickness, }\end{array}$ & $1.80(0.90-3.61)$ & 0.10 \\
& & & 0.09 \\
& and ulceration & & \\
\hline
\end{tabular}

*Mitotic rate was not considered covariate since the prognostic value in the clinic is limited to tumor stage I melanoma.

Supplementary Table S4. Effect of SYNPO2 expression on melanoma-related death

\begin{tabular}{llll}
\hline & Model & HR $(95 \%-C l)^{*}$ & P-value \\
\hline ILMN_1688220 & Unadjusted $(\mathrm{n}=202)$ & $2.04(1.11-3.85)$ & 0.02 \\
& Adjusting age and gender $(\mathrm{n}=202)$ & $2.04(1.09-3.85)$ & 0.03 \\
& $\begin{array}{l}\text { Adjusting age, gender, and tumor } \\
\text { thickness ( } \mathrm{n}=200)\end{array}$ & $2.04(1.08-3.85)$ & 0.03 \\
& Unadjusted ( $\mathrm{n}=202)$ & $1.22(1.00-1.52)$ & 0.05 \\
& Adjusting age and gender ( $\mathrm{n}=202)$ & $1.19(0.95-1.47)$ & 0.13 \\
& $\begin{array}{l}\text { Adjusting age, gender, and tumor } \\
\text { thickness ( } \mathrm{n}=200)\end{array}$ & $1.16(0.93-1.43)$ & 0.19 \\
& & & \\
\hline
\end{tabular}

*Hazard ratio per unit of log2 (expression) (i.e. per doubling gene expression). All the analyses controlled the batch of effect. Ulceration and mitotic rate were not considered covariates since data were incomplete for these patient samples. 
Supplementary information

Supplementary Table S5a. Primers for promoter methylation analysis by BMCA of six candidate genes

\begin{tabular}{|c|c|c|c|c|c|c|}
\hline Gene & & Primer sequence & $\begin{array}{l}\text { CpG's in } \\
\text { Amplicon }\end{array}$ & $\begin{array}{c}\text { Position Relative } \\
\text { to TSS }\end{array}$ & $\begin{array}{l}\mathrm{Tm}\left({ }^{\circ} \mathrm{C}\right) \\
\text { Unmeth. }\end{array}$ & $\begin{array}{l}\operatorname{Tm}\left({ }^{\circ} \mathrm{C}\right) \\
\text { Meth. }\end{array}$ \\
\hline SYNPO2 & $\begin{array}{l}\mathrm{F} \\
\mathrm{R}\end{array}$ & $\begin{array}{l}\text { ATGGTTATTATTGGGGTTTTGGGTAA } \\
\text { TAAACTCCAACCAAAAACGCATATAC }\end{array}$ & 6 & 283 - to 28 - & 77 & 79 \\
\hline M CHR1 & $\begin{array}{l}\mathrm{F} \\
\mathrm{R}\end{array}$ & $\begin{array}{l}\text { GTTGTTAGGTTACGGAGGAAGATTT } \\
\text { TATTGGTTGGATGGATTTGGAAGT }\end{array}$ & 9 & $413+$ to $572+$ & 81 & 84 \\
\hline clorf106 & $\begin{array}{l}F \\
R\end{array}$ & $\begin{array}{l}\text { GGAATGAAAATTGGTTTTAGTTAGGTTAG } \\
\text { CAAAACATCTATCCCCTAAAACATACC }\end{array}$ & 30 & 337 - to 19 - & 80 & 84 \\
\hline HIST1H3G & $\begin{array}{l}\mathrm{F} \\
\mathrm{R}\end{array}$ & $\begin{array}{l}\text { GGTAGTTTGAGATGGTTCGTATTAAGTAGA } \\
\text { AATCAACAACTCAATCGACTTCTAATAAC }\end{array}$ & 21 & 11- to $189+$ & 78 & 83 \\
\hline ZNF35 & $\begin{array}{l}\mathrm{F} \\
\mathrm{R}\end{array}$ & $\begin{array}{l}\text { GGGTTTTTTAGTTGCGTATAGTGAGT } \\
\text { ACCAAACCCCAAATAAACAACAAC }\end{array}$ & 12 & $75+$ to $281+$ & 81 & 83 \\
\hline GNMT & $\begin{array}{l}F \\
R\end{array}$ & $\begin{array}{l}\text { GATTTTAGGGGATGGAGTGGTAATT } \\
\text { ACAACCCCACCTAACCAATAACAAAT }\end{array}$ & 18 & 335 - to 57 - & 79.8 & 82.6 \\
\hline
\end{tabular}

Supplementary Table S5b. Primers for SYNPO2 promoter methylation analysis by MSP.

\begin{tabular}{|c|c|c|c|c|c|}
\hline Gene & & Sense primer $\left(5^{\prime}->3^{\prime}\right)$ & Antisense primer $\left(3^{\prime}->5^{\prime}\right)$ & $\begin{array}{c}\text { Annealing } \mathrm{T} \\
\left({ }^{\circ} \mathrm{C}\right)\end{array}$ & $\begin{array}{c}\text { No. of } \\
\text { PCR } \\
\text { cycles }\end{array}$ \\
\hline \multirow{3}{*}{ SYNPO2 } & Flank & GAGGATATTTTTTTGTGTGTGAAG & CTACAACCRCTACCCCAACC & 56 & 30 \\
\hline & $U$ & TTTTTTTTTTTTGAAGGTGGGTT & CCCAACCACCTACTACAAATTTATACA & 66 & 30 \\
\hline & M & TTTTTTTTTTCGAAGGTGGGTC & AACCGCCTACTACGAATTTATACG & 66 & 30 \\
\hline
\end{tabular}

Supplementary Table S5c. Primers for SYNPO2 mRNA expression analysis by qPCR.

\begin{tabular}{llll}
\hline Gene & Sense primer $\left(5^{\prime}->3^{\prime}\right)$ & Antisense primer $\left(3^{\prime}->5^{\prime}\right)$ & $\begin{array}{c}\text { Amplification } \\
\text { efficiency }\end{array}$ \\
\hline SYNP02 & TCACAGCAGACCTCACAAGC & GCATCCGTTAGAAGAAGGGCA & $104 \%\left(\mathrm{R}^{\wedge} 2=0.986\right)$ \\
TBP & CACGAACCACGGCACTGATT & TTTTCTTGCTGCCAGTCTGGAC & $102 \%\left(\mathrm{R}^{\wedge} 2=0.996\right)$ \\
CPSF6 & AAGATTGCCTTCATGGAATTGAG & TCGTGATCTACTATGGTCCCTCTCT & $102 \%\left(\mathrm{R}^{\wedge} 2=0.996\right)$ \\
\hline
\end{tabular}




\section{Supplementary Figures}

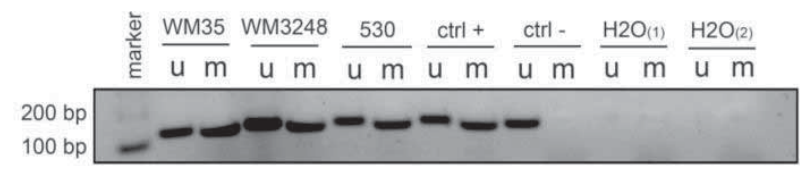

Supplementary Figure S1. SYNPO2 amplification products from MSP are shown for melanoma cell lines WM35, WM3248 and 530. u, unmethylated; m, methylated; ctrl +, positive control (lymphocyte DNA treated with Sss1 methyltransferase); ctrl -, negative control (DNA from human umbilical vein endothelial cells); $\mathrm{H} 2 \mathrm{O}(1)$, no template control for first amplification with flanking primers; $\mathrm{H} 2 \mathrm{O}(2)$, no template control for second amplification with primers specific for methylated and unmethylated DNA.

SYNPO2

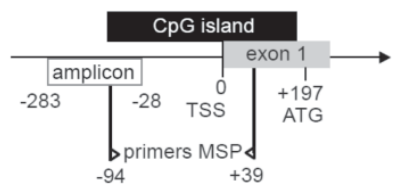

MCHR1

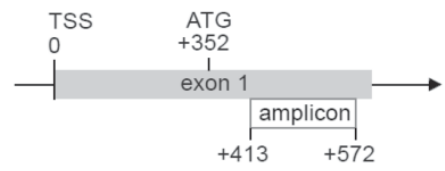

C10rf106

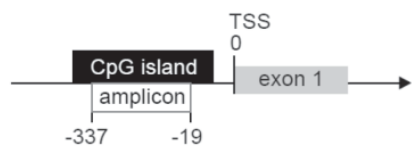

HIST1H3G

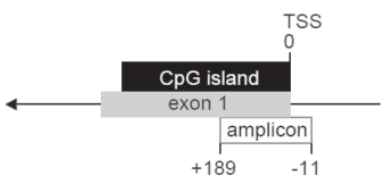

ZNF35

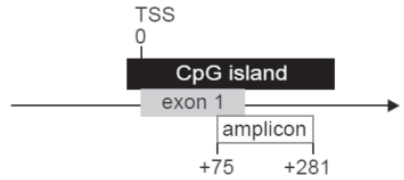

GNMT

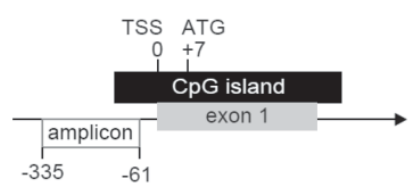

Supplementary Figure S2. Schematic representation of gene promoter regions with $\mathrm{CpG}$ island and first exon of six candidate genes. Location of region amplified by BMCA primers is labelled as [amplicon]. Location of MSP primers is labelled as > primers MSP<. TSS, transcription start site, ATG, start codon for translation. 


\section{CHAPTER 7}

Comprehensive epigenomic and transcriptomic analysis of melanoma identifies LY75 CpG island promoter methylation as an independent marker of poor clinical outcome

Karin van den Hurk, Véronique J.L. Winnepenninckx, Danique L. van den Kerkhof, Linda Gao, Geert Trooskens, Tim De Meyer, Marloes M. Oosterhof, Remco van Doorn, Joost J. van den Oord, Wim Van Criekinge, William M. Gallagher, Manon van Engeland, 


\section{ABSTRACT}

Cutaneous melanoma is the most deadly form of skin cancer with increasing incidence rate. Identification of patients with aggressive disease at diagnosis is important to improve patient outcome. Promoter $\mathrm{CpG}$ island methylation has been recognized to play a central role in oncogenesis and detection of cancer-associated events results in useful biomarkers. A comprehensive study of epigenetic aberrations in melanoma may identify methylation markers that improve the assessment of melanoma prognosis.

Using a workflow combining methyl-binding domain (MBD)-sequencing and RNAsequencing on melanoma cell lines, Illumina Infinium HumanMethylation450 analyses of 14 nevi, and publically available methylation data on 459 melanoma tissues from The Cancer Genome Atlas, methylation markers were identified that predict prognosis of melanoma patients. Validation of identified markers was performed using methylation-specific PCR (MSP) in an independent series of 123 primary melanomas. Cox proportional hazards regression was applied to examine prognostic value of candidate methylation markers.

In total, we identified 85 gene promoters showing CpG island hypermethylation in melanoma (cell lines and clinical specimens) versus healthy control (normal melanocytes and nevi) samples. Stepwise backward elimination of a saturated multivariate Cox proportional hazards model including Breslow thickness, ulceration, tumor location, disease stage, gender, and age as covariates identified that LY75 promoter methylation $(\mathrm{HR}=4.442 ; 95 \%-\mathrm{Cl} 2.307-8.553, \mathrm{P}<.001)$ together with ulceration ( $\mathrm{HR}=2.262 ; 95 \%-\mathrm{Cl} 1.164-4.396, \mathrm{P}=.016)$, and metastatic disease at diagnosis $(\mathrm{HR}=5.069 ; 95 \%-\mathrm{Cl} 2.489-10.325, \mathrm{P}<.001)$ were significant predictors of melanoma survival.

Taken together, LY75 methylation was identified as a strong predictor of poor melanoma prognosis and identified patients with aggressive disease at diagnosis independent of current prognostic parameters. This might aid in the identification of patients who require more extensive surgery, adjuvant treatment, and closer follow-up which could ultimately lead to improved clinical outcomes. 


\section{Introduction}

Cutaneous melanoma is a deadly skin tumor with continuously rising incidence, resulting in a growing healthcare burden ${ }^{1,2}$. Worldwide, roughly 232,000 new cases and 55,000 deaths were reported in $2012^{3}$. Patients diagnosed early with localized disease have a five-year survival rate of more than $95 \%$ after treatment by surgical excision alone ${ }^{4}$. If the cancer is more advanced, however, survival rates drop substantially, i.e. $30 \%$ to $60 \%$ after five years, primarily depending on the tumor thickness, i.e. Breslow's depth. Metastatic disease generally leads to poor patient outcomes, as treatment options were limited for a long time. However, rapid development of next-generation sequencing technologies has identified key genetic alterations and molecular pathways involved in melanoma development and provided the basis for novel targeted therapies ${ }^{5}$. Moreover, novel immunomodulatory therapies are successfully being developed for melanoma treatment ${ }^{6}$.

Currently, the American Joint Committee on Cancer (AJCC) classifies patients predominantly based on histological features of the primary tumor, i.e. Breslow thickness, ulceration, and mitotic rate, and indicates that the initial biopsy is a critical component of both diagnosis and staging ${ }^{7}$. In addition, the presence of advanced disease stage (stage III/IV) and, to a lesser extent, patient age, gender, and tumor location, are prognostic melanoma factors. Breslow thickness is viewed as the most important prognostic parameter; however, $20-30 \%$ of patients diagnosed with thin melanomas ( $\leq 2.0 \mathrm{~mm}$ thickness) still die from their disease ${ }^{8,9}$. Hence, improvements to the current staging system that lead to more accurate prediction of prognosis are warranted, allowing clinicians to better address prognosis of individual patients. Moreover, it is of importance to identify high-risk patients with aggressive disease at an early stage as these patients may benefit from more extensive surgery, adjuvant therapy, and closer follow-up.

Malignant transformation of healthy melanocytes involves both genetic and epigenetic alterations ${ }^{10}$ and differences in DNA-methylation patterns between healthy and malignant tissues have emerged as promising biomarkers ${ }^{11,12}$. So far, DNAmethylation profiling of melanoma has generally focused on selected genes and examined limited number of specimens, often lacked examination of non-malignant samples or adequate controls, and lacked independent validation ${ }^{10}$. Additionally, efforts to study DNA-methylation profiles of primary melanoma suggest that DNAmethylation is associated with prognostic melanoma features ${ }^{13-18}$. We hypothesized that DNA-methylation markers might be useful to improve the prediction of prognosis of melanoma patients and developed a strategy to efficiently identify such markers.

Here, a workflow encompassing analysis of methyl-binding domain (MBD)sequencing and RNA-sequencing on melanoma cell lines and normal melanocytes was integrated with Illumina Infinium HumanMethylation450 (Infinium-450K) analyses on 14 common nevi and publically available methylation data on 459 melanoma tissues from The Cancer Genome Atlas (TCGA). The TCGA samples were particularly useful for 
prognostic marker identification as these were commonly (80\%) obtained from melanoma metastases and the majority of the remaining primary tumor tissues (85\%) were from thick melanomas ( $>4 \mathrm{~mm}$ thickness), i.e. from patients with a poor prognosis. To further optimize successful identification of prognostic methylation markers, we used the molecular profiles of CDH11 and GNMT as 'guide genes' to define cutoff values of our analyses that would efficiently discover prognostic methylation events. These guide genes were selected (1) based upon our previous work in which we observed that $\mathrm{CDH} 11$ and GNM T methylation increased significantly during tumor progression ${ }^{19}$ and (2) based on a literature study that revealed that both genes are known to be involved in the metastatic process in melanoma ${ }^{20}$ or other malignancies ${ }^{21-24}$.

This approach efficiently and accurately identified differentially methylated promoter CPG islands between healthy melanocytes and nevi on one hand, and malignant melanomas on the other. Methylation of lymphocyte antigen 75 (LY75), also known as CD-205 or DEC-205, was shown to be a strong marker that predicted poor clinical outcome independent of the currently used prognosticators in an independent melanoma series.

\section{Materials and methods}

\section{Cell culture and MBD-sequencing}

MBD-sequencing was performed on six melanoma cell lines (WM35, WM3248, WM164, A375, M14, SK-MEL-28) and normal human epidermal melanocytes (NHEM) provided by Dr. Léon van Kempen (McGill University, Montreal, Canada). Authentication of all cell lines was performed using short tandem repeat (STR) profiling (DSMZ, Braunschweig, Germany). WM cell lines were cultured in W489 medium consisting of four parts of MCDB153 (Sigma-Aldrich, Zwijndrecht, The Netherlands) and one part of L15 (Sigma-Aldrich, Zwijndrecht, The Netherlands), A375, M14, and SKMEL-28 cells were cultured in Dulbecco's modified Eagle's medium (Invitrogen, Breda, the Netherlands). Cells were supplemented with $2 \%$ or $10 \%$ heat inactivated fetal calf serum (Hyclone Perbio Science, Erembodegem-Aalst, Belgium), respectively. NHEM cells were cultured in ready-to-use medium supplied by Promocell (Heidelberg, Germany). Genomic DNA was isolated using the Puregene ${ }^{\circledR}$ DNA isolation kit (Gentra systems, Minneapolis, MN) according to the manufacturer's instructions.

Genomic DNA of all samples was subjected to methylation-enrichment sequencing using the MethylCap kit with high-salt elution (Diagenode, Liege, Belgium) as described previously ${ }^{25}$. For each sample, and each methylation core, the maximum read count was used in downstream analyses. Importantly, all cores that showed methylation in NHEM were excluded as potentially interesting regions. A summary score was calculated for methylation cores that fulfilled this requirement by adding up the read 
counts of all six cell lines for each individual core, with a score $>11$ serving as a cutoff point to identify methylation-positive regions as defined by the 'guide genes'.

Total RNA sequencing

The list of differentially methylated genes obtained from MBD-sequencing analyses was subsequently fine-tuned by selecting for functional methylation, i.e. methylation associated with downregulated gene expression ${ }^{26}$. Therefore, RNA-sequencing on WM35, WM3248, M14, and SK-MEL-28 cells was performed. In brief, total ribonucleic acid (RNA) was isolated using the standard procedure for TRIzol ${ }^{\circledR}$ RNA extraction (Invitrogen, Bleiswijk, The Netherlands) and stored at $-80^{\circ} \mathrm{C}$. For total RNA sequencing, library preparation was carried out using a modified version of the Illumina 'Directional mRNA-sequencing Sample Preparation' protocol with total RNA instead of mRNA. Ribosomal DNA was depleted from the DNA fraction using Illumina's Duplex-Specific Thermostable Nuclease normalization protocol for bidirectional mRNA sequencing. Single read 36bp sequencing was carried out on an Illumina Genome Analyzer II. The $36 \mathrm{bp}$ reads were mapped onto the human reference genome (GRCh37/hg19) using Bowtie17 (software version 0.12.7). Reads were discarded if they had mismatches in the seed (i.e. first 28 nucleotides) or mapped onto multiple locations in the genome. Expression levels of 49,506 genes (Ensembl version 56; http://www.ensembl.org) were quantified for the 4 melanoma cell lines. This was done by integrating the coverage of the total directional RNA mapped reads on the same strand and within the boundaries of every gene. These values were consequently divided by total sample coverage to obtain a normalized expression value for every gene. All genes with DNA-methylation in their promoter region, identified via MBD-sequencing, for which silenced transcripts could be identified, were considered as potential candidates since the respective methylation event was deemed to be likely functional.

\section{Infinium-450K data}

To select for gene regions that were also methylated in patient samples, publically available genome-wide methylation data from the TCGA consisting of 96 primary melanomas and 363 melanoma metastases were analyzed on Illumina Infinium HumanMethylation450 BeadChips (Infinium-450K). Since the TCGA had no methylation data available on control samples, we performed Infinium-450K assays on 14 freshfrozen nevi, collected from the archives of the University Hospital of Leuven, Belgium, to be able to select for melanoma-specific methylation (Supplementary Table S1). Genomic DNA from the 14 nevus samples was extracted as described previously ${ }^{27}$. DNA quantification was performed using a Qubit 2.0 plate reader (Invitrogen, Bleiswijk, The Netherlands) and PicoGreen dye (Invitrogen, Bleiswijk, The Netherlands). DNA quality was inspected on agarose gels stained with SYBR ${ }^{\circledR}$ Safe (Invitrogen, Bleiswijk, The Netherlands). Bisulfite conversion of DNA samples was carried out using the EZ DNA methylation kit (Zymo Research, Orange, CA) and converted DNA was hybridized 
on Infinium-450K BeadChips, following the Illumina Infinium HD Methylation protocol as described elsewhere ${ }^{28}$.

To select genes that were methylated in clinical melanoma specimens $(n=459)$ as compared with healthy nevi $(n=14)$, a t-test was applied to identify probes with a significant increase in $\beta$-value, i.e. $>0.2$ in melanomas versus nevi. To correct for multiple hypothesis testing, q-values were calculated based on the false discovery rate and stringently selected for differentially methylated probes with a $\mathrm{q}$-value $<1 \mathrm{E}^{-6}$ as determined by the guide genes, CDH11 and GNM T.

\section{Patient samples}

Promoter CpG island methylation was examined in a well-characterized series of formalin-fixed, paraffin-embedded (FFPE) common nevi $(n=20)$ and primary melanomas ( $n=123$ ) of patients diagnosed at the Maastricht University Medical Centre, The Netherlands and University Hospital Leuven, Belgium. Collection, storage and use of all tissues and patient data were performed in agreement with the "Code for Proper Secondary Use of Human Tissue in the Netherlands". All of the used samples and corresponding data were de-linked and anonymized. Usage of both melanoma and healthy tissue samples was approved by the Maastricht Pathology Tissue Collection (MPTC) scientific committee. Detailed clinicopathological information of melanoma samples is shown in Table 1, with characteristics of nevus samples listed in Supplementary Table S1.

DNA isolation, bisulfite conversion, and promoter CpG island methylation analyses

A 4- $\mu$ m section of each FFPE tissue block was stained with haematoxylin \& eosin (H\&E) and reviewed by an experienced dermato-pathologist (VW). Cases that contained $>50 \%$ nevus or melanoma cells were included. Subsequently, ten sections of $10 \mu \mathrm{m}$ were cut and another H\&E section was made to confirm the percentage of nevus and melanoma cells. Next, slides were deparaffinised and DNA was extracted following macro dissection with the QIAamp DNA Micro Kit (Qiagen, Venlo, The Netherlands). NanoDrop quantification was used to estimate the quality and concentration of extracted DNA (NanoDrop ND-1000 Spectrophotometer). Sodium bisulphite modification of 500ng genomic DNA was performed using the EpiTect Bisulfite Kit (Qiagen, Venlo, The Netherlands) according to the manufacturer's instructions.

Following bisulfite conversion, nested, multiplex methylation-specific polymerase chain reaction (MSP) analyses were performed as described elsewhere ${ }^{19}$. Primer sequences and conditions are shown in Supplementary Table S2. PCR reactions were performed with controls for unmethylated alleles (unmethylated human control DNA, EpiTect Control DNA, Qiagen, Cat. no. 59568), methylated alleles (normal lymphocyte DNA treated in vitro with Sssl methyltransferase [New England Biolabs]), and a notemplate DNA control. Ten $\mu$ l of each MSP reaction was directly loaded onto $2 \%$ agarose gels containing GelStar Nucleic Acid Gel Stain (Cambrex, New Jersey, USA), and 
visualized under UV illumination. To ensure reproducibility, MSP reactions were performed in duplicate starting from DNA amplification with flanking primers. Discordant results were analyzed a third time, and the majority vote principle was used to determine the methylation status.

Table 1. Clinicopathological characteristics and methylation frequencies of candidate genes of 123 primary melanoma cases with follow-up

\begin{tabular}{|c|c|c|}
\hline Characteristics & No. of Patients* & $\%$ \\
\hline \multicolumn{3}{|l|}{ Gender } \\
\hline Female & 82 & 67 \\
\hline Male & 41 & 33 \\
\hline \multicolumn{3}{|l|}{ Age (years) } \\
\hline Mean & $59.9 \pm 16.9$ & \\
\hline$\leq 50$ years & 37 & 30 \\
\hline$>50$ years & 86 & 70 \\
\hline \multicolumn{3}{|l|}{ Disease stage } \\
\hline Localized - Stage I/II & 103 & 84 \\
\hline Metastasized - Stage III/IV & 20 & 16 \\
\hline \multicolumn{3}{|l|}{ Breslow thickness, mm } \\
\hline $0.01-1.0$ & 32 & 26 \\
\hline $1.01-2.0$ & 29 & 24 \\
\hline $2.01-4.0$ & 29 & 24 \\
\hline$>4.0$ & 33 & 27 \\
\hline \multicolumn{3}{|l|}{ Ulceration } \\
\hline Absent & 86 & 70 \\
\hline Present & 37 & 30 \\
\hline \multicolumn{3}{|l|}{ Mitotic Rate } \\
\hline$<1 / \mathrm{mm}^{2}$ & 23 & 19 \\
\hline$\geq 1 / \mathrm{mm}^{2}$ & 99 & 81 \\
\hline \multicolumn{3}{|l|}{ TILs } \\
\hline Absent & 29 & 24 \\
\hline Non-brisk & 69 & 57 \\
\hline Brisk & 24 & 20 \\
\hline \multicolumn{3}{|l|}{ Histological subtype } \\
\hline SSM & 85 & 73 \\
\hline NM & 21 & 18 \\
\hline LMM & 9 & 8 \\
\hline ALM & 2 & 2 \\
\hline \multicolumn{3}{|l|}{ Location } \\
\hline Head and neck & 21 & 17 \\
\hline Trunk & 33 & 28 \\
\hline Extremities & 67 & 55 \\
\hline \multicolumn{3}{|l|}{ Distant metastasis formation } \\
\hline No & 80 & 65 \\
\hline Yes & 43 & 35 \\
\hline \multicolumn{3}{|l|}{ Disease-related death } \\
\hline No & 81 & 66 \\
\hline Yes & 42 & 34 \\
\hline Mean follow-up (months) & $75.3 \pm 57.0$ & \\
\hline
\end{tabular}


Statistical analyses

Cox proportional hazards regression was used to evaluate the effect of gene methylation and clinicopathological variables on melanoma-specific survival, resulting in hazard ratios (HRs) and their corresponding 95\% confidence intervals $(95 \%-\mathrm{Cl})$. Stepwise backward elimination was applied to explore the best model to predict melanoma-specific outcome. For LY75 methylation, the Cox proportional hazards model was used to evaluate the effect of methylation on distant metastasis formation (melanoma-free survival). Survival time was defined as the time between first diagnosis and the first date of diagnosis of a distant metastasis. Akaike Information Criterion (AIC) was used to assess the predictive capacity of models with single and multiple methylation markers. The model with the lowest AIC was chosen as the best model. All reported $\mathrm{P}$-values were two-sided, and $\mathrm{P}<.05$ was considered statistically significant. Analyses were performed using the statistical package IBM SPSS Statistics 21 (IBM, New York, USA) and R (R Foundation for Statistical Computing, Vienna, Austria).

\section{Results}

\section{Identification of hypermethylated promoter CpG islands linked to tumor progression and outcome}

To improve the prediction of prognosis of melanoma patients, a strategy was developed to efficiently identify prognostic methylation eventis for melanoma. Figure 1 depicts the workflow of the used gene identification strategy. To increase the effectiveness of the marker identification procedure, i.e. decrease the chance of identifying false positive markers and increase the likelihood of identifying true and reproducible markers, we integrated newly generated and publicly available data using three different technologies, i.e. MBD-sequencing, RNA-sequencing, and Infinium-450K profiling. MBD-sequencing was performed to identify genes that were differentially methylated between normal melanocytes derived from healthy individuals (NHEM), and melanoma cells (WM35, WM3248, WM164, A375, M14, and SK-MEL-28). To select for functional methylation associated with downregulated gene expression, RNAsequencing was performed on WM35, WM3248, M14, and SK-MEL-28 cells and genes for which no evidence of silenced transcripts could be identified were excluded. MBDsequencing and RNA-sequencing data from the same cell lines were matched hereby selecting silenced, hypermethylated genes representing a functional melanoma cell line's DNA methylome. To select for melanoma-specific methylation alterations that are present in clinical samples, Infinium-450K profiling data on 14 nevi studied inhouse and publically available primary and metastasized melanoma samples from the TCGA were compared. All cell line and patient data were integrated by choosing cutoff values as dictated by the guide genes $\mathrm{CDH} 11$ and GNM T. Subsequently, focus was 

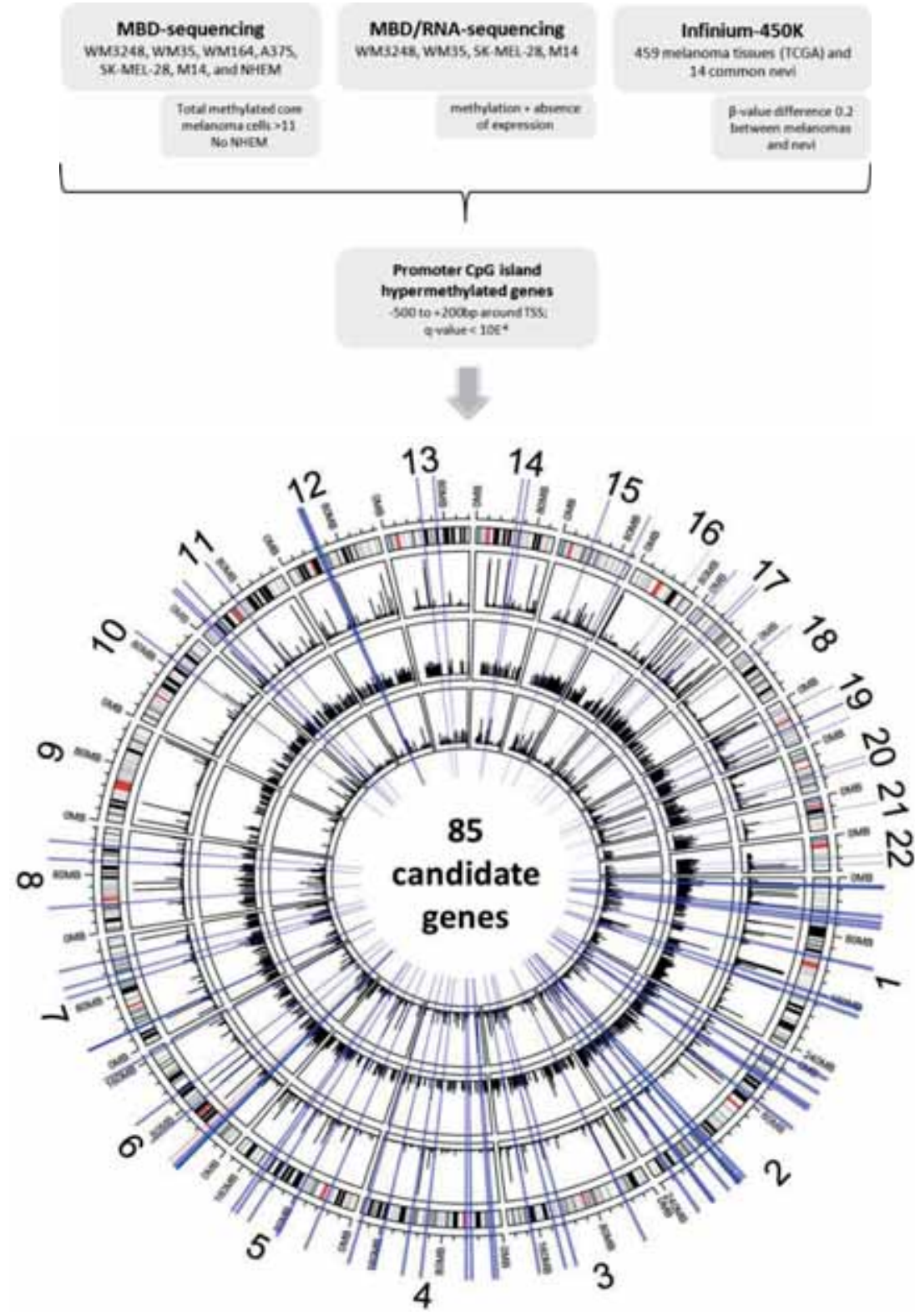

Figure 1. Flow chart of identification of hypermethylated genes in melanoma. Using MBD-sequencing and RNA-sequencing we examined functional methylation alterations in cell lines. Newly generated (nevi) and publically available TCGA Infinium-450K data were used to select for methylation changes that were present in clinical melanoma specimens. All datasets were integrated and selected for promoter $\mathrm{CpG}$ island hypermethylated genes, cutoff values were determined by using CDH11 and GNMT as guide genes. The identified genes (illustrated in blue) are presented in circos plot depiction representing Infinium-450K (-log P-value difference melanomas versus nevi), MBD-sequencing (total methylated mapped reads per core), and RNA-sequencing (reads per kilobase per million mapped reads) data reading from inside to outside. Guide genes (GNMT, 6p12 and CDH11, 16q22) are illustrated in red. 
turned on hypermethylation of promoter CpG islands located between -500 to +200 base pairs around the transcription start site. This approach identified 85 robustly methylated candidate markers (Figure 1, Supplementary Table S3). A major advantage of using the TCGA methylation dataset was that this biased our gene selection towards metastasis-related methylation events, i.e. a large proportion (80\%) of the TCGA specimens were melanoma metastases and the largest part of the primary melanomas (85\%) had a tumor thickness $>4.0 \mathrm{~mm}$.

Next, genes were selected for validation using MSP, a technique suited for diagnostic purposes. Functionally unknown genes, pseudogenes and homeobox genes (14 genes) were excluded. Subsequently, Infinium-450K data and MBD-sequencing data for individual genes was visually inspected and genes that harbored 'background methylation' in nevi ( $\beta$-value $>0.2$ ) or had a restrictive region of melanoma-specific methylation (total of 28 genes) were not retained (Supplementary Figure S1 depicts examples of excluded genes), because MSP is highly sensitive and would most likely detect methylation levels above $\beta$-value of 0.2 when not performed quantitatively ${ }^{29}$. Furthermore, genes of which the differentially methylated region did not overlap between MBD-sequencing and Infinium-450K data were excluded (4 genes), retaining 41 genes. Beside the guide genes, CDH11 and GNMT, we also identified CLDN11 and PPP1R3C, i.e. genes that were previously shown to be hypermethylated in melanoma specimens $^{19}$. From the remaining 37 candidates, the 20 most promising genes (based on visual inspection of MBD-sequencing and Infinium-450K data), for which we were able to design MSP primers, were selected, i.e. ADAM 32, ATP5G2, CIDEA, CORIN, CLDN7, DENND2D, DES, DLEU7, DNM 3, DYSF, ENTPD3, GPR135, HAAO, LY75, OTP, OVOL1, PAX6, PTGDR, TAL1, and UCHL1.

\section{Validation of candidate methylation markers}

The 20 selected genes were further validated using MSP, first on the cell lines that were subjected to MBD-sequencing, and next on an independent series consisting of 20 common nevi and 20 primary melanomas (Table 2). Due to technical reasons, i.e. large amount of sample fall-out, MSP analysis of DES was not further investigated. The majority of the selection, i.e. 14 genes: CORIN, CLDN7, DENND2D, DNM3, DYSF, ENTPD3, GPR135, HAA0, LY75, OVOL1, PAX6, PTGDR, TAL1, and UCHL1, were hypermethylated in melanomas versus nevi (Table 2). Methylation of CIDEA and DLEU7 was present in all examined tissues and cell lines, including NHEM cells (Table 2), probably due to the presence of low methylation levels that are detected by MSP. To increase the likelihood of identification of prognostic methylation markers, genes with a methylation frequency of $>15 \%$ in nevi were not further analyzed. Hence, 11 genes (CORIN, CLDN7, DENND2D, DNM3, DYSF, ENTPD3, GPR135, HAAO, LY75, PAX6, and TAL1) were retained for further analyses (Table 2). In addition, the guide genes and previously validated genes ${ }^{19}, \mathrm{CDH} 11, \mathrm{CLDN11}, \mathrm{GNMT}$, and PPP1R3C were included for further study as these genes might have prognostic value in addition to their 
previously described diagnostic relevance. For these genes, a higher methylation frequency was observed in metastatic melanomas compared to primary melanomas ${ }^{19}$.

Table 2. Candidate gene selection

\begin{tabular}{llcccc}
\hline Gene & Ensemble gene ID & $\begin{array}{c}\text { Meth. Cell } \\
\text { lines }\end{array}$ & Meth. NHEM & $\begin{array}{c}\text { \% Meth. Pilot } \\
\text { melanoma }\end{array}$ & $\begin{array}{c}\text { \% Meth. Pilot } \\
\text { common nevi }\end{array}$ \\
\hline CLDN7 & ENSG00000181885 & $6 / 6$ & No & 70 & 15 \\
CORIN & ENSG00000145244 & $6 / 6$ & No & 55 & 0 \\
DENND2D & ENSG00000162777 & $6 / 6$ & No & 85 & 5 \\
DNM3 & ENSG00000197959 & $6 / 6$ & No & 55 & 0 \\
DYSF & ENSG00000135636 & $6 / 6$ & No & 40 & 0 \\
ENTPD3 & ENSG00000168032 & $6 / 6$ & No & 65 & 10 \\
GPR135 & ENSG00000181619 & $5 / 6$ & No & 70 & 0 \\
HAAO & ENSG00000162882 & $6 / 6$ & No & 45 & 0 \\
LY75 & ENSG00000054219 & $6 / 6$ & No & 35 & 5 \\
PAX6 & ENSG00000007372 & $6 / 6$ & No & 80 & 10 \\
TAL1 & ENSG00000162367 & $6 / 6$ & No & 60 & 60 \\
\hline ADAM 32 & ENSG00000197140 & $6 / 6$ & No & 80 & 65 \\
ATP5G2 & ENSG00000135390 & $6 / 6$ & No & 65 & 100 \\
CIDEA & ENSG00000176194 & $6 / 6$ & Yes & 100 & 100 \\
DLEU7 & ENSG00000186047 & $6 / 6$ & Yes & 100 & 85 \\
OTP & ENSG00000171540 & $6 / 6$ & No & 90 & 40 \\
OVOL1 & ENSG00000172818 & $6 / 6$ & No & 75 & 20 \\
PTGDR & ENSG00000168229 & $6 / 6$ & No & 70 & 25 \\
UCHL1 & ENSG00000154277 & $6 / 6$ & No & 75 & \\
\hline PFOMOterS &
\end{tabular}

Promoters of 19 candidate genes were analyzed for their methylation status in melanoma cell lines and NHEM, and a pilot of 20 primary CMM and 20 common nevus samples. Eleven genes, depicted on top part of the table, were selected for further analyses

\section{LY75 methylation is a strong independent predictor of poor melanoma prognosis}

Next, we examined the methylation status of the 15 remaining genes in a wellcharacterized series of 123 primary melanomas with follow-up data. In this series, higher Breslow thickness, presence of ulceration, and presence of metastatic disease at diagnosis were the main prognostic indicators $(P<.001$, Table 3; Kaplan-Meier survival curves depicted in Figure 2A, B, and C, respectively). Additionally, older age at diagnosis, presence of tumor mitoses, and location on the head and neck were significant predictors of poor prognosis (Table 3), indicating that this series reflected the overall disease progression in a similar tendency as the general population.

We next applied univariate Cox proportional hazards regression analyses to examine the prognostic value of the 15 candidate methylation markers and identified that the methylation status of ten genes (LY75, HAAO, CDH11, DNM 3, ENTPD3, TAL1, CLDN11, GPR135, CLDN7, and PPP1R3C) significantly predicted poor melanomaspecific survival (Table 3). When corrected for multiple hypothesis testing by using the Bonferroni method, methylation of $\mathrm{LY} 75, \mathrm{HAAO}$, and $\mathrm{CDH} 11$, remained significant predictors of poor prognosis; adjusted P-values of <.001, .004, and .045, respectively. 

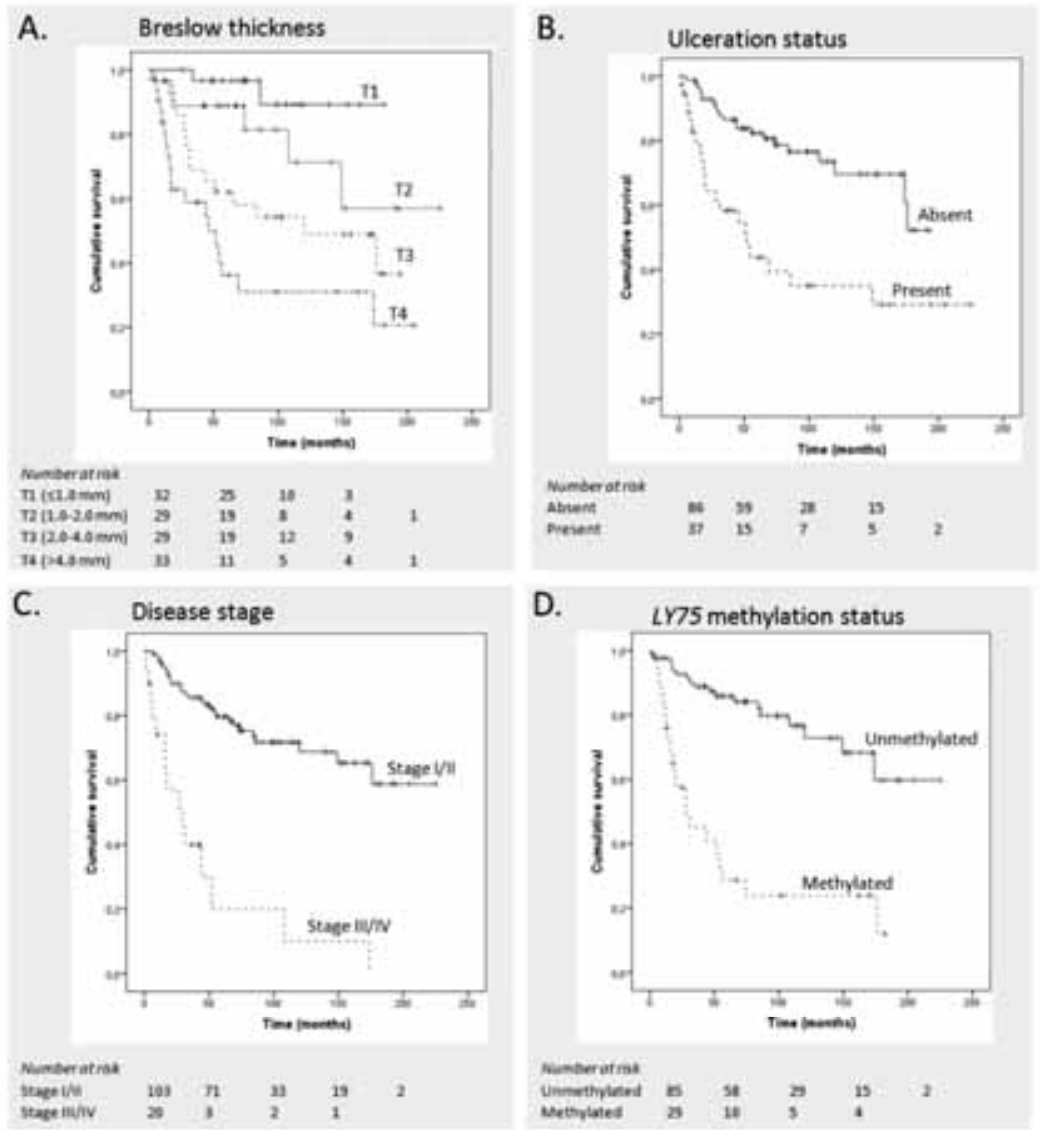

Figure 2. Kaplan-Meier survival curves of the best prognostic markers. A. Kaplan-Meier curve of melanomaspecific survival of patients grouped according to primary tumor thickness divided by AJCC tumor stage. B. Kaplan-Meier curve of melanoma-specific survival of patients grouped according to the presence or absence of tumor ulceration. C. Kaplan-Meier curve of melanoma-specific survival of patients grouped according to localized disease (Stage I/II) and metastatic disease (Stage III/IV). D. Kaplan-Meier curve of melanomaspecific survival of patients grouped according to LY75 methylation.

Multivariate analysis with known prognostic markers revealed that Breslow thickness, advanced disease stage, and location on the head/neck were independent statistically significant predictors of poor survival (Table 3). Subsequently, the prognostic effect of individual methylation markers was evaluated in a multivariate model together with current prognostic markers. Interestingly, in multivariate analyses, LY75 methylation remained a statistically significant $(\mathrm{HR}=4.011,95 \%-\mathrm{Cl} 1.693-9.502, \mathrm{P}=.002)$ predictor of poor survival (Table 3; Figure 2D). Next, backward stepwise elimination was applied on a saturated multivariate Cox proportional hazards regression model to further screen for the most predictive combination of risk factors for survival of melanoma patients. 


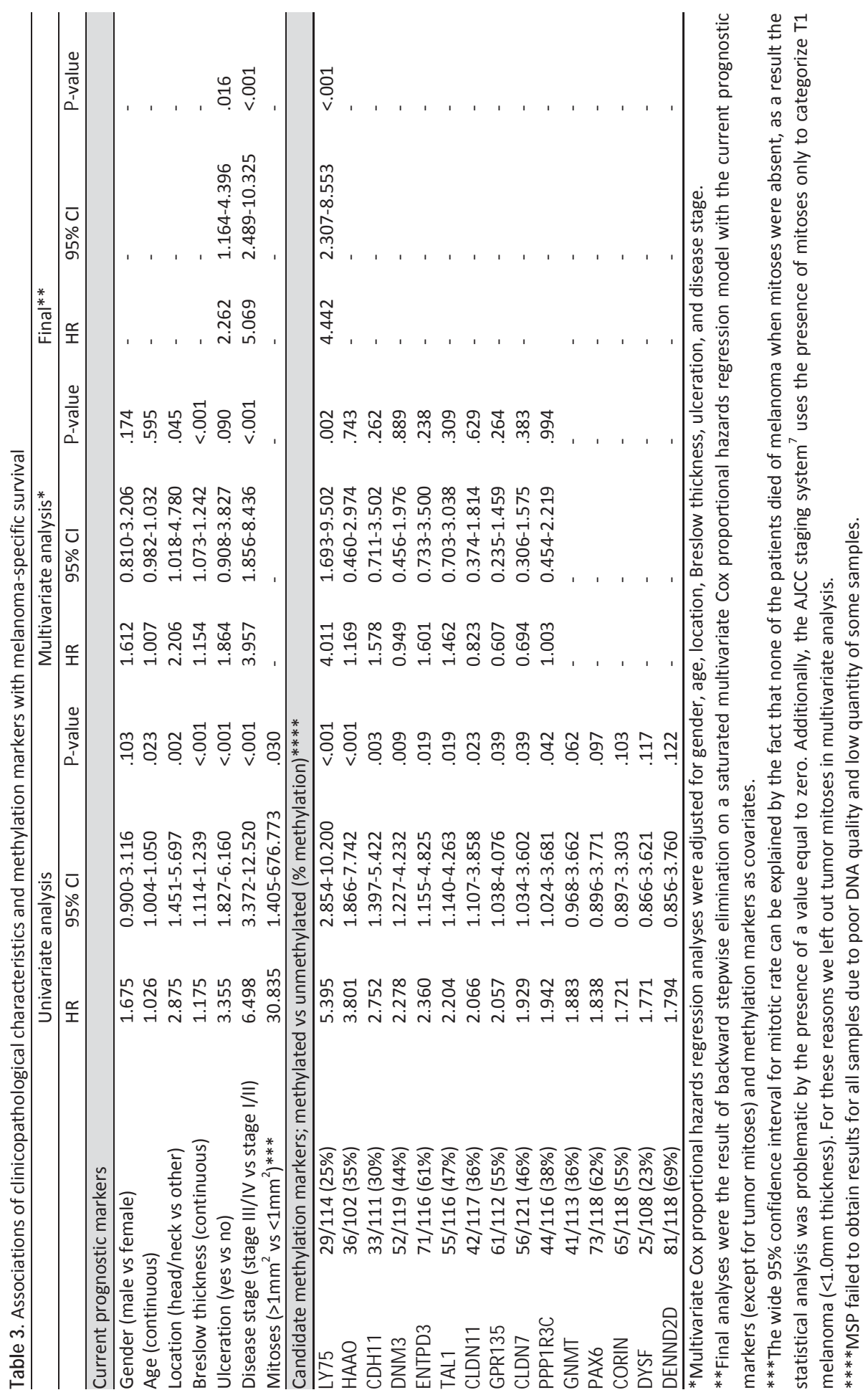


For this, all covariates listed in Table 3 were incorporated. Tumor ulceration and metastatic disease at diagnosis were, together with LY75 methylation, the most significant predictors of survival.

Using AIC, the added value of other prognosticators and methylation markers was examined to select the best model to predict adverse prognosis of melanoma. This revealed that the presence of LY75 methylation, absence of GPR135 methylation, ulceration, stage III/IV at diagnosis, male gender, and age represented the best prognosis prediction model. As the biological significance of GPR135 methylation was ambiguous, i.e. in univariate analysis methylation was associated with a worse prognosis and in multivariate analysis with a good prognosis; this covariate was removed from the model. Gender and age were statistically non-significant covariates; however, according to the AIC the adding of this information leads to a better fit of the model (AIC=183.94).

\section{LY75 methylation predicts distant metastasis formation in stage I/ II patients}

Since melanoma survival largely depends on the formation of lethal metastases, we asked whether LY75 methylation was a significant predictor of distant metastases formation in stage I and II patients. Of 95 stage I and II patients with known methylation status, a total of 26 patients developed metastatic disease. Using univariate analysis, we observed a strong prognostic value of LY75 methylation to predict distant metastasis formation, $\mathrm{HR}=7.835,95 \%-\mathrm{Cl} 3.554-17.274, \mathrm{P}<.001$. Applying multivariate analyses, promoter methylation of $\mathrm{LY}_{75}\left(\mathrm{HR}_{\mathrm{L} Y 75}=7.924,95 \%-\mathrm{Cl} 3.492-\right.$ $17.980, \mathrm{P}<.001)$ remained the best predictor of metastatic disease development together with ulceration $\left(\mathrm{HR}_{\text {ulceration }}=3.477,95 \%-\mathrm{Cl} 1.579-7.655, \mathrm{P}=.002\right)$ and age $\left(H R_{\text {age }}=1.040,95 \%-C l\right.$ 1.009-1.072, $\left.\mathrm{P}=.011\right)$.

\section{Validation of prognostic value of LY/5 methylation}

To validate the observed association of LY75 methylation with distant metastasis formation we evaluated TCGA data, although this was not totally independent information as the same samples were used for identification purposes. The TCGA dataset provides clinical follow-up data for 44 primary melanomas of which 14 patients recurred. For analysis, a single representative probe was selected (cg24478096) and as cutoff a normalized $\beta$-value of 0.2 was chosen, that is, samples with $\beta$-value $>0.2$ were scored as methylated and vice versa. Kaplan-Meier survival analysis showed that primary melanomas that were methylated had a significantly higher risk to develop metastatic disease (log-rank $P=.020$, Figure 3). Backward stepwise elimination on a saturated multivariate Cox proportional hazards regression model with disease stage, Breslow thickness, tumor ulceration, gender, and age as covariates revealed that LY75 methylation was the best single marker to predict recurrence in this series $\left(\mathrm{HR}_{\mathrm{LY} 75}=3.568,95 \%-\mathrm{Cl} 1.142-11.149, \mathrm{P}=.029\right)$. 


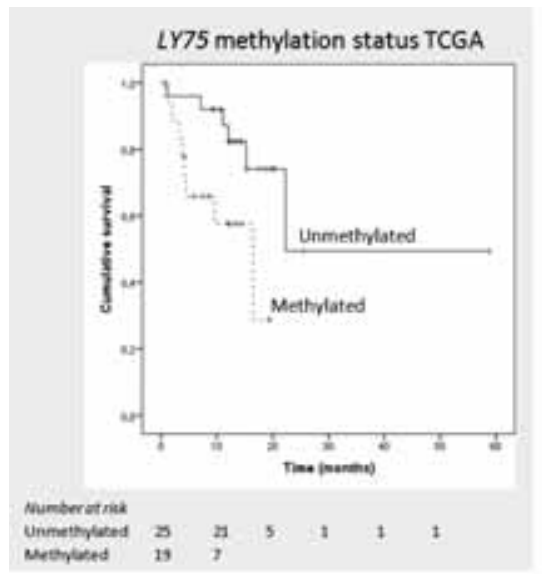

Figure 3. Kaplan-Meier survival curve of recurrence-free survival of TCGA patients grouped according to LY75 methylation status at probe cg24478096.

\section{Discussion}

Cutaneous melanoma is a highly aggressive skin cancer that accounts for approximately $75 \%$ of skin cancer-related deaths. Despite an increased understanding of the biology of melanoma development and the identification of molecular alterations that accompany melanoma progression ${ }^{10,30}$, the AJCC melanoma staging and classification system has not yet incorporated potential molecular alterations ${ }^{7}$. However, improvements to the current staging system are necessary to more accurately identify individual patients with aggressive disease at diagnosis. These patients might benefit from additional therapy leading to improved clinical management and better patient outcome.

Here, we presented a workflow that identified functional promoter $\mathrm{CpG}$ island methylation alterations in melanoma that might be associated with disease progression and identified LY75 methylation as an independent prognostic marker that outperformed Breslow thickness. Additionally, methylation of HAAO and CDH11 were found to possess prognostic value to predict poor prognosis of melanoma in univariate analyses. Cadherin-11 (CDH11), here used as guide gene for candidate gene selection, is an important mediator of cellular adhesion and loss of $\mathrm{CDH} 11$ expression through methylation of its promoter region has previously been identified to play a role in melanoma metastasis ${ }^{20}$. 3-hydroxyanthranilate 3,4-dioxygenase (HAAO) is an enzyme that catalyzes the conversion of 3-hydroxyanthranilate to quinolinic acid, of which its function in cancer remains to be elucidated ${ }^{31}$. HAAO has previously been described as frequently methylated in several malignancies, such as prostate cancer ${ }^{32,33}$ and ovarian cancer $^{34}$. Moreover, prognostic relevance of HAAO methylation was shown in endometrial carcinomas ${ }^{35}$. This is the first study to report on the prognostic implication of HAAO methylation in melanoma. 
Lymphocyte antigen 75 (LY75) was identified as an independent prognostic predictor of melanoma survival, i.e. patients with LY75 methylated tumors had an approximately 4-fold higher risk to die from their disease. Using stepwise backward elimination on multivariate models with all potential risk factors, including known prognostic melanoma metrics (Breslow thickness, ulceration, presence of metastatic disease, location, gender, and age), it was shown that LY75 methylation, ulceration, and the presence of metastatic disease at diagnosis represents the best model to predict poor disease outcome. Importantly, among stage I and II melanoma patients, LY75 methylation was the strongest predictor $(\mathrm{HR}=7.924)$ of distant metastasis development in a model together with tumor ulceration and older age at diagnosis. LY75 methylation outperformed Breslow thickness, the most important clinical prognostic parameter. This is especially of interest since the incidence of patients diagnosed with thin melanoma has been rising and an increasing proportion of melanoma-related deaths occur among these patients ${ }^{8,9,36}$. Thus, notwithstanding their generally favorable prognosis, thin melanomas contribute considerably (approximately $25 \%$ ) to melanoma mortality. The identification of a strong relationship between LY75 methylation and poor prognosis that was irrespective of Breslow thickness provides a promising lead to identify high-risk patients, that are not detected by traditional risk factors, who might benefit from adjuvant therapy and closer follow-up. This finding requires additional validation, preferably in large prospective, population-based cohorts to determine the potential to implement LY75 methylation as molecular marker in routine clinical practice.

LY75 also known as CD-205 or DEC-205, is a collagen-binding mannose family receptor that is predominantly expressed on thymic cortical epithelium and myeloid dendritic cell subsets ${ }^{37}$. LY75 has been reported to play a role in the endocytic uptake of antigen leading to both $\mathrm{CD}^{+}$and $\mathrm{CD}^{+}$T-cell response ${ }^{37-39}$. Therefore, the poor clinical outcome of patients with LY75-methylated tumors might be partly explained by poor immune recognition, although we could not observe a significant association of methylation with the absence of tumor-infiltrating lymphocytes (TILs) in our series (data not shown). However, it might be that the TILs are functionally defective or incompletely activated as is commonly seen during tumor progression ${ }^{40}$. Melanoma is increasingly treated with immunomodulatory therapies, such as anti-CTLA4, and antiPD1 antibodies that exploit the capacity of $\mathrm{CD}^{+}$T-cells to kill immunogenic melanoma cells ${ }^{41,42}$. Response rates of anti-CTLA-4 and anti-PD1 therapies are approximately $10 \%$ and $40 \%$, respectively ${ }^{6}$. Biomarkers predicting therapy response are thus far lacking ${ }^{43}$. It would be of interest to examine if LY75 methylation might reflect poor response to immune therapies and useful as predictive biomarker as well.

Other indications that the LY75 gene plays a role in cancer, such as melanoma, comes from the observation that LY75 expression is diminished in several malignancies, including colorectal and breast carcinomas ${ }^{44-47}$. A functional relationship of LY75 promoter CpG island hypermethylation that resulted in loss of expression has been reported in human dilated cardiomyopathy ${ }^{48}$. LY75 expression has been 
correlated with cell differentiation and decreased proliferative potential suggesting that LY75 suppresses tumor growth ${ }^{46}$. Furthermore, loss of LY75 expression is associated with tumor development and progression ${ }^{44,47}$, and might inhibit cell proliferation and enhance differentiation through an interaction with the IL4 receptor $^{46,47}$. Additionally, the predicted collagen-binding properties of LY75 might reflect enhanced cell adhesion. In ovarian cancer cells, upregulation of LY75 in association with overexpression of the interleukin-6 receptor (IL6R $\alpha$ ) resulted in enhanced adherence of tumor cells to the omentum, suggesting a related function and shared pathway of IL6 and LY75 ${ }^{49}$. Thus, the prognostic relevance of LY75 methylation in melanoma might be the direct result of increased tumor growth and loss of cell-cell adhesion perhaps caused by disturbed collagen production. Interestingly, knock-down of ly75 in a zebrafish model resulted in a noticeable skin detachment phenotype, potentially due to deregulated collagen production ${ }^{48}$. Furthermore, downregulation of LY75 has been found to be associated with TERT immortalization of urothelial cells ${ }^{50}$. TERT promoter mutations were recently identified at high frequencies in cutaneous melanoma and correlated with poor prognosis ${ }^{51-53}$. Future studies should aim to investigate the role of LY75 methylation and expression including the possible relationship with TERT mutations in cutaneous melanoma.

In summary, the workflow combining MBD/RNA-sequencing, Infinium-450K data and public TCGA data in combination with usage of two guide genes, efficiently identified specific regions in promoter CpG islands of 85 genes that were differentially and functionally methylated between healthy melanocytes and melanoma cells. Integration of multiple data sets and techniques enabled identification of stable and reproducible markers decreasing the chance of finding false positive results, a problem inherent to biomarker identification efforts ${ }^{54}$. LY75 methylation was recognized as a strong, independent predictor of poor prognosis, both in predicting melanoma-specific death and predicting the formation of distant metastases in stage I and II melanoma patients. More insight into the role of LY75 in the pathobiology of melanoma will strengthen the evidence of LY75 methylation as melanoma biomarker. In addition, another crucial aspect of biomarker research, i.e. independent validation on large prospective studies using similar detection techniques, is required to ultimately incorporate this marker into clinical practice and guide diagnosis, therapy and followup of patients with LY75 methylated melanomas.

\section{Acknowledgements}

We thank Dr. Léon van Kempen for providing the melanoma cell lines. Roy Cloots, Kathleen Daenen, and Jaleesa Van der Meer are acknowledged for excellent technical support. This work was supported by Profileringsfonds Maastricht University Medical Center (grant number PF=278); and by an EU FP7 Marie Curie Industry-Academia Partnerships and Pathways (IAPP) research programme, Target-Melanoma (grant number 230614). 


\section{References}

1. MacKie RM, Hauschild A, Eggermont AM. Epidemiology of invasive cutaneous melanoma. Ann Oncol, 2009. 20 Suppl 6: p. vi1-7.

2. Ferlay J, Shin HR, Bray F, et al. Estimates of worldwide burden of cancer in 2008: GLOBOCAN 2008. Int J Cancer, 2010. 127(12): p. 2893-2917.

3. Ferlay J, Soerjomataram I, Ervik M, Dikshit R, Eser S, Mathers C, Rebelo M, Parkin DM, Forman D, Bray, F. GLOBOCAN 2012 v1.0, Cancer Incidence and Mortality Worldwide: IARC CancerBase No. 11 [Internet]. Lyon, France: International Agency for Research on Cancer; 2013. Available from: http://globocan.iarc.fr, accessed on 01/09/2014.

4. Gray-Schopfer V, Wellbrock C, Marais R. Melanoma biology and new targeted therapy. Nature, 2007. 445(7130): p. 851-857.

5. Griewank KG, Scolyer RA, Thompson JF, et al. Genetic alterations and personalized medicine in melanoma: progress and future prospects. J Natl Cancer Inst, 2014. 106(2): p. djt435.

6. Miller DM, Flaherty KT, Tsao H. Current status and future directions of molecularly targeted therapies and immunotherapies for melanoma. Semin Cutan Med Surg, 2014. 33(2): p. 60-67.

7. Balch CM, Gershenwald JE, Soong SJ, et al. Final version of 2009 AJCC melanoma staging and classification. J Clin Oncol, 2009. 27(36): p. 6199-6206.

8. Criscione VD, Weinstock MA. Melanoma thickness trends in the United States, 1988-2006. J Invest Dermatol, 2010. 130(3): p. 793-797.

9. Whiteman DC, Baade PD, Olsen CM. More People Die from Thin Melanomas $(1 \mathrm{~mm})$ than from Thick Melanomas (>4 mm) in Queensland, Australia. J Invest Dermatol, 2014. p. 1190-1193.

10. van den Hurk K, Niessen HE, Veeck J, et al. Genetics and epigenetics of cutaneous malignant melanoma: a concert out of tune. Biochim Biophys Acta, 2012. 1826(1): p. 89-102.

11. Laird PW. The power and the promise of DNA methylation markers. Nat Rev Cancer, 2003. 3(4): p. 253-266.

12. Heyn H, Esteller M. DNA methylation profiling in the clinic: applications and challenges. Nat Rev Genet, 2012. 13(10): p. 679-692.

13. Conway K, Edmiston SN, Khondker ZS, et al. DNA-methylation profiling distinguishes malignant melanomas from benign nevi. Pigment Cell Melanoma Res, 2011. 24(2): p. 352-360.

14. Sigalotti L, Covre A, Fratta $E$, et al. Whole genome methylation profiles as independent markers of survival in stage IIIC melanoma patients. J Transl Med, 2012. 10: p. 185.

15. Gao L, Smit MA, van den Oord JJ, et al. Genome-wide promoter methylation analysis identifies epigenetic silencing of MAPK13 in primary cutaneous melanoma. Pigment Cell Melanoma Res, 2013. 26(4): p. 542-554.

16. Rakosy Z, Ecsedi $S$, Toth $R$, et al. Integrative genomics identifies gene signature associated with melanoma ulceration. PLoS One, 2013. 8(1): p. e54958.

17. Thomas NE, Slater NA, Edmiston SN, et al. DNA methylation profiles in primary cutaneous melanomas are associated with clinically significant pathologic features. Pigment Cell Melanoma Res, 2014. 27(6): p. 1097 1105.

18. Ecsedi S, Hernandez-Vargas $\mathrm{H}$, Lima SC, et al. DNA methylation characteristics of primary melanomas with distinct biological behaviour. PLoS One, 2014. 9(5): p. e96612.

19. Gao L, van den Hurk K, Moerkerk PT, et al. Promoter CpG Island Hypermethylation in Dysplastic Nevus and Melanoma: CLDN11 as an Epigenetic Biomarker for Malignancy. J Invest Dermatol, 2014. p.

20. Carmona FJ, Villanueva A, Vidal A, et al. Epigenetic disruption of cadherin-11 in human cancer metastasis. J Pathol, 2012. 228(2): p. 230-240.

21. Deng Z, Niu G, Cai L, et al. The prognostic significance of CD44V6, CDH11, and beta-catenin expression in patients with osteosarcoma. Biomed Res Int, 2013. 2013: p. 496193.

22. Li L, Ying J, Li H, et al. The human cadherin 11 is a pro-apoptotic tumor suppressor modulating cell stemness through Wnt/beta-catenin signaling and silenced in common carcinomas. Oncogene, 2012. 31(34): p. 39013912.

23. Song $\mathrm{YH}$, Shiota $\mathrm{M}$, Kuroiwa $\mathrm{K}$, et al. The important role of glycine $\mathrm{N}$-methyltransferase in the carcinogenesis and progression of prostate cancer. Mod Pathol, 2011. 24(9): p. 1272-1280.

24. Huang YC, Chen M, Shyr YM, et al. Glycine N-methyltransferase is a favorable prognostic marker for human cholangiocarcinoma. J Gastroenterol Hepatol, 2008. 23(9): p. 1384-1389.

25. De Meyer T, Mampaey E, Vlemmix M, et al. Quality evaluation of methyl binding domain based kits for enrichment DNA-methylation sequencing. PLoS One, 2013. 8(3): p. e59068.

26. van Vlodrop IJ, Niessen HE, Derks $\mathrm{S}$, et al. Analysis of promoter $\mathrm{CpG}$ island hypermethylation in cancer: location, location, location! Clin Cancer Res, 2011. 17(13): p. 4225-4231.

27. van den Hurk K, Balint, B., Toomey S., O'Leary, P.C., Unwin, L., Sheahan, K., McDermott, E.W., Murphy, I., van den Oord, J.J., Rafferty, M., FitzGerald, D., Moran, J., Cummins, R., MacEneaney, O., Kay, E., O'Brien, C.P., 
Finn, S.P., Heffron, C.C.B.B., Murphy, M., Yela, R., Power, D.G., Regan, P.J., McDermott, C., O’Keeffe, A., Orosz, Z., Donnellan, P.P., Crown, J.P., Hennessy, B.T, and Gallagher, W.M. . High-throughput oncogene mutation profiling reveals demographic differences in BRAF mutation rates among melanoma patients. Melanoma Research. Mel Res, 2015. In press: $p$.

28. Sandoval J, Heyn H, Moran S, et al. Validation of a DNA methylation microarray for $450,000 \mathrm{CpG}$ sites in the human genome. Epigenetics, 2011. 6(6): p. 692-702.

29. Derks S, Lentjes MH, Hellebrekers DM, et al. Methylation-specific PCR unraveled. Cell Oncol, 2004. 26(5-6): p. 291-299.

30. Miller AJ, Mihm MC, Jr. Melanoma. N Engl J Med, 2006. 355(1): p. 51-65.

31. Colabroy KL, Zhai H, Li T, et al. The mechanism of inactivation of 3-hydroxyanthranilate-3,4-dioxygenase by 4chloro-3-hydroxyanthranilate. Biochemistry, 2005. 44(21): p. 7623-7631.

32. Mahapatra S, Klee EW, Young $\mathrm{CY}$, et al. Global methylation profiling for risk prediction of prostate cancer. Clin Cancer Res, 2012. 18(10): p. 2882-2895.

33. Litovkin $\mathrm{K}$, Joniau S, Lerut $\mathrm{E}$, et al. Methylation of PITX2, HOXD3, RASSF1 and TDRD1 predicts biochemical recurrence in high-risk prostate cancer. J Cancer Res Clin Oncol, 2014. 140(11): p. 1849-1861.

34. Huang YW, Jansen RA, Fabbri E, et al. Identification of candidate epigenetic biomarkers for ovarian cancer detection. Oncol Rep, 2009. 22(4): p. 853-861.

35. Huang YW, Luo J, Weng YI, et al. Promoter hypermethylation of CIDEA, HAAO and RXFP3 associated with microsatellite instability in endometrial carcinomas. Gynecol Oncol, 2010. 117(2): p. 239-247.

36. Welch HG, Woloshin S, Schwartz LM. Skin biopsy rates and incidence of melanoma: population based ecological study. BMJ, 2005. 331(7515): p. 481.

37. Jiang W, Swiggard WJ, Heufler C, et al. The receptor DEC-205 expressed by dendritic cells and thymic epithelial cells is involved in antigen processing. Nature, 1995. 375(6527): p. 151-155.

38. Bozzacco L, Trumpfheller C, Siegal FP, et al. DEC-205 receptor on dendritic cells mediates presentation of HIV gag protein to CD8+ T cells in a spectrum of human MHC I haplotypes. Proc Natl Acad Sci U S A, 2007. 104(4): p. 1289-1294.

39. Cheong $\mathrm{C}$, Choi JH, Vitale L, et al. Improved cellular and humoral immune responses in vivo following targeting of HIV Gag to dendritic cells within human anti-human DEC205 monoclonal antibody. Blood, 2010. 116(19): p. 3828-3838.

40. Marincola FM, Jaffee EM, Hicklin DJ, et al. Escape of human solid tumors from T-cell recognition: molecular mechanisms and functional significance. Adv Immunol, 2000. 74: p. 181-273.

41. Brahmer JR, Tykodi SS, Chow LQ, et al. Safety and activity of anti-PD-L1 antibody in patients with advanced cancer. N Engl J Med, 2012. 366(26): p. 2455-2465.

42. Hodi FS, O'Day SJ, McDermott DF, et al. Improved survival with ipilimumab in patients with metastatic melanoma. N Engl J Med, 2010. 363(8): p. 711-723.

43. Griewank KG, Ugurel S, Schadendorf D, et al. New developments in biomarkers for melanoma. Curr Opin Oncol, 2013. 25(2): p. 145-151.

44. al-Tubuly AA, Luqmani YA, Shousha S, et al. Differential expression of gp200-MR6 molecule in benign hyperplasia and down-regulation in invasive carcinoma of the breast. Br J Cancer, 1996. 74(7): p. 1005-1011.

45. Tungekar MF, Gatter KC, Ritter MA. Bladder carcinomas and normal urothelium universally express gp200MR6, a molecule functionally associated with the interleukin 4 receptor (CD 124). Br J Cancer, 1996. 73(4): p. 429-432.

46. Al-Tubuly AA, Spijker R, Pignatelli $M$, et al. Inhibition of growth and enhancement of differentiation of colorectal carcinoma cell lines by MAb MR6 and IL-4. Int J Cancer, 1997. 71(4): p. 605-611.

47. Kaklamanis L, Koukourakis MI, Leek R, et al. Loss of interleukin 4 receptor-associated molecule gp200-MR6 in human breast cancer: prognostic significance. Br J Cancer, 1996. 74(10): p. 1627-1631.

48. Haas J, Frese KS, Park YJ, et al. Alterations in cardiac DNA methylation in human dilated cardiomyopathy. EMBO Mol Med, 2013. 5(3): p. 413-429.

49. Giridhar PV, Funk HM, Gallo CA, et al. Interleukin-6 receptor enhances early colonization of the murine omentum by upregulation of a mannose family receptor, LY75, in ovarian tumor cells. Clin Exp Metastasis, 2011. 28(8): p. 887-897.

50. Chapman EJ, Kelly G, Knowles MA. Genes involved in differentiation, stem cell renewal, and tumorigenesis are modulated in telomerase-immortalized human urothelial cells. Mol Cancer Res, 2008. 6(7): p. 1154-1168.

51. Horn S, FigI A, Rachakonda PS, et al. TERT promoter mutations in familial and sporadic melanoma. Science, 2013. 339(6122): p. 959-961.

52. Huang FW, Hodis E, Xu MJ, et al. Highly recurrent TERT promoter mutations in human melanoma. Science, 2013. 339(6122): p. 957-959.

53. Griewank KG, Murali R, Puig-Butille JA, et al. TERT promoter mutation status as an independent prognostic factor in cutaneous melanoma. J Natl Cancer Inst, 2014. 106(9)

54. Ioannidis JP. Biomarker failures. Clin Chem, 2013. 59(1): p. 202-20 


\section{Supplementary information}

Supplementary Table S1. Samples used for methylation analysis

\begin{tabular}{lll}
\hline Characteristics & No. of Patients & $\%$ \\
\hline Common nevi used for Infinium-450K analyses $(\mathrm{n}=14)$ & & \\
\hline Gender & 5 & 36 \\
Female & 9 & 64 \\
Male & $20.6 \pm 24$. & \\
Age (years) & 3 & 21 \\
Location & 8 & 57 \\
$\quad$ Head and neck & 3 & 21 \\
Trunk & & \\
Extremities & 10 & 50 \\
\hline Common nevi used for validation of candidate genes with MSP $(\mathrm{n}=20)$ & 50 \\
Gender & 10 & \\
Female & $31.7 \pm 14.3$ & 22 \\
Male & & 57 \\
Age (years) & 3 & 21 \\
Location & 11 & \\
Head and neck & 5 & \\
Trunk & & \\
Extremities & & \\
\hline
\end{tabular}


Supplementary information

Supplementary Table S2a. MSP primers of 15 candidate genes

\begin{tabular}{|c|c|c|c|c|c|}
\hline \multirow{2}{*}{$\begin{array}{l}\text { Gene } \\
\text { CORIN }\end{array}$} & \multirow[b]{2}{*}{ Flank } & \multirow{2}{*}{$\begin{array}{l}\text { Sense primer }\left(5^{\prime}->3^{\prime}\right) \\
\text { TTTATTTATGAAATAGTTTTTTGTTTT }\end{array}$} & \multirow{2}{*}{$\begin{array}{l}\text { Antisense primer }\left(\mathbf{3}^{\prime}->\mathbf{5}^{\prime}\right) \\
\text { AAACTAAAAAACCATCACACCTAAC }\end{array}$} & \multirow{2}{*}{$\begin{array}{l}\mathbf{T}\left({ }^{\circ} \mathrm{C}\right) \\
56\end{array}$} & \multirow{2}{*}{$\begin{array}{c}\begin{array}{c}\text { PCR } \\
\text { cycles }\end{array} \\
30\end{array}$} \\
\hline & & & & & \\
\hline & $\mathrm{U}$ & GTTTTTTGTTTTTGTTTTGGAAGAGT & ССТAACTACAATAAAACAACAAATCATCA & 66 & 30 \\
\hline & M & TTGTTTTCGTTTCGGAAGAGC & ACTACGATAAAACAACGAATCATCG & 66 & 30 \\
\hline \multirow[t]{3}{*}{$\mathrm{CDH} 11$} & Flank & GYGGGTYGAGGAGTAGATGT & TCACCTAAAACCCTTAAAAATAAA & 56 & 30 \\
\hline & $\mathrm{U}$ & TGTGGGGGTTGTTTGTAGTTGTT & AAAATAAACACAACCTCCAAACCA & 68 & 25 \\
\hline & M & GGGGGTCGTTCGTAGTCGTC & AACGCAACCTCCGAACCG & 68 & 25 \\
\hline \multirow[t]{3}{*}{ CLDN11 } & Flank & GGTATTGTTTAGTTTAGGTTTAGGTATA & ACCCAATCATTAATAAAAATAATCAC & 56 & 30 \\
\hline & U & AGGTATAGTTGTGAGGGGTGAGGTAT & CCAATCCAACCCACAAAACTCA & 66 & 30 \\
\hline & M & TAGTCGTGAGGGGCGAGGTAC & GATCCAACCCACGAAACTCG & 66 & 30 \\
\hline \multirow[t]{3}{*}{ CLDN7 } & Flank & TGAGGTTTGTTAGGGGTGTTT & CCCAAAAATCCCAAACTCC & 56 & 30 \\
\hline & $U$ & GAGGTTTGTTAGGGGTGTTTTGTAGT & CAAACTAAATTTCCCTCAAACACCA & 66 & 30 \\
\hline & M & TTGTTAGGGGCGTTTCGTAGC & GAACTAAATTTCCCTCGAACACCG & 66 & 30 \\
\hline \multirow[t]{3}{*}{ DENND2D } & Flank & TTTAGGGGTTATGGATGGGTT & ACCCTAACCCCRACTCCC & 56 & 30 \\
\hline & $\mathrm{U}$ & GGTTATGGATGGGTTTGGTTGTT & CCCAACTCCCCAATACCCACA & 66 & 30 \\
\hline & M & TTATGGATGGGTTCGGTCGTC & CGACTCCCCGATACCCACG & 66 & 30 \\
\hline \multirow[t]{3}{*}{ DNM 3} & Flank & GTGTAGTTTGGTAGYGGTGTTT & AAAAATAACATAAAATCAACAACAAC & 56 & 30 \\
\hline & U & GGTAGTGGTGTTTTGGTGGTGGT & CAACAACAACATTATTCTCTTTCAACA & 66 & 30 \\
\hline & M & CGGTGTTTCGGTGGTGGC & CGACAACGTTATTCTCTTTCAACG & 66 & 30 \\
\hline \multirow[t]{3}{*}{ DYSF } & Flank & AATGTYGTGTTATTGGGAGATTT & ACTCCAATAAACTAAACTAAATCCC & 56 & 30 \\
\hline & $\mathrm{U}$ & GGAGTATTAGATTATAGTTTGATGGAGTTT & TCACCCCACTTATCAACCAACA & 66 & 30 \\
\hline & M & GAGTATTAGATTATAGTTCGACGGAGTTC & CCCGCTTATCAACCGACG & 66 & 30 \\
\hline \multirow[t]{3}{*}{ ENTPD3 } & Flank & GGYGTTTGAGTTGATATTTTTTTA & CRAATCCCCTAATCTTACCTATAC & 56 & 30 \\
\hline & U & GAGTTGATATTTTTTTAGTGTTGGTTGT & ССТAATCTTACCTATACAAAACCAATTCA & 68 & 30 \\
\hline & M & GATATTTTTTTAGCGTTGGTCGC & GATATTTTTTTAGCGTTGGTCGC & 68 & 30 \\
\hline \multirow[t]{3}{*}{ GNMT } & Flank & GGGTTAAGTGGGTAGAGGGTT & GGGTTAAGTGGGTAGAGGGTT & 56 & 30 \\
\hline & $U$ & GGTTTTGAGGGTTTTTTTTTTGTT & CCAAACTTTAAACCAAACACCCA & 68 & 30 \\
\hline & M & GTTTCGAGGGTTTTTTTTTCGTC & ACTTTAAACCGAACGCCCG & 68 & 30 \\
\hline \multirow[t]{3}{*}{ GPR135 } & Flank & TTTTGTTGTTTAGTTITGGTAATTG & AACGACGAACAAACAAAACAAC & 56 & 30 \\
\hline & $U$ & TGATTGTGAAGTATTGGTAGTTTTGTATT & CAAAACAACACCATAAACAAATCCA & 64 & 30 \\
\hline & M & ATTGTGAAGTATCGGTAGTTTCGTATC & CAACGCCGTAAACAAATCCG & 64 & 30 \\
\hline \multirow[t]{3}{*}{ HAOO } & Flank & ATTAAAGTTTATTAGGGGGTAAAGTT & CRCTCCATAACTATCCCRAAC & 56 & 30 \\
\hline & $\mathrm{U}$ & GGTTTTAAGTTTTTATTATGGGGTTGT & CCCACAACTCCACCCAACCA & 66 & 30 \\
\hline & M & TTAAGTTTTTATTACGGGGTCGC & GCAACTCCGCCCAACCG & 66 & 30 \\
\hline \multirow[t]{3}{*}{ LY75 } & Flank & TTAGGATGAGGATAGGTTGGG & CAAACTAAAAAACAACAAAACTATAAC & 56 & 30 \\
\hline & U & GGATAGGTTGGGTGATTTTTTGTT & AAACTATAACATCAAAACACCCAACA & 64 & 30 \\
\hline & M & GGTTGGGCGATTTTTCGTC & TATAACGTCGAAACACCCAACG & 64 & 30 \\
\hline \multirow[t]{3}{*}{ PAX6 } & Flank & GGGTGGGGAGAAGTAGGTTT & TCCTCATTAACTACCCRACCC & 56 & 30 \\
\hline & U & GGAGAAGTAGGTTTTTGTTTGGTT & ССТСАТТААСТАСССАACCCACA & 66 & 27 \\
\hline & M & GAGAAGTAGGTTTTCGTTCGGTC & ATTAACTACCCGACCCGCG & 66 & 27 \\
\hline \multirow[t]{3}{*}{ PPP1R3C } & Flank & GTYGTTTTAAGTTTGAGGTATTGG & AAACRTACAAAAAACTATCTAAACATC & 56 & 30 \\
\hline & U & AGGTATTGGTGTTTTGTTTGGGT & ACCAACTAAAACCAACCACATAACA & 66 & 30 \\
\hline & M & TGGCGTTTCGTTTGGGC & ACTAAAACCAACCGCGTAACG & 66 & 30 \\
\hline \multirow[t]{3}{*}{ TAL1 } & Flank & AAATGAATTATTTGGTTTATAATGGT & CCACTCACRTTCCAAACCTC & 56 & 30 \\
\hline & U & TGGTTTATAATGGTTGAGGTGTTTATT & AАACCTCATTAACATAAACCAAAACA & 66 & 30 \\
\hline & M & TTTATAATGGTCGAGGCGTTTATC & CCTCGTTAACATAAACCGAAACG & 66 & 30 \\
\hline
\end{tabular}


Supplementary Table S2b. MSP primers of candidate genes that were not further progressed

\begin{tabular}{|c|c|c|c|c|c|}
\hline \multicolumn{2}{|l|}{ Gene } & \multirow{2}{*}{$\begin{array}{l}\text { Sense primer }\left(5^{\prime}->3^{\prime}\right) \\
\text { AAGGGAGTTGGATGTTTTAGTTT }\end{array}$} & \multirow{2}{*}{$\begin{array}{l}\text { Antisense primer }\left(3^{\prime}->5^{\prime}\right) \\
\text { AAAAAATCRAAAATTACCAAAAAC }\end{array}$} & \multirow{2}{*}{$\begin{array}{l}\mathrm{T}\left({ }^{\circ} \mathrm{C}\right) \\
56\end{array}$} & \multirow{2}{*}{$\begin{array}{c}\begin{array}{c}\text { PCR } \\
\text { cycles }\end{array} \\
30\end{array}$} \\
\hline ADAM 32 & Flank & & & & \\
\hline & $U$ & TGGATGTTTTAAGTTTTGGGGTGTAT & ACAACATTCTCCAAAAACCCCA & 64 & 30 \\
\hline & M & ATGTTTTAGTTTCGGGGCGTAC & ACGTTCTCCGAAAACCCCG & 64 & 30 \\
\hline \multirow[t]{3}{*}{ ASB3 } & Flank & YGAGTTTGAAAAATTTGGTTTAA & AAAACACCRCCCCCTCC & 56 & 30 \\
\hline & U & TTGGTTTAAGTGTTTTTTTGTGAGGT & AACACCCAAACCTAACATCCCA & 66 & 30 \\
\hline & M & GTTTAAGCGTTTTTCGTGAGGC & CCCGAACCTAACGTCCCG & 66 & 30 \\
\hline \multirow[t]{3}{*}{ ATP5G2 } & Flank & GGGAGGGYGTTGTTTATTTTA & СТАACTCCTAAAACAATCTAAAAATAAC & 56 & 30 \\
\hline & $\mathrm{U}$ & GGAGGGTGTTGTTTATTTTAATTTGT & AACACCTACAACCCACTATAAAATTACA & 68 & 30 \\
\hline & M & GGCGTTGTTTATTTTAATTCGC & CTACGACCCGCTATAAAATTACG & 68 & 30 \\
\hline \multirow[t]{3}{*}{ CIDEA } & Flank & GTTTGTAAATTAGGTGATAGTTGG & CCAAAACCCCCAAAAACC & 56 & 30 \\
\hline & 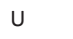 & ATGTATTTTTGGTTGTTGTTGTAGTTGT & AАACCCAАТССССТСАСАТСА & 64 & 30 \\
\hline & M & TTTTGGTCGTTGTTGTAGTCGC & CCGATCCCCTCGCATCG & 64 & 30 \\
\hline \multirow[t]{3}{*}{ DES } & Flank & TTATGAGTTAGGTTTATTCGTTTAGTTA & ACRAACTAAAAAAACCCTTAAAAC & 56 & 30 \\
\hline & $\mathrm{U}$ & TATGAGTTAGGTTTATTTGTTTAGTTAGTGT & CTTAAAACCAAAACCCACCCA & 68 & 30 \\
\hline & M & GTTAGGTTTATTCGTTTAGTTAGCGC & AACCGAAACCCGCCCG & 68 & 30 \\
\hline \multirow[t]{3}{*}{ DLEU7 } & Flank & GGTTTTGTATTTTGGTTTAGATGG & ССАAАСТСАССТTСAAATAAATAAA & 56 & 30 \\
\hline & $U$ & TATTTTGGTTTAGATGGTGATGTGTAGT & CCACACTAACCAACTCCAAAATCA & 64 & 30 \\
\hline & M & GTTTAGATGGCGATGCGTAGC & CGCTAACCAACTCCGAAATCG & 64 & 30 \\
\hline \multirow[t]{3}{*}{ NKAPL } & Flank & TTYGTTTGGTAATTGATAGGAAG & CTAAACCRAAATACTAAAAACATAAAC & 56 & 30 \\
\hline & $U$ & TGTGTGGGAGGTTGATTTTAGTGT & CATAAACCACACCTCAACACTAAACA & 68 & 30 \\
\hline & M & CGTGGGAGGTCGATTTTAGTGC & GCGCCTCAACGCTAAACG & 68 & 30 \\
\hline \multirow[t]{3}{*}{ OTP } & Flank & TTTAGGTGGGTAGAAATTTTTTG & AAAAAAACCAAACAACAACCC & 56 & 30 \\
\hline & U & ATTTTTTGTGAGTTTTTGGATGTGT & AAAAAAAAACAACATAAACTCAAAACA & 64 & 30 \\
\hline & M & TGCGAGTTTTTGGACGTGC & AAAAAACGACGTAAACTCAAAACG & 64 & 30 \\
\hline \multirow[t]{3}{*}{ OVOL1 } & Flank & CCACTAAAACCRACCCAACC & AGTTGTTTAGTTAAGTTTTTGGGAT & 56 & 30 \\
\hline & U & TTAGTTAAGTTTTTGGGATTTTGTGTT & AAACTCCTAAAAAAACACAAAACCA & 66 & 30 \\
\hline & M & AAGTTTTTGGGATTTCGCGTC & CCTAAAAAAACGCGAAACCG & 66 & 30 \\
\hline \multirow[t]{3}{*}{ PTGDR } & Flank & GGTATTAGAGTTTGTTTTTATTGAGAA & AATCACACCCCTCTTTAAAAAAC & 56 & 30 \\
\hline & $\mathrm{U}$ & TAGAGTTTGTTTTTATTGAGAATGTAGTGT & AAAAAACAAAACACTCTACAAAATAAACA & 68 & 30 \\
\hline & M & TGTTTTTATTGAGAACGTAGCGC & CGAAACGCTCTACAAAATAAACG & 68 & 30 \\
\hline \multirow[t]{3}{*}{ UCHL1 } & Flank & AGATTGTAAGGTTTGGGGGTT & САСТATAAAACCTATACAAAAAAAACA & 56 & 30 \\
\hline & $\mathrm{U}$ & TGGGGGTTTGGTTGTATTATTTT & AAACCAAACAAAAAAAAAACAAACA & 66 & 30 \\
\hline & M & GGGGGTTCGGTCGTATTATTTC & CCAAACGAAAAAAAAACGAACG & 66 & 30 \\
\hline
\end{tabular}


Table S3. Overview of 85 candidate genes

\begin{tabular}{|c|c|c|c|}
\hline Gene & Ensemble gene ID & chr & Gene description \\
\hline AC004017.1 & ENSG00000187568 & 19 & cDNA FL44663 fis, clone BRACE3003866 \\
\hline AC079790.2 & ENSG00000225214 & 2 & \\
\hline ACP1 & ENSG00000143727 & 2 & acid phosphatase 1 , soluble \\
\hline ADAM 32 & ENSG00000197140 & 8 & $\begin{array}{l}\text { Disintegrin and metalloproteinase domain-containing protein } 32 \\
\text { Precursor }\end{array}$ \\
\hline ATP5G2 & ENSG00000135390 & 12 & $\begin{array}{l}\text { ATP synthase lipid-binding protein, mitochondrial Precursor (ATP } \\
\text { synthase proteolipid P2)(ATPase protein 9)(ATPase subunit c) }\end{array}$ \\
\hline ATXN80S & ENSG00000230223 & 13 & $\begin{array}{l}\text { ATXN8 opposite strand (non-protein coding) (ATXN8OS), non- } \\
\text { coding RNA }\end{array}$ \\
\hline BLCAP & ENSG00000166619 & 20 & $\begin{array}{l}\text { Bladder cancer-associated protein (Bladder cancer } 10 \text { kDa } \\
\text { protein)(Bc10) }\end{array}$ \\
\hline BOLL & ENSG00000152430 & 2 & Protein boule-like \\
\hline C8orf47 & ENSG00000177459 & 8 & Uncharacterized protein C8orf47 \\
\hline CALCB & ENSG00000175868 & 11 & $\begin{array}{l}\text { Calcitonin gene-related peptide } 2 \text { Precursor (Calcitonin gene- } \\
\text { related peptide II)(CGRP-II)(Beta-type CGRP) }\end{array}$ \\
\hline $\mathrm{CCDC37}$ & ENSG00000163885 & 3 & Coiled-coil domain-containing protein 37 \\
\hline $\mathrm{CDH} 11$ & ENSG00000140937 & 16 & Cadherin-11 Precursor (Osteoblast cadherin)(OB-cadherin)(OSF-4) \\
\hline CIDEA & ENSG00000176194 & 18 & $\begin{array}{l}\text { Cell death activator CIDE-A (Cell death-inducing DFFA-like effector } \\
\text { A) }\end{array}$ \\
\hline CLDN11 & ENSG00000013297 & 3 & Claudin-11 (Oligodendrocyte-specific protein) \\
\hline CLDN7 & ENSG00000181885 & 17 & Claudin-7 \\
\hline COL14A1 & ENSG00000187955 & 8 & Collagen alpha-1(XIV) chain Precursor (Undulin) \\
\hline COL2A1 & ENSG00000139219 & 12 & $\begin{array}{l}\text { Collagen alpha-1(II) chain Precursor (Alpha-1 type II collagen) } \\
\text { [Contains Chondrocalcin] }\end{array}$ \\
\hline CORIN & ENSG00000145244 & 4 & $\begin{array}{l}\text { Atrial natriuretic peptide-converting enzyme (Pro-ANP-converting } \\
\text { enzyme)(Corin)(Heart-specific serine proteinase ATC2) }\end{array}$ \\
\hline CYP1B1 & ENSG00000138061 & 2 & $\begin{array}{l}\text { (Transmembrane protease. serine 10) } \\
\text { Cytochrome P450 1B1 (EC 1.14.14.1)(CYPIB1) }\end{array}$ \\
\hline DDIT4L & ENSG00000145358 & 4 & $\begin{array}{l}\text { DNA-damage-inducible transcript 4-like protein (Protein regulated } \\
\text { in development and DNA damage response } 2 \text { ) }\end{array}$ \\
\hline DENND2D & ENSG00000162777 & 1 & DENN domain-containing protein 2D \\
\hline DES & ENSG00000175084 & 2 & Desmin \\
\hline DLEU7 & ENSG00000186047 & 13 & deleted in lymphocytic leukemia, 7 \\
\hline DNM 3 & ENSG00000197959 & 1 & Dynamin-3 (EC 3.6.5.5)(Dynamin, testicular)(T-dynamin) \\
\hline DYSF & ENSG00000135636 & 2 & $\begin{array}{l}\text { Dysferlin (Dystrophy-associated fer-1-like protein)(Fer-1-like } \\
\text { protein 1) }\end{array}$ \\
\hline E2F8 & ENSG00000129173 & 11 & Transcription factor E2F8 (E2F-8) \\
\hline
\end{tabular}


Table S3. Overview of 85 candidate genes continued

\begin{tabular}{|c|c|c|c|}
\hline Gene & Ensemble gene ID & chr & Gene description \\
\hline ENTPD3 & ENSG00000168032 & 3 & $\begin{array}{l}\text { Ectonucleoside triphosphate diphosphohydrolase } 3 \text { (Ecto-ATP } \\
\text { diphosphohydrolase)(ATPDase)(Ecto-apyrase)(CD39 antigen-like }\end{array}$ \\
\hline EPHX3 & ENSG00000105131 & 19 & $\begin{array}{l}\text { 3)(HB6) } \\
\text { Abhydrolase domain-containing protein } 9 \text { Precursor }\end{array}$ \\
\hline FAIM 2 & ENSG00000135472 & 12 & Fas apoptotic inhibitory molecule 2 (Protein lifeguard) \\
\hline FAM 149A & ENSG00000109794 & 4 & $\begin{array}{l}\text { (Transmembrane BAX inhibitor motif-containing protein } 2 \text { ) } \\
\text { amily with sequence similarity } 149, \text { member } A\end{array}$ \\
\hline FAM 174B & ENSG00000185442 & 15 & Membrane protein FAM174B Precursor \\
\hline FAM 83F & ENSG00000133477 & 22 & Protein FAM83F \\
\hline $\mathrm{FBXO2}$ & ENSG00000116661 & 1 & F-box protein 2 \\
\hline $\mathrm{FBX027}$ & ENSG00000161243 & 19 & F-box only protein 27 (F-box/G-domain protein 5) \\
\hline FBX044 & ENSG00000132879 & 1 & F-box protein 44 \\
\hline GFRA3 & ENSG00000146013 & 5 & GDNF family receptor alpha-3 Precursor (GFR-alpha-3) \\
\hline GNMT & ENSG00000124713 & 6 & Glycine N-methyltransferase \\
\hline GPR135 & ENSG00000181619 & 14 & Probable G-protein coupled receptor 135 \\
\hline GUCY1A3 & ENSG00000164116 & 4 & $\begin{array}{l}\text { Guanylate cyclase soluble subunit alpha-3 (GCS-alpha-3) (Soluble } \\
\text { guanylate cyclase large subunit)(GCS-alpha-1) }\end{array}$ \\
\hline HAAO & ENSG00000162882 & 2 & $\begin{array}{l}\text { 3-hydroxyanthranilate 3,4-dioxygenase (3-hydroxyanthranilic acid } \\
\text { dioxygenase)(HAD)(3-hydroxyanthranilate oxygenase)(3-HAO) }\end{array}$ \\
\hline HCG4P3 & ENSG00000237669 & 6 & HLA complex group 4 pseudogene 3 \\
\hline HCG4B & ENSG00000227262 & 6 & HLA complex group 4B (non-protein coding) \\
\hline HLA-J & ENSG00000204622 & 6 & $\begin{array}{l}\text { major histocompatibility complex, class I, J (pseudogene) (HLA-J), } \\
\text { non-coding RNA }\end{array}$ \\
\hline HORMAD2 & ENSG00000176635 & 22 & HORMA domain-containing protein 2 \\
\hline HOXA11 & ENSG00000005073 & 7 & Homeobox protein Hox-A11 (Hox-1I) \\
\hline HOXA7 & ENSG00000122592 & 7 & Homeobox protein Hox-A7 (Hox-1A)(Hox 1.1) \\
\hline HOXA9 & ENSG00000078399 & 7 & Homeobox protein Hox-A9 (Hox-1G) \\
\hline HOXD12 & ENSG00000170178 & 2 & Homeobox protein Hox-D12 (Hox-4H) \\
\hline HS3ST1 & ENSG00000002587 & 4 & $\begin{array}{l}\text { Heparan sulfate glucosamine 3-O-sulfotransferase } 1 \text { Precursor } \\
\text { (Heparan sulfate D-glucosaminyl 3-O-sulfotransferase 1) (Heparan } \\
\text { sulfate 3-O-sulfotransferase 1)(h3-OST-1) }\end{array}$ \\
\hline HSPB9 & ENSG00000197723 & 17 & Heat shock protein beta-9 (HspB9)(Cancer/testis antigen 51 )(CT51) \\
\hline KCNQ5 & ENSG00000185760 & 6 & $\begin{array}{l}\text { Potassium voltage-gated channel subfamily KQT member } 5 \\
\text { (Voltage-gated potassium channel subunit Kv7.5) (Potassium } \\
\text { channel subunit alpha KvLOT5)(KOT-like 5) }\end{array}$ \\
\hline
\end{tabular}


Table S3. Overview of 85 candidate genes continued

\begin{tabular}{|c|c|c|c|}
\hline Gene & Ensemble gene ID & chr & Gene description \\
\hline $\mathrm{KCP}$ & ENSG00000135253 & 7 & Cysteine-rich motor neuron 2 protein Precursor (CRIM-2) \\
\hline KLHDC9 & ENSG00000162755 & 1 & $\begin{array}{l}\text { (Cysteine-rich BMP regulator } 2)(\text { Kielin/chordin-like protein } 1) \\
\text { Kelch domain-containing protein } 9 \text { (Kelch/ankyrin repeat- } \\
\text { containing cyclin A1-interacting protein) }\end{array}$ \\
\hline KRT7 & ENSG00000135480 & 12 & $\begin{array}{l}\text { Keratin, type II cytoskeletal } 7 \text { (Cytokeratin-7)(CK-7)(Keratin- } \\
\text { 7)(K7)(Sarcolectin) }\end{array}$ \\
\hline LY6G5C & ENSG00000204428 & 6 & Lymphocyte antigen 6 complex locus protein G5c Precursor \\
\hline LY75 & ENSG00000054219 & 2 & $\begin{array}{l}\text { Lymphocyte antigen } 75 \text { Precursor (DEC-205)(gp200-MR6)(CD205 } \\
\text { antigen) }\end{array}$ \\
\hline MGA & ENSG00000174197 & 15 & MAX gene-associated protein \\
\hline NCAM 2 & ENSG00000154654 & 21 & Neural cell adhesion molecule 2 Precursor (N-CAM 2) \\
\hline NFIA & ENSG00000162599 & 1 & Nuclear factor 1 A-type (Nuclear factor 1/A)(NF1-A)(NFI-A)(NF- \\
\hline OSR1 & ENSG00000143867 & 2 & $\begin{array}{l}\text { I/A)(CCAAT-box-binding transcription factor)(CTF)(TGGCA-binding } \\
\text { protein) } \\
\text { Protein odd-skipped-related } 1\end{array}$ \\
\hline OTP & ENSG00000171540 & 5 & Homeobox protein orthopedia \\
\hline OVOL1 & ENSG00000172818 & 11 & Putative transcription factor Ovo-like 1 (hOvo1) \\
\hline PAX6 & ENSG00000007372 & 11 & Paired box protein Pax-6 (Oculorhombin)(Aniridia type II protein) \\
\hline PCSK9 & ENSG00000169174 & 1 & $\begin{array}{l}\text { Proprotein convertase subtilisin/kexin type } 9 \text { Precursor (EC 3.4.21.- } \\
\text { )(Proprotein convertase PC9)(Subtilisin/kexin-like protease }\end{array}$ \\
\hline PDLIM 4 & ENSG00000131435 & 5 & $\begin{array}{l}\text { PC9)(Neural apoptosis-regulated convertase 1)(NARC-1) } \\
\text { PDZ and LIM domain protein } 4 \text { (LIM protein RIL)(Reversion-induced } \\
\text { LIM protein) }\end{array}$ \\
\hline PON3 & ENSG00000105852 & 7 & Serum paraoxonase/lactonase 3 \\
\hline PPP1R14A & ENSG00000167641 & 19 & $\begin{array}{l}\text { Protein phosphatase } 1 \text { regulatory subunit } 14 \mathrm{~A} \text { ( } 17 \mathrm{kDa} \text { PKC- } \\
\text { potentiated inhibitory protein of PP1)(CPI-17) }\end{array}$ \\
\hline PPP1R3C & ENSG00000119938 & 10 & $\begin{array}{l}\text { Protein phosphatase } 1 \text { regulatory subunit } 3 C \text { (Protein phosphatase } \\
1 \text { regulatory subunit 5)(R5)(Protein targeting to glycogen)(PTG) }\end{array}$ \\
\hline PROM 1 & ENSG00000007062 & 4 & $\begin{array}{l}\text { Prominin-1 Precursor (Prominin-like protein 1)(Antigen } \\
\text { AC133)(CD133 antigen) }\end{array}$ \\
\hline PTGDR & ENSG00000168229 & 14 & Prostaglandin D2 receptor (Prostanoid DP receptor)(PGD receptor) \\
\hline PTGER4 & ENSG00000171522 & 5 & $\begin{array}{l}\text { Prostaglandin E2 receptor EP4 subtype (PGE receptor, EP4 } \\
\text { subtype)(Prostanoid EP4 receptor) }\end{array}$ \\
\hline RBP1 & ENSG00000114115 & 3 & $\begin{array}{l}\text { Retinol-binding protein } 1 \text { (Cellular retinol-binding protein I)(CRBP- } \\
\text { I)(Cellular retinol-binding protein)(CRBP) }\end{array}$ \\
\hline SATB2 & ENSG00000119042 & 2 & $\begin{array}{l}\text { DNA-binding protein SATB2 (Special AT-rich sequence-binding } \\
\text { protein 2) }\end{array}$ \\
\hline SIM 1 & ENSG00000112246 & 6 & Single-minded homolog 1 \\
\hline SLC26A4 & ENSG00000091137 & 7 & Pendrin (Sodium-independent chloride/iodide transporter) \\
\hline SLC4A10 & ENSG00000144290 & 2 & $\begin{array}{l}\text { Sodium-driven chloride bicarbonate exchanger (Solute carrier } \\
\text { family } 4 \text { member 10) }\end{array}$ \\
\hline SLFN13 & ENSG00000154760 & 17 & Schlafen family member 13 \\
\hline
\end{tabular}


Table S3. Overview of 85 candidate genes continued

\begin{tabular}{|c|c|c|c|}
\hline Gene & Ensemble gene ID & chr & Gene description \\
\hline SYCN & ENSG00000179751 & 19 & syncollin \\
\hline $\mathrm{T}$ & ENSG00000164458 & 6 & Brachyury protein (T protein) \\
\hline TAL1 & ENSG00000162367 & 1 & $\begin{array}{l}\text { T-cell acute lymphocytic leukemia protein } 1 \text { (TAL-1)(Stem cell } \\
\text { protein)(T-cell leukemia/lymphoma protein } 5 \text { ) }\end{array}$ \\
\hline TMEM 155 & ENSG00000164112 & 4 & Protein TMEM155 Precursor \\
\hline TRIM 36 & ENSG00000152503 & 5 & $\begin{array}{l}\text { Tripartite motif-containing protein } 36 \text { (Zinc-binding protein } \\
\text { Rbcc728)(RING finger protein 98) }\end{array}$ \\
\hline TULP1 & ENSG00000112041 & 6 & Tubby-related protein 1 (Tubby-like protein 1) \\
\hline UCHL1 & ENSG00000154277 & 4 & $\begin{array}{l}\text { Ubiquitin carboxyl-terminal hydrolase isozyme L1 (UCH- } \\
\text { L1)(Ubiquitin thioesterase L1)(Neuron cytoplasmic protein }\end{array}$ \\
\hline WFDC2 & ENSG00000101443 & 20 & WAP four-disulfide core domain 2 \\
\hline
\end{tabular}


EPHX3
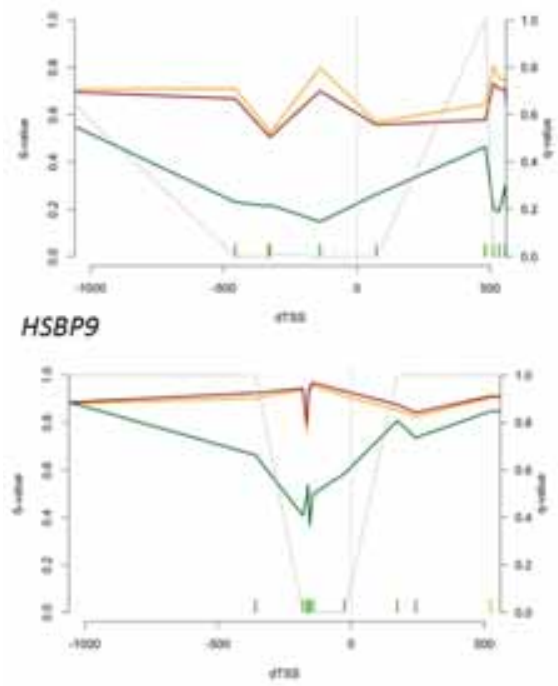

TMEM155

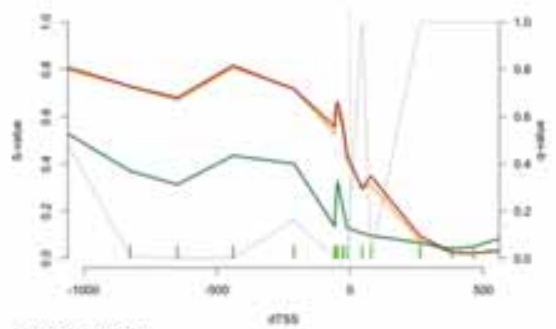

HORMAD2

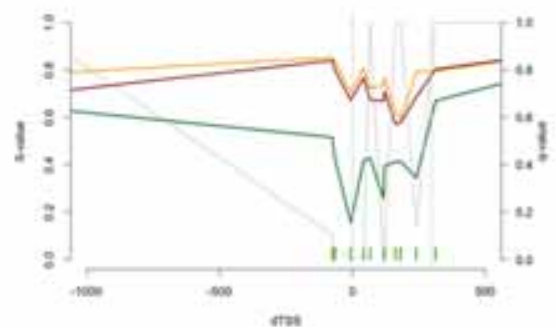

Figure S1. Examples of excluded genes based on visual inspection of Infinium-450K data. $X$-axis depicts the position relative to the gene's transcription start site, with the Infinium probes indicated with green vertical lines. The color code is as follows: green line, methylation curve of common nevi $(n=14)$; orange line, primary melanomas TCGA $(n=96)$; red line, metastatic melanomas TCGA $(n=363)$. Primary (left) $Y$-axis shows the $B$ values as a measurement of DNA-methylation levels. Secondary (right) $Y$-axis and the light grey line depict the false discovery rate q-value, and where statistically significant methylated regions occur. 



\section{CHAPTER 8}

General discussion 
Cutaneous melanoma represents the most aggressive skin cancer and is driven by an accumulation of genetic and epigenetic alterations. Treatment of melanoma patients is increasingly based on the molecular features of the tumor and personalized or precision medicine is becoming prominent in the clinical management of melanoma. There is a continued effort to elucidate the clinical significance of molecular information along with the identification of novel molecular cancer-associated aberrations. The research described in this thesis aimed to profile (epi)genetic alterations that characterize melanoma development and progression to enhance the understanding of melanoma pathogenesis and identify novel, clinically relevant biomarkers that could guide melanoma management and progress personalized medicine.

As reviewed in Chapter 2, melanoma encompasses a highly heterogeneous disease in terms of histology, clinical behavior, and (epi)genotype. Molecular alterations affect important signaling pathways during pathogenesis and an interplay of genetic and epigenetic changes is responsible for deregulated gene expression levels, which has been demonstrated for the regulation of the INK4b-ARF-INK4a and M ITF loci. Although the genetic components underlying melanoma are well studied, a thorough understanding of epigenetic alterations and their interactions is still missing to form a holistic and complete understanding of the behavior of this disease. Current efforts from The Cancer Genome Atlas (TCGA) Research Network in profiling and analyzing the molecular background (both genetic and epigenetic) of cutaneous melanoma via integration of molecular aberrations on the DNA, RNA, and protein level are ongoing ${ }^{1}$. This combined analysis of multiple datasets will further advance our knowledge of melanoma and is important in finding the biologically relevant changes.

Activating oncogene mutations have emerged as clinically relevant melanoma biomarkers. The presence of BRAF mutated melanoma in about $50 \%$ of patients rapidly translated into therapeutic decision-making as these patients can receive novel targeted treatment with BRAF or MEK inhibitors ${ }^{2}$. Within a high-throughput genotyping screen that is described in Chapter 3, we unexpectedly identified a low frequency of the most common $\mathrm{BRAF}^{\mathrm{V} 600 \mathrm{E}}$-mutant genotype among melanoma patients in Ireland. A total of 689 Irish melanoma patients were screened for BRAF ${ }^{\mathrm{V} 600 \mathrm{E}}$ mutations and it was observed that the mutation was present in $24 \%$ of cases $(19 \%$ of primary melanomas, $30 \%$ of metastases) indicating that, compared to the mutation frequency of approximately $50 \%$ in other countries, only a minority of Irish patients could benefit from drugs targeting this mutated molecule. The underlying cause of this relatively low BRAF mutation prevalence in Ireland remains to be clarified; however, it may be that a different geographical genetic background of Irish patients consequently gives rise to melanoma with a different etiology. Importantly, this observation emphasizes the necessity to investigate the generalizability of research findings that are performed on distinct populations as it may be inaccurate to generalize research conclusions more widely. This might also be true for reported therapeutic responses 
and possible mechanisms of therapeutic resistance. Because the accuracy and applicability of this information is of key importance to optimize clinical patient management, it is essential that research is performed among distinct geographic populations and/or among populations with different ancestries, and thus genetic background, to identify differences between diverse subgroups. Irreproducibility of research findings is estimated to range from $75 \%$ to $90 \%{ }^{3}$ and might be partly related to fundamental differences between patient groups. Hence, taking into account patient diversity, adequate subgroup analyses of large patient series is a top priority in biomarker research to truly reach a better patient care using personalized medicine.

Currently, clinical BRAF mutation testing mainly focuses on differences between patients, however, intrapatient heterogeneity is also relevant as the mutation status might be acquired over time during tumor progression ${ }^{4}$. Additionally, intratumor heterogeneity is a key factor that may lead to primary drug resistance, but might also account for acquired resistance ${ }^{5}$. It has been observed that BRAF inhibitors in wild-type BRAF melanomas paradoxically activate the MAPK pathway leading to adverse effects $^{6,7}$. Thus, for optimal patient management, it is critical to reliably determine the presence of the BRAF mutation and the amount of intratumor and intrapatient heterogeneity of BRAF mutation status as this might influence treatment decisions. As described in Chapter 4, contradictory statements about the heterogeneity of BRAF mutation status in melanomas exist; studies reporting on a substantial amount of BRAF heterogeneity used a variety of DNA-based molecular techniques ${ }^{8-11}$. Using the highly sensitive and specific immunohistochemical (IHC) technique (VE1 antibody), we and others $^{12-16}$ have shown that the amount of intratumor and intrapatient BRAF heterogeneity is low. The advantages of using IHC are that this technique enables the determination of the mutation in routinely processed formalin-fixed and paraffinembedded (FFPE) tumor specimens, it determines the mutation in single cells, and visualization simultaneously confirms that these are in fact melanoma cells. The low amount of $\mathrm{BRAF}^{\mathrm{V} 600 \mathrm{E}}$ heterogeneity indicates that a single needle biopsy or surgical excision is likely to provide all relevant information. Furthermore, as IHC has a high level of sensitivity and specificity in detecting the most common BRAF ${ }^{\mathrm{V} 600 \mathrm{E}}$ mutation, is rapid and has low-costs, it can be applied in clinical diagnostics. However, immunonegative cases need to be analyzed for the presence of non-V600E mutations using alternative methods, such as direct sequencing or mutation-specific PCR.

The finding that BRAF ${ }^{\mathrm{V} 600 \mathrm{E}}$ immunopositive melanomas display low frequency of heterogeneity indicates that the mutation is a common clonal driver event. The mutation was initially thought to be an early and critical step of malignant transformation as the mutation has the highest frequency in benign nevi, the first step in the melanoma progression model ${ }^{17}$, and is present in half of melanomas ${ }^{18}$. However, we and others ${ }^{19}$ observed that initial malignant lesions, i.e. melanoma in situ and radial-growth phase melanoma, are only rarely mutated, suggesting that the mutation is more likely to occur at later stages of melanoma progression. This in addition implies that a different molecular route underlies the development of these early malignant 
lesions, which seems likely as most nevi are stable and the rate of malignant progression is very low due to the induction of cellular senescene by mutant BRAF in nevi ${ }^{20}$. The observation that many nevi and primary melanomas contain cells with both BRAF wild-type and BRAF mutant cells (polyclonality of BRAF) while metastatic melanomas are in most cases homozygous for the mutation also suggests that the founding of the BRAF mutation is not an initial event but occurs later during melanoma progression $^{21,22}$. Interestingly, BRAF mutations lack prognostic significance in primary melanomas $^{23-28}$, whereas in metastasized tumors, the presence of mutant BRAF is associated with poor disease outcome independent of treatment ${ }^{27,28}$. Thus, evidence is accumulating that BRAF mutations have important implications during late disease progression opposed to initiating melanoma. Hence, other molecular changes are most likely responsible for the initiation of melanocyte transformation.

Epigenetic alterations, such as DNA methylation, non-coding RNAs, histone modification, and chromatin remodeling, all resulting in altered gene expression levels, are believed to occur early in cancer progression ${ }^{29}$ and are emerging as valuable melanoma biomarkers (Chapter 2). In this thesis we decided to focus on promoter CpG island methylation because of its and tight association with gene silencing in cancer ${ }^{30}$ and its clinical potential as biomarker ${ }^{31}$. The promoter CpG island hypermethylation status of a selected panel of 12 genes was studied in line with melanoma progression in Chapter 5. These genes were identified using Illumina's Infinium HumanMethylation27K (Infinium-27K) platform, examining genome-wide methylation profiles of 24 primary melanomas and five common nevi ${ }^{32}$. A gradual increase in DNAmethylation frequency was observed between common and dysplastic nevus samples. That is, promoter CpG island methylation of CTNT1, HOXA9, and PLEKHG6 as determined with bisulfite melting curve analysis (BMCA), and methylation of PPP1R3C and MAPK13, as determined with methylation-specific PCR (MSP) was more prominent in dysplastic nevi as compared with common nevi. Interestingly, the next step in progression from dysplastic nevus to primary melanoma was accompanied by a marked increase in methylation levels signifying a role for disruption of methylation patterns in the process of malignant transformation.

The accuracy of melanoma diagnosis is critical as it defines both treatment and prognosis of patients ${ }^{33}$. However, the histological differentiation of melanoma from dysplastic nevus can be ambiguous in a substantial number of cases ${ }^{34-36}$ as the morphology of dysplastic nevi may closely resemble melanoma ${ }^{37,38}$. As a result, misdiagnosis of melanoma is one of the most frequent causes of malpractice, occurring in approximately $15 \%$ of cases and largely involves false negative diagnoses ${ }^{39}$. In this regard the diagnostic potential of CDH11, CLDN11, GNMT, MAPK13, and PPP1R3C methylation in discriminating dysplastic nevus from primary melanoma was examined (Chapter 5). A diagnostic model comprising of CDH11, CLDN11, and PPP1R3C methylation was developed and validated in two sample series, analyzing a total of 144 dysplastic nevi and 161 primary melanomas, and was able to discriminate these lesions with a specificity of $89 \%$ and a sensitivity of $67 \%$. Hence, this study showed that 
methylation alterations might add in the accurate diagnosis of difficult lesions. Next, we need to determine the usefulness of this marker panel in those lesions that are truly difficult to diagnose and are leading to discordant diagnosis between pathologists. Furthermore, for implementation in clinical practice it is necessary to obtain large-scale evidence, i.e. the identified markers need to be validated and reproduced in large external cohorts using standardized protocols to reveal its clinical utility. Most identified biomarkers to date fail to take this necessary step in the translational process and therefore lack clinical impact ${ }^{40}$. In Chapter 7 the methylation frequencies of CDH11, CLDN11, PPP1R3C, and GNMT were examined in a partially different melanoma series and methylation levels were slightly lower as compared with the results obtained in Chapter $\mathbf{5}$. This further stresses the necessity of validation studies. The reason for the discrepancy in methylation frequencies might partly be explained by fundamental differences between these patient series, e.g. the series examined in Chapter 7 contained considerably more thin melanomas $(<2.0 \mathrm{~mm}$ thickness), i.e. 50\% versus 35\% and 29\% in series 1 and 2 of Chapter 5, respectively. Adding other methylated genes might further improve the sensitivity (and specificity) of the diagnostic test described in Chapter 5, i.e. methylation of DNM 3, DYSF, HAAO, and LY75 was found in $<5 \%$ in dysplastic nevi ( $n=117$, data not shown) and in up to $44 \%$ of primary melanomas (Chapter 7). Furthermore, other types of molecular information could also be considered to improve the diagnostic test, that is, the usefulness of IHC detection of ING4, CUL1, BRG1, and BCL2L11 expression ${ }^{41}$, as well as detection of cell cycle phase markers ${ }^{42}$ have been shown to differentiate melanomas from dysplastic nevi. A multivariate biomarker prediction model should be used to carefully assess the best combination of biomarkers to diagnose melanoma ${ }^{43}$. Additionally, for implementation in a routine clinical setting, e.g. in diagnostic molecular pathology laboratories, the proposed molecular assay should be reliable, robust, reproducible, sensitive, easy to detect, and able to investigate all potential markers with constrains of limited amount of tissue, time, and budget ${ }^{44}$. Methylation biomarkers can be easily and rapidly measured at low-cost (multiplex) using low amounts of genomic DNA extracted from FFPE material by methylation-specific PCR (MSP) and have therefore great clinical potential ${ }^{31}$.

The acquisition of metastatic capacity is the next step in melanoma progression and critical since metastasized melanoma is difficult to manage due to its resistance to traditional and also novel therapies leading to poor patient outcome ${ }^{45}$. In spite of the availability of several prognostic factors, i.e. Breslow thickness, ulceration, mitotic rate, tumor location, gender, and age $^{33}$, it remains challenging for clinicians to identify patients that are at high-risk to develop metastatic disease. Using the Infinium-27K genome-wide DNA methylation data ${ }^{32}$ that were used to screen for diagnostic methylation markers in Chapter 5, we continued to study differential methylation patterns between primary melanomas and its association with clinical outcome in Chapter 6. Promoter CPG island hypermethylation and gene expression levels of SYNPO2 were examined in independent sample series for prognostic significance in 
predicting melanoma-specific survival. Our findings indicate that methylation and diminished gene expression of SYNPO2 is associated with aggressive behavior. That is, patients with methylated SYNPO2 or diminished gene expression levels had a 2-fold increased risk to die from their disease that was independent of Breslow thickness, the most important clinical prognostic parameter ${ }^{33}$. SYNPO2 encodes myopodin, which is involved in cell motility and growth and has a reported tumor suppressor function ${ }^{46-51}$. The exact biological mechanism that is responsible for the aggressive phenotype in melanoma remains to be investigated.

The Infinium-27K that was used to screen for methylated genes in Chapter $\mathbf{5}$ and $\mathbf{6}$ interrogates about $27,000 \mathrm{CpG}$ sites located within promoter regions of roughly 15,000 genes. As this technique has a limited resolution Illumina developed a second beadchip array, Infinium HumanMethylation450K (Infinium-450K), covering 99\% of all RefSeq genes and approximately 450,000 CpG sites overall ${ }^{52}$. However, compared with sequencing techniques, Infinium-450K analysis is still limited because the probes are generally designed for single $\mathrm{CpG}$ sites resulting in suboptimal resolution. To increase the chance of finding accurate and reproducible biomarkers, we integrated both sequencing and array-based techniques in Chapter 7 to progress our search for prognostic methylation markers. That is, using novel methyl-binding domain (MBD)sequencing in combination with RNA-sequencing we comprehensively mapped the functional melanoma cell line DNA methylome. A major advantage of MBD-sequencing is that multiple methylated cytosines in close proximity are studied in a genome-wide manner $^{53}$. Publically available TCGA methylation data (infinium-450K) and Infinium$450 \mathrm{~K}$ analysis on common nevi was integrated to select for methylation changes that were present in clinical melanoma specimens, and to further fine-tune the differentially methylated region in clinical tissues. The clinical TCGA samples were predominantly from metastatic sites and thick primary melanomas, i.e. from patients with poor prognosis. Hence, the identified methylation changes likely harbor prognostic value. In total, we identified 85 robustly methylated gene promoters that represent promising methylation markers for melanoma. As the methylation markers were identified by integrating multiple datasets and techniques, this reduces the chance of finding false positive results and reflects robust and stable DNA hypermethylation of our candidate markers, emphasizing their clinical promise. We identified that methylation of LY75, HAAO, and $\mathrm{CDH} 11$ had prognostic value in melanoma of which LY75 was shown to be a strong, independent marker for poor prognosis. That is, patients diagnosed with LY75 methylated primary melanoma had a 4-fold increased risk to die from their disease. Notably, in stage I and II patients, methylation of LY75 reflected an 8-fold increased risk to develop distant metastases, as compared with patients with LY75 unmethylated tumors. In comparison to methylation of SYNPO2, LY75 methylation was not only independent of Breslow thickness, but remained a strong predictor of poor prognosis after adjusting for all known prognostic risk factors. The significance of LY75 methylation, in addition to SYNPO2, HAAO, and CDH11 methylation, should be further addressed in large-scale 
independent, preferably prospective populations, from diverse ethnicities, with sufficient statistical power and well characterized long term follow-up before these biomarkers can be introduced in clinical practice as a prognostic tool. Our data indicate that the independent strength and high hazard ratio of LY75 methylation, together with the efficient identification via integration of different datasets and techniques, stresses the reproducibility and robustness of the marker. Therefore, LY75 methylation is the most promising prognostic marker identified in this thesis with genuine clinical potential $^{54}$. The identification of prognostic value of SYNPO2 on the other hand might be more important in advancing our knowledge regarding the biological mechanisms underlying the metastatic process of melanoma.

The role of LY75 methylation/inactivation in melanoma progression still remains to be clarified. The gene is involved in antigen processing ${ }^{55}$ and it seems possible that tumors displaying LY75 methylation are capable to bypass immune recognition consequently leading to a more aggressive disease phenotype. The immune system is known to play a critical role in cancer biology and evading immune destruction is recognized as a novel hallmark of cancer $^{56}$. Compared to other malignancies, melanoma appears to be a highly immunogenic cancer ${ }^{57}$. Treatment of melanoma with immunomodulators has shown major achievements, however, response rates are relatively low and biomarkers for patient stratification are still lacking ${ }^{58}$. Further examination of LY75 methylation in melanoma should also encompass the study of immunomodulators and investigate if LY75 methylation and/or gene expression can be used as possible predictive marker for (poor) therapeutic response.

Interestingly, the high immunogenicity of melanoma might be related to its high mutational burden (also observed in Chapter 3 ) relative to other cancers ${ }^{59}$. BRAF ${ }^{\mathrm{V} 600 \mathrm{E}}$ for example has been shown to initiate an immune reaction to the primary melanoma ${ }^{26,60}$ and the study of $\mathrm{BRAF}^{\mathrm{V} 600 \mathrm{E}}$ expression described in Chapter 4 confirmed a positive association between $\mathrm{BRAF}^{\mathrm{V} 600 \mathrm{E}}$ and tumor infiltrating lymphocytes. Additional evidence is accumulating that MAPK pathway inhibition sensitizes the immune system to target the tumor ${ }^{61}$. Therefore, combining BRAF inhibitors and immunotherapy in theory has strong potential for the successful treatment of melanoma. Currently, the first clinical trials combining BRAF/MEK inhibition and immunotherapy have been started and it will be of great interest to evaluate their efficacy ${ }^{61}$.

Moreover, BRAF ${ }^{\mathrm{V} 600 \mathrm{E}}$ has been associated with alterations in DNA-methylation patterns in melanoma ${ }^{62-64}$. Interestingly, some evidence indicates that BRAF ${ }^{\mathrm{V} 600 \mathrm{E}}$ actually causes widespread promoter hypermethylation, also referred to as the CpG island methylator phenotype (CIMP), in melanoma cells ${ }^{65}$. However, findings from few other studies ${ }^{32,66}$, with limited clinical sample size or using cell lines, did not reveal an association between the $\mathrm{BRAF}^{\mathrm{V} 600 \mathrm{E}}$ mutation and genome-wide DNA-methylation levels. Therefore, future studies should aim to elucidate the relationship between BRAF $^{\mathrm{V} 600 \mathrm{E}}$ and DNA methylation using large-scale sample cohorts and stratification according to clinical subtype should be performed. That is, mutant BRAF is 
predominantly present in the superficial spreading melanoma subtype ${ }^{27}$ and an association with DNA methylation might be limited to this subtype. In addition, efforts from the TCGA melanoma project identified a pattern of high DNA methylation at CpG islands that was associated with IDH1 mutations ${ }^{67}$. Introducing the IDH1 ${ }^{\mathrm{R} 132 \mathrm{H}}$ mutation in a human colorectal cancer cell line did result in altered DNA-methylation levels and thus supports a causal role for mutant IDH1 in driving epigenetic changes ${ }^{68}$. Further indications that CIMP can be caused by IDHI and IDH2 mutations come from studies in glioblastomas $^{69,70}$, leukemia ${ }^{71}$, and glioma ${ }^{72}$. IDH1 and IDH2 mutations in melanoma are found in up to $10 \%$ of cases $^{73}$. In Chapter 3 we identified that $4 \%$ of 154 melanomas carried a mutation in IDH1 while IDH2 mutations were not identified. Interestingly, IDH1 and IDH2 mutations have been shown to affect the ability of TenEleven Translocation (TET) proteins to initiate the DNA demethylation pathway ${ }^{74}$. That is, TET proteins are responsible for the conversion of 5-methylcytosine $(5 \mathrm{mC})$ into 5hydroxymethylcytosine $(5 \mathrm{hmC})$ resulting in demethylation and this mechanism is impaired by IDH mutations ${ }^{75}$. Hence, the association between IDH mutations and CIMP is likely to go through the inhibition of TET proteins. The global loss of $5 \mathrm{hmC}$ as measured by IHC was shown to be an epigenetic hallmark of melanoma that might be applied as a diagnostic tool to improve the diagnosis and prognosis of melanoma as the loss of $5 \mathrm{hmC}$ correlated with melanoma progression ${ }^{76}$. Still, to better understand the mechanisms by which $5 \mathrm{hmc}$ loss induces tumor intitiation and/or progression, it is necessary to identify the genes that are regulated by changes in $5 \mathrm{hmC}$ during tumor evolution. Downregulation of IDH2, TET1, TET2, and TET3 in melanoma was also observed and likely caused the loss of $5 \mathrm{hmC}$ as re-expression of IDH2 and TET2 increased $5 \mathrm{hmC}$ levels, suppressed melanoma growth and increased tumor-free survival in animal models ${ }^{76}$. In addition to mutations of IDH1 and IDH2, mutant TET2 has been detected in melanoma ${ }^{77}$. Interestingly, in fibroblasts cells (NIH3T3), reduction of TET1-3 expression was caused by BRAF ${ }^{\mathrm{V} 600 \mathrm{E}}$ and resulted in low $5 \mathrm{hmC}$ levels ${ }^{78}$. Mutations in DNA methyltransferases, DNM T1 and DNM T3A, have also been found in cancer and further acknowledge the interplay between genetics and epigenetics in establishing the disease phenotype ${ }^{79}$. Regardless of the exact mechanisms involved in causing genome-wide DNA-methylation alterations in melanoma and other malignancies, the observation that DNA-methylation changes occur commonly and frequently in melanoma, underscore their biomarker potential.

Thus, the above evidence suggests that CIMP is a true phenomenon in melanoma that needs to be better defined, since there is only one study by Tanemura et al. ${ }^{47}$ that proposed a selectively chosen melanoma CIMP panel (methylation of RASSF1A, TFPI2, RARB, WIF1, SOCS1, GATA4, MINT17, and MINT31) that was never validated. Among the primary melanoma specimens that were analyzed for the methylation status of 15 genes in Chapter 7, roughly $25 \%$ of tumors displayed extensive hypermethylation, i.e. methylation of $>10$ genes, an equal proportion of tumors (25\%) showed hardly evidence of methylation, i.e. $\leq 1$ methylated gene. This suggests that approximately one quarter of melanomas display CIMP, half of the melanomas have intermediate 
levels of DNA methylation, and one quarters of melanomas lack DNA methylation. It would be of interest to further study the molecular background, including the role of $5 \mathrm{hmC}$, of these different tumor groups and correlate this with clinical and pathological characteristics to identify if CIMP-high tumors behave differently from CIMP-low tumors. The former might be ideal candidates for treatment with epigenetic therapy ${ }^{80}$ or for combination treatment of HDAC inhibitors (epigenetic modifier) and immunotherapy as this might synergize in anti-tumor effects ${ }^{81}$. Additionally, the melanoma CIMP needs to be better defined in that different studies can be compared $^{82}$, i.e. is there a specific set of methylated genes that is synonymous to CIMP? To be able to answer this question it is essential to differentiate the driver from the passenger methylation events, i.e. drivers push cells towards cancer whereas passengers are only a by-product of cancer cell development. In comparison with genetic research where efforts have been made to identify melanoma driver mutations $^{83}$, an understanding of driver epigenetic, DNA-methylation changes of melanoma is missing.

One of the genes that was identified in this thesis as being methylated frequently in melanoma, the glycine N-methyltransferase (GNMT), has been implicated in methylgroup metabolism and in maintaining normal methylation levels of the genome ${ }^{84}$. In hepatocellular carcinoma, GNMT hypermethylation led to gene silencing that could promote the establishment of DNA hypermethylation at specific gene promoters ${ }^{85}$. Interestingly, 63\% of the GNMT methylated tumors that were analyzed in Chapter 7 displayed CIMP (>10 methylated genes), which is significantly more $(\mathrm{P}<.001$, two-sided Fisher's exact test) compared to $9 \%$ of the GNMT unmethylated tumors that displayed frequent hypermethylation. This finding suggests that GNMT might be involved in CIMP and therefore might be a good candidate gene as part of a CIMP-panel for melanoma.

In conclusion, over the past decades major advances have been made in the understanding of melanoma biology that is directly reflected by the increase in therapeutic options for melanoma patients since 2011. As a result, molecular pathology is becoming increasingly important in melanoma management. Exploring tumor biology will lead to the identification of biologically and clinically relevant biomarkers. Adequate markers should guide clinicians in diagnostic, prognostic/therapeutic decision-making. Specific tumor markers such as our identified 5-marker panel in Chapter $\mathbf{5}$ are able to discriminate between dysplastic nevus and melanoma and provide novel insights in melanoma biology. The strong, robust, and independent prognostic methylation of LY75 might be used in the clinic to identify high-risk patients that might benefit from adjuvant therapy. This marker is particularly worthy of further examination of its reproducibility and validity in a large, independent cohort, which could lead to a potential clinical translation. Integration of genetic and epigenetic alterations is expected to further contribute to personalized patient management of melanoma. Taken together, the findings presented in this thesis 
support the potential of molecular markers as important tools for fine-tuning diagnosis, prognosis, and therapeutic guidance for melanoma patients. Future in vitro, in vivo, and marker validation studies are essential to explore the biological role and tumor suppressor function of the identified markers and their potential as novel biomarkers in melanoma. 


\section{References}

1. http://cancergenome.nih.gov/

2. Flaherty $\mathrm{KT}$, Hodi FS, Fisher DE. From genes to drugs: targeted strategies for melanoma. Nat Rev Cancer, 2012. 12(5): p. 349-361.

3. Begley CG, loannidis JP. Reproducibility in Science: Improving the Standard for Basic and Preclinical Research. Circ Res, 2015. 116(1): p. 116-126.

4. Bedard PL, Hansen AR, Ratain MJ, et al. Tumour heterogeneity in the clinic. Nature, 2013. 501(7467): p. 355 364.

5. Turner NC, Reis-Filho JS. Genetic heterogeneity and cancer drug resistance. Lancet Oncol, 2012. 13(4): p. e178-185.

6. Hatzivassiliou G, Song K, Yen I, et al. RAF inhibitors prime wild-type RAF to activate the MAPK pathway and enhance growth. Nature, 2010. 464(7287): p. 431-435.

7. Heidorn SJ, Milagre C, Whittaker S, et al. Kinase-dead BRAF and oncogenic RAS cooperate to drive tumor progression through CRAF. Cell, 2010. 140(2): p. 209-221.

8. Yancovitz M, Litterman A, Yoon J, et al. Intra- and inter-tumor heterogeneity of BRAF(V600E))mutations in primary and metastatic melanoma. PLoS One, 2012. 7(1): p. e29336.

9. Colombino $\mathrm{M}$, Capone $\mathrm{M}$, Lissia $\mathrm{A}$, et al. BRAF/NRAS mutation frequencies among primary tumors and metastases in patients with melanoma. Journal of clinical oncology : official journal of the American Society of Clinical Oncology, 2012. 30(20): p. 2522-2529.

10. Heinzerling L, Baiter M, Kuhnapfel S, et al. Mutation landscape in melanoma patients clinical implications of heterogeneity of BRAF mutations. Br J Cancer, 2013. 109(11): p. 2833-2841.

11. Saint-Jean M, Quereux G, Nguyen JM, et al. Is a single BRAF wild-type test sufficient to exclude melanoma patients from vemurafenib therapy? J Invest Dermatol, 2014. 134(5): p. 1468-1470.

12. Long GV, Wilmott JS, Capper D, et al. Immunohistochemistry is highly sensitive and specific for the detection of V600E BRAF mutation in melanoma. Am J Surg Pathol, 2013. 37(1): p. 61-65.

13. Capper D, Preusser M, Habel A, et al. Assessment of BRAF V600E mutation status by immunohistochemistry with a mutation-specific monoclonal antibody. Acta Neuropathol, 2011. 122(1): p. 11-19.

14. Marin C, Beauchet A, Capper D, et al. Detection of BRAF p.V600E Mutations in Melanoma by Immunohistochemistry Has a Good Interobserver Reproducibility. Arch Pathol Lab Med, 2013. p.

15. Boursault L, Haddad V, Vergier B, et al. Tumor homogeneity between primary and metastatic sites for BRAF status in metastatic melanoma determined by immunohistochemical and molecular testing. PLoS One, 2013. 8(8): p. e70826.

16. Menzies AM, Lum T, Wilmott JS, et al. Intrapatient homogeneity of BRAFV600E expression in melanoma. Am J Surg Pathol, 2014. 38(3): p. 377-382.

17. Clark WH, Jr., From L, Bernardino EA, et al. The histogenesis and biologic behavior of primary human malignant melanomas of the skin. Cancer Res, 1969. 29(3): p. 705-727.

18. Pollock PM, Harper UL, Hansen KS, et al. High frequency of BRAF mutations in nevi. Nat Genet, 2003. 33(1): p. 19-20.

19. Dong J, Phelps RG, Qiao R, et al. BRAF oncogenic mutations correlate with progression rather than initiation of human melanoma. Cancer Res, 2003. 63(14): p. 3883-3885.

20. Michaloglou C, Vredeveld LC, Soengas MS, et al. BRAFE600-associated senescence-like cell cycle arrest of human naevi. Nature, 2005. 436(7051): p. 720-724.

21. Lin J, Takata M, Murata H, et al. Polyclonality of BRAF mutations in acquired melanocytic nevi. J Natl Cancer Inst, 2009. 101(20): p. 1423-1427.

22. Lin J, Goto $\mathrm{Y}$, Murata $\mathrm{H}$, et al. Polyclonality of BRAF mutations in primary melanoma and the selection of mutant alleles during progression. Br J Cancer, 2011. 104(3): p. 464-468.

23. Maldonado JL, Fridlyand J, Patel $\mathrm{H}$, et al. Determinants of BRAF mutations in primary melanomas. Journal of the National Cancer Institute, 2003. 95(24): p. 1878-1890.

24. Shinozaki M, Fujimoto A, Morton DL, et al. Incidence of BRAF oncogene mutation and clinical relevance for primary cutaneous melanomas. Clin Cancer Res, 2004. 10(5): p. 1753-1757.

25. Akslen LA, Angelini S, Straume O, et al. BRAF and NRAS mutations are frequent in nodular melanoma but are not associated with tumor cell proliferation or patient survival. J Invest Dermatol, 2005. 125(2): p. 312-317.

26. Edlundh-Rose $\mathrm{E}$, Egyhazi $\mathrm{S}$, Omholt $\mathrm{K}$, et al. NRAS and BRAF mutations in melanoma tumours in relation to clinical characteristics: a study based on mutation screening by pyrosequencing. Melanoma Res, 2006. 16(6): p. $471-478$.

27. Long GV, Menzies AM, Nagrial AM, et al. Prognostic and clinicopathologic associations of oncogenic BRAF in metastatic melanoma. J Clin Oncol, 2011. 29(10): p. 1239-1246. 
28. Mann GJ, Pupo GM, Campain AE, et al. BRAF mutation, NRAS mutation, and the absence of an immunerelated expressed gene profile predict poor outcome in patients with stage III melanoma. J Invest Dermatol, 2013. 133(2): p. 509-517.

29. Esteller M. Epigenetics in cancer. N Engl J Med, 2008. 358(11): p. 1148-1159.

30. Herman JG, Baylin SB. Gene silencing in cancer in association with promoter hypermethylation. N Engl J Med, 2003. 349(21): p. 2042-2054.

31. Laird PW. The power and the promise of DNA methylation markers. Nat Rev Cancer, 2003. 3(4): p. 253-266.

32. Gao L, Smit MA, van den Oord JJ, et al. Genome-wide promoter methylation analysis identifies epigenetic silencing of MAPK13 in primary cutaneous melanoma. Pigment Cell Melanoma Res, 2013. 26(4): p. 542-554.

33. Balch CM, Gershenwald JE, Soong SJ, et al. Final version of 2009 AJCC melanoma staging and classification. J Clin Oncol, 2009. 27(36): p. 6199-6206.

34. Meyer LJ, Piepkorn M, Goldgar DE, et al. Interobserver concordance in discriminating clinical atypia of melanocytic nevi, and correlations with histologic atypia. J Am Acad Dermatol, 1996. 34(4): p. 618-625.

35. Weinstock MA, Barnhill RL, Rhodes AR, et al. Reliability of the histopathologic diagnosis of melanocytic dysplasia. The Dysplastic Nevus Panel. Arch Dermatol, 1997. 133(8): p. 953-958.

36. Pozo L, Naase M, Cerio R, et al. Critical analysis of histologic criteria for grading atypical (dysplastic) melanocytic nevi. Am J Clin Pathol, 2001. 115(2): p. 194-204.

37. Farrahi F, Egbert BM, Swetter SM. Histologic similarities between lentigo maligna and dysplastic nevus: importance of clinicopathologic distinction. J Cutan Pathol, 2005. 32(6): p. 405-412.

38. Hussein MR. Melanocytic dysplastic naevi occupy the middle ground between benign melanocytic naevi and cutaneous malignant melanomas: emerging clues. J Clin Pathol, 2005. 58(5): p. 453-456.

39. Troxel DB. Pitfalls in the diagnosis of malignant melanoma: findings of a risk management panel study. Am J Surg Pathol, 2003. 27(9): p. 1278-1283.

40. Ioannidis JP. Biomarker failures. Clin Chem, 2013. 59(1): p. 202-204.

41. Zhang G, Li G. Novel multiple markers to distinguish melanoma from dysplastic nevi. PLoS One, 2012. 7(9): p. e45037.

42. Kiszner G, Wichmann B, Nemeth IB, et al. Cell cycle analysis can differentiate thin melanomas from dysplastic nevi and reveals accelerated replication in thick melanomas. Virchows Arch, 2014. 464(5): p. 603-612.

43. Taylor JM, Ankerst DP, Andridge RR. Validation of biomarker-based risk prediction models. Clin Cancer Res, 2008. 14(19): p. 5977-5983.

44. Dubbink HJ, Deans ZC, Tops BB, et al. Next generation diagnostic molecular pathology: critical appraisal of quality assurance in Europe. Mol Oncol, 2014. 8(4): p. 830-839.

45. Eggermont AM, Spatz A, Robert C. Cutaneous melanoma. Lancet, 2014. 383(9919): p. 816-827.

46. Conway C, Mitra A, Jewell R, et al. Gene expression profiling of paraffin-embedded primary melanoma using the DASL assay identifies increased osteopontin expression as predictive of reduced relapse-free survival. Clin Cancer Res, 2009. 15(22): p. 6939-6946.

47. Tanemura A, Terando AM, Sim MS, et al. CpG island methylator phenotype predicts progression of malignant melanoma. Clin Cancer Res, 2009. 15(5): p. 1801-1807.

48. Denk AE, Bettstetter M, Wild PJ, et al. Loss of maspin expression contributes to a more invasive potential in malignant melanoma. Pigment Cell Res, 2007. 20(2): p. 112-119.

49. Cebrian V, Alvarez M, Aleman A, et al. Discovery of myopodin methylation in bladder cancer. J Pathol, 2008. 216(1): p. 111-119.

50. Jewell R, Elliott F, Laye J, et al. The clinicopathological and gene expression patterns associated with ulceration of primary melanoma. Pigment Cell Melanoma Res, 2015. 28(1): p. 94-104.

51. De Ganck A, De Corte V, Staes A, et al. Multiple isoforms of the tumor suppressor myopodin are simultaneously transcribed in cancer cells. Biochem Biophys Res Commun, 2008. 370(2): p. 269-273.

52. Sandoval J, Heyn H, Moran S, et al. Validation of a DNA methylation microarray for $450,000 \mathrm{CpG}$ sites in the human genome. Epigenetics, 2011. 6(6): p. 692-702.

53. Yegnasubramanian S, Lin X, Haffner $M C$, et al. Combination of methylated-DNA precipitation and methylation-sensitive restriction enzymes (COMPARE-MS) for the rapid, sensitive and quantitative detection of DNA methylation. Nucleic Acids Res, 2006. 34(3): p. e19.

54. Ioannidis JP. How to make more published research true. PLoS Med, 2014. 11(10): p. e1001747.

55. Jiang W, Swiggard WJ, Heufler C, et al. The receptor DEC-205 expressed by dendritic cells and thymic epithelial cells is involved in antigen processing. Nature, 1995. 375(6527): p. 151-155.

56. Hanahan D, Weinberg RA. Hallmarks of cancer: the next generation. Cell, 2011. 144(5): p. 646-674.

57. Blankenstein T, Coulie PG, Gilboa E, et al. The determinants of tumour immunogenicity. Nat Rev Cancer, 2012. 12(4): p. 307-313.

58. Griewank KG, Ugurel S, Schadendorf D, et al. New developments in biomarkers for melanoma. Curr Opin Oncol, 2013. 25(2): p. 145-151. 
59. Greenman C, Stephens P, Smith R, et al. Patterns of somatic mutation in human cancer genomes. Nature, 2007. 446(7132): p. 153-158.

60. Andersen $\mathrm{MH}$, Fensterle J, Ugurel S, et al. Immunogenicity of constitutively active V599EBRaf. Cancer Res, 2004. 64(15): p. 5456-5460.

61. Hu-Lieskovan S, Robert L, Homet Moreno B, et al. Combining targeted therapy with immunotherapy in BRAFmutant melanoma: promise and challenges. J Clin Oncol, 2014. 32(21): p. 2248-2254.

62. Liu D, Liu X, Xing M. Epigenetic genes regulated by the BRAFV600E signaling are associated with alterations in the methylation and expression of tumor suppressor genes and patient survival in melanoma. Biochem Biophys Res Commun, 2012. 425(1): p. 45-50.

63. Thomas NE, Slater NA, Edmiston SN, et al. DNA methylation profiles in primary cutaneous melanomas are associated with clinically significant pathologic features. Pigment Cell Melanoma Res, 2014. 27(6): p. 1097 1105.

64. Ecsedi S, Hernandez-Vargas $\mathrm{H}$, Lima SC, et al. DNA methylation characteristics of primary melanomas with distinct biological behaviour. PLoS One, 2014. 9(5): p. e96612.

65. Hou P, Liu D, Dong J, et al. The BRAF(V600E) causes widespread alterations in gene methylation in the genome of melanoma cells. Cell Cycle, 2012. 11(2): p. 286-295.

66. Tellez CS, Shen L, Estecio MR, et al. CpG island methylation profiling in human melanoma cell lines. Melanoma Res, 2009. 19(3): p. 146-155.

67. Watson IR. Comprehensive genomic characterization of cutaneous melanoma. The Cancer Genome Atlas' 3rd Annual Scientific Symposium, May 12-13, 2014, Bethesda, Maryland, 2014. p.

68. Duncan CG, Barwick BG, Jin G, et al. A heterozygous IDH1R132H/WT mutation induces genome-wide alterations in DNA methylation. Genome Res, 2012. 22(12): p. 2339-2355.

69. Noushmehr H, Weisenberger DJ, Diefes K, et al. Identification of a CpG island methylator phenotype that defines a distinct subgroup of glioma. Cancer Cell, 2010. 17(5): p. 510-522.

70. Turcan S, Rohle D, Goenka A, et al. IDH1 mutation is sufficient to establish the glioma hypermethylator phenotype. Nature, 2012. 483(7390): p. 479-483.

71. Figueroa ME, Abdel-Wahab O, Lu C, et al. Leukemic IDH1 and IDH2 mutations result in a hypermethylation phenotype, disrupt TET2 function, and impair hematopoietic differentiation. Cancer Cell, 2010. 18(6): p. 553567.

72. Christensen $B C$, Smith $A A$, Zheng $S$, et al. DNA methylation, isocitrate dehydrogenase mutation, and survival in glioma. J Natl Cancer Inst, 2011. 103(2): p. 143-153.

73. Shibata T, Kokubu A, Miyamoto M, et al. Mutant IDH1 confers an in vivo growth in a melanoma cell line with BRAF mutation. Am J Pathol, 2011. 178(3): p. 1395-1402.

74. Dang L, White DW, Gross S, et al. Cancer-associated IDH1 mutations produce 2-hydroxyglutarate. Nature, 2010. 465(7300): p. 966.

75. Kroeze LI, van der Reijden BA, Jansen JH. 5-Hydroxymethylcytosine: An epigenetic mark frequently deregulated in cancer. Biochim Biophys Acta, 2015. p.

76. Lian CG, Xu Y, Ceol C, et al. Loss of 5-hydroxymethylcytosine is an epigenetic hallmark of melanoma. Cell, 2012. 150(6): p. 1135-1146.

77. Song $\mathrm{F}, \mathrm{Amos} \mathrm{Cl}$, Lee JE, et al. Identification of a melanoma susceptibility locus and somatic mutation in TET2. Carcinogenesis, 2014. 35(9): p. 2097-2101.

78. Kudo $\mathrm{Y}$, Tateishi $\mathrm{K}$, Yamamoto $\mathrm{K}$, et al. Loss of 5-hydroxymethylcytosine is accompanied with malignant cellular transformation. Cancer Sci, 2012. 103(4): p. 670-676.

79. Alvarez-Mugica M, Cebrian V, Fernandez-Gomez JM, et al. Myopodin methylation is associated with clinical outcome in patients with T1G3 bladder cancer. J Urol, 2010. 184(4): p. 1507-1513.

80. Lee JJ, Murphy GF, Lian CG. Melanoma epigenetics: novel mechanisms, markers, and medicines. Lab Invest, 2014. 94(8): p. 822-838.

81. Kroesen M, Gielen P, Brok IC, et al. HDAC inhibitors and immunotherapy; a double edged sword? Oncotarget, 2014. 5(16): p. 6558-6572.

82. Hughes LA, Melotte V, de Schrijver J, et al. The CpG island methylator phenotype: what's in a name? Cancer Res, 2013. 73(19): p. 5858-5868.

83. Hodis E, Watson IR, Kryukov GV, et al. A landscape of driver mutations in melanoma. Cell, 2012. 150(2): p. 251-263.

84. Esteban S, Moya P, Fernandez-Suarez A, et al. Diagnostic and prognostic utility of methylation and protein expression patterns of myopodin in colon cancer. Tumour Biol, 2012. 33(2): p. 337-346.

85. Huidobro C, Torano EG, Fernandez AF, et al. A DNA methylation signature associated with the epigenetic repression of glycine $\mathrm{N}$-methyltransferase in human hepatocellular carcinoma. J Mol Med (Berl), 2013. 91(8): p. 939-950. 



\section{Valorization}


The incidence of cutaneous melanoma has markedly increased, and will most likely continue to do so, in people of European ancestry and is most likely related to an increased exposure to ultraviolet radiation since the early $1970 \mathrm{~s}^{1}$. In 2012, melanoma was the fourth most common cancer in both men and women in The Netherlands ${ }^{2}$. Melanoma incidence in the Netherlands is one of the highest in Europe; 5,287 new cases and 793 deaths were reported in $2012^{3}$. With an increasing incidence of approximately $4.5 \%$ each year, the burden of melanoma to society has increased rapidly ${ }^{4}$. Hence, melanoma has become a significant health care problem and the predicted future trends are worrying in terms of disease burden and health care costs.

From a scientific point of view, the research presented in this thesis contributes to understanding the behavior of cutaneous melanoma by mapping molecular alterations in clinical melanocytic specimens. In addition to the scientific relevance, the knowledge generated in this thesis has substantial societal and economical value.

For society it is of importance that patients will receive an accurate diagnosis and consequently the best possible (personalized) treatment and disease outcome ${ }^{5}$. The current assessment of melanoma diagnosis is based on histopathological features of the lesion, however, in approximately $15 \%$ of cases melanoma is misdiagnosed leading to suboptimal clinical management ${ }^{6}$. Therefore, in The Netherlands an expert Pathology Panel was set up by the Dutch Melanoma Working Group which can be approached to provide an expert's opinion on problematic cases. It was revealed that of a total of $1217^{7}$ and $1069^{8}$ examined cases, underdiagnoses of melanoma and overdiagnoses of nevi could be prevented by this expert panel in approximately 12 $14 \%$ and $13-15 \%$, respectively ${ }^{7,8}$. Spitz nevi and dysplastic nevi were most often challenged with diagnostic difficulties. It was shown that invasive melanoma was underdiagnosed in 37 of $133(28 \%)^{7}$ and 44 of $176(25 \%)^{8}$ of lesions initially diagnosed as dysplastic nevi highlighting the difficulty to distinguish melanoma from dysplastic nevus based on histopathology alone. It is unclear how many misdiagnoses of invasive melanoma actually occur in clinical practice. However, the consequences of a melanoma misdiagnosis can be immense. It is believed that each year approximately 75 melanoma patients presented in the clinic with metastatic disease could have been prevented if a re-excision and sentinel node procedure had taken place after the pathological examination ${ }^{9}$.

When a melanoma diagnosis has been made, the patients' prognosis is currently assessed by taking into account patient and tumor characteristics, i.e. age, gender, tumor location, tumor thickness, ulceration status, mitotic rate, and the presence of local or distant metastatic disease ${ }^{5}$. In patients without metastatic disease, the tumor thickness is key in determining the clinical management, i.e. thin melanomas $(<2.0 \mathrm{~mm}$ thickness) will be excised with $1 \mathrm{~cm}$ margins, whereas thicker melanomas are excised more widely, with $2 \mathrm{~cm}$ margins ${ }^{10}$. Moreover, the melanoma thickness and ulceration status directs if a sentinel node procedure will be performed to rule out lymph node metastasis $^{10}$. However, $20-30 \%$ of patients diagnosed with thin melanomas $(<2 \mathrm{~mm}$ 
thickness) still die from their disease and thus were likely undertreated ${ }^{11,12}$. Hence, the current assessment of prognosis of melanoma patients is, similar to diagnosis, suboptimal.

The work presented in this thesis identified novel methylation markers that might be translated to the clinic to improve the diagnosis and prognosis of melanoma. The identified diagnostic marker panel consisting of promoter $\mathrm{CpG}$ island methylation of CLDN11, CDH11, PPP1R3C, GNMT, and MAPK13 might help clinicians in the diagnosis of difficult (dysplastic) lesions. That is, patients could be better diagnosed based on a combination of histopathology and their biomarker profile. Consequently, the formation of lethal metastatic disease might be prevented in those patients that were misdiagnosed based on the use of histopathology alone. Also, the addition of molecular information, such as promoter CpG island methylation of SYNPO2 and LY75, to the classical prognostic factors might improve the assessment of melanoma prognosis as these biomarkers identify patients with aggressive disease at diagnosis independent of the tumor thickness. Particularly the strong independent prognostic value of LY75 methylation emphasizes clinical potential and warrants extensive further examination.

Up to now thousands of putative cancer biomarkers have been previously identified and published, but only few of the clinically useful biomarkers have been successfully validated for routine clinical practice ${ }^{13}$. One of the reasons why most biomarkers never reach clinical practice is that the vast majority of markers are not further developed into a clinical assay after their identification ${ }^{14}$. We searched for commercial opportunities to further exploit and develop the most promising novel prognostic marker, LY75, into a clinical biomarker. Patenting LY75 methylation as a prognostic marker for melanoma and possibly other cancer types is expected to enhance the validation and translational process of the biomarker and increase the success of clinical application ${ }^{14}$. That is, the process from identification to clinical implementation is expensive and will only take place when commercial or economical interest is secured by protecting the marker.

The validation/translation process of a biomarker like LY75 methylation involves several phases ${ }^{15}$. After the first identification of the marker, a clinical assay needs to be developed that will assess the marker status, in casu LY75 methylation, in a patient's primary tumor after initial surgery. Retrospective longitudinal repository studies need to be performed to validate and reproduce the clinical value of the marker. Even more important are prospective screening studies examining the detection rate (sensitivity) and the false referral rate (specificity) of the test. The final phase before possible clinical application of the biomarker represents a prospective trial study ${ }^{15}$. That is, patients with the presence of the tumor biomarker receive additional therapy (such as wider tumor excision, sentinel node procedure, more active follow-up or adjuvant therapy) and are compared to a control group of patients who also display the tumor biomarker but do not receive additional treatment. This last validation phase 
addresses whether the addition of the biomarker, in casu LY75 methylation, in the clinical diagnosis of melanoma actually reduces the disease burden and melanoma mortality in a reference population. After clinical validation of the marker, clinical utility studies need to be performed to assess if the molecular marker is actually used as intended and leads to the desired effect in clinical practice ${ }^{15}$.

Ultimately, a simple molecular test that is suitable for routine clinical testing, for example methylation-specific PCR, will guide clinicians in prognostic/therapeutic decision-making via the identification of patients who are likely to benefit from additional treatment. This will improve melanoma management and will benefit the society as individual morbidity and mortality is spared.

The ability of biomarkers to improve melanoma diagnosis and prognosis and consequently to advance personalized treatment of melanoma will benefit the economy as well. Currently, health care costs are rapidly increasing due to novel expensive therapies. Cancer treatment costs in The Netherlands have almost doubled from 1994 to 2005 (from 1,400 to 2,600 million euros) ${ }^{17}$. Due to the development of more promising, yet expensive, new treatments (see also Chapter 1) the health care costs for melanoma are expected to rise. The putative biomarkers identified in this thesis might derive economic value by guiding melanoma management via selection of the best possible (personalized) treatment and minimize the likelihood of potential costly adverse events or unnecessary therapies ${ }^{18}$. More tailored management of cancers such as melanoma by using biomarkers is believed to result in a reduction in health care costs that is potentially greater than in any other area of current medical research $^{14}$.

Taken together, the knowledge generated in this thesis will not only be of meaning for the scientific community, but the identified biomarkers are expected to have a societal impact as they are key to better patient care, and to have an economical impact due to a reduction in medical costs. 


\section{References}

1. Arnold M, Holterhues C, Hollestein LM, et al. Trends in incidence and predictions of cutaneous melanoma across Europe up to 2015. J Eur Acad Dermatol Venereol, 2014. 28(9): p. 1170-1178.

2. Ferlay J, Soerjomataram I, Ervik M, Dikshit R, Eser S, Mathers C, Rebelo M, Parkin DM, Forman D, Bray, F. GLOBOCAN 2012 v1.0, Cancer Incidence and Mortality Worldwide: IARC CancerBase No. 11 [Internet]. Lyon, France: International Agency for Research on Cancer; 2013. Available from: http://globocan.iarc.fr, accessed on 01/09/2014.

3. Nederlandse Kankerregistratie, beheerd door IKNL C August 2014 (website: http://www.cijfersoverkanker.nl/).

4. Holterhues C, Hollestein LM, Nijsten T, et al. Burden of disease due to cutaneous melanoma has increased in the Netherlands since 1991. Br J Dermatol, 2013. 169(2): p. 389-397.

5. Balch CM, Gershenwald JE, Soong SJ, et al. Final version of 2009 AJCC melanoma staging and classification. J Clin Oncol, 2009. 27(36): p. 6199-6206.

6. Troxel DB. Pitfalls in the diagnosis of malignant melanoma: findings of a risk management panel study. Am J Surg Pathol, 2003. 27(9): p. 1278-1283.

7. van Dijk MC, Aben KK, van Hees F, et al. Expert review remains important in the histopathological diagnosis of cutaneous melanocytic lesions. Histopathology, 2008. 52(2): p. 139-146.

8. Veenhuizen KC, De Wit PE, Mooi WJ, et al. Quality assessment by expert opinion in melanoma pathology: experience of the pathology panel of the Dutch Melanoma Working Party. J Pathol, 1997. 182(3): p. 266-272.

9. P.J. van Diest PAJBeMRvD. Frequentie van melanoommetastase zonder primaire lokalisatie. Nederlands Tijdschrift voor Oncologie, 2012. 9(4): p. 157-161.

10. www.oncoline.nl/melanoom. p.

11. Criscione VD, Weinstock MA. Melanoma thickness trends in the United States, 1988-2006. J Invest Dermatol, 2010. 130(3): p. 793-797.

12. Whiteman DC, Baade PD, Olsen CM. More People Die from Thin Melanomas $(1 \mathrm{~mm})$ than from Thick Melanomas (>4 mm) in Queensland, Australia. J Invest Dermatol, 2015. 135(4): p. 1190-1193.

13. Poste G. Bring on the biomarkers. Nature, 2011. 469(7329): p. 156-157.

14. Drucker E, Krapfenbauer K. Pitfalls and limitations in translation from biomarker discovery to clinical utility in predictive and personalised medicine. EPMA J, 2013. 4(1): p. 7.

15. Pepe MS, Etzioni R, Feng Z, et al. Phases of biomarker development for early detection of cancer. J Natl Cancer Inst, 2001. 93(14): p. 1054-1061.

16. Bossuyt MM, Reitsma JB, Linnet K, et al. Beyond Diagnostic Accuracy: The Clinical Utility of Diagnostic Tests. Clinical Chemistry, 2012. 58(12): p. 1636-1643.

17. Uyl-de Groot CA, de Groot S, Steenhoek A. The economics of improved cancer survival rates: better outcomes, higher costs. Expert Rev Pharmacoecon Outcomes Res, 2010. 10(3): p. 283-292.

18. John E Schneider, Manpreet K Sidhu, Cynthia Doucet, et al. Economics of Cancer Biomarkers. Personalized Medicine, 2012. 9(8): p. 829-837. 



\section{Summary}

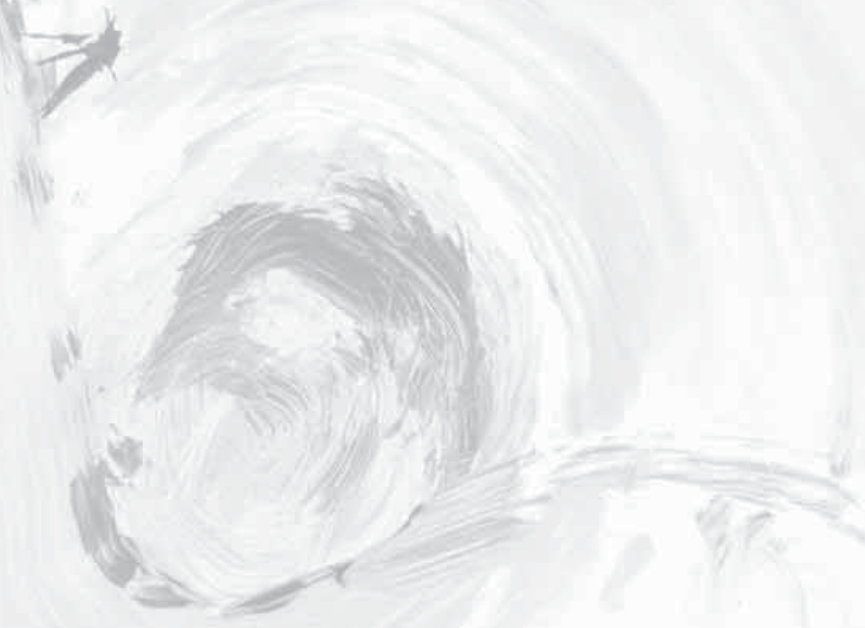


Cutaneous melanoma is a highly aggressive cancer that originates from melanocytes which are the pigment producing cells in the skin. Melanoma is the leading cause of skin cancer related death and a major health burden due to its fast rising incidence rate. In case of localized disease, stage I and II, melanoma can be cured via surgical excision; ten-year survival rates are $90 \%$ (stage I) but can decrease to $40 \%$ (stage II) mainly depending on the tumor thickness (Breslow's depth). Patients with local metastatic disease, stage III, represent a heterogeneous group and ten-year survival rate is between $25 \%-70 \%$. Melanoma that has spread to distant metastatic sites, stage IV, is almost always incurable, even in spite of recent advances in targeted and immunomodulatory therapies. Rapidly growing knowledge of the molecular mechanisms implicated in melanoma development and progression is becoming increasingly important in the clinical guidance of melanoma as described in Chapter 1.

The main purpose of this thesis was to profile (epi)genetic aberrations in melanoma to enhance our understanding of melanoma biology and to identify novel, clinically relevant biomarkers. In Chapter $\mathbf{2}$ we provide an overview of the current knowledge of genetic and epigenetic alterations in melanoma. The genetic components underlying melanoma and the resulting deregulation of important signaling pathways, such as aberrant MAPK and PI3K signaling, are clearly emerging. A complete picture of the epigenetic contributions on DNA (DNA methylation), RNA (non-coding RNAs), and protein level (histone modifications, Polycomb group proteins, and chromatin remodeling) is however missing. Genetic and epigenetic interactions in the aberrant regulation of the INK4b-ARF-INK4a and MITF loci are accumulating and we point out that it is the interplay between genetic and epigenetic mechanisms that effectively lead to distorted gene expression patterns in melanoma.

To increase our knowledge of mutational events that underlie melanoma progression we adapted high-throughput genotyping to profile 159 known single nucleotide mutations in 33 cancer-related genes in 154 melanoma tissues across two European countries, i.e. Ireland and Belgium (Chapter 3). Unexpectedly, demographic differences in BRAF mutation rates, which represent one of the most important biomarkers for melanoma patients to date, were discovered. That is, melanoma patients from Ireland harbored a significantly lower BRAF mutation rate ( 20\%) compared with patients from Belgium or elsewhere (50\%). The low incidence of $\mathrm{BRAF}^{\mathrm{V} 600 \mathrm{E}}$ among Irish melanoma patients was confirmed in five independent cohorts using different detection methods and in total, 165 of 689 (24\%) Irish cases had the mutant $\mathrm{BRAF}^{\mathrm{V} 600 \mathrm{E}}$ genotype. The observation that melanoma-driving mutations vary by demographic area will have important implications for the clinical management of this disease.

Another challenge of precision medicine like treatment with mutant BRAF inhibitors is the development of drug resistance. Various mechanisms of drug resistance have been described, amongst them the existence of molecular heterogeneity within individual tumors (intratumor heterogeneity) and between 
tumors within a single patient (intrapatient heterogeneity). In Chapter $\mathbf{4}$ we used immunohistochemistry to determine the extent of intratumor and intrapatient heterogeneity of BRAF ${ }^{\mathrm{V} 600 \mathrm{E}}$ and examined if morphological tumor heterogeneity correlates with $\mathrm{BRAF}^{\mathrm{V} 600 \mathrm{E}}$ expression. In general, $\mathrm{BRAF}^{\mathrm{V} 600 \mathrm{E}}$ intratumor and intrapatient heterogeneity was very rare. In most cases, a diffuse homogeneous immunostaining was seen indicating that this genetic aberration is a common clonal event in melanoma. Although BRAF ${ }^{\mathrm{V} 600 \mathrm{E}}$ was found in all morphological subtypes, it was observed that the presence of the mutation is positively associated with the epithelioid cell type.

The role of DNA-methylation in the development and progression of melanoma was investigated in Chapters 5-7 as this holds great promise to obtain novel insights in biology and for the identification of biomarkers.

Previously published Infinium HumanMethylation27K data were utilized to study the deregulation of DNA methylation in different stages of melanocytic neoplasia (Chapter 5). Promoter CpG island methylation analyses on a selected panel of 12 genes revealed progressive methylation trends during melanoma progression; methylation of dysplastic nevi was intermediate between common nevi and melanoma. The potential diagnostic value of methylation markers in distinguishing dysplastic nevus from primary melanoma was subsequently investigated in two patient series. A diagnostic 5marker panel comprising of CDH11, CLDN11, GNMT, MAPK13, and PPP1R3C methylation was generated of which CLDN11 methylation was the best single biomarker to discriminate between dysplastic nevus and melanoma. The addition of these methylation markers together with traditional histopathology might add in the accurate diagnosis of difficult lesions.

As it remains challenging for clinicians to identify patients who are at high-risk to develop metastatic disease we continued to compare methylation profiles of primary melanoma from patients with different outcome (Chapter 6). Re-analysis of the Infinium HumanMethylation27K data that were also used in Chapter $\mathbf{5}$ yielded six hypermethylated genes in melanoma with metastatic behavior: MCHR1, SYNPO2, Clorf106, HIST1H3G, ZNF35, and GNMT. Further validation studies recognized prognostic significance of promoter CpG-island hypermethylation $(n=113)$ and diminished gene expression $(n=202)$ of SYNPO2 in melanoma. Moreover, the prognostic value of SYNPO2 was independent of Breslow thickness, i.e. the most important prognostic clinical parameter.

In Chapter 7 we combined novel methyl-binding domain (MBD-)sequencing and RNA-sequencing on melanoma cell lines with publically available Infinium HumanMethylation450K data from The Cancer Genome Atlas (TCGA) to efficiently identify prognostic methylation markers for melanoma that are accurate and reproducible. Stringent analysis with the use of the molecular profiles of $\mathrm{CDH} 11$ and GNMT as 'guide genes' identified a total of 85 robustly methylated gene promoters that represent putative melanoma biomarkers. Aberrant methylation of LY75 was 
identified as a strong predictor of poor melanoma prognosis in an independent validation series $(n=114)$ and identified patients with aggressive disease at diagnosis independent of current prognosticators.

The major findings of the presented studies are summarized and discussed in Chapter 8. This thesis advanced the biological knowledge of melanoma and identified methylation markers that can be translated to the clinic to improve the diagnosis and prognosis of melanoma. Future studies are required to confirm the biomarker potential of these genes and to unravel their tumor suppressor function.

In addition to the scientific relevance of the data, the valorization paragraph highlights the societal and economical value that can be generated. Patenting of LY75 methylation is expected to progress the validation and translational process of the biomarker and increase the success of clinical application. This will ultimately lead to improved personalized patient care and a reduction in medical costs. 


\section{Samenvatting}


Het cutane melanoom is een agressieve vorm van kanker die ontstaat uit de pigmentcellen, melanocyten, in de huid. Het melanoom is de voornaamste oorzaak van huidkanker gerelateerde sterfte en vanwege het snel toenemende aantal een steeds groter wordend gezondheidsprobleem. In het geval van gelokaliseerde ziekte, stadium I en II, kan het melanoom worden genezen via operatieve verwijdering. De 10-jaars overleving varieert van $90 \%$ (stadium I), maar kan dalen tot $40 \%$ (stadium II), voornamelijk afhankelijk van de dikte van het melanoom (Breslow's dikte). Patiënten met lokale gemetastaseerde ziekte, stadium III, vertegenwoordigen een heterogene groep met een 10 -jaars overleving van $25 \%-70 \%$. Wanneer het melanoom zich op afstand heeft verspreid, stadium IV, dan is de ziekte bijna altijd ongeneesbaar. De snel groeiende kennis over de moleculaire mechanismen die betrokken zijn bij de ontwikkeling en de progressie van het melanoom wordt in toenemende mate belangrijk in de klinische behandeling van deze ziekte. Een overzicht van de nieuwe behandelingen van het melanoom wordt gegeven in hoofdstuk 1.

Vanwege de snelle ontwikkeling van 'gepersonaliseerde geneeskunde' waarbij het moleculaire profiel van de patiënt (of zijn/haar tumor) als uitgangspunt dient bij het bepalen van de behandeling, is de pathologische evaluatie van het melanoom steeds vaker gebaseerd op een combinatie van traditionele histopathologie met moleculaire analyse. De belangrijkste doelstelling van dit proefschrift was het in kaart brengen van (epi)genetische afwijkingen in het melanoom om ons begrip van melanoombiologie te verbeteren, en om nieuwe klinisch relevante biomarkers te identificeren. Deze nieuwe markers kunnen bijdragen aan het bepalen van de meest optimale behandeling van de patiënt en is belangrijk voor het bespoedigen van de medische zorg naar gepersonaliseerde geneeskunde.

Hoofdstuk 2 omvat een overzicht van de huidige kennis van genetische en epigenetische veranderingen in het melanoom. $\mathrm{Er}$ is al veel kennis over de genetische componenten die ten grondslag liggen aan het melanoom en resulteren in deregulatie van belangrijke signaleringspaden, zoals verstoorde MAPK en PI3K signalering. Een compleet beeld van epigenetische bijdragen die kunnen plaatsvinden op het niveau van DNA (DNA methylatie), RNA (non-coding RNAs), en eiwit (histon modificaties, Polycomb groep eiwitten en chromatine remodeling) is nog niet beschikbaar. Zoals aangetoond voor regulatie van twee belangrijke melanoom loci, INK4bB-ARF-INK4a en MITF, wordt het steeds duidelijker dat genetische en epigenetische gen afwijkingen opstapelen. We wijzen erop dat het samenspel tussen beide effectief leidt tot verstoorde gen expressie patronen in melanomen.

Door middel van high-throughput genotypering onderzochten we in hoofdstuk 3 een totaal van 159 mutaties in 33 kanker-gerelateerde genen in 154 melanomen afkomstig van lerland en België. Onverwacht ontdekten we demografische verschillen in het aantal BRAF mutaties, momenteel één van de belangrijkste melanoom biomarkers. Melanoom patiënten uit lerland bleken een significant lagere BRAF mutatie frequentie te bevatten van ongeveer $20 \%$, vergeleken met patienten uit België 
of andere landen (50\%). De lage incidentie van de meest voorkomende BRAF ${ }^{\mathrm{V} 600 \mathrm{E}}$ mutatie onder lerse melanoom patiënten werd met behulp van verschillende detectiemethoden bevestigd in vijf onafhankelijke cohorten. In totaal hadden 165 van de 689 (24\%) lerse patiënten een melanoom met het mutante BRAF ${ }^{\mathrm{V} 600 \mathrm{E}}$ genotype. De constatering dat melanoom drijvende mutaties variëren per populatie zal implicaties hebben voor de klinische behandeling van deze ziekte.

Een andere uitdaging van opkomende gepersonaliseerde geneeskunde is de ontwikkeling van resistentie tegen deze nieuwe medicijnen. Dit is ook een veelvoorkomend probleem bij patiënten die behandeld worden met specifieke mutante BRAF remmers; medicijnen die het defect in de tumor, een mutatie in het BRAF gen, gericht aanpakken. Verschillende mechanismen van resistentie zijn beschreven in de literatuur, waaronder het bestaan van moleculaire heterogeniteit in één tumor (intratumor heterogeniteit) en tussen verschillende tumoren binnen één enkele patiënt (intrapatiënt heterogeniteit). In hoofdstuk 4 gebruikten we immunohistochemie om de mate van intratumor en intrapatiënt heterogeniteit van mutante $\mathrm{BRAF}^{\mathrm{V}}{ }^{\mathrm{GOE}}$ expressie te bepalen. Ook bestudeerden we of verschillen in de vorm van tumor cellen, ook wel morfologische tumor heterogeniteit genoemd, correleert met $\mathrm{BRAF}^{\mathrm{V} 600 \mathrm{E}}$ expressie. Over het algemeen was de intratumor en intrapatiënt heterogeniteit van $\mathrm{BRAF}^{\mathrm{V} 600 \mathrm{E}}$ erg laag. In de meeste gevallen werd een diffuse homogene immunokleuring geobserveerd, wat betekent dat deze genetische afwijking een klonale gebeurtenis is in het melanoom. Hoewel BRAF ${ }^{\mathrm{V} 600 \mathrm{E}}$ werd gevonden in alle morfologische subtypen, werd er geobserveerd dat de mutatie positief geassocieerd is met het epithelioide celtype.

In hoofdstukken 5-7 werd de rol van DNA-methylering bestudeerd in de ontwikkeling en progressie van het melanoom om nieuwe inzichten te verkrijgen in melanoom biologie en voor de identificatie van nieuwe biomarkers. Afwijkende DNA-methylering is de best bestudeerde epigenetische verandering in kanker en methylering van de promoter-regio van een gen is sterk geassocieerd met de uitschakeling van genen die in een normale situatie tumorgroei zouden onderdrukken. De stabiliteit en hoge frequentie van DNA-methylering in kanker, de mogelijkheid van het bepalen van methylering in klinische paraffine-ingebed, formaline-gefixeerde weefsels, alsmede de makkelijke en goedkope testen (zoals methylatie-specifieke PCR) die beschikbaar zijn voor het meten van DNA-methylatie, zorgen voor veelbelovende mogelijkheden van deze epigenetische afwijking als biomarker.

Voorheen gepubliceerde Infinium HumanMethylation27K data werd gebruikt om de deregulatie van DNA-methylatie in verschillende stadia van melanocytische neoplasmen te bestuderen (hoofdstuk 5). Promoter CpG eiland methylatie analyses op een geselecteerd panel van 12 genen onthulden progressief toenemende methyleringspatronen tijdens de verschillende stadia van tumor progressie. De frequentie van methylatie in normale nevi was minimaal, een toename in methylatie levels werd gezien in dysplastische nevi, en een scherpe toename in methylatie 
frequentie was zichtbaar in primaire en uitgezaaide (metastatische) melanomen. De potentiële diagnostische waarde van methylatiemarkers voor het onderscheiden van dysplatische nevi en primaire melanomen werd vervolgens bestudeerd in twee patienten series. Een diagnostisch 5-marker panel bestaande uit CDH11, CLDN11, GNMT, MAPK13 en PPP1R3C methylatie werd samengesteld waarvan CLDN11 methylatie de beste biomarker bleek te zijn om onderscheid te maken tussen goedaardige dysplastische nevi en maligne melanomen. De toevoeging van deze methylatiemarkers aan traditionele histopathologie kan mogelijk bijdragen aan de accurate diagnose van moeilijke letsels.

Voor artsen blijft het daarnaast lastig om patiënten te identificeren die een hoog risico hebben op de ontwikkeling van metastatische ziekte. Deze patiënten hebben een slechtere prognose en zouden daardoor profijt kunnen hebben van meer radicale behandeling. In hoofdstuk 6 vergeleken we methylerings profielen van primaire melanomen van patiënten die geen metastatische ziekte ontwikkelden versus patiënten die dit wel deden. Re-analyse van de Infinium HumanMethylation27K data, ook gebruikt in hoofdstuk 5, leverde zes gehypermethyleerde genen op in melanomen met een metastatisch gedrag: M CHR1, SYNPO2, Clorf106, HIST1H3G, ZNF35 en GNMT. Verdere validatie studies toonden prognostische waarde aan van promoter $\mathrm{CpG}$-eiland hypermethylatie $(n=113)$ en verminderde gen expressie $(n=202)$ van het SYNPO2 gen in melanomen. Daarbij was deze prognostische waarde onafhankelijk van de dikte van het melanoom, de belangrijkste prognostische klinische parameter.

De nieuwste technologieën werden in hoofdstuk 7 aangewend om op een efficiënte manier accurate en reproduceerbare prognostische methylatie markers voor melanomen te identificeren. Dat wil zeggen, MBD-sequencing, voor het bestuderen van genoomwijde DNA-methylatiepatronen, en RNA-sequencing, voor het bepalen van gen expressie, werd uitgevoerd op melanoom cellijnen en gecombineerd met publiek beschikbare Infinium HumanMethylation450K data van "The Cancer Genome Atlas" (TCGA). Stringente statistische analyse, gebruik makend van de moleculaire profielen van $\mathrm{CDH} 11$ en GNMT als 'leidraad genen', identificeerden een totaal van 85 robuust gemethyleerde gen promoters die vermoedelijke melanoom biomarkers representeren. Afwijkende methylatie van LY75 werd geïdentificeerd als een sterke voorspeller van slechte melanoom prognose in een onafhankelijke validatie serie $(n=114)$ en identificeerde patiënten met een agressief ziektebeeld tijdens de eerste diagnose onafhankelijk van huidige prognostische voorspellers.

De belangrijkste bevindingen van de gepresenteerde studies zijn samengevat en bediscussieerd in hoofdstuk 8. Dit proefschrift heeft de biologische kennis van het melanoom vergroot en DNA-methylatie markers geïdentificeerd die kunnen worden vertaald naar de kliniek om de melanoom diagnose en prognose te verbeteren. Verdere studies zijn nodig om het biomarker potentieel van deze genen te bevestigen en om hun tumor onderdrukkende functie te ontrafelen. 
Naast de wetenschappelijke relevantie van de data wordt in de valorisatie paragraaf de maatschappelijke en economische waarde die kan worden gegenereerd uit deze thesis uiteen gezet. Het patenteren van LY75 methylering zal naar verwachting de validatie en het translationele proces van de biomarker bespoedigen en de kans op het succes van een klinische toepassing vergroten. Uiteindelijk zal dat leiden tot verbeterde gepersonaliseerde patiëntenzorg en een reductie van medische kosten. 

Dankwoord 
Heerlijk! Ik ben aangekomen bij het schrijven van het leukste deel van dit proefschrift (velen van jullie zijn het vast met me eens): Het Dankwoord!

Natuurlijk wil ik beginnen met het bedanken van mijn promotieteam. Mijn promotor, Prof. dr. van Engeland, beste Manon, heel veel dank voor je motiverende enthousiasme en je steun gedurende mijn PhD-tijd. Jij hebt het voor mij mogelijk gemaakt mij op diverse terreinen te ontwikkelen en in de loop der jaren omgetoverd tot moeder AiO.

Mijn eerste co-promotor, Dr. Winnepenninckx, beste Véronique, bedankt dat je me wegwijs hebt gemaakt in de wereld van de dermatopathologie. Ik denk dat het begin van mijn AiO traject voor ons beide even spannend was, jij begon met mij aan je eigen melanoom onderzoekslijn binnen Maastricht.

Mijn tweede co-promotor, Dr. Van Neste, beste Leander, jij werd iets later aan het promotie team toegevoegd; een zeer waardevolle toevoeging! Dankjewel voor je hulp bij het analyseren van de sequencing en array data en bij het afronden van mijn promotietraject!

Ook dank aan alle co-auteurs voor jullie inzet en prettige samenwerking.

Een speciaal woord van dank aan Prof. dr. Joost van den Oord. Beste Joost, het feit dat $u$ als enige op al mijn publicaties staat zegt eigenlijk al voldoende! Hartelijk dank voor uw wetenschappelijk input en het aanleveren van kostbaar patiëntenmateriaal. Zonder uw hulp was mijn thesis waarschijnlijk maar half zo dik geweest.

Prof. dr. Gallagher, dear Liam, I had a great time working at OncoMark Ltd. on the Target-Melanoma project. 'Thanks a million' for all opportunities afforded to me by you and the OncoMark-team. I truly had a 'grand time' in Dublin.

Dr. van Doorn en Dr. Gao, beste Remco en Linda, onze samenwerking was zeer prettig en waardevol! Dank voor de leerzame besprekingen en discussies over de methylerings-data die geresulteerd hebben in twee mooie publicaties in de JID.

Ons afdelingshoofd: Prof. dr. Zur Hausen, beste Axel, hartelijk dank voor uw wetenschappelijke bijdrage en voor het managen van onze afdeling. Ik heb hier vele jaren met plezier gewerkt!

Prof. dr. Speel, beste Ernst-Jan, bedankt voor de leerzame discussies over de BRAF IHC data. Ivana, leuk dat we samen het BRAF paper tot een publicatie hebben weten te brengen. Veel succes met je verdere carrière!

Zonder paranimfen is promoveren maar half zo leuk! Dankjewel Nina en Joep dat jullie me bijstaan tijdens mijn verdediging, net zoals jullie dat gedaan hebben tijdens de rest van mijn promotie-periode. Nina, mijn enthousiasme en passie voor wetenschap is sterk toegenomen tijdens onze afstudeerstage; enkele jaren later zijn we (bijna) allebei doctor! Jebent een fantastische vriendin! (En een speciaal bedankje voor Kevin, wat is mijn kaft mooi geworden!!!) Joep, van de kleine demo tot aan de uns40 hebben we onze promotietijd met elkaar gedeeld. Bij jou kon ik altijd terecht voor het delen van 
de successen, maar ook de frustraties die inherent zijn aan promotieonderzoek, bedankt!

Al mijn (ex)-collega's van de Epigenetica-groep; bedankt voor alle gezelligheid op het lab en daarbuiten! Veerle, bedankt voor je luisterend oor en het fijne steuntje of duwtje in de rug wanneer dit nodig was. Je bent een mooie carrière aan het bouwen! Leuk dat ik dat een aantal jaren van dichtbij heb kunnen meemaken.

Hanneke, Kim en Jürgen; de (ex)-post-docs, dankjewel voor jullie betrokkenheid, ook nadat jullie pathologie al (deels) hadden verlaten. Lieve Hanneke, van collega's zijn we goede vriendinnen geworden. Memorabel voor mij zijn de halve marathon in Berlijn en de fantastische roadtrip door lerland! (Imke, super leuk dat je samen met Hanneke naar lerland op vakantie kwam, speciaal voor jou scheen de zon!). Kim, dankjewel voor je hulp onlangs tijdens een 'paniek-afrond-momentje'. Jürgen (Veki!), have I finally convinced you that melanoma-work can be interesting as well!? I'll never forget the good times we had and our nice chats about research/epigenetics!

Muriel en Joep, het was erg prettig om met jullie te discussiëren en brainstromen, helaas hebben we veel te kort met ons drietjes een kamer gedeeld. Succes met het afronden van jullie eigen thesis!

De 'baby-AiO's, Sophie, Nathalie, Zheng en Tim; jullie zijn inmiddels allang baby-af, de eerste artikels al (bijna) gescoord. Veel succes met jullie verdere promotie! Als jullie nog wat hulp nodig hebben van jullie AiO-mama dan hoor ik wel! Zheng, hope you were able to read the above lines. Anyways, it was great to have you as roommate during my last PhD-time. All the best in the future!

Lindsay and Yuichi, too bad we were colleagues for such a short time. Lindsay, never forget you're part of the winning team! Yuichi, enjoy my desk with the window view :-)

Niet te vergeten alle ex-AiOs, Iris, Ingrid, Carolina, Marjolein, Sarah en Linda uit Amsterdam; bedankt voor de plezierige tijd op het lab! Iris, van het Bernardinus college via het epigenetica lab richting de klinische chemie. Leuk dat we straks weer min of meer collega's worden! Ingrid, binnenkort wonen we dichter bij elkaar in de buurt, dan moeten we echt nog eens afspreken! Ik werd jouw vervangster in het 'AiOhok' op de uns40. Carolina, het was dan maar een korte tijd, maar wel erg leuk om even 'hok-genootjes' te zijn geweest. Marjolein, ik durf het eigenlijk niet te vragen... is het review gepubliceerd?? Veel succes in Eindhoven! Sarah, jouw promotie is de eerste die ik meemaakte, jammer dat we maar zo kort collega's zijn geweest. Linda, uit Amsterdam bracht je altijd gezelligheid mee met je bezoekjes aan Maastricht. Helaas is ons artikel nog steeds geen publicatie geworden, maar hopelijk heb je de hoop nog niet opgegeven. Het gaat vast nog wel gebeuren!

Uiteraard kan een lab zonder analisten niet functioneren, Kim W., Edith, Jaleesa, Kathleen, Peter, sinds kort Gregorio en al even weg Kim v S.; bedankt voor al jullie tips 
en hulp in het lab. Peter, fijn dat jij wat melanoom werk kon overnemen gedurende mijn verblijf in Dublin. Kim W., Kim v S. en Jaleesa, bedankt voor jullie onmisbare hulp met IHC en MSP. Kathleen, het snijden van de weefselblokjes was bij jou in goede handen. Na mijn eigen snij-ervaring was ik blij dat jij en Roy dit klusje van mij konden overnemen. Verrassend genoeg maak ik nu van bloed mijn werk! Guido (en jouw team), fijn dat ik bij jou ook altijd terecht kon voor ondersteuning met het labwerk. Ook Mat, Anique, Benoit en Ruud, hartelijk dank voor jullie vriendelijkheid en behulpzaamheid gedurende de afgelopen jaren.

Roy and Balazs, together we were the 'Melanoma Dream-team'. Roy, zowel in Maastricht als Dublin was het prettig samenwerken. Balazs, you are the kindest person I have ever met! When I am in Hungary, I will visit you!

All other former colleagues at OncoMark Ltd.; Mairin, Liam, Dara, Gillian Q., Gillian $\mathrm{OH} .$, Karen, Miriam, Bozena, Marina, Michael, Jesu, and Arman, thanks for making my stay in Dublin so enjoyable!

Ook alle (ex)-AiOs buiten de epigenetica-groep mogen hier niet ontbreken. Tjinta, Suzanne, Floor en Dorian, jullie hebben ook een tijd aan de sfeer op het lab bijgedragen. Tjinta, doordat we beide aan huidkanker-onderzoek werken was er al snel een klik! Veel succes met het afronden van je eigen promotie, bijna klaar! Suus en Floor, wat lijkt onze tijd in de kleine demo alweer lang geleden he... Het was een leuk begin van mijn AiO-tijd, ook samen met alle andere ex-kleine demo genootjes (Joep, Timo, Karen, Jeroen, Annette, David, indira, Bea.... dankjewel voor alle gezelligheid!). Dorian, ik ben benieuwd naar je gezinnetje; veel plezier samen met Stephanie en je dochtertje in York.

Verder veel dank aan alle studenten die in de afgelopen jaren een bijdrage geleverd hebben aan het melanoom onderzoek, jullie waren onmisbaar! Aimée, Susan, Marloes en Danique $(2 \mathrm{x} ;-))$.

De andere onderzoekers bij Pathologie, Anke, Dorit, Iris, Sreedhar en natuurlijk alle (ex)-cardio's: Bedankt voor de kletsmomenten op de gang en gezelligheid.

Bij het secretariaat stond de deur altijd voor mij open. Lieve Audrey, bedankt voor al je hulp en steun. Alweer een AiO over de streep! Elly en Cor, jullie vele hulp met van alles en nog wat heb ik zeer gewaardeerd. Danielle en Ingrid, jullie ook hartelijk bedankt voor jullie behulpzaamheid, onder andere met het plannen van afspraken, lang niet altijd even gemakkelijk!

Daarnaast zijn er buiten werk om ook genoeg mensen een vermelding in dit dankwoord waard... Nina, Violet, Cindy (mijn zeealtzus!), Rinske en Vera, wat zijn jullie toch lieve vriendinnen! Wat heb ik met ieder van jullie wat afgekletst en gelachen. Ook 
tijdens mindere momenten staan jullie voor me klaar. Dankjewel voor jullie vriendschap, jullie betekenen veel voor mij!

Anniek, Sandra, Yvette, Michelle, Kirsten G., Kirsten P., Lieveke, Evelien, Pieter, Huub, Tom, Dion, Joost en Floris; De VVV! Wat zijn we toch een bijzondere vriendengroep! Bedankt voor alle leuke momenten, reisjes, feestjes... Dat er nog veel meer herinneringen gemaakt mogen worden!

Natuurlijk mag ik mijn muziekvrienden van BBL, NLBB en Kempenbloei Achel (En ja Nico, ook daarbuiten!) niet vergeten. Super bedankt voor veel mooie momenten, concerten, concoursen en de leuke reisjes. Al was ik de laatste tijd een stuk minder op het podium te vinden, muziek was gedurende mijn AiO-tijd een heerlijke uitlaatklep en fantastische hobby!

Mary en Fons, mijn fantastische schoonouders, dankjewel dat jullie me zo liefdevol op hebben genomen in de familie. Tom en Romy, heerlijk ook om jullie als familie erbij gekregen te hebben. Ik verheug me erop om op korte termijn wat dichter bij jullie in de buurt te wonen!

Lieve pap en Hatice, dankjewel voor jullie interesse in mijn bezigheden. Dat bezoekje aan Turkije gaat er nu zeker eens snel van komen! En natuurlijk mijn lieve oma, wat is het toch altijd fijn met u kletsen. Bedankt voor het delen van uw wijsheid.

Mijn lieve broer en zus, wat is het toch fijn om jullie kleine zusje te zijn! Big-bro, lieve Martin, ik weet dat je apetrots op me bent, wat ik niet weet is of jij weet dat ik ook enorm trots op jou ben! Lieve Marianne, indirect dankzij dit boekje konden we samen Australië doorcrossen in onze Wicky, deels in het water gevallen, maar alles is goed gekomen en wat was het leuk!! Bedankt dat jij er altijd voor me bent, je bent een top zus!

Mam en Arie, jullie zouden nu enorm trots op mij zijn! Helaas heb ik Arie veel te kort gekend, een bijzondere man die mijn onderzoek reuze interessant vond.

Lieve mams, wat had ik jouw gezicht graag willen zien bij het geven van mijn proefschrift. Ik weet nog goed hoe jij heerlijk buiten in het zonnetje het schilderij van deze omslag hebt gemaakt. Heel speciaal dat dit schilderij nu mijn proefschrift omvat, zo heb je het toch gezien...

Lieve Frank, heerlijk om met jou samen het leven te delen, wat hebben we het getroffen met elkaar! Bedankt voor je liefde, je kookkunsten, je warmte, je onvoorwaardelijke steun en jouw heerlijke armen om me heen. Ik verheug me op onze aankomende verhuizing naar het westen van Nederland. En uiteraard op het ontkurken van de volgende champagnefles! 

Curriculum vitae

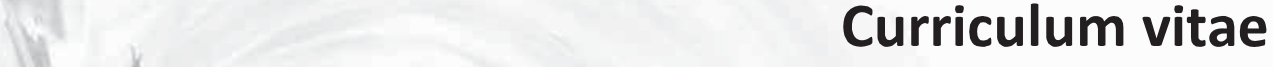




\section{About the author}

Karin van den Hurk was born on July 2nd 1985, in Valkenburg a/d Geul, The Netherlands. She completed secondary school at the Bernardinus College in Heerlen in 2003. In the same year, she started her academic Bachelor studies in Health Sciences, with a minor in Movement Sciences and a major in Bioregulation and Health, at Maastricht University. From January to April 2006 she took optional education at the University of Kuopio, Finland, which was supported by an Erasmus study grant. For her Bachelor thesis she performed an internship at the Department of Human Biology at Maastricht University under supervision of Prof. dr. J. Plat to explore the effect of plant sterols and plant stanols on immune function. Thereafter, in 2007, she continued her studies with a Master in Physical Activity and Health, specialization Metabolism and Nutrition at the Maastricht University, The Netherlands. For her Master thesis she performed an internship at the Department of Physiology at Maastricht University under supervision of Dr. D.G. Molin and Dr. H.E. Popeijus to examine the role of Notch signaling in human coronary artery smooth muscle cells. She graduated with distinction in August 2008. In addition to her academic education she studied Trumpet with Dhr. T.P. Wolters at the Classical Music Department of Maastricht Conservatory, The Netherlands.

In November 2008, Karin started her PhD training with Prof. dr. M. van Engeland, Dr. V.J.L. Winnepenninckx, and Dr. L.P.J. Van Neste at the Department of Pathology of the Maastricht University Medical Centre, working on a project to study the (epi)genetics of cutaneous melanoma. In May 2012, she moved to Dublin, Ireland, to undertake a Marie-Curie Fellowship as part of a Marie-Curie Industry-Academia Partnerships and Pathways (IAPP) Programme, Target-M elanoma. Here she worked for a private company, OncoMark Ltd., that is centred on developing biomarker tests to support cancer diagnostics and therapeutics. She returned to Maastricht in May 2013 to continue her research on cutaneous melanoma (epi)genetics which resulted in this dissertation. In June 2015, Karin started her training in Clinical Chemistry at the Sint Lucas Andreas Hospital in Amsterdam. 


\section{List of publications}

K. van den Hurk, V. J.L. Winnepenninckx, D.L. van den Kerkhof, L. Gao, G. Trooskens, T. De Meyer, M.M. Oosterhof, R. van Doorn, J.J. van den Oord, W. Van Criekinge, W.M. Gallagher, M. van Engeland, L. Van Neste, Comprehensive epigenomic and transcriptomic analysis of melanoma identifies LY75 CpG island promoter methylation as an independent marker of poor clinical outcome. M anuscript in preparation

L. Gao*, K. van den Hurk*, J. Nsengimana*, J.P. Laye, J.J. van den Oord, S. Beck, N.A. Gruis, W.H. Zoutman, M. van Engeland, J.A. Newton-Bishop, V.J.L. Winnepenninckx, R. van Doorn, Prognostic significance of promoter hypermethylation and diminished gene expression of SYNPO2 in melanoma, J Invest Dermatol, (2015). *Equal contribution

K. van den Hurk, B. Balint, S. Toomey, P.C. O'Leary, L. Unwin, K. Sheahan, E.W. McDermott, I. Murphy, J.J. van den Oord, M. Rafferty, D.M. FitzGerald, J. Moran, R. Cummins, O. MacEneaney, E.W. Kay, C.P. O'Brien, S.P. Finn, C.C. Heffron, M. Murphy, R. Yela, D.G. Power, P.J. Regan, C.M. McDermott, A. O'Keeffe, Z. Orosz, P.P. Donnellan, J.P. Crown, B.T. Hennessy, W.M. Gallagher, High-throughput oncogene mutation profiling shows demographic differences in BRAF mutation rates among melanoma patients, Melanoma Res, 25 (2015) 189-99.

I. Verlinden*, K. van den Hurk*, R. Clarijs, A.P. Willig, C.M. Stallinga, G.M. Roemen, J.J. van den Oord, A. Zur Hausen, E.J. Speel*, V.J. Winnepenninckx*, BRAF ${ }^{\text {V600E }}$ immunopositive Melanomas Show Low Frequency of Heterogeneity and Association With Epithelioid Tumor Cells: A STROBE-Compliant article, Medicine (Baltimore), 93 (2014) e285. *Equal contribution

L. Gao*, K. van den Hurk*, P.T. Moerkerk, J.J. Goeman, S. Beck, N.A. Gruis, J.J. van den Oord, V.J. Winnepenninckx*, M. van Engeland*, R. van Doorn*, Promoter CpG Island Hypermethylation in Dysplastic Nevus and Melanoma: CLDN11 as an Epigenetic Biomarker for Malignancy, J Invest Dermatol, 134 (2014) 2957-2966. *Equal contribution

T. Brinkhuizen, K. van den Hurk, V.J. Winnepenninckx, J.P. de Hoon, A.M. van Marion, J. Veeck, M. van Engeland, M.A. van Steensel, Epigenetic changes in Basal Cell Carcinoma affect SHH and WNT signaling components, PLoS One, 7 (2012) e51710.

L.C. van Kempen, K. van den Hurk, V. Lazar, S. Michiels, V. Winnepenninckx, M. Stas, A. Spatz, J.J. van den Oord, Loss of microRNA-200a and c, and microRNA-203 expression at the invasive front of primary cutaneous melanoma is associated with increased thickness and disease progression, Virchows Arch, 461 (2012) 441-448. 
K. van den Hurk, H.E. Niessen, J. Veeck, J.J. van den Oord, M.A. van Steensel, A. Zur Hausen, M. van Engeland, V.J. Winnepenninckx, Genetics and epigenetics of cutaneous malignant melanoma: a concert out of tune, Biochim Biophys Acta, 1826 (2012) 89102.

F. Brull, R.P. Mensink, K. van den Hurk, A. Duijvestijn, J. Plat, TLR2 activation is essential to induce a Th1 shift in human peripheral blood mononuclear cells by plant stanols and plant sterols, J Biol Chem, 285 (2010) 2951-2958. 
